Routledge Explorations in Energy Studies

\title{
DILEMMAS OF ENERGY TRANSITIONS IN THE GLOBAL SOUTH
} BALANCING URGENCY AND JUSTICE

Edited by

Ankit Kumar, Johanna Höffken and Auke Pols

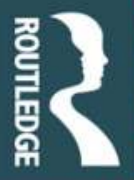




\section{Dilemmas of Energy Transitions in the Global South}

This book explores how, in the wake of the Anthropocene, the growing call for urgent decarbonisation and accelerated energy transitions might have unintended consequences for energy poverty, justice and democracy, especially in the global South.

Dilemmas of Energy Transitions in the Global South brings together theoretical and empirical contributions focused on rethinking energy transitions conceptually from and for the global South, and highlights issues of justice and inclusivity. It argues that while urgency is critical for energy transitions in a climate-changed world, we must be wary of conflating goals and processes, and enquire what urgency means for due process. Drawing from a range of authors with expertise spanning environmental justice, design theory, ethics of technology, conflict and gender, it examines case studies from countries including Bolivia, Sri Lanka, India, The Gambia and Lebanon in order to expand our understanding of what energy transitions are, and how just energy transitions can be done in different parts of the world. Overall, driven by a postcolonial and decolonial sensibility, this book brings to the fore new concepts and ideas to help balance the demands of justice and urgency, to flag relevant but often overlooked issues, and to provide new pathways forward.

This volume will be of great interest to students and scholars of energy transitions, environmental justice, climate change and developing countries.

Ankit Kumar is a Lecturer in Development and Environment at the University of Sheffield, the United Kingdom.

Johanna Höffken is an Assistant Professor in Innovation Sciences at Eindhoven University of Technology (TU/e), The Netherlands.

Auke Pols is a Lecturer in Responsible Innovation and the Ethics of Technology at Wageningen University \& Research, The Netherlands. 
"This book makes a deep-diving contribution to an important issue: how to ensure rapid climate action by transitioning energy systems whilst recognising this as a deeply socio-ethical process. The editors distinguish between urgency and justice to explore questions that everyone involved in energy transitions research or practice must engage with."

\section{Rob Raven, Monash Sustainable Development Institute, Monash University, Australia}

"Kumar, Höffken and Pols have assembled an outstanding collection of essays that situates the energy transition firmly within the Anthropocene. [They] put justice at the core of the energy transition. They do this by showcasing the dynamics and politics of energy transition in a diverse set of geographical contexts. The multisite insights from this collection show that the energy transition generates new forms of carbon colonialism. The book also reveals multiple inequalities embedded in energy transitions, as shown, for example, in gendered patterns of inclusion and exclusion. Accessible and engaging, this book will inform the growing work of critical energy scholars, whether they are seeking to understand how to activate just energy transitions or trying to avoid the mistakes of the past."

- Vanesa Castan Broto, Urban Institute and

Department of Geography, University of Sheffield, United Kingdom

"This important collection on just transitions in the global South casts a new empirical light onto an otherwise shadowy area of inquiry. The chapters bring to attention the complexity and nuance needed to understand the implications for the energy transition on materials, land, labour and nature-cultures. This book offers new empirical insights for why justice needs to be at the centre of climate mitigation efforts with the world's most vulnerable, and why moving fast without careful thought and participation - building with haste - could reproduce the same old inequities, this time in the name of decarbonisation. The authors give us much to think about and wrestle with - a truly timely collection for this moment."

- Dustin Mulvaney, Department of Environmental Studies, San José State

University, USA 


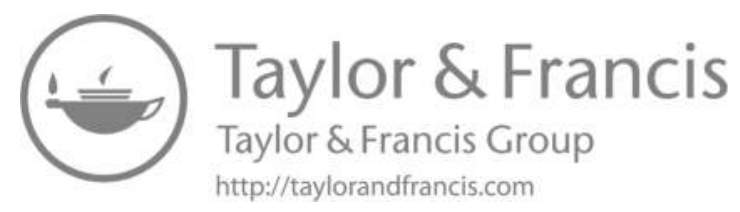




\section{Routledge Explorations in Energy Studies}

\section{Decarbonising Electricity Made Simple}

Andrew F. Crossland

\section{Wind and Solar Energy Transition in China}

Marius Korsnes

\section{Sustainable Energy Education in the Arctic}

The Role of Higher Education

Gisele M. Arruda

\section{Electricity and Energy Transition in Nigeria}

Norbert Edomah

\section{Renewable Energy Uptake in Urban Latin America}

Sustainable Technology in Mexico and Brazil

Alexandra Mallett

\section{Energy Cooperation in South Asia}

Utilizing Natural Resources for Peace and Sustainable Development Mirza Sadaqat Huda

Perspectives on Energy Poverty in Post-Communist Europe

Edited by George Jiglau, Anca Sinea, Ute Dubois and Philipp Biermann

Dilemmas of Energy Transitions in the Global South

Balancing Urgency and Justice

Edited by Ankit Kumar, Johanna Höffken and Auke Pols

For more information about this series, please visit: www.routledge.com/Routled ge-Explorations-in-Energy-Studies/book-series/REENS 


\section{Dilemmas of Energy Transitions in the Global South}

Balancing Urgency and Justice

\section{Edited by}

Ankit Kumar, Johanna Höffken and Auke Pols 
First published 2021

by Routledge

2 Park Square, Milton Park, Abingdon, Oxon OX14 4RN

and by Routledge

605 Third Avenue, New York, NY 10158

Routledge is an imprint of the Taylor \& Francis Group, an informa business

(C) 2021 selection and editorial matter, Ankit Kumar, Johanna Höffken and Auke Pols; individual chapters, the contributors

The right of Ankit Kumar, Johanna Höffken and Auke Pols to be identified as the authors of the editorial material, and of the authors for their individual chapters, has been asserted in accordance with sections 77 and 78 of the Copyright, Designs and Patents Act 1988.

The Open Access version of this book, available at www.taylorfrancis.com, has been made available under a Creative Commons Attribution-Non Commercial-No Derivatives 4.0 license.

Trademark notice: Product or corporate names may be trademarks or registered trademarks, and are used only for identification and explanation without intent to infringe.

British Library Cataloguing-in-Publication Data

A catalogue record for this book is available from the British Library

Library of Congress Cataloging-in-Publication Data

Names: Kumar, Ankit, 1985- editor.

Title: Dilemmas of energy transitions in the global south: balancing urgency and justice / edited by Ankit Kumar, Johanna Höffken and Auke Pols.

Description: Abingdon, Oxon; New York, NY: Routledge, 2021.

Series: Routledge explorations in energy studies | Includes bibliographical references and index.

Identifiers: LCCN 2020056909 (print) | LCCN 2020056910 (ebook) |

ISBN 9780367486440 (hbk) | ISBN 9780367486457 (ebk)

Subjects: LCSH: Energy industries--Developing countries.

Sustainable development-Developing countries. | Environmental

justice-Developing countries.

Classification: LCC HD9502.D442 D55 2021 (print) |

LCC HD9502.D442 (ebook) | DDC 333.7909172/4-dc23

LC record available at https://lccn.loc.gov/2020056909

LC ebook record available at https://lccn.loc.gov/2020056910

ISBN: 978-0-367-48644-0 (hbk)

ISBN: 978-1-032-01546-0 (pbk)

ISBN: 978-0-367-48645-7 (ebk)

DOI: $10.4324 / 9780367486457$

Typeset in Times New Roman

by Deanta Global Publishing Services, Chennai, India 


\section{Contents}

List of figures $\quad$ ix

Editors $\mathrm{x}$

List of contributors $\quad$ xi

Preface xiv

1 Urgency vs justice: A politics of energy transitions in the age of the Anthropocene

ANKIT KUMAR, AUKE POLS, AND JOHANNA HÖFFKEN

2 Insights from an assemblage perspective for a (better) understanding of energy transitions: Facing the challenge of sustainability in Lebanon's energy crisis

DANA ABI GHANEM

3 Constructing an inclusive vision of sustainable transition to decentralised energy: Local practices, knowledge, values and narratives in the case of community-managed grids in rural India ANNA MELNYK AND ABHIGYAN SINGH

4 Bolivia's energy transition in harmony with nature: Reality or delusion?

PAOLA VILLAVICENCIO-CALZADILLA AND ROMAIN MAUGER

5 Scalar biases in solar photovoltaic uptake: Socio-materiality, regulatory inertia and politics 


\section{viii Contents}

6 Energy transitions in a post-war setting: Questions of equity, justice and democracy in Sri Lanka

GZ. MEENILANKCO THEIVENTHRAN

7 Energising change: Clean cooking and the changing social position of women

MINI GOVINDAN AND RASHMI MURALI

8 "Women don't ride bicycle[s], only men ride bicycles": Gender and justice in mobility transitions

MARY GREENE AND ANNE SCHIFFER

9 Energy transitions in the global South: Towards just urgency and urgent justice

JOHANNA HÖFFKEN, AUKE POLS, AND ANKIT KUMAR 


\section{Figures}

2.1 Diesel generator wires visible in the foyer of an apartment building in Beirut 29

2.2 Lead-acid batteries mounted on a cradle in the attic of Layla's house 31

3.1 Map of India with the location of Chhattisgarh highlighted 43

3.2 Photographs of a mini-grid at the field-site. Notice the solar panels on the ground and a battery-bank inside a control-room 44

3.3 Automatic timer and load-limiter 45

3.4 Power Distribution Network (PDN) with extra cables connected by the villagers

3.5 A "movie theatre" set-up with a television-set connected to a compact disc (CD) player and with cots and chairs for the villagers to sit

4.1 Yearly evolution of hydroelectric, thermal generation and alternative energies (GWh) (SIN) (1992-2018). Created by the authors, based on AE's data (2019, pp. 63-65)

4.2 Evolution of the electricity generation's share per energy source. Created by the authors, based on the Ministerio de Hidrocarburos y Energía's data (2014, p. 127)

4.3 The gorge of El Bala, from the Beni River (this zone would be flooded if the El Bala dam project is successful). 2018. Picture taken by the authors

7.1 Cook stove mould (left), finished mud stove (right) 114

7.2 Map of Karnataka with administrative divisions 


\section{Editors}

Ankit Kumar is a Lecturer in Development and Environment at the Department of Geography, the University of Sheffield. He received his $\mathrm{PhD}$ in Geography working on social and cultural aspects of access to modern energy in through solar lighting in rural India. Ankit's research interests are situated around climate and energy justice in the global South. He enquires justice questions working at the nexus of culture, knowledge and politics. Conceptually he draws from critical development studies, postcolonial studies and environmental geographies. He has published in several journals including Transactions of the Institute of British Geographers, Social and Cultural Geography, Antipode and Energy Research and Social Science.

Auke Pols is a lecturer in responsible innovation and the ethics of technology at the Knowledge, Technology and Innovation group at Wageningen University $\&$ Research. He works on ethical aspects of energy transitions and energy innovation processes in the global South. His research projects include investigations into the sustainability of biofuel production and use, the development and implementation of smart grids in India, and the institutionalisation of responsibility towards society in research conducting and funding organisations.

Johanna Höffken is an Assistant Professor in the group Technology, Innovation and Society at Eindhoven University of Technology (TU/e), The Netherlands. Trained as a social scientist using qualitative research methods, her areas of expertise include (sustainable) development studies and science and technology studies. Johanna is interested in the socio-contextual aspects that shape and embed innovations and interventions. She studies this mainly in the context of the global South on questions around energy (access) and organisation. Her current research, funded under Europe's H2020 programme, revolves around justice questions, innovation and energy communities in Europe and India. 


\section{Contributors}

Dana Abi Ghanem is a Research Fellow at the Centre for Sustainable Engineering at Teesside University, where she is pursuing her research interests in energy and society in both the global North and the global South. Her work focuses on energy infrastructures and everyday life, with a particular interest in the processes shaping our engagement with energy-related services. This work relates to new energy technologies, policies and practices in the energy sector and their implications for urban sustainability, energy justice and wellbeing.

Mary Greene is an Assistant Professor in the Sociology of Sustainable Consumption at the Environmental Policy Group, Wageningen University \& Research in The Netherlands. Mary's research employs human geographic and sociological concepts and methods to research complex contextual processes shaping consumption. Before moving to The Netherlands in 2019, Mary received her PhD and worked as a researcher and lecturer at the National University of Ireland. Mary is a member of SCORAI, the European Sociological Association and the Royal Geographical Society. She is committed to socially impactful work and sits on the board of the community cycling cooperative, An Mheitheal Rothar, in Galway.

Mini Govindan, a Fellow at TERI, has more than 15 years of experience in the fields of gender, energy, climate change, natural resources management and sustainable development, and has handled more than 20 projects as principal investigator/team member in the field of energy access, water and sanitation, climate change and poverty eradication. Mini is also conversant with the application of various qualitative and participatory tools such as PRA exercise, assessing the scope of people's participation, perception analysis, stakeholder analysis, systematic review and gender analysis.

Romain Mauger is a postdoctoral fellow at the Groningen Centre of Energy Law and Sustainability, University of Groningen (The Netherlands). Previously, he worked as a wind farm developer and legal advisor in France. His PhD on the energy transition legal framework in France was awarded in 2017, by the University of Montpellier. Currently, Dr Mauger is part of an H2020 project (SMILE - SMart IsLand Energy systems) and analyses the relevant legal frameworks for smart grid technologies. His research interests include energy 
and environmental law, the energy transition in general and concepts such as climate and energy justice or just transition.

Anna Melnyk is a PhD candidate in Ethics and Philosophy of Technology at TU Delft with an MSc in Philosophy of Science, Technology, and Society specialising in technologies and values. Her current research is a part of the ERC Advanced Grant research project "Design for Changing Values in SocioTechnical Systems", wherein Anna studies the interplay between values, technologies and diverse stakeholders in the energy transition in order to develop design strategies to manage value change in the energy sector. This includes investigating technologically induced moral change that leads to the energy sector's decentralisation by community participation.

Rashmi Murali, Research Associate at TERI, has experience in the fields of renewable energy, gender, water-energy-food nexus and eco-tourism. Rashmi's key expertise lies in conducting primary and secondary research, field work, community engagement, qualitative analysis, documentation and developing knowledge products like journal papers, book chapters and research reports among others. Her academic qualifications include Master's degrees in physics and renewable energy.

Siddharth Sareen is an associate professor in energy and environment at the Department of Media and Social Sciences at the University of Stavanger, Norway. He works on the governance of energy transitions at multiple scales and currently leads a JPI Climate funded project on socially inclusive digitisation for deep decarbonisation in medium-sized European cities. His emerging research focus is on socially just, low-carbon urban mobility transitions. Siddharth has published in dozens of international journals, has edited the book Enabling Sustainable Energy Transitions and serves on the editorial boards of several journals, including Energy Research \& Social Science.

Anne Schiffer is Senior Lecturer in Design at Leeds Beckett University, UK. She is the author of Reframing Energy Access: Insights from The Gambia. Her research employs human-centred design as a process to help tackle real world challenges including in the areas of sustainable energy transitions, water and energy access. Dr Schiffer received a PhD from Queen's University Belfast and previously worked as community energy campaigner for Friends of the Earth Scotland. She is a Senior Fellow of the Higher Education Academy, Member of the African Studies Association UK and recently joined the Island Studies Journal editorial board.

Abhigyan Singh is an Assistant Professor at the Faculty of Industrial Design Engineering of Delft University of Technology (TU Delft), The Netherlands. He has lived, studied, and worked in India, Finland and The Netherlands. He is a design anthropologist who explores the convergence of design, energy studies and anthropology in the context of emerging energy systems. An example of such a work is his interdisciplinary doctoral dissertation, "Conceptualizing 
inter-household energy exchanges: an anthropology-through-design approach". His research has also been exhibited at diverse venues such as Dutch Design Week and CUMULUS Exhibition.

Gz. MeeNilankco Theiventhran is a PhD Research Fellow at the Department of Computer Science, Electrical Engineering and Mathematical Sciences at the Western Norway University of Applied Sciences. He has an interdisciplinary background comprising political science, geography and engineering, and 15 years' work experience involving project management, public policy, and international development. His research mainly concerns equity and justice aspects of energy transitions in the global South and pays specific attention to geopolitical dynamics and policy challenges confronting developing countries in achieving clean energy transitions.

Paola Villavicencio-Calzadilla is a postdoctoral fellow at the Faculty of Law of the Universitat Rovira i Virgili - URV (Spain). She holds a Master's degree and a PhD in Environmental Law, both from the URV. She was a postdoctoral fellow at the North-West University (South Africa) from 2015 to 2018. She has been involved in several research projects and was a research fellow at the IUCN Environmental Law Centre (Germany) and the Groningen Centre of Energy Law and Sustainability of the University of Groningen (The Netherlands). Her research focuses on climate change law and governance, climate justice and energy justice and the Rights of Nature. 


\section{Preface}

Writing a book is very much like instigating a local energy transition. At first glance, the challenge seems technical, one of simply putting the right words in the right order. Inevitably, however, the question arises what the "right" words and the "right" order are, how much time we want to take to get these just right, and who gets to decide on what's right anyway. In the end, a book, like an energy transition, is as much a social as a technical product: like we see the solar panels and the windmills in the field, but not the mineral miners, developers, policy makers and deliberating citizens surrounding them, in a book we see only the words and not the people who contributed to their realisation. This preface aims to give insight into those people and processes by which this book came to be.

First, this work is the capstone of, and its Open Access publication has been financed by, the research project 'Developing and implementing smart grids in India' (project no. 313-99-307). This project has been partly funded under the Societally Responsible Innovation research programme by the Netherlands Organisation for Scientific Research (NWO). As required by this funding scheme, this project has also been partly funded by Power Research Electronics B.V. and by Rural Spark Energy India Pvt Ltd. Without these funders and their involvement in the research project through Menno Kardolus (PRE) and Marcel van Heist and Evan Mertens (Rural Spark), the editors of this book could not have teamed up, and the book would not have existed.

Second, this research project would not have been realised if a number of excellent researchers had not committed time and energy to the writing of the proposal and the execution of the project. For this, we thank particularly Geert Verbong, our principal investigator, whose contributions to the project from beginning to end have been invaluable. Furthermore, we would like to thank Andreas Spahn and members of the ECIS seminar, where we discussed our ideas from Eindhoven University of Technology, the Netherlands; and Shirish Garud, Amit Kumar and V.S.K.V. Harish from TERI, India. We are also grateful to the members of the project's valourisation panel for advising us on the scope and the direction of the project: Naqui Anwer, Priya Dagar, Alekhya Datta, Shantanu Dixit, Mini Govindan, Willem Helwegen, the late Wil Kling, Suman Lahiri, Ashis Kumar Sahu, Rajesh Mediratta, Jelle Nijdam, Basudev Prasad, Smita Rakesh and E.A.S. Sarma. Finally, we are grateful to all the people in Bihari villages who agreed to 
make time for us during the fieldwork phases of our project and extended their hospitality to us on various occasions. Rita Kumari and Rina Kumari (our dear Didies) in Bankebazar deserve a special mention here for their generosity and openness towards us.

Third, this research project inspired us to organise a workshop on energy transitions in the global South, at which many presentations were given that, after lots of inspiring discussions and suggestions, eventually found their way into this book. For making this workshop a success, we would like to thank all presenters: Lotte Asveld, Sumedha Basu, Kirsten Campbell, Padmasai Lakshmi Bhamidipati, Itay Fischhendler, Matthias Galan, Anika Nasra Haque, André Neto-Bradley, Zoë Robaey and Carlos Tornel, as well as the authors of the chapters of this edited volume. Furthermore, we would like to thank all attendees of the workshop for their valuable questions, comments and insights. We would especially like to thank Anna Lena Gompelmann for her organisational support.

Fourth, for helping us shape up our book proposal and making the book a reality we would like to thank Routledge, particularly Annabelle Harris, Oindrila Bose and Matthew Shobbrook, as well as four anonymous reviewers.

Fifth and more personally, the editors would like to thank those near and dear to them for their love, patience and moral support, sometimes from very far away. Ankit would like to thank Dr Abhilash and Neelam Singh, who continue to be a constant source of inspiration, local conduits and sparring partners. Johanna would like to thank the two As in her team, Auke and Ankit, for a project well done. Auke would like to thank his wife Marijke and his sons Leendert and Thijmen for joy and grounding. 


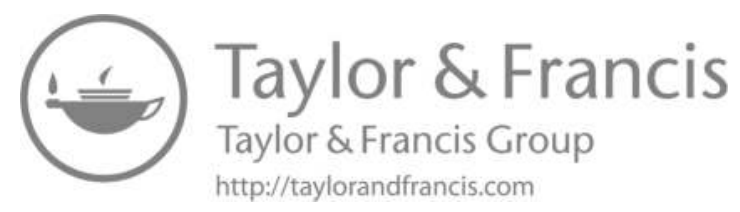




\title{
1 Urgency vs justice \\ A politics of energy transitions in the age of the Anthropocene
}

\author{
Ankit Kumar, Auke Pols, and Johanna Höffken
}

\section{Introduction}

As climate change becomes widely accepted as a climate crisis, calls for faster and more extensive energy transitions are growing, and rightly so. The United Nations Framework Convention on Climate Change has called for a need to go "Further, Faster, Together" for Climate Action. ${ }^{1}$ As the discourse of crisis, urgency and emergency becomes dominant, however, we risk losing sight of political and ethical consequences of energy transitions for people's everyday lives, especially in the global South. Many actions involved in urgently ramping up energy transitions, for example, adopting more solar photovoltaics (PV), electric vehicles and batteries, or reducing cumulative energy demand, create unintended consequences for marginal communities like energy poverty, curtailment of democracy, injustices, waste and local environmental destruction. Some of these impacts are now becoming apparent, for example, the mining of conflict minerals to feed the growing demand for raw materials to make solar panels, batteries and electric vehicles.

This book argues that while urgency is crucial for energy transitions in a climate-changed world, we need to be wary of haste. We must be cautious of conflating goals and processes of sustainable development and enquire what urgency means for due process. Justice needs thought, participation and deliberation. Questions regarding where, when, why, how and for whom particular pathways of energy transitions are adopted, and what impacts these pathways have on others, are crucial for practical success as well as ethical acceptability of those transitions. Taking the space and time in which these transitions take place into account is critical in thinking through these dilemmas. This introduction draws together the chapters in this book into a narrative of how space and time matter to energy transitions to navigate the dilemma between urgency and justice. One particular aim of this book is to bring new concepts and ideas from the global South into the discussion on energy transitions to help navigate this dilemma, to flag relevant but often overlooked issues and to provide new pathways for the future. In this introduction we show how we do so: by first examining the concepts of "urgency" and "justice" and the tensions between them, and then showing how our individual book chapters address those tensions. 


\section{Kumar et al.}

\section{The Anthropocene: urgency at the cost of justice?}

Scientists tell us that we live in a new epoch or geological age: Anthropocene, the age of humans (Chakrabarty, 2009; Davis and Todd, 2017; Tolia-Kelly, 2016; Yusoff, 2018). Noel Castree (2015: 302) explains that, no matter what actions we take now to make amends, "Homo sapiens - most especially those in the West have already altered the planet's future through their past (post-1800) and present actions". All humans are now involved in geography - Earth-writing - by "writing themselves into Earth history" (Castree, 2015: 302).

Dipesh Chakrabarty (2012) proposes two images that describe how human beings inhabit the Anthropocene: humans as a geological force and humans as a political force. The main scientific ideas behind the Anthropocene see humans as a geological force. Humans, that is all of us together, emerge as a collective author of actions that have resulted in climate change. As a political force we seek justice. This is premised on the idea that, theoretically, all humans are equal rights-bearing citizens, even though we know that practically full justice is unachievable. Aiming to pursue the latter is what we describe as a politics for/of justice.

It is these two aspects of being human in the Anthropocene that give rise to the core of the dilemma of urgency vs justice. As geological beings, we need to set aside individual differences and work together to mitigate our uncoordinated but collective negative impact on the planet. As political beings, we seek recognition of our individual differences, challenges and ambitions. We draw the argument of urgency vs justice from these two seemingly incompatible images of human beings: one that prompts us to think of a universal human agency, and the other where we must think of difference (see also Banerjee, 2017). The Anthropocene has thrown at us a challenge of balancing urgency and justice. The problem in front of us is how to accommodate individual differences while coordinating rapid and meaningful collective action.

The two aspects of being human in the Anthropocene are mirrored in an ambiguity in the word "global". Chakrabarty (2017a) reminds us that the "globes" in globalisation and global warming, while often conflated, are different. While global warming relates to the Earth's behaviour as a planet (a planetary phenomenon), globalisation relates to networks and connections created by humans and motivated by capital and power (a human phenomenon). The politics that we commonly pursue, whether the everyday kind or the geopolitics kind, is firmly situated in the domain of the human. The problem is that, while we struggle to grapple with a planetary phenomenon, we attempt this "from within the politics of the institutions that were created to deal with the 'globe' of 'globalization' with all the assumptions of 'stable' Holocene conditions built into them" (Chakrabarty, 2017a: 168). The Anthropocene demands a structural redesign of our political institutions that is able to manage the "globe" of "global warming" by pushing humans to work together as "one humanity". Such an institutional reform would require a politics beyond humans, one that is zoecentric, i.e., concerned with all life on Earth (Chakrabarty, 2017b). 
Castree (2015: 302) explicates that, in addition to the Anthropocene, the two interrelated ideas of planetary boundaries and tipping points have suggested that "humans are entering terra incognita". They have given rise to the idea of a crisis that needs an urgent response. For example, the idea of planetary boundaries proposes nine limits or boundaries inside which humans can function in a "safe operating space" created by Holocene conditions (Rockström et al., 2009). A cursory look at the planetary boundaries depicted in green and red colours, overlaid on an image of the Earth, along with the use of phrases like "safe operating space", bring a sense of alarm and evokes an idea of emergency - a red alarm flashing (see D'Souza (2018) on the question of scarcity, limits and the Anthropocene).

This sense of urgency is not misplaced. Indeed, there is enough scientific evidence that we are either very close to, or have gone beyond, various tipping points (IPCC, 2019; Lenton et al., 2019). However, Swyngedouw's (2019) warning that this narrative about the Anthropocene helps make climate change post-political is important to keep in mind. By this, Swyngedouw means that the geological/physical narrative of what the Anthropocene is and how we should manage it assumes that there are no alternatives to capital and market economy, the basic structures and conditions for social and economic order. ${ }^{2}$ The concern here is that if we let "the naming of a geo-social epoch and a contingent 'truth' of nature decide our politics", we might disavow a persistent intra-human politics of climate change, and instead, as evidence suggests is happening in policy-making across the globe, ${ }^{3}$ reinforce and amplify the discriminatory conditions that capitalism and colonialism have worked to entrench in society (Swyngedouw, 2019: 256). In short, such an approach will lead to the exclusion of an explicit politics of justice. In addition, we must listen carefully to the "calls to decolonize the Anthropocene that demand that we move beyond a politics of urgency to examine the slow, historical processes of erasure under colonialism and imperialism" (Gergan, 2017: 490; Davis and Todd, 2017). As Kathryn Yusoff (2018) reminds us, geology and the Anthropocene are deeply embedded with a history of racialisation, racial discrimination and colonisation (see also Saldanha, 2020; Tolia-Kelly, 2016).

In addition, the urgency debate and the need to unify under an Anthropocene narrative could "further delegitimize alternate forms of cultural knowledge and embodied practices and, in so doing, reproduce and reinforce injustices" (Schmidt et al., 2016: 194). By focusing solely on the planetary aspect, the Anthropocene narrative pushes for a redesign of political institutions in order to manage the "globe" of "global warming". Ironically, however, this narrative takes for granted, or is indifferent to, the human aspect that those institutions currently strive to safeguard. That is, from Chakrabarty's (2012) two images of humans, the dominant narrative of Anthropocene chooses the geological human and attempts to sideline the political human. Having said that, the imperative for us "to stress that the Anthropocene is a master-narrative should not detract from the suggestion that it is a narrative" (Jazeel, 2019: 227) (emphasis added). Indeed, conceptual approaches like postcolonial theory and Buen Vivir open doors for other narratives, narratives that do not view urgency and justice as incompatible by default. 


\section{Kumar et al.}

Indeed, other narratives have emerged from the global North that address both urgency and justice. For example, Kate Raworth (2017) has extended the planetary boundaries model with social (lower) boundaries, below which human needs and justice are compromised. The degrowth movement (Hickel, 2020; Nirmal and Rocheleau, 2019) aims to redefine human wellbeing in a planetfriendly way. However, as postcolonial scholars have pointed out, the question of how to manage the urgency-justice dilemma itself is not debated on an equal playing field. Political, economic and scientific institutions emphasise and amplify narratives from the global North compared to those from the global South. What is important then is that we use the narrative of the Anthropocene to show the importance of decolonising political, economic and scientific institutions, not to deny urgency, but to create space for new narratives on the dilemma to be considered. Following Jazeel (2019: 227) then, rather than a recolonisation of knowledge, a closure, we could work with the idea of the Anthropocene to create an opening for decolonising our knowledge systems, and to work towards "multiepistemic literacy" (Jazeel, 2019: 227, referring to Juanita Sundberg, 2014). Sundberg (2014: 34) explains that the term multiepistemic literacy, proposed by Sami scholar Rauna Kuokkanen, indicates "learning and dialogue between epistemic worlds" and an exchange between a diversity of political, ethical and epistemological positions. It is in this spirit that we work with the idea of the Anthropocene. We look for a more political Anthropocene; one that tackles the urgency of collective action, while keeping a politics of justice at its centre.

\section{Questions of justice in an era of urgency}

Energy transitions are predominantly understood in terms of transitions from highcarbon energy sources and high quantities of energy use to low-carbon energy sources and reduced energy consumption. This is the dominant understanding that a post-political Anthropocene discourse drives. However, this is only one part of energy transitions. In most parts of the global South, energy transitions take a different form. A large part of the population in countries of the global South still depend on older/traditional forms of more polluting and hazardous energy sources like kerosene for lighting and wood or charcoal for cooking. Following from this, a fulcrum of the urgency vs justice debate for the global South is how to combine greenhouse gases emission mitigation and rapid transitions to cleaner forms of energy with the rapid upscaling of access to energy and progress in human development - poverty reduction, improvement of quality of life, gender and racial equity. The main way in which these two goals have been brought together in the last two to three decades is through the deployment of decentralised small-scale renewable energy technologies. While these have had some success in benefitting particular groups of people, they have also met with strong criticism. An analysis of dominant interventions to address both the urgency and justice problems shows that these initiatives tend to buy into the Anthropocene's one-sided narrative and proceed from a simplistic view on justice. 
Scholars and practitioners argue that small-scale renewable energy slots well into this need to balance a transition from high- to low-carbon energy and from traditional to modern energy (Mahapatra and Dasappa, 2012; Yadav et al., 2019). This prominent role of small-scale renewable energy is driven by a substantial body of literature that argues that modern energy access is central to human development. Energy access extends working hours, reduces wastage of time and bodily energy, fosters livelihoods, improves education and raises human development indicators. Energy also supports information flows, entertainment, better health services and indoor air quality (Riva et al., 2018; Ryan, 2014; Schiffer, 2016). Much of the academic and policy literature on energy access gives importance to three specific development outcomes: education, livelihoods and health (Castán Broto and Kirshner, 2020; Kemmler and Spreng, 2007; Pachauri et al., 2012; Srivastava and Rehman, 2006).

And while many studies show how providing access to modern energy has improved the lives of many, scholars need to remain cautious as often these claims are based on overly simplistic and intuitive assumptions, such as: if only people had electric lights, they would be able to study in the evening when it is dark outside. Such assumptions often do not take into account the social, cultural and political conditions that affect who gets to use the technology, and for what purposes (Abi Ghanem, 2018; Kumar, 2018; see Abi Ghanem in this volume). Energy experiences are also deeply gendered (Osunmuyiwa and Ahlborg, 2019; Ryan, 2014; Standal and Winther, 2016; Govindan and Murali; Green and Schiffer in this volume). These social, cultural, political and economic conditions have received less attention from research and practice communities; instead, studies focus disproportionately on technical and financial aspects of energy access projects. Much like the Anthropocene narrative, such studies can become preoccupied with making the technology feasible, affordable and sustainable and fail to consider how its use may affect the local social order, and vice versa. Emerging critical energy research in the global South has revealed a number of aspects that complicate the idea of quick climate change and development fixes through renewable energy technologies. Drawing together literature on decentralised renewable energy, we outline four criticisms of the idea that they present a quick fix to climate change and development challenges to put things in perspective and outline some important areas of critical energy research towards balancing urgency and justice. Most chapters in this book address one or more of these criticisms.

The first is the question of carbon colonialism. The Earth's atmosphere has a limited carbon budget or carbon space. This refers to the maximum emissions of greenhouse gases that can be allowed before we hit the tipping point of irreversible climate change. Carbon colonialism embodies the idea that global North countries, in the name of supporting development and ecological restoration projects to benefit humanity, use their money and power to colonise the discursive and physical spaces in the global South, in order to mask and remedy their historic emissions and to prevent future emissions from global South countries (Lyons and Westoby, 2014). Burnham et al. (2013: 229) bring up the idea of carbon colonialism and explain that "forms of neocolonialism" may emerge from market 


\section{Kumar et al.}

mechanisms that curtail "the Global South's use of their natural resources so that the North may rectify past emissions and continue current ones". Putting a price on and commodifying emission responsibilities means that historical injustices of extraction and colonisation, which have led to inequalities of wealth between (as well as within) the global North and South, can continue in new forms. This commodification of responsibilities allows richer countries and companies to hegemonise and govern markets for low-carbon energy and emissions credits, sidelining weaker actors who may not be able to afford these. This has the potential to foreclose future development pathways for many global South countries. Global North actors, meanwhile, may feel justified in continuing to emit greenhouse gases, as such projects remove incentives for them to reduce or end their use of fossil fuels (Burnham et al., 2013).

Second, Balls and Fischer (2019: 473) raise the issue of democracy and distributional justice in access to energy. They persuasively demonstrate that even though many energy transition interventions are normatively framed as more just and inclusive, because they are market-based and not embedded in national partypolitics, this does not mean that they actually are more just and inclusive. This is because those technologies, by being embedded in market mechanisms, discriminate based on payment capacities (Balls and Fischer, 2019; Kumar, 2019b). In addition, while many citizens do try to organise themselves to further their interests in affordable and sustainable energy, they bump against a lack of concrete mechanisms to ensure accountability and effective energy delivery (Balls and Fischer, 2019). Boamah (2020: 7) attests to this with evidence from three subSaharan African countries. Boamah explains that, while self-organised, smallscale energy projects provide avenues of reduced state dependence, self-control and democratised energy generation and consumption, such projects require citizens to, on their own, fund energy systems or negotiate rentals ${ }^{4}$ with private companies (Boamah, 2020). Therefore, while these energy systems might promise to navigate the delay from the state in extending energy access, and the high infrastructure costs of state-sponsored energy systems, they also perpetuate a neoliberal system where citizens do not have recourse of traditional mechanisms of claim making, at the same time letting the state off the hook for its responsibilities towards citizens. When the state is responsible for such provisions, citizens are able to organise themselves politically in various ways, ${ }^{5}$ which is not possible within the realm of the market (see also Kumar, 2021). In addition, even when these projects claim to work with "the community", they often imagine a liberal, individualistic notion of the community, one that is compatible with the market, rather than local socio-cultural relationships (Kumar and Taylor Aiken, 2020). The chapters by Abi Ghanem, Sareen and Theiventhran address some of these questions of democracy and distribution in the contexts of Lebanon, Portugal and Sri Lanka, respectively.

Why then, given these challenges, do many multi-lateral and bi-lateral organisations and Northern states promote market-based small-scale renewable energy "solutions" in the global South (Cross, 2019a; Davies, 2018; Gent and Tomei, 2017)? Monyei et al. (2018: 68) explain that a possible cause for this might be the 
"influence of 'Western reality' on the energy narrative" of developing countries. By "Western narrative", they mean particular imaginaries of what "appropriate" and "adequate" energy have come to mean for researchers and practitioners in the global North and how these imaginaries and meanings permeate (often through advocacy from countries in the North) energy policy and discourse in the global South. They argue that many global North countries continue emitting greenhouse gases while indulging in "the wholesale promotion of renewables", which can be "a perverse approach and an act of 'energy bullying', without consciousness of what it means to have energy sufficiency and energy mobility" (Monyei et al., 2018: 68). This brings us back to the questions of democracy, participation and distributional justice. These have been inadequately understood and conceptualised from a global South perspective.

A third issue is that of the prominent place that non-state actors have taken in the provision of energy, especially electricity, in the last decade(Kumar, 2021). Most of these actors promote a market-based approach that puts energy, historically a public good, into the realm of private resource or private commodity. The rationale for this is that market actors, unlike state actors, will be pressured by free competition to develop cost-effective energy technologies tailored to local demand. This market mantra, Cross $(2013,2019 \mathrm{~b}$ : 16) reminds us through Bill Gates' words, is built around the idea of "doing well by doing good", that sets in motion "a politics of hope, founded in the promise of" market-based small-scale low-carbon energy. It assumes that both urgency (to address the climate crisis) and justice (conceptualised as addressing human needs) manifest themselves as market demands that private parties can, will and should address.

However, the market-based idea puts a lot of focus on selling more, urgently to make wider impact - and often ignores the longer-term sustainability of the energy transition interventions, as Turner (2019) has shown through her work in Sri Lanka. Once high-tech Western energy technologies break down, they often cannot be repaired or replaced locally and people go back to the high-carbon, polluting and dangerous sources of energy they had been using (Kumar et al., 2019) and the promises of both urgency and justice remain unfulfilled. Indeed, we need to ask which actors, interests and timescales "neoliberal market-based interventions and entrepreneurialism" privilege and with what implications, especially for disadvantaged groups (Ockwell et al., 2018: 123; see also Byrne and Mbeva, 2017). More recently, the question of energy products that conform to particular quality standards, and the need to distinguish them from low-quality products, based on the idea that "customers pay for quality", has emerged (Balls, 2020; Groenewoudt et al., 2020). However, what quality means, whether quality standards are a way to include and exclude particular actors, and whether especially poor customers are willing and able to make significant long-term investments in energy technologies are questions that need to be explored.

A fourth question relates to gender and racial justice. Working with Silvia Wynter's arguments, Yusoff (2018) has very persuasively shown how racialisation and racial injustices are central to the idea of the Anthropocene. Yusoff (2018) argues that the historical uses and abuses of energy, whether physical 


\section{Kumar et al.}

energy or fossil energy, have been premised on colonisation and racial exploitation, whether of black and indigenous amarican slaves or indentured South Asians. Cross (2019a: 463) reminds us that energy transition interventions do not only change technologies, but also the social relationships in a community, and how people experience the world around them. It is therefore important to consider those effects as well when designing interventions. Standal and Winther (2016: 43) show that while energy access helps women's empowerment, it can also dent "women's agency, by upholding and perhaps even strengthening subversive structures such as patriarchy and dowry", for example access to electricity resulting in demands for electronic goods as dowry. They explain that this is a result of women being imagined only as "end users" in energy policy and a lack of women's involvement in designing and development of appropriate policies and measures. Baruah (2015: 71) argues that "in addition to creating opportunities for women in technology installation, repair, dissemination, awareness generation, and marketing, there is a growing need within the energy sector to involve women in the formal engineering aspects of technology design and innovation". There is a growing recognition that gender and racial diversity are key to designing technologies and projects right from the onset. Baruah (2015) questions whether having all-male energy teams has resulted in a lack of focus on cooking solutions. Similarly, Balls and Fischer (2019: 472) report how microgrid operators in India choose people with the "right caste and social position" to manage and maintain microgrids in the villages (see also Sharma, 2020; Singh et al., 2017). Kumar (2018, 2019a) and Kumar and Shaw (2020) have discussed in detail how genderand caste-based socio-cultural factors mediate access to energy and the benefits of energy transition projects in Indian villages. Govindan and Murali and Greene and Schiffer address these concerns in their chapters from India and The Gambia respectively.

There are a number of other important issues around the question of just transitions, like land (McEwan, 2017; Yenneti and Day, 2015), electronic and other waste (Cross and Murray, 2018; Dustin Mulvaney et al., 2009; Kumar and Turner, 2020), labour (Mulvaney, 2013, 2014) and environmental impacts (Lakhanpal, 2019; Mulvaney, 2013) that sit at the fulcrum of the urgency and justice debate that we have picked up. It is not possible to go into all of them in this introduction, but by flagging them here we hope that others will pick them up for detailed discussions elsewhere.

\section{Pathways for (re)thinking energy justice in an era of urgency}

After having raised the issue of urgency vs justice and outlined some justice pitfalls of urgent energy transitions in the global South, the question in front of us is: how do we bring together these two ideas - one that calls for abstract universal unity and the other for the recognition of individual needs and differences? As the climate emergency begins to dominate the energy transitions discourse, there are growing calls for urgent decarbonisation and energy transitions. More emphasis is being put on new technological solutions like solar PV, digitalisation 
of electricity infrastructure and electric vehicles (Healy and Barry, 2017; Kern and Rogge, 2016; Sovacool and Geels, 2016). If not thought through carefully, such technological interventions will have unintended consequences for energy poverty, justice and democracy, especially in the global South (Healy and Barry, 2017).

In agreement with Donna Haraway (2015: 160) we could say that "our job is to make the Anthropocene as short/thin as possible and to cultivate with each other in every way imaginable epochs to come that can replenish refuge". To further this endeavour, we need to progress anti- and de-colonial thought within a somewhat colonising discourse of energy transitions (as flagged in the earlier section). How to do this? Chapters of this book illustrate the risks of a universal hegemonic energy transitions idea. By bringing them together we can identify some pathways developed in the global South that can bring urgency and justice together.

Abi Ghanem, in her chapter "Insights from an assemblage perspective for a (better) understanding of energy transitions: facing the challenge of sustainability in Lebanon's energy crisis" shows how post-structural theories could help bring into analysis a range of actors and issues that structural theories are often not able to accommodate. As Abi Ghanem argues, such theoretical deployments are "not only helpful in establishing the grounding for context-based approaches by tracing the spatiality and temporality of informality, but can also orient us in the direction of inclusive energy futures that are more achievable in the short term". Driven by an assemblage approach, Abi Ghanem brings together the understanding of the historical structuring of Lebanon's electricity system with that of its contemporary everyday operations and upkeep. Seeing the electricity system as an open-whole (Bennett, 2010) helps put focus on a range of actors that enter, inhabit and exit the electricity assemblages, in a way that never stabilises. This dynamic perspective illustrates how some injustices remain stable throughout the changes, but also shows how people navigate them in their everyday life.

Melnyk and Singh question the idea of "sustainability" in energy transitions in their chapter "Constructing an inclusive vision of sustainable transition to decentralised energy: local practices, knowledge, values and narratives in the case of community-managed grids in rural India”. They critique the idea of high-tech low-carbon energy solutions as an embodiment of the hegemonised idea of sustainability and energy transitions emanating from the global North. Indeed, a wide and unquestioning trust in techno-economic solutions backed by capitalism is a reminder that a political opportunity to drastically change the world, driven by the idea of Anthropocene, could easily be hijacked by neoliberal utopian visions that depoliticise the Anthropocene (Swyngedouw, 2019; Swyngedouw and Ernstson, 2018). Driven by the idea of "hidden histories", Melnyk and Singh urge us to focus on "local narratives and socio-material networks" that will excavate the positions of marginal actors like labour, community and the non-human within the sustainability discourse. Drawing on cases of decentralised electricity grids in India, they propose a more in-depth and honest engagement with local knowledge and improvisational responses (Kumar, 2019a). This pathway is not only for 
material justice for many, but also for discursive justice through the decolonisation of our knowledge systems.

With their chapter on "Bolivia's energy transition in harmony with nature: reality or delusion?" Villavicencio-Calzadilla and Mauger bring us a more ecocentric chapter, compared to our mostly anthropocentric volume. Taking a critical legal perspective, they ask if Bolivia's idea of giving legal rights to Mother Earth helps develop an energy transition that is in harmony with nature. Their chapter is critical from the outset, as it departs from and questions the normative assumption that transitioning to cleaner forms of energy automatically means being more harmonious with nature. Indeed, a point that we raised earlier comes back here, as Villavicencio Calzadilla and Mauger argue that "an energy transition in harmony with nature will require not only technological transformations, but also major structural changes (economic, social, legal and political)". Buen Vivir or Vivir Bien, as a new way of thinking about the relationship between humans and nature, can drive an "epochal thinking" of the Anthropocene, which Dipesh Chakrabarty (2018) asks for, clearing paths for justice for humans and non-humans, perhaps progressing an ecocentric justice agenda. But Villavicencio Calzadilla and Mauger remind us that, although discursively present in the legal system, these agendas are not being materially practised in Bolivia for the moment.

Continuing this quest for alternative knowledge systems and politics, Sareen, in a chapter titled "Scalar biases in solar photovoltaic uptake: socio-materiality, regulatory inertia and politics", demonstrates how learnings from the global South could be effectively deployed to understand justice issues in the global North. This is politically subversive as it flips the "usual" flow of theoretical knowledge: using a "methodological approach from a study" on scalar biases in energy transitions in India to understand the case of "solar rollout governance in Portugal". Sareen persuasively argues that "the socio-materiality of energy infrastructure, regulatory inertia and path dependence, and political influence on energy development" drives a bias towards large-scale solar developments (for example solar parks), and away from small- and micro-scale interventions like solar home systems. This bias, although accelerating climate mitigation, has crucial justice impacts - land grabbing, displacement, and maintaining unequal power structures embedded in centralised energy systems. In Sareen's words, the dilemma between urgency and justice is "premised on entrenched modalities of governance and energy infrastructure". These need to be shaken up in order to facilitate more just energy transitions.

Theiventhran poses the novel question of justice in post-war settings, where a transition to peace and racial equity needs to be embedded into any plans for transitions to low-carbon energy. His chapter, "Energy transitions in a post-war setting: questions of equity, justice and democracy in Sri Lanka”, poses another challenge to the normative understanding of energy transitions as "good". Theiventhran asks: "why [do] renewable energy projects in the post-war societies encounter resistance even though they are clean and green?" He argues that in a context like Sri Lanka, where wounds of racial conflict and injustices are not yet healed, "equity and justice need to take centre stage". Indeed, not just in conflict 
settings, we need be alert to the fact that "energy injustice is produced historically, geographically and materially" and that these injustices are "more than matters of prices and income and involve structural differences that have evolved over time and space".

Staying in South Asia and raising another critical justice agenda, which we discussed earlier, Govindan and Murali provide insights into how gender and caste intersect with each other to problematise participative energy projects. Their chapter "Energising change: clean cooking and the changing social position of women" demonstrates that while organisations in India are working to mainstream "gender" in energy access projects by supporting women entrepreneurs and salespersons, caste bias often gets in their way. This connects to wider discourses on gender-race intersectionality. Govindan and Murali demonstrate that while women entrepreneurs from lower castes in India have to deal with moral judgements on "working women", owing to their caste identities, they are also often not allowed to enter the homes and kitchens of higher caste families. The urgency of energy transitions here is directly hampered by caste injustices faced by women who build clean cook stoves.

In another chapter focused on gender, Greene and Schiffer traverse the NorthSouth split to comparatively analyse historical energy practices in The Gambia and Ireland. Their chapter, "Women don't ride bicycle[s], only men ride bicycles': gender and justice in energy transitions”, argues that research on transport energy practices and equity has not given much focus on "power, capability ... patterns of social differentiation" that have led to "sidelining of equity within energy focused practice-based research". Through their comparative work, Greene and Schiffer find that "mobility careers trajectories ... are both shaped by and shape gendered norms and social roles, embodied and performed in private and public space". They conclude by "calling for greater consideration of gendered patterns of inclusion and exclusion in daily dynamics of energy systems as imperative for achieving just transitions".

Driven by a postcolonial sensibility, one that "provincialises Europe" (Chakrabarty, 2008) and forces us to think through heterogeneity, this book frames the challenge in front of us as follows: how do we work with the disjunctive images of humans together? This is because, while the Anthropocene calls us to unite, as the chapters in the book illustrate, its impacts are, and will be, felt differently (Jazeel, 2019). If we need to politically, or even discursively, understand, experience and respond as a geological force, such a response needs to be built through alliances that are ethically structured with those marginal groups at the centre who are most vulnerable to geo-political and global policy changes, as well as to the impacts of environmental change (Jazeel, 2019). As Madden (2019) reflects, all spaces on Earth increasingly reflect a concern for, and impacts of, the climate crisis. This is being overlaid on other socio-cultural and economic crises, so that "the climate crisis is also itself constitutively shaped by other ... problems, processes, and hierarchies" (Madden, 2019: 2). Evidence of these hierarchies is manifesting in new neoliberal projects around smart grids and cities and ecogentrification that exclude the more vulnerable citizens (Rice et al., 2019). Indeed, 


\section{Kumar et al.}

focusing on techno-fixes that exacerbate existing socio-cultural and economic crisis risks tipping the political Anthropocene, as Swyngedouw (2019) warns, into the apolitical or post-political "anthropo(Obs)cene". To recentre the voices of the marginal groups, we raise this question of justice in the era of urgency. While building a wider alliance of responsibility, one that a politics of the Anthropocene demands, we keep a firm footing in the politics of intra-human justice, one that a politics of the Anthropocene cannot (and cannot be allowed to) avoid.

\section{Notes}

$1 \mathrm{https} / /$ unfccc.int/news/time-to-go-further-faster-together. Accessed 1 Oct 2020.

2 See Kalmbach et al. (2020: 279) on the "allure of technological fix" for crises like the Anthropocene and their calls for a more historical and cultural analysis of this allure.

3 Some dominant proposed solutions for the climate crisis are large alternative energy farms and electric vehicles developed by private capital. These have already exacerbated processes of mineral extraction and land grabbing, evicting and polluting local pastoral and aboriginal communities (Mulvaney, 2013, 2014; Yenneti and Day, 2015).

4 The electricity rentals for these systems are often many times higher than state provisions of energy.

5 See, for example, Chatterjee's (2004) discussion on the politics of claim through civil and political societies.

6 This has led to a productive debate around the concept of energy bullying. See Boamah (2020), Monyei et al. $(2018,2019)$ and Todd et al. (2019).

\section{References}

Abi Ghanem D. (2018) Energy, the city and everyday life: Living with power outages in post-war Lebanon. Energy Research and Social Science 36(April 2017). Elsevier: 36-43. DOI: 10.1016/j.erss.2017.11.012.

Balls J.N. (2020) Low-cost, adaptable solutions sell: Re-thinking off-grid solar diffusion at the bottom of the pyramid in India. Energy Research \& Social Science 70(September). Elsevier Ltd: 101811. DOI: 10.1016/j.erss.2020.101811.

Balls J.N. and Fischer H.W. (2019) Electricity-centered clientelism and the contradictions of private solar microgrids in India. Annals of the American Association of Geographers 109(2). Routledge: 465-475. DOI: 10.1080/24694452.2018.1535312.

Banerjee S. (2017) Beyond the intimations of mortality: Chakrabarty, Anthropocene, and the politics of the (im)possible. Mediations 2(Summer): 1-14. Available at: http://www .mediationsjournal.org/articles/Chakrabarty_Anthropocene.

Baruah B. (2015) Creating opportunities for women in the renewable energy sector: Findings from India. Feminist Economics 21(2): 53-76. DOI: 10.1080/13545701.2014.990912.

Bennett J. (2010) The agency of assemblages. In: Bennett, J. (ed.), Vibrant Matter: A Political Ecology of Things. Durham, NC: Duke University Press, p. 200.

Boamah F. (2020) Desirable or debatable? Putting Africa's decentralised solar energy futures in context. Energy Research and Social Science 62(December 2019). Elsevier: 101390. DOI: 10.1016/j.erss.2019.101390.

Burnham M., Radel C., Ma Z., and Laudati, A. (2013) Extending a geographic lens towards climate justice, part 2: Climate action. Geography Compass 7(3): 228-238. DOI: $10.1111 /$ gec 3.12033 . 
Byrne R. and Mbeva K. (2017) The political economy of state-led transformations in propoor low carbon energy: A case study of solar PV in Kenya. Transformations EnergyKenya. 91. Brighton. Available at: https://opendocs.ids.ac.uk/opendocs/bitstream/hand le/123456789/12968/EnergytranslKenya.pdf?sequence=1\&isAllowed=y.

Castán Broto V. and Kirshner J. (2020) Energy access is needed to maintain health during pandemics. Nature Energy. DOI: 10.1038/s41560-020-0625-6.

Castree N. (2015) Changing the Anthropo(s)cene: Geographers, global environmental change and the politics of knowledge. Dialogues in Human Geography 5(3): 301-316. DOI: $10.1177 / 2043820615613216$.

Chakrabarty D. (2008) Provincializing Europe: Postcolonial Thought and Historical Difference. Postcolonial Thought and Historical Difference. Princeton: Princeton University Press. DOI: 10.1525/ae.2002.29.1.214.

Chakrabarty D (2009) The climate of history: Four theses. Critical Inquiry 35(2): 197-222.

Chakrabarty D. (2012) Postcolonial studies and the challenge of climate change. New Literary History 43(1): 1-18. DOI: 10.1353/nlh.2012.0007.

Chakrabarty D. (2017a) Afterword. South Atlantic Quarterly 116(1): 163-168. DOI: 10.1215/00382876-3749403.

Chakrabarty D. (2017b) The politics of climate change is more than the politics of capitalism. Theory, Culture \& Society 34(2-3): 25-37. DOI: 10.1177/0263276417690236.

Chakrabarty D. (2018) The Crisis of Civilisation: Exploring Global and Planetary Histories. New Delhi: Oxford University Press.

Chatterjee P. (2004) The Politics of the Governed. New York: Columbia University Press.

Cross J. (2013) The 100th object: Solar lighting technology and humanitarian goods. Journal of Material Culture 18(August): 367-387. DOI: 10.1177/1359183513498959.

Cross J. (2019a) Selling with prejudice: Social enterprise and caste at the bottom of the pyramid in India. Ethnos 84(3): 458-479. DOI: 10.1080/00141844.2018.1561487.

Cross J. (2019b) The solar good: Energy ethics in poor markets. Journal of the Royal Anthropological Institute 25(S1): 47-66. DOI: 10.1111/1467-9655.13014.

Cross J. and Murray D. (2018) The afterlives of solar power: Waste and repair off the grid in Kenya. Energy Research \& Social Science 44(August 2017). Elsevier: 100-109. DOI: $10.1016 /$ j.erss.2018.04.034.

D’Souza R. (2018) Environmentalism and the politics of pre-emption: Reconsidering South Asia's environmental history in the epoch of the Anthropocene. Geoforum (January). Elsevier: 0-1. DOI: 10.1016/j.geoforum.2018.09.033.

Davies G. (2018) Clean energy product markets in sub-Saharan Africa: Complex market devices and power asymmetries. Energy Research \& Social Science 42: 80-89. DOI: 10.1016/j.erss.2018.03.009.

Davis H. and Todd Z. (2017) On the Importance of a date, or decolonizing. Acme: An International Journal for Critical Geographers 16(4): 761-780. Available at: https:// www.acme-journal.org/index.php/acme/article/view/1539.

Dustin M., Vicki B., Monica C., Sheila D., Lauren O., Simon K., Serena M., William R., Esperanza S., Peter S. and Ananth Sridhar D.Y. (2009) Silicon Valley Toxics Coalition: Toward a just and sustainable solar energy industry. San Jose: Silicon Valley Toxics Coalition. Available at: http://www.vermontfuel.com/2012_Files_files/Silicon_Valley _Toxics_Coalition_-_Toward_a_Just_and_Sust.pdf.

Gent D. and Tomei J. (2017) Electricity in Central America: Paradigms, reforms and the energy trilemma. Progress in Development Studies 17(2): 116-130. DOI: $10.1177 / 1464993416688826$. 


\section{Kumar et al.}

Gergan M.D. (2017) Living with earthquakes and angry deities at the Himalayan Borderlands. Annals of the American Association of Geographers 107(2): 490-498. DOI: 10.1080/24694452.2016.1209103.

Groenewoudt A.C., Romijn H.A. and Alkemade F. (2020) From fake solar to full service: An empirical analysis of the solar home systems market in Uganda. Energy for Sustainable Development 58. The Authors: 100-111. DOI: 10.1016/j. esd.2020.07.004.

Haraway D. (2015) Anthropocene, Capitalocene, Plantationocene, Chthulucene: Making kin. Environmental Humanities 6: 159-165.

Healy N. and Barry J. (2017) Politicizing energy justice and energy system transitions: Fossil fuel divestment and a "just transition". Energy Policy 108(June). Elsevier Ltd: 451-459. DOI: 10.1016/j.enpol.2017.06.014.

Hickel J. (2020) What does degrowth mean? A few points of clarification. Globalizations 0(0). Taylor \& Francis: $1-7$. DOI: 10.1080/14747731.2020.1812222.

IPCC (2019) Global Warming of $1.5^{\circ} \mathrm{C}$. An IPCC Special Report on the impacts of global warming of $1.5^{\circ} \mathrm{C}$ above pre-industrial levels and related global greenhouse gas emission pathways, in the context of strengthening the global response to the threat of sustainable dev. Ipcc_Sr15. Available at: https://www.ipcc.ch/sr15/download/\#full.

Jazeel T. (2019) Postcolonialism. Oxon/New York: Routledge.

Kalmbach K., Marklund A. and Åberg A. (2020) Crises and technological futures: Experiences, emotion, and action. Technology and Culture 61(1): 272-281. DOI: 10.1353/tech.2020.0001.

Kemmler A. and Spreng D. (2007) Energy indicators for tracking sustainability in developing countries. Energy Policy 35(4): 2466-2480. DOI: 10.1016/j.enpol.2006.09.006.

Kern F. and Rogge K.S. (2016) The pace of governed energy transitions: Agency, international dynamics and the global Paris agreement accelerating decarbonisation processes? Energy Research and Social Science 22. Elsevier Ltd: 13-17. DOI: 10.1016/j.erss.2016.08.016.

Kumar, A. (2021) Expertise, legitimacy and subjectivity: Three techniques for a will to govern low carbon energy projects in India. Environment and Planning C: Politics and Space 0(0): 1-19. DOI: 10.1177/2399654420965565.

Kumar A. (2018) Justice and politics in energy access for education, livelihoods and health: How socio-cultural processes mediate the winners and losers. Energy Research and Social Science 40(January 2017). Elsevier: 3-13. DOI: 10.1016/j.erss.2017.11.029.

Kumar A. (2019a) Between metis and techne: Politics , possibilities and limits of improvisation. Social \& Cultural Geography 00(00). Routledge: 1-24. DOI: 10.1080/14649365.2019.1645201.

Kumar A. (2019b) Beyond technical smartness: Rethinking the development and implementation of sociotechnical smart grids in India. Energy Research and Social Science 49. Elsevier Ltd: 158-168. DOI: 10.1016/j.erss.2018.10.026.

Kumar A. and Shaw R. (2020) Transforming rural light and dark under planetary urbanisation: Comparing ordinary countrysides in India and the UK. Transactions of the Institute of British Geographers 45(1): 155-167. DOI: 10.1111/tran.12342.

Kumar A. and Taylor Aiken G. (2020) A postcolonial critique of community energy: Searching for community as solidarity in India and Scotland. Antipode 0(0): 1-22. DOI: 10.1111/anti.12683.

Kumar, A. and Turner, B. (2019) Sociomaterial solar waste: Afterlives and lives after of small solar. In: Bombaerts G, Jenkins K, Sanusi YA, et al. (eds) Energy Justice 
Across Borders. Switzerland: Springer International Publishing, pp. 155-173. DOI: 10.1007/978-3-030-24021-9_8.

Kumar A., Ferdous R., Luque-Ayala A., et al. (2019) Solar energy for all? understanding the successes and shortfalls through a critical comparative assessment of Bangladesh, Brazil, India, Mozambique, Sri Lanka and South Africa. Energy Research \& Social Science 48(March 2018). Elsevier: 166-176. DOI: 10.1016/j.erss.2018.10.005.

Lakhanpal S. (2019) Contesting renewable energy in the global south: A case-study of local opposition to a wind power project in the Western Ghats of. Environmental Development 30(February). Elsevier Ltd: 51-60. DOI: 10.1016/j.envdev.2019.02.002.

Lenton T.M., Rockström J., Gaffney O., et al. (2019) Climate tipping points - too risky to bet against. Nature 575: 592-595.

Lyons K. and Westoby P. (2014) Carbon colonialism and the new land grab: Plantation forestry in Uganda and its livelihood impacts. Journal of Rural Studies 36. Elsevier Ltd: 13-21. DOI: 10.1016/j.jrurstud.2014.06.002.

Madden D. (2019) Editorial: City of emergency. City 0(0). Taylor \& Francis: 1-4. DOI: $10.1080 / 13604813.2019 .1648734$.

Mahapatra S. and Dasappa S. (2012) Rural electrification: Optimising the choice between decentralised renewable energy sources and grid extension. Energy for Sustainable Development 16(2). Elsevier Ltd: 146-154. DOI: 10.1016/j.esd.2012.01.006.

McEwan C. (2017) Spatial processes and politics of renewable energy transition: Land, zones and frictions in South Africa. Political Geography 56. Elsevier Ltd: 1-12. DOI: 10.1016/j.polgeo.2016.10.001.

Monyei C.G., Jenkins K., Serestina V., et al. (2018) Examining energy sufficiency and energy mobility in the global south through the energy justice framework. Energy Policy 119(November 2017). Elsevier Ltd: 68-76. DOI: 10.1016/j.enpol.2018.04.026.

Monyei Chukwuka G., Jenkins K.E.H, Monyei Chukwuemeka G., et al. (2019) Response to Todd, De Groot, Mose, McCauley and Heffron's critique of "Examining energy sufficiency and energy mobility in the global south through the energy justice framework". Energy Policy 133(August): 1-5. DOI: 10.1016/j.enpol.2019.110917.

Mulvaney D. (2013) Opening the black box of solar energy technologies: Exploring tensions between innovation and environmental justice. Science as Culture 22(2). Routledge: 230-237. DOI: 10.1080/09505431.2013.786995.

Mulvaney D. (2014) Are green jobs just jobs? Cadmium narratives in the life cycle of Photovoltaics. Geoforum 54. Pergamon: 178-186. DOI: 10.1016/J. GEOFORUM.2014.01.014.

Nirmal P. and Rocheleau D. (2019) Decolonizing degrowth in the post-development convergence: Questions, experiences, and proposals from two Indigenous territories. Environment and Planning E: Nature and Space 0(0): 251484861881947. DOI: 10.1177/2514848618819478.

Ockwell D., Byrne R., Hansen U.E., et al. (2018) The uptake and diffusion of solar power in Africa: Socio-cultural and political insights on a rapidly emerging socio-technical transition. Energy Research and Social Science 44(May). Elsevier: 122-129. DOI: 10.1016/j.erss.2018.04.033.

Osunmuyiwa O. and Ahlborg H. (2019) Inclusiveness by design? Reviewing sustainable electricity access and entrepreneurship from a gender perspective. Energy Research \& Social Science 53(October 2018). Elsevier: 145-158. DOI: 10.1016/j.erss.2019.03.010.

Pachauri S., Brew-Hammond A., Barnes D.F., et al. (2012) Energy access for development. Global Energy Assessment (GEA): 1401-1458. DOI: 10.1017/cbo9780511793677.025. 


\section{Kumar et al.}

Raworth K. (2017) Why it's time for Doughnut economics. IPPR Progressive Review 24(3): 216-222. DOI: 10.1111/newe.12058.

Rice J.L., Cohen D.A., Long J., Jurjevich J.R. (2019) Contradictions of the climate-friendly city: New perspectives on eco-gentrification and housing justice. International Journal of Urban and Regional Research. DOI: 10.1111/1468-2427.12740.

Riva F., Ahlborg H., Hartvigsson E., Pachauri S., Colombo, E. (2018) Electricity access and rural development: Review of complex socio-economic dynamics and casual diagrams for more appropriate energy modelling. Energy for Sustainable Development 43. International Energy Initiative: 203-223. DOI: https://doi.org/10.1016/j.esd.2018. 02.003 .

Rockström J., Steffen W., Noone K., Persson, A., Stuart Chapin, F., Lambin, E. F., Lenton, T. M., Scheffer, M., Folke, C., Schellnhuber, H. J., Nykvist, B., de Wit, C. A., Hughes, T., van der Leeuw, S., Rodhe, H., Sörlin, S., Snyder, P. K., Costanza, R., Svedin, U., Falkenmark, M., Karlberg, L., Corell, R. W., Fabry, V. J., Hansen, J, Walker, B., Liverman, D., Richardson, K., Crutzen, P., and Foley, J. A. (2009) A safe operation space for humanity. Nature 461(September): 472-475.

Ryan S.E. (2014) Rethinking gender and identity in energy studies. Energy Research \& Social Science 1. Elsevier Ltd.: 96-105. DOI: 10.1016/j.erss.2014.02.008.

Saldanha A. (2020) A date with destiny: Racial capitalism and the beginnings of the Anthropocene. Environment and Planning D: Society and Space 38(1): 12-34. DOI: $10.1177 / 0263775819871964$.

Schiffer A. (2016) Empowered, excited, or disenfranchised? Unveiling issues of energy access inequality and resource dependency in The Gambia. Energy Research \& Social Science 18. Elsevier Ltd: 50-61. DOI: 10.1016/j.erss.2016.04.011.

Schmidt J.J., Brown P.G. and Orr C.J. (2016) Ethics in the Anthropocene: A research agenda. Anthropocene Review 3(3): 188-200. DOI: 10.1177/2053019616662052.

Sharma A. (2020) 'We do not want fake energy': The social shaping of a solar microgrid in rural India. Science, Technology and Society (April 2018): 1-17. DOI: 10.1177/0971721820903006.

Singh A., Strating A.T., Romero Herrera N.A., van Dijk H.W., Keyson D.V. (2017) Towards an ethnography of electrification in rural India: Social relations and values in household energy exchanges. Energy Research \& Social Science 30(November 2016). Elsevier: 103-115. DOI: 10.1016/j.erss.2017.06.031.

Sovacool B.K. and Geels F.W. (2016) Further reflections on the temporality of energy transitions: A response to critics. Energy Research \& Social Science 22. Elsevier Ltd: 232-237. DOI: 10.1016/j.erss.2016.08.013.

Srivastava L. and Rehman I. (2006) Energy for sustainable development in India: Linkages and strategic direction. Energy Policy 34(5): 643-654. DOI: 10.1016/j. enpol.2005.11.016.

Standal K. and Winther T. (2016) Empowerment through energy? impact of electricity on care work practices and gender relations. Forum for Development Studies 43(1). Taylor \& Francis: 27-45. DOI: 10.1080/08039410.2015.1134642.

Sundberg J (2014) Decolonizing posthumanist geographies. Cultural Geographies 21(1): 33-47. DOI: $10.1177 / 1474474013486067$.

Swyngedouw E. (2019) The Anthropo (Obs) cene. In: Antipode Editorial Collective (ed.) Keywords in Radical Geography: Antipode at 50. John Wiley \& Sons Ltd, pp. 253-258. 
Swyngedouw E. and Ernstson H. (2018) Interrupting the anthropo-obscene: Immunobiopolitics and depoliticizing ontologies in the Anthropocene. Theory, Culture and Society 35(6): 3-30. DOI: 10.1177/0263276418757314.

Todd I., De Groot J., Mose T., McCauley D., Heffron R.J. (2019) Response to "Monyei, Jenkins, Serestina and Adewumi examining energy sufficiency and energy mobility in the global south through the energy justice framework". Energy Policy 132(May): 44-46. DOI: 10.1016/j.enpol.2019.05.012.

Tolia-Kelly D.P. (2016) Anthropocenic culturecide: An epitaph. Social and Cultural Geography 17(6). Routledge: 786-792. DOI: 10.1080/14649365.2016.1193623.

Turner B. (2019) Diffusion on the ground: Rethinking the logic of scale and access in off-grid solar. Energy Research and Social Science 50(November 2018): 1-6. DOI: 10.1016/j.erss.2018.11.005.

Yadav P., Malakar Y. and Davies P.J. (2019) Multi-scalar energy transitions in rural households: Distributed photovoltaics as a circuit breaker to the energy poverty cycle in India. Energy Research and Social Science 48(January 2018). Elsevier: 1-12. DOI: 10.1016/j.erss.2018.09.013.

Yenneti K. and Day R. (2015) Procedural (in)justice in the implementation of solar energy: The case of Charanaka solar park, Gujarat, India. Energy Policy 86(2015). Elsevier: 664-673. DOI: 10.1016/j.enpol.2015.08.019.

Yusoff K. (2018) A Billion Black Anthropocenes or None. Forerunners. Minneapolis: University of Minnesota Press. DOI: 10.5749/9781452962054.010236200 


\title{
2 Insights from an assemblage perspective for a (better) understanding of energy transitions
}

\author{
Facing the challenge of sustainability in \\ Lebanon's energy crisis
}

\author{
Dana Abi Ghanem
}

\section{Introduction}

This chapter takes the case of the electricity infrastructure in Lebanon to demonstrate how assemblage as a theoretical perspective can be useful in advancing thinking on energy and sustainability transitions in cities of the global South. It builds on qualitative research conducted in Lebanon on the power outages that blight the everyday life of the country's denizens, delving into their history in the context of the civil war and the subsequent post-war developments that have shaped electricity services since. Whilst the example of Lebanon is not necessarily representative of the various challenges and priorities facing cities with regards to energy access and sustainability, the purpose here is to contribute an analytical lens that can advance our thinking and policy making on energy transitions in the global South.

In Lebanon, electricity services face a major crisis. The electricity generated is insufficient to meet demand (Bouri and El-Assad, 2016), resulting in unreliable services and scheduled power outages. This has become an endemic problem for the country's residents that began during the Lebanese civil war (1975-1990) and continues to this day (Abi Ghanem, 2018; Moore and Collins, 2020). Post-war reconstruction efforts since the early 1990s (World Bank, 1996) have led to a rise in living standards and consequently a rise in demand for electricity services. However, the energy sector is still hampered by corruption and mismanagement, whereby subsequent investment in the network infrastructure fails to fill the supply gap (Abdelnour, 2003). The corrupt practices also involve the national utility company - Électricité du Liban (EDL) - which has not been able to recoup monthly billing nor control illegal connections to the grid (Moore and Collins, 2020) and is in deficit (UN-ESCWA, 2017). With Lebanon relying heavily on imported fuel oil (OECF/IEA, 2014), the energy sector is responsible for a large part of the country's external debt (World Bank, 2019) and has become a financial burden on the country's economy.

Furthermore, recent developments in the region, namely the Syrian war that began in 2011 and is still ongoing, compounded the problem, with the usual 
electricity imports from Syria disrupted (Bouri and El-Assad, 2016) and the influx of thousands of Syrian refugees escaping the violence, which increased electricity demand. All these factors contribute to perennial power outages and load shedding that have impacted many communities in Lebanon since the early 1990s (Bouri and El-Assad, 2016), and have worsened since 2011. The power outages have become normalised and their effects integrated into the rhythm of everyday life in Lebanon (Abi Ghanem, 2018). However, the power outages do not affect everyone in the same way: communities in metropolitan Beirut (the capital) have lived with a schedule of between three and four hours of outage per day, whilst those in the suburbs and the rest of the country endure around six to eight hours of outage daily. In order to meet their electricity needs, the vast majority of people came to rely on an informal network of electricity provision, which gradually grew as a result of this shortage (Abi Ghanem, 2018; Bouri and El-Assad, 2016). The informal system provides electricity to households to cover most outages. At a considerable cost, they not only exacerbate the economic burden and the energy poverty of many households, but also worsen urban air pollution since they are based on diesel generators and located within urban areas (Shihadeh et al., 2013).

As mentioned before, the electricity situation in Lebanon is presented here to make a case for engaging with assemblage theory when exploring energy for development. In the last decade, pathways and plans have been developed for the energy sector in the country, emphasising the need for a reliable infrastructure in order to drive much-needed growth and development (Abosedra et al., 2009). The 2010 Energy Programme (Bassil, 2010) promised administrative and legal reforms, including mechanisms for privatising supply and liberalising the energy market, establishing a regulatory body and investing in renewable energy technologies (RETs). From the plan, a National Renewable Action Plan has been developed and two phases for a National Energy Efficiency Action Plan have been implemented (Jouni et al., 2016). However, the overall reforms and projects outlined in the 2010 Energy Programme are yet to be implemented, owing to political and financial impediments in the country (UN-ESCWA, 2017).

In principle, scrutiny of these plans reveals the extent of the investment and financing needed, and the considerable legal and institutional reform required to bring about the desired change (Machnouk et al., 2019). What can be gleaned from overviewing these documents are the debates on the viability of different approaches and their extent, such as the liberalisation of the energy market to allow new entrants to generate and sell electricity. The expansive list of technological options belies socio-economic and local structures that can inhibit uptake and deepen the energy divide. From a sociological lens, one insight that can be elicited is the notion of energy services centred on the "modern infrastructure ideal" (Graham and Marvin, 2001), and one can trace this project in Lebanon as beginning with the large-scale investments in water and hydroelectric energy from the 1960s (Abd El-Al, 2018). Building on the legacy of the Litani River project (consisting of a large irrigation system and several hydroelectric power plants), the new Energy Programme for Lebanon continues to be dominated by a centralised market-led and state-regulated energy system based on investment in 
large water and energy projects including dams, additional thermal power plants and large-scale PV farms (LCEC, 2016). Further assessment of these plans is beyond the scope of this chapter; suffice to say that insofar as national-level strategy is concerned, an idealised large-scale infrastructure for electricity provision remains the overriding vision.

In practice, the aforementioned RET plans have succeeded in developing a small part of Lebanon's energy sector towards renewable sources (c.f. Moore and Collins, 2020). The extensive uptake of comprehensive reforms, however, is impeded by the political system (Obeid, 2020) and therefore a considerable sustainable energy transition driven by large-scale investment is unlikely given the political instability in the country and the deficit-ridden EDL (UN-ESCWA, 2017). However, given the worsening socio-economic conditions in Lebanon (World Bank, 2019), urgency is required, which cannot wait for political reforms or the legal and regulatory framework (AUB-IFI, 2019), both necessary for largescale sustainable investments in the energy sector (Machnouk et al., 2019). This is evident in that where success is observed, it has been limited to small-scale projects (Moore and Collins, 2020). From this perspective, it can be argued that these plans obfuscate the myriad complexities that have arisen over the years (during and since the civil war), including the socio-political inertia and the reality of informal services and self-generation. In particular, they ignore the notion of hybrid configurations of electricity provision (Verdeil, 2019; Castan Broto et al., 2018) that needs to assimilate the informal network of electricity providers into future energy planning. This is especially the case for Lebanon, given the vested interests that established informal electricity providers have (Rose, 2018; Rosen, 2018 ) and their entrenched power in the country's political system (Moore and Collins, 2020).

This research recognises that the everyday experience of energy access across the different urban areas of Lebanon - their noisy and polluting generators, the different household appliances and equipment, the intermingling wires, as well as the complicated routines and everyday strategies adopted by people to accommodate power outages - all together make up the infrastructure that serves the electricity needs of the country's inhabitants. It is in delineating these networks and associations that we begin to truly understand the energy challenge: how these energy services come to be and come to shape towns and cities, which nowadays are ever more under pressure to drive forward sustainable energy transitions. By doing so, we acknowledge the services' power and influence over any propensity to transition to a more sustainable energy system and the role they could play in the future of energy provision for Lebanon.

Perspectives from geography and science and technology studies (STS) have, over the years, argued for better-informed and context-based approaches to understanding energy and infrastructure (Furlong, 2011; Graham and McFarlane, 2015; Rutherford and Coutard, 2014). In this chapter, these approaches are used to develop an account of infrastructure with a focus on how electricity services in Lebanon are experienced, explaining how the different logics of access have emerged. Thinking through assemblage (McFarlane and Anderson, 2011), these 
disruptions are used as a point through which to trace the entanglements of the electricity infrastructure. These entanglements cut across political pivot points, economic imaginaries and the socio-technical. Following the wires of Lebanon's networked infrastructure elicits not only the heterogeneity of the system that it is characterised by today, but also sheds light on some elements of its history and, importantly, the emergence of the informal system of provision, which has come to significantly influence people's everyday experience of energy and public services (Abi Ghanem, 2018).

Employing an assemblage lens can enrich not only our understanding of the present situation, but open up various possibilities - potentials - for future energy transitions, where such potentials are not often explicit in development practice. Furthermore, an assemblage perspective highlights the agency of networks and pushes our thinking in relation to infrastructure beyond technological systems that can be acted upon and influenced through policy, and instead recognise how these networks can emerge and grow in unexpected directions. In the case of Lebanon, such divergence is a call to appreciate the complexity of the informal electricity provision and how it shapes everyday life. In doing so, we can begin to question notions of lawful state provision set against the informal generator "mafias", as they are often referred to in the media and by the lawmakers themselves (Mohsen, 2012; Rose, 2018). This chapter argues for the potential of the "coming together" of existing and future actors and networks to realise an inclusive approach, in order to sustainably tackle the energy crisis in the country. For energy transitions, the hope is that this study can point towards fresh theoretical tools that can articulate more inclusive and just energy transitions viable in the near future.

\section{Background}

In parallel to the state-owned electricity infrastructure in Lebanon, self-generation has emerged to supplement the much-needed electricity services for residents and businesses in the country. As mentioned earlier, Lebanon's national electricity supplier, EDL, has failed to provide continuous electricity services, and self-generation emerged as a result, supplying approximately $40 \%$ of electricity consumption in Lebanon (Bouri and El-Assad, 2016). In parallel to the infrastructure development plans that have been put in place in the post-war years to augment electricity generation and fill the supply gap (World Bank, 2008), self-generation in the shape of an informal system of provision expanded duing Lebanon's civil war and since the early 1990s, mainly based on privately owned diesel generators.

Throughout the war years, people with the financial means were able to procure small diesel-powered generators for their homes and small businesses (Awada, 1988) in order to supply a few hours of electricity during the extended power cuts brought about by the fighting. After Lebanon's civil war ended, the informal system of provision evolved and consolidated into privately owned generator services dominated by two forms: (1) local entrepreneurs (Verdeil, 2009) who provide subscription services at the neighbourhood level; and (2) co-owned 
medium to large generators that serve residents of apartment blocks, where a building's residents manage their own diesel generator to service all apartments. Since then, recently built real estate developments have come to include large diesel-based generators to serve the apartments even before they are sold. It remains that the most prevalent source of augmented supply for the majority of residents, particularly medium and lower-income neighbourhoods, are the services provided by the local entrepreneurs, where participating homes have to pay a connection charge as well as the monthly subscription fee in return for five or ten amperes ${ }^{1}$ of electricity supply. These service providers have become increasingly prolific in the last 30 years and prevail in both urban and rural settings (Abi Ghanem, 2018), as fewer households opt to manage their own small diesel generators given the additional effort and costs associated with it. A recent survey reports that $66 \%$ of Lebanon's households rely in some way on diesel generators to fill the power outage gap (UNDP, 2018). The widespread presence of these services - particularly those dotted around urban areas - is a significant contributor to local air pollution (Baayoun et al., 2019), resulting in serious environmental health risks for the urban residents (Shihadeh et al., 2013).

Currently, the privately owned generator-based electricity providers function within an ambiguous legal structure. Over the years, exploitative practices have emerged in light of the increasing demand for subscriptions, such as steep prices per ampere and the monopolising behaviour of several providers in different parts of the country, where it could be that a single private generator service controls all neighbourhood connections. In response, in 2010, the government sought to control the cost of informal providers by decree from the Ministry of Energy and Water $^{2}$ through imposing a monthly subscription tariff enforced by local municipalities on private providers in their jurisdictions (Gabillet, 2010). Despite that, the services remain costly for the average household in Lebanon, which is effectively burdened by two electricity bills: one for the national provider, EDL, at approximately 9.5 US cents per $\mathrm{kWh}$ and another for the private providers, which is on average 45 cents per kWh (Bouri and El-Assad, 2016; Hamdan et al., 2012). This double bill equates to many households (46\%) paying up $8.4 \%$ of their income on electricity services (UNDP, 2018). The services are normalised in the citizen's everyday life and embedded in the cities and towns, where new housing blocks are built with space for a generator and sometimes include pre-agreed deals with neighbourhood generator services (Verdeil, 2016; Abi Ghanem, 2018). This means many homeowners and tenants do not have a choice when it comes to informal electricity supply. Moreover, as lower-income households living outside Beirut suffer longer power outages, they pay more for their subscriptions. Lowerincome households are also less likely to live in developments that offer access to co-owned or internally owned generator services, whereas those who do (middle or high-income households) pay relatively less to augment their electricity supply (Verdeil, 2016).

As such, the energy crisis in Lebanon and its negative socio-environmental impacts make the need for a sustainable energy transition ever more urgent. On the policy level, the Energy Programme proposed by the Ministry of Energy and 
Water (Bassil, 2010) included provision for the development and growth of the renewable energy sector, though this is yet to be fully ratified (UN-ESCWA, 2017). More recently, the procurement of electricity from the two Turkish power ships $^{3}$ (Bouri and El-Assad, 2016) have further increased the country's electricity costs and are indicative of the energy impasse the country faces; its inability to meet local electricity demand beyond augmenting power generation (Bouri and El-Assad, 2016). In parallel to the successive governments' effort to secure energy, Lebanon has succeeded in fulfilling its targets in terms of energy efficiency and renewable energy (El-Khoury, 2016), mostly by pushing for solar thermal heaters. Though limited in scale, recently, licences have been granted for three solar PV farms and one wind farm, which should provide cheaper energy to EDL in the future. Thinking along the multiple scales of electricity in Lebanon, from the increasing financial and environmental burden to policy, informality and the technological impasse, can be daunting. However, by closely examining the failing and disrupted services, we are presented with an opportunity to better understand infrastructures in the context of energy transitions. As networks that do not function seamlessly, they reveal their components and highlight the opportunities for change and improvement that are needed.

To consider further opportunities towards greener and more sustainable systems that constitute not only socio-technical trajectories but a more in-depth examination of the implications for justice and wellbeing, a more nuanced approach is needed and often argued for in the socio-economic literature. For example, Moore and Collins (2020) argue for a place-based and people-centred approach, and call for a strategy that goes beyond the traditional top-down structural reforms and investments often promoted by development agencies. They recommend a decentralised energy system that benefits from "citizen insights" (Moore and Collins, 2020: highlights). These examples can be context-specific and are the product of the spatial arrangements they occupy. One such initiative is the Beirut Solar Map project (Berjawi et al., 2017), which, whilst providing a techno-economic assessment of the potential for rooftop solar PV solutions on the densely urbanised capital, has to grapple with the reality of diesel-based generators (their cost, the level of consumption they provide) and contrast that with the benefits of PV technology. Similarly, a recent assessment of the potential for distributed power generation for Lebanon builds on the current informal dieselbased generator market (ESMAP, 2020). This signals that to truly engage with bottom-up, decentralised and hybrid options for a sustainable energy transition, we need to develop a clearer understanding of the "messy" and dispersed nature of the energy infrastructure.

\section{An assemblage approach for thinking through energy transitions}

Assemblage thinking has benefited energy research in recent years (Kumar et al., 2019), highlighting the heterogeneity and diversity of energy services (Lawhon et al., 2018). Building on concepts of assemblage and networks, the notion of 
heterogenous infrastructure configurations has been put forward as a tool for examining and understanding service provision in a way that moves beyond rigid institutional categorisations (state, private, community), as well as the division of infrastructure as formal and informal. It calls for "comparative thinking about the conditions of possibility for incremental change" (Lawhon et al., 2018, 722). In doing so, it emphasises the need to move away from the technology-focused approach still dominant in explorations of energy transitions, and to instead engage critically with energy in a manner that emphasises the processual and emergent nature of infrastructure (Farias, 2011).

The concept of assemblage (DeLanda, 2016; Deleuze and Parnet, 2007) or assemblage thinking (Farias and Bender, 2011; McFarlane, 2011; McFarlane and Anderson, 2011) is, thus, used here to understand the complex relations between myriad elements of the Lebanese electricity problems, which can be social and material, historical and current. An assemblage is best described as "a multiplicity constituted by heterogeneous terms ... which establishes liaisons, relations between them" (Deleuze and Parnet, 2007, 52). Questions in relation to energy and energy services have benefited from assemblage thinking in recent years, where it has shed light on their heterogeneity and diversity, as well as normative concerns including matters of justice and access (Walker and Day, 2013). The multiplicity of scales and the varying geographies of energy (Bouzarovski and Petrova, 2015, 34) alongside its inconspicuous nature (Shove, 2003) and its entanglements in dispersed practices of consumption and production (van Vliet et al., 2005) that are in constant flux, require thinking about energy holistically.

McFarlane (2011) distinguishes between assemblage as a descriptive term and assemblage as an analytical approach, an orientation. As a tool, this helps in bringing into the analysis the different components of the system of electricity provision in Lebanon. It simply aids in generating tools for understanding the challenges and needs from energy infrastructure and to think of them beyond their technological elements. Crucially, assemblage as an approach when studying infrastructures invites us to view the energy system as an "open whole" (Bennet, 2005, 461) that is continuously emerging in space and time. In this way, we see the different components that an assemblage is composed of change, assemble and reassemble, but nonetheless, altogether the different components give the whole its agency. It is the notion of the agency of the assemblage that is important here, and that helps in moving beyond the analysis of the physical and social-cultural constituents of an infrastructure as a socio-technical system that is simply acted upon.

Luque-Ayala et al. (2016) draw attention to the fact that assemblage thinking explains how power works. When considering the case of Lebanon, where formal and informal providers co-exist and where the burden of that is carried by the people, being attentive to how power relations are embedded, and where and how this power can be challenged, is important. This power is not only held by the different members of the assemblage. In the case of Lebanon, we can begin to trace the power of the informal sector through their embeddedness in the urban built 
environment, and through the socio-economic fabric of the different communities they serve. Their strength and influence can be conceived through those sociomaterial relations (Silver, 2015). As Kumar et al. (2019) argue, paying attention to power makes it possible to explore "how power operates through the push of multiple stakeholders, in multiple sites and through a range of diverse practices" (p. 167).

Examining the electricity infrastructure in the case of Lebanon, we find that an assemblage perspective is not only helpful in establishing the grounding for context-based approaches by tracing the spatiality of the infrastructure, but also eliciting the temporality of energy by helping to unpack the flows that constitute the everyday dynamics of electricity service provision. We do so by exploring the heterogeneity of electricity provision in Lebanon, i.e. the growth of an informal electricity network that holds significant influence and power today, as well as an exploration of the historical moments that led to the rise of nonstate actors' and their interventions in the management and delivery of energy services during the war. As such, this chapter reflects on fieldwork conducted over several research visits to Beirut. The research began with a one-month visit in October 2015 and was followed up with further research trips in November 2016, April 2017 and August 2017. These visits focused on conducting a wide range of interviews with ministry officials, academics and experts, energy consultants, operators of generator services and households. The households interviewed included residents in metropolitan Beirut, the suburbs and peri-urban areas surrounding the capital.

Another visit in April 2018 was dedicated to conducting historical research on electricity infrastructure during the civil war. This relied on newspaper archives: the Lebanese daily newspaper Annahar and the now-defunct daily newspaper Assafir, ${ }^{4}$ as well as historic accounts and biographies of prominent political figures and their contemporaries of the civil war years, declassified reports of the civil war period from government sources and grey literature consisting of policy papers and decrees of the Ministry of Energy and Water. These sources were used to document the different incidents that involved the electricity infrastructure, its services and the use of generators. In addition to the archives, historical research involved interviews with several war veterans, local authority figures active during the civil war years and former EDL engineers involved in electricity service provision during the civil war. As such, combining research into the historical rise of informality in Lebanon as well as how it currently functions can enrich not only our understanding of the present situation, the actual (McFarlane, 2011), but open up the possibility for future energy transitions that are not often laid out in development discourses, in other words, the potential. This thinking raises questions of what a more sustainable (and just) future for cities of the global South can look like (Lawhon et al., 2018). In this way, it should stimulate an "alternative way of thinking, being and organising" for infrastructures (Knox, 2017) that builds on plural forms of energy transitioning involving a wider network of existing and future actors (both formal and informal) to realise fairer and greener energy futures. 


\section{Glimpses into the social history of Lebanon's infrastructure failures}

In this section, the current hybrid nature of energy supply in Lebanon is explained from a situated historical perspective by presenting some integral moments during the civil war when an energy assemblage was visible. As Awada (1988) shows, the civil war brought about resilience measures that secured residents' basic needs during periods of fighting. In doing this research, the belief that, prior to the war, electricity provision was universal and uninterrupted was pervasive amongst those interviewed. However, electrification, which began in the late 1920s initially as a colonially established private company that was nationalised in 1964, was not universal and not always available across the different regions (Abu-Rish, 2015; Kassir, 2003), neither was the level of electricity access sufficient to meet the aspirations of the emerging middle class in the early years of the Lebanese Republic (Abu-Rish, 2014). The subsequent hacks as a form of resilience by the "creative" Lebanese (Moore and Collins, 2020) are not simply a war-time response to electricity shortages, rather a challenge by the marginalised poor to the rooted inequality in access to state services. Infrastructure development in Lebanon has always favoured commercial regions and the capital Beirut (Nagel, 2002), and this is also the case in Lebanon's electricity sector since its inception (Abu-Rish, 2015). Therefore, whilst uneven access to electricity services predates the civil war, the purpose of focusing on these moments (leading up to and during the civil war) is to trace the current entrenchment of informal electricity service provision in the country. In doing so, we avoid the pitfall of simply linking the overall electricity crisis in Lebanon to the civil war alone.

Regarding the civil war, its early stages from 1976 to 1982 involved predominantly Christian right-wing political parties with their associated militias, opposed by several leftist parties allied with the Palestinian Liberation Organisation (PLO), who took refuge in Lebanon in 1973 after being expelled from Jordan. One of the right-wing parties, the Kataeb, developed - alongside their political and paramilitary organisation - civil committees whose remit was to lobby government for reform and community development (Frieha, 2017). These committees were later mobilised to provide basic services in lieu of the national infrastructure services for the neighbourhoods they controlled in East Beirut, particularly when the latter were disrupted during battles. These included health, public works, social services, financial services, information, and education. In their work, they intersected with the provision of water and electricity and early on initiated the distribution of kerosene lighting appliances, candles and oil heaters during winter. Their stated objective of doing so was to preserve the dignity of the Lebanese society during the violent impasse and strengthen the resilience of the residents in these areas.

On the left, the PLO, led by Yasser Arafat, were also strong advocates of "steadfastness", and also provided infrastructure and social services by establishing NGOs and cooperative associations. When, during the war, their supply of electricity (coming from the part of Beirut under the control of the right-wing 
militia) was disconnected, they embarked on a new cable connection to access electricity from Jiyyeh station, a thermal power plant south of Beirut. The work on this cable was barely complete when the first phase of the war ended in autumn 1976. In 1978, the work resumed, connecting Beirut to Jiyyeh station and allowing the PLO to continue from their main headquarters in West Beirut (Awada, 1988). The PLO's electricity hack that year sought not only to respond to the hostility of the Christian right-wing militias, but also to congeal the moral and financial support of the national and international allies of the PLO and to showcase the steadfastness and strength of its followers. This moment portrays how electricity access assembled into a crucial development of the civil war: opening up the system of the "informal" and the illegitimate to take shape and become enmeshed into what it means to survive in the city during these precarious times.

Informal patterns of electricity services were also assembled to reveal a neoliberal imaginary for Lebanon's post-war reconstruction in 1983. Believing the war to be close to conclusion, the Lebanese entrepreneur Rafic Hariri (who would later become the country's prime minister) demonstrated a possible rebirth of the then destroyed Beirut downtown by lighting Ma'arad [Exhibition] Street (Bkassini, 2015). Through his company Libano-Oger (Farshakh, 2006), he was sub-contracted by the Municipality of Beirut to maintain and rehabilitate roads and city infrastructure. Given the destruction brought about by the civil war, most of the work consisted of removal of debris and rubble, and the reopening of roads and streets. ${ }^{5}$ One of the projects that Hariri felt strongly about was the relighting of metropolitan Beirut (Shalak, personal communication, 28 March 2018). Although he began in the central neighbourhoods that were inhabited during the war, the lighting of Ma'arad Street remains salient given its location in downtown Beirut, which was a deserted no-man's land at the time (Nagel, 2002). Temporary connections and transformers were used to light up the street, whilst shops and business were invited to reopen for the day to celebrate the revival. Once again, this moment in the history of the temporary, informal and improvised provision of electricity services shows how this assemblage - although fleeting - materialises that yearning for more peaceful times but, crucially, lays down the contours of a neoliberal future for the city of Beirut, defined by a reconstructed commercial centre and supported by functioning infrastructure.

These three examples illustrate how informal electricity services were assembled as sites for reclaiming state power and identity, enabling resistance to perceived threat, and revitalising development and reconstruction driven by neoliberal market forces. Seen this way, the social history of the conflict and of informality in infrastructure services are intertwined. Even though universal access to electricity was never achieved prior to the start of the civil war in 1976, the intersection of salient moments of informality with pivotal moments of the civil war have produced many of the current dominant meanings of electricity provision, whether focused on the capability and role of the legitimate state in services provisioning or the perceived threat of non-state actors on infrastructure control that fester ethnic divisions. These assemblages have determined the extent of informality in upending formal infrastructures of the state, as well as the depth 
of socio-political and ideological drivers in the country's social milieu today. In these moments, the hybridity of service provision and notions of their legitimacy versus the role of the state become visible.

\section{Heterogenous provision in post-war Lebanon}

As mentioned before, Lebanon's electricity provision is characterised by continuous load shedding and power outages, which vary between different areas. Often, coastal cities and towns receive relatively more electricity than more peripheral regions such as peri-urban or rural areas. Indeed, the spatial disparity in managing and augmenting power supply encounters an intricate topography constituted by who supplies the electricity, by what means and in what contractual capacity (Verdeil, 2016). Another differentiation is the type of diesel generator provision a household has access to. Tracing the origins of diesel generator supply, Awada (1988) reported its widespread use along with kerosene rations for electricity, heating and lighting to the households at the beginning of the civil war. These practices widened and, by the late 80 s and early 90 s, there was a proliferation of individual diesel generators, to the extent that the reliance of homes and business on them was perceived as a form of resilience and considered a viable temporary measure for post-war recovery as outlined by the CIA report from that year (US Directorate of Intelligence, 1983). Today, whilst individual small to medium generators still exist, these are mainly in rural parts of the country where they are mostly used by business owners.

Across the country, the informal network of private electricity providers, driven by local entrepreneurs, pervades. Informal electricity supply is based around large diesel generators with wires pouring out of main inverter boxes to neighbouring residents and businesses. These connections run alongside district level low-voltage distribution networks, where the cables and fuse boxes sit alongside the utility connectors and dangle off the electricity poles on the streets. The informal provider's electricity supply "station" in the neighbourhood houses the switches to each building; congregated there are the owners and their electricians. Across the street, you might find a generator, another in a silencer encasing, wires stretched across walls, weaving their way into homes through doorways and windows. Despite their improvised appearance, these informal networks congeal not only through their physical state and ubiquity across the built environment, but through their function, which is dispersed through affective and socio-material moments. One example is Sahar, who bought a newly built apartment in a block outside the capital. When purchasing on the plan, she was informed of "the private provider. His cables and connections were already in place and for every flat in the building there was a placeholder for the ampere meter and the switch". She explains, "it was up to us whether we wanted to activate that connection, but he's the only provider for his neighbourhood. He won't let anyone else do business on his turf'. This example shows how the informal system, integrated coherently in the built environment and emerging as a "mafia" structure (Mohsen, 2012; Rose, 2018), is assembled. In this example, the pre-installation of the informal wiring provides 


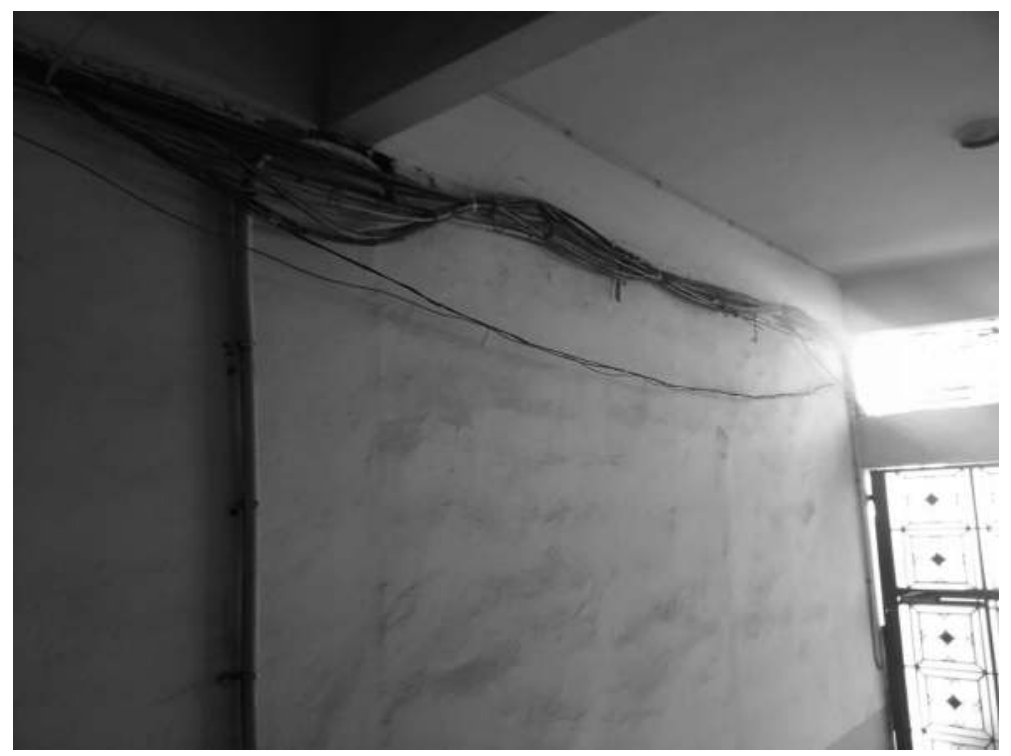

Figure 2.1 Diesel generator wires visible in the foyer of an apartment building in Beirut.

an added level of invisibility, in line with the many dimensions of infrastructure (Leigh-Star, 1999).

As mentioned before, another form of supply is co-ownership, and typically involves residents of an apartment block or building sharing ownership of a relatively larger supply asset that is managed and maintained by the apartment blocks' residents. Costs are shared and the day-to-day service of supply is handled by the building concierge or caretaker. A more recent form of supply follows the contours of the current private providers, but the ownership of the generator and transmission facilities is either community-based organisations or local authorities, and these are often supported financially by political parties. Finally, an oft-cited and less understood (on the practical everyday level) mode of provision is "hacking" or theft of electricity from low-voltage power lines using circuit breakers, with such modes of provision common in poorer and more informal urban settlements, including refugee camps. The purpose of outlining the different informal electricity provision structures is to highlight the intricate relationships that ensue from these supply modes, as well as the differentiated affective and practical outcomes from these arrangements on those who experience and participate in the making of them. For example, different social relations emerge between neighbours in a building who co-own a generator, where economic or financial exchange shapes interactions between them. In a similar way, an informal subscription to a private provider is not purely an economic exchange, as our findings suggest; many subscribers are friends and family whilst the generator owner is also a neighbour and an acquaintance. These contracts are 
held together by not only the wires, but by notions of community, neighbourliness and trust.

After all, the private generator entrepreneurs in many parts of the country are themselves members of these communities. Amongst different providers is competition and cooperation, where factors such as the limits of the network, costs and practical measures precede the securing of a new client. Joseph, a generator owner interviewed in this study, tells me he has turned down subscription requests and recommended a competitor when a customer has a request that he could not fulfil. He added, "he [the competition] doesn't take away my clients, but I don't mind if he does sometimes". The amiable relations are extended in some cases to subscribers, such as Emile, who prefers to do business with Joseph because "he knows him". His wife explains,

we've been with this provider for as long as he's been here, as soon as he got a generator. We've never changed. I don't like to change. Some people here have changed to an "outsider", I mean why? If a person born and bred in your neighbourhood is providing this service, why would we switch to an outsider? I don't like it. I am very principled.

In some way, notions of community and identity are realised through these relationships, and it raises the question of whether active forms of discrimination take place through these informal electricity connections. In other neighbourhoods, the merits of one provider over another are highlighted in how polite the fee collectors are or in the provision of modern automatic switches so that "I don't have to run downstairs to switch the supply over", as Sahar explains. In this instance, the automatic switches ensure the seamlessness of the informal supply arrangement where daily disruptions are avoided or minimised. These, it should be noted, further enhance the invisibility of the informal infrastructure, noted earlier, and its concealment not only within the physical built structures, but also in the routines and rhythms of everyday life.

These heterogenous configurations are also affective. Much like the desired politeness of subscription fee collectors, the power outages and the resulting reliance on informal services bring to the fore reactions and emotions. One notable observation is feelings of abandonment by the state that has "forgotten about its citizens", as Hala tells me; a feeling that overwhelms her as she walks back home through darkened streets lit dimly by the lights from the windows of households "who can afford it". In these daily experiences, the social and political reality of Lebanon are expressed clearly in the darkness and heightened feelings in relation to the role of the state. Theft on the network by using a circuit breaker is less talked about, but Amin - who works as a taxi driver by day - provides his family with electricity by "hacking". He assures me it is safe, adding, "if my parents need light, I will sort it out. Not my brother though, he's not man enough". With Amin, although his theft is out of necessity, the act engenders his role as the good son and underscores his masculinity and power. Though Amin's theft is not unique and parallels historical precedents, it is also a response to pressing needs that he feels can only be provided in this way. 
The examples above show how the informal assemblage wields power, but households can - in some instances - untangle themselves to prevent the burdens and negative impacts of the power outages. Layla will not talk to me about her experience with the private provider in her neighbourhood, "it upsets me", she explains. Instead, she lavished us with more cakes and coffee until her son Salim arrived to show us the UPS system he installed in her attic, as "he knows how it works. He got the idea from working with this IT business. They had the same thing in place", she explains. In her attic, a large UPS system with three lead-acid batteries are carefully mounted onto a steel cradle to automatically rock in place, ensuring the longest battery life (Figure 2.2). This system provides enough electricity to power her fridgefreezer and TV, as well as charging a mobile phone. These are carefully assembled into the network of curtailed household energy consumption, in the timing of washing and ironing, a reconsideration of domestic priorities, and most of all the distress and anxiety that Layla avoids. For her, living outside the capital, her power outages were longer and her bills higher, and by the end of every month, she dreaded "the sight of the private generator's fee collector" walking through her front yard.

By conceptualising the provision of electricity, both formal and informal, as balanced assemblages that are constantly in the making, we avoid unhelpful dichotomies of "state" vs "non-state", "mafia" vs "community". Notions of corruption and theft can be understood in how they are made possible across different scales. The aim of this research was to explore the everyday practices of provisioning electricity services in ways that go beyond these binary labels. On an everyday level, this is necessary if a bottom-up approach to sustainable energy transitions is desired. Accounting for electricity services as material, social and

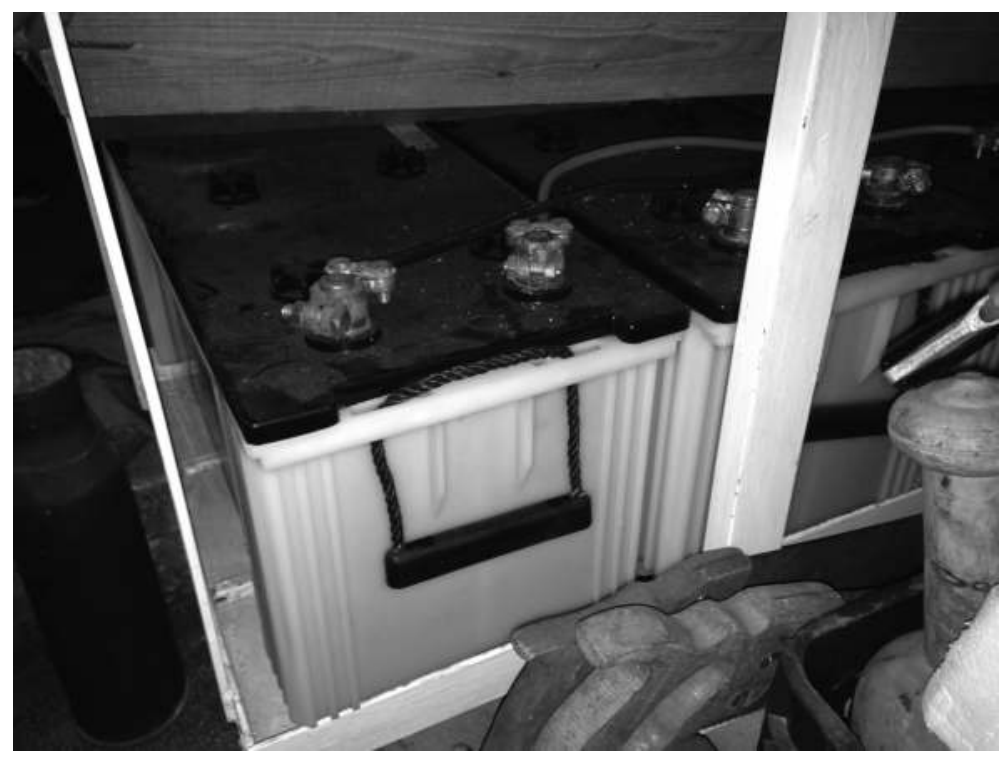

Figure 2.2 Lead-acid batteries mounted on a cradle in the attic of Layla's house. 
political flows, constituent of human and nonhuman elements (Latour, 2005) and emerging as assemblages, opens up the possibility to outline a broader and more inclusive stakeholder engagement at the community level in ways that can be conducive to a greener energy system of provision. By understanding how an individual household can actuate their agency amidst the web of cables, switches and meters, we can then truly build towards a bottom-up approach for a transition to a more equitable and sustainable energy supply. Importantly, this is a call for a pragmatic approach that seeks to engage with all elements of informal supply, rather than the measures that the government has attempted in order to curb the power of the private providers, a recent one being by imposing the installation of metering for the clients of the informal providers (c.f. Rose, 2018).

\section{Conclusion}

In this chapter, the case of Lebanon's ongoing electricity failures was explored through an assemblage perspective. The analysis brought together the lived experience of the informal electricity services and a consideration of the historical moments during the civil war where different formations of informality took shape. The historical contextualisation is not intended as an explanation for the origins of informality. Although it highlights significant moments of its emergence, the assemblage perspective provided a lens through which a study of the experiences of the civil war can be made. Like Braudel (1982, cited in DeLanda, 2016), the aim is to retell these moments by bringing to the fore the agency of diverse entities: the flows of electricity, improvised electrical connections, the city and the streets as well as the people - who are not heroic figures. In this way, the informal electricity assemblages are broadened and their agency is traced both spatially and temporally. Kumar et al. (2019) recommend an assemblage perspective in order to attend to the "socio-technical configurations ... that are continually being assembled, disassembled and reassembled in time and space" (p. 174). Understanding how these processes constituted these assemblages will empower researchers and policy makers of energy in the context of just and urgent transitions to design interventions that are attuned to the existing "ways of doing" electricity and in a way that achieves legitimacy and durability. In so doing, we can begin to challenge the received wisdom of large decentralised infrastructure projects.

In this chapter, a similar view is taken. By employing an assemblage lens, a rich account of the workings of the informal systems of electricity provision was possible, tracing moments in history and accounting for the current realities of energy infrastructure. In the three historical moments, the agency of energy provision highlighted the technology's politics. The historical exploration showed how the assemblage of electricity services took shape through political attempts at resilience, steadfastness and recovery. These moments opened up possibilities of self-provisioning not only as an inevitable consequence to the destruction of infrastructure due to violent infighting, but as a necessity for survival and continuity rooted in national and communitarian beliefs. These connections can be seen in the present day; in the relationships between the providers and the households, 
in the prevalent theft on the network and in the general acceptance of political parties' involvement in generator-based informal provisioning. Accordingly, the challenge of electricity provision is introduced not as a physical network with power plants and pylons that can be acted upon, or fixed. Rather, the multiple ways that the meanings and everyday dynamics of electricity provision drove and have been driven in the past and to this day attest to its continuity, processual nature (Farias, 2011) and agency. In this way, the hybridity of electricity provision through state and non-state actors cannot be ignored.

To address Lebanon's energy crisis, recent governments have sought to price out informal electricity providers (Rose, 2018), but much-needed RET investment plans are yet to be comprehensively realised (LCEC, 2016) and the necessary reforms for the energy sector have not yet been implemented (Obeid, 2020). Government plans such as the Energy Programme (Bassil, 2010) have failed to realise the much-needed system changes and to meet the levels of electricity generation needed. These plans, although ambitious, seek to depoliticise the electricity crisis in the country and neglect the realities of informal electricity services and their rootedness in Lebanon's cities, built environment and everyday life. With the ubiquity of informal provision in mind, an alternative is an approach that is inclusive of the multiplicity of stakeholders that seeks to find commonalities through the various elements of the informal assemblage. By building on local and community-level connections, a plan that incorporates the informal networks of provision and that includes its physical, human and cultural capital, can be an effective strategy to implement distributed renewable energy sources for electricity supply. This approach is arguably more achievable in the context of urgency and can be conducive to prosperity (Moore and Collings, 2020). For example, the connections of private electricity providers can open up the space for implementing microgeneration solutions such as rooftop solar PV. The propensity of householders to shift between different sources of light and electricity enables us to envision energy access that is more diverse, where the heterogeneity and "messiness" can be seen by policy and decision makers as an advantage. By opening up, the challenge is to collaborate with a wider network of actors and change agents where diesel generator owners are invited to participate in cleaner energy opportunities. What should be emphasised is their embeddedness in their communities rather than the oft-cited "mafia" descriptors they are labelled with (Rosen, 2018).

As affective infrastructures (Knox, 2017), notions of historical and current government failures can instead be mobilised into empowering processes of cooperation and collaboration. In better understanding the relational dynamics of energy assemblages as they emerged in the past and as they continue to unfold, we might begin to see an "alternative way of thinking, being and organizing" infrastructures (p. 380). Seen this way, the sites of failure, when explored through the lens of assemblage, are socio-material entanglements that have the potential to produce new energy landscapes that are decentralised, greener and potentially more prosperous (Moore and Collins, 2020). Community-level self-generation is then not an abandonment by the state but an empowering direction towards a sustainable energy policy for the country. 


\section{Dana Abi Ghanem}

Lebanon still faces a considerable challenge when it comes to driving a vision of a greener and more sustainable energy future for its citizens. The ailing physical infrastructure, the mismanagement of natural and financial resources, coupled with a maligned informal system of provision, can seem insurmountable. To the onlooker, they can even suggest that to bring in low-carbon targets is premature. However, the green energy options that the country can exploit should be an integral part of the solution. The decentralisation model is itself not void of questionable political circuits of power, as observed by Verdeil (2019) in the case of local authority-led electricity provision. However, to respond positively to the demands of the people who are suffering energy injustices, a socially and culturally informed approach that engages positively with a multiplicity of actors is argued here as the alternative but necessary orientation to overcome the ecological and political impasse in the country.

\section{Notes}

1 The five and ten amperes are the most common options and indicated in the Lebanese authorities' description of the generator service. The choice depends on the size and income of the household.

2 Decree was issued by the Ministry of Energy and Water (14/10/2010); pursuant to the decision of Council of Ministers No. 2 dated 14/12/2011) to control generator services tariffs through the publishing of monthly permitted tariffs for five amperes and ten amperes respectively.

3 The Turkish power ships, owned by Karadeniz Holding, have since 2013 supplied 25\% of the total electricity demand in Lebanon at a cost of USD 130 million per year for the Lebanese treasury. However, the USD 140 million in unpaid dues suggests that solutions based purely on supply augmentation are unsustainable given the much-needed reforms in the electricity sector that are yet to be implemented.

4 The Annahar newspaper archive was accessed at their headquarters: An-Nahar Bldg., Martyrs' Sq., Marfa' Sector, Beirut, 2014 5401. The archive of Assafir was accessed at the media archives of the American University of Beirut Jafet Library, P.O. Box 11-0236, Riad El-Solh/Beirut 1107 2020, Lebanon.

5 The re-opening of roads and city streets was a common practice after militias closed them off as part of their retaliatory tactics during some of the urban street fighting that was a common occurrence throughout the civil war.

\section{References}

Abd El Al, I. (2018). Historical background on the Litani river. In: Shaban A. and Hamzé M. (eds) The Litani River, Lebanon: An Assessment and Current Challenges. Springer, Cham, pp. 15-31.

Abdelnour, Z. (2003). The corruption behind Lebanon's electricity crisis. Middle East Intelligence Bulletin, 5, pp. 8-9. Available at: https://www.meforum.org/meib/articles /0308_11.htm [Accessed 19 August 2020].

Abi Ghanem, D. (2018) Energy, the city and everyday life: Living with power outages in post-war Lebanon. Energy Research \& Social Science, 36, 36 - 43.

Abosedra, S., Dah, A. and Ghosh, S. (2009). Electricity consumption and economic growth: the case of Lebanon. Applied Energy, 86(4), pp. 429-432. doi:10.1016/j. apenergy.2008.06.011 
Abu-Rish, Z. (2014). On Power Cuts, Protests, and Institutions: A Brief History of Electricity in Beirut (Part One). Jadaliyya. Available at: http://www.jadaliyya.com/ Details/30564/On-Power-Cuts,-Protests,-and-Institutions-A-Brief-History-of-Elect ricity-in-Beirut-Part-One [Accessed 7 October 2016].

Abu-Rish, Z. (2015). Electricity in Early Independence Lebanon, Setting the Agenda. 22nd September [online]. Lebanese Centre for Policy Studies. Available at: https://www.lcp s-lebanon.org/agendaArticle.php?id=55 [Accessed 19 August 2020].

AUB-IFI (2019). Policy Brief: An Emergency Action Plan for Rescuing Lebanon's Energy Sector, Energy Policy and Security Programme. American University of Beirut-Issam Fares Institute Policy Brief, December 2019. Available at: https:// www.aub.edu.lb/ifi/Documents/programs/energy_policy_and_security/documents /20191210_energy_rescue_plan/20191210_energy_rescue_plan.pdf [Accessed 31 August 2020].

Awada, F. (1988). La gestion des services urbains à Beyrouth pendant la guerre: 1975 1985, Vol. 5. Talence : Interurba CNRS-ORSTOM.

Baayoun, A., Itani, W., El-Helou, J., Halabi, L., Medlej, S., El-Malki, M., Moukhaddar, A., Kai Aboujaoude, M., Kabakian, V., Mounajed, H., Mokallad, T., Shihadeh, A., Lakkis, I. and Saliba, N. (2019). Emission inventory of key sources of air pollution in Lebanon. Atmospheric Environment, 215, 116871. doi:10.1016/j. atmosenv.2019.116871

Bassil, G. (2010). Policy Paper for the Electricity Sector. Ministry of Energy and Water, Lebanese Republic.

Bennet, J. (2005). The agency of assemblage and the North American blackout. Public Culture 17(3), pp. 445-465. doi:10.1215/08992363-17-3-445

Berjawi, A.H., Najem, S., Faour, G., Abdallah, C. and Ahmad, A. (2017). Assessing Solar PV's Potential in Lebanon. Issam Fares Institute for Public Policy and International Affairs. American University of Beirut, Beirut, Lebanon. Available at: https://www.aub .edu.lb/ifi/Documents/publications/working_papers/2016-2017/20170808_solar_pvs.p df [Accessed 15 November 2020].

Bkassini, G. (2015). Rafic Hariri: Seerat Amal [Rafic Hariri: A Biography of Hope]. Al-Mustakbal Newspaper (9 February 2015). Available at: https://www.lebanese-forc es.com/2015/02/13/rafik-hariri-hope-biography/ [Accessed 24 August 2020].

Bouri, E. and El-Assad, J. (2016). The Lebanese Electricity Woes: an estimation of the economical costs of power interruptions. Energies, 9, p. 583. doi:10.3390/en9080583.

Bouzarovski, S. and Petrova, S. (2015). A global perspective on domestic energy deprivation: overcoming the energy poverty-fuel poverty binary. Energy Research \& Social Sciences, 10, pp. 31-40. doi:10.1016/j.erss.2015.06.007.

Castan Broto, V., Baptista, I., Kirshner, J., Smith, S. and Neves Alves, S. (2018). Energy justice and sustainability transitions in Mozambique. Applied Energy, 228, pp. 645655. doi:10.1016/j.apenergy.2018.06.057.

Day, R. and Walker, G. (2013). Household energy vulnerability as "assemblage". In: Bickerstaff K., Walker G. and Bulkeley H. (eds) Energy Justice in a Changing Climate: Social Equity Implications of the Energy and Low-Carbon Relationship, Zed Books, London/New York, pp. 14-29.

DeLanda, M. (2016). Assemblage Theory. Edinburgh University Press, Edinburgh.

Deleuze, P. and Parnet, C. (2007). Dialogues II. Columbia University Press, New York.

El Khoury, P. (2016). Beyond 2016. Available at: https://beirutenergyforum.com/p16/Day $\% 203 /$ Session $\% 2012 /$ It's\%20the \%20time\%20to\%20apply\%20law\%20288\%20A\%2 0call\%20to\%20the\%20private\%20sector.pdf [Accessed 15 November 2020]. 


\section{Dana Abi Ghanem}

ESMAP (2020). Distributed Power Generation for Lebanon: Market Assessment and Policy Pathways. (May), World Bank, Washington, DC. https://openknowledge.wor ldbank.org/handle/10986/33788?locale-attribute=es [Accessed 15 November 2020].

Farias, I. (2011). Introduction: decentring the object of urban studies. In: Farías I. and Bender T. (eds) Urban Assemblages: How Actor-Network Theory Changes Urban Studies. Routledge, London, pp. 1-24.

Farias, I. and Bender, T. (2011). Urban Assemblages: How Actor-Network Theory Changes Urban Studies. Routledge, London.

Farshakh, G. (2006). El-Fadel Shalak: Tajrubati ma'a El-Hariri [Al-Fadel Shalak: My days with Hariri]. Arab Scientific Publishers, Beirut.

Fawaz, M. (2009). Neoliberal urbanity and the right to the city: a view from Beirut's periphery. Development and Change, 40(5), pp. 827-852. doi:10.1111/j.14677660.2009.01585.x [Accessed 24 July 2017].

Freiha, G. (2017). Ma'a Bashir: thikrayat wa muthakarat [With Bashir: Memories and a Memoir], 2nd Ed. Entire East Publishing and Distribution, Beirut.

Furlong, K. (2011). Small technologies, big change: rethinking infrastructure through STS and geography. Progress in Human Geography, 34(4), pp. 460-482. doi:10.1177/0309132510380488

Gabillet, P. (2010). Le commerce des abonnements aux générateurs électriques au Liban: Des modes de régulation locaux diversifiés [The trade in rental agreements for electric generators in Lebanon: diversified forms of local regulations]. Géocarrefour, 85(2), pp. 153-163. doi:10.4000/geocarrefour.7861.

Graham, S. and Marvin, S. (2001) Networked Infrastructures, Technological Mobilities and the Urban Condition. Routlege, London.

Graham, S. and McFarlane, C. (2015) Introduction. In: Graham S. and McFarlane C. (eds) Infrastructural Lives: Urban Infrastructure in Context. Routledge, London, pp. 1-14.

Hamdan, H., Ghajar, R. and Chedid, R. (2012). A simulation model for reliability-based appraisal of an energy policy: the case of Lebanon. Energy Policy, 45, pp. 293-303. doi:10.1016/j.enpol.2012.02.034

Jouni, A., Najjar, R. and Mourtada, A. (2016). Evaluation of national energy action plan: the case of the Lebanese NEEAP (2011-2015). IEEE 3rd International Conference on Renewable Energy for Developing Countries (REDEC), Beirut, pp. 1-5. doi:10.1109/ REDEC.2016.7577564. [Accessed 15 November 2020].

Kassir, S. (2003). Beirut [Originally published in French entitled: Histoire de Beyrouth], University of California Press, Oakland, CA.

Knox, H. (2017). Affective Infrastructures and the Political Imaginations. Public Cultures, 29(2), pp. 363-384. doi:10.1215/08992363-3749105

Kumar, A., Ferdous, R., Luque-Ayala, A., McEwan, C., Power, M., Turner, B. and Bulkeley, H. (2019). Solar energy for all? Understanding the successes and shortfalls through a critical comparative assessment of Bangladesh, Brazil, India, Mozambique, Sri Lanka and South Africa. Energy Research \& Social Science, 48(1), pp. 66-176. doi:10.1016/j.erss.2018.10.005.

Latour, B. (2005). Reassembling the Social. Oxford University Press, Oxford.

Lawhon, M., Nilsson, D., Silver, J., Ernstson, H. and Lwasa, S. (2018). Thinking through heterogeneous infrastructure configurations. Urban Studies, 55(4), pp. 720-732. doi:10.1177/0042098017720149.

LCEC (2016). The National Renewable Energy Action Plan for the Republic of Lebanon 2016-2020. Ministry of Enegy and Water, Lebanese Republic. Available at: http:/ 
/lcec.org.lb/Content/uploads/LCECOther/161214021429307 NREAP_DEC14.pdf [Accessed 24 August 2020].

Luque-Ayala, A. and Silver, J. (eds). (2016) Energy, Power and Protest on the Urban Grid: Geographies of the Electric City. Routledge, London.

Machnouk, S., El Houseini, H., Kateb, R. and Stephan, C. (2019). The Energy Regulation Market Review, Edition 8-Lebanon. The law reviews. Available at: https://thelawr eviews.co.uk/edition/the-energy-regulation-and-markets-review-edition-8/1194563/ lebanon [Accessed 24 August 2020].

McFarlane, C. (2011). The city as assemblage: dwelling and urban space. Environment and Planning D: Society and Space, 29(4), pp. 649-671. Available at: http://www.envplan .com/abstract.cgi?id=d4710 [Accessed 17 April 2017].

McFarlane, C. and Anderson, B. (2011). Thinking with assemblage. Area, 43, pp. 162164. doi:10.1111/j.1475-4762.2011.01012.x.

Mohsen, A. (2012). Lebanon's Electricity Mafia. Al-Akhbar Newspaper (June 29 2012). Available at: http://english.ak-akhbar.come/node/9087 [Accessed 24 October 2017].

Moore, H. and Collins, H. (2020). Decentralised renewable energy and prosperity for Lebanon. Energy Policy: 111102. doi:10.1016/j.enpol.2019.111102.

Nagel, C. (2002). Reconstructing space, re-creating memory: sectarian politics and urban development in post-war Beirut. Political Geography, 21(5), pp. 717-725. doi:10.1016/ S0962-6298(02)00017-3.

Obeid, J. (2020). Commentary: Lebanon: The 3-Decade Impossible Power Sector Reforms. Italian Institute for International Political Studies (ISPI), Milan, Italy. Available at: https://www.ispionline.it/en/pubblicazione/lebanon-3-decade-impossible-power-sector -reforms-25377 [Accessed 24 August 2020].

OECD/IEA (2014). IEA Statistics: Energy Imports, Net (Percentage of Energy Use). Available at: https://data.worldbank.org/indicator/EG.IMP.CONS.ZS?locations=LB [Accessed 24 August 2020].

Rose, S. (2018). Lebanese Government Tries to Rein in Billion-Dollar 'Generator Mafias'. The National (November 8 2018). Available at: https://www.thenational.ae/world/ mena/lebanese-government-tries-to-rein-in-billion-dollar-generator-mafias-1.789451 [Accessed 24 August 2020].

Rosen, K. (2018). Inside the Haywire World of Beirut's Electricity Brokers. Wired (August 29 2018). Available at: https://www.wired.com/story/beruit-electricity-brokers/ [Accessed 24 August 2020].

Rutherford, J. and Coutard, O. (2014). Urban energy transitions: places, processes and politics of socio-technical change. Urban Studies, 51(7), pp. 1353-1377. doi:10.1177/0042098013500090.

Shihadeh, A., AlHelou, M., Saliba, N., Jaber, S., Alaeddine, N., Ibrahim, E., Salahieh, Z. and Chiit, M. (2013). Effect of Distributed Electric Power Generation on Household Exposure to Airborne Carcinogens in Beirut. Research Study Report January 2013, Issam Fares Institute Climate Change Programme, American University of Beirut. Available at: https://www.aub.edu.lb/ifi/Documents/events/2012-2013/20130207ifi rsr_cc_effect\%20Diesel.pdf [Accessed 15 October 2015].

Shove, E. (2003). Comfort, Cleanliness and Convenience: The Social Organisation of Normality. Berg, Oxford.

Silver, J. (2015). Disrupted infrastructures: an urban political ecology of interrupted electricity in Accra. International Journal of Urban and Regional Research, 39, pp. 84-1003. doi:10.1111/1468-2427.12317. 
Star, S.L (1999). The ethnography of infrastructure. American Behavioral Scientist, 43, pp. 377-391. doi:10.1177/00027649921955326

UNDP (2018). Energy Efficient Home Appliances: Perspectives from Lebanese Consumers. UNDP-CEDRO, Beirut, Lebanon. Available at: file:///Users/u0033639/Downloads/ CEDRO\%20_\%20Energy\%20Efficient\%20Home\%20Appliances.pdf. [Accessed 15 November 2020].

UN-ESCWA (2017). Case Study on Policy Reforms to Promote Renewable Energy in Lebanon. A paper for the United Nations Development Account project on promoting renewable energy investments for climate change mitigation and sustainable development. United Nations-Economic and Social Commission for Western Asia. Beirut, Lebanon. Available at: file://Users/u0033639/Downloads/policy-reforms-pr omote-renewable-energy-lebanon-english.pdf [Accessed 24 August 2015].

US Directorate of Intelligence (1983). Lebanon: Decaying Infrastructure-An Intelligence Assessment. Central Intelligence Agency, approved for release July 2002. Available at: https://www.cia.gov/library/readingroom/document/cia-rdp84s00927r0002000200 04-7 [Accessed 14 May 2017].

Van Vliet, B., Chappells, H. and Shove, E. (2005). Infrastructures of Consumption: Environmental Innovation in the Utility Industries. Earthscan, London.

Verdeil, E. (2009). Électricité et territoires: un regard sur al crise libanese. Revue Tiers Monde, 2(2), 421-436. doi: 10.3917/rtm.198.0421

Verdeil, E. (2016). Beirut, metropolis of darkness: the politics of urban electricity grids. In: Luque-Ayala A. and Silver J. (eds) Energy, Power and Protest on the Urban Grid: Geographies of the Electric City. Routledge, London, pp. 155-175.

Verdeil, E. (2019). Securitisation of urban electricity supply: a political ecology perspective on the cases of Jordan and Lebanon. In: Yacobi H. and Nassara M. (eds) Routledge Handbook on Middle Eastern Cities. Routledge, London, pp. 246-264. Available at: https://halshs.archives-ouvertes.fr/halshs-02176158/document [Accessed 24 August 2020].

World Bank (1996). Staff Appraisal Report: The Republic of Lebanon-Power Sector Restructuring and Transmission Expansion Project. Available at: http://documents1 .worldbank.org/curated/en/938971468772462743/pdf/multi-page.pdf [Accessed 24 August 2020].

World Bank (2008). Republic of Lebanon, Electricity Sector Public Expenditure Review. Report No. 41421-LB. World Bank, Washington, DC. Available at: http://hdl.handle .net/10986/7990 [Accessed 24 August 2020].

World Bank (2019). Lebanon Electricity Transmission Project P170769. World Bank Publication. Available at: http://documents.worldbank.org/curated/en/2358315628649 51356/text/Concept-Project-Information-Document-PID-Lebanon-Electricity-Tra nsmission-Project-P170769.txt [Accessed 31 August 2020]. 


\title{
3 Constructing an inclusive vision of sustainable transition to decentralised energy
}

\author{
Local practices, knowledge, values and \\ narratives in the case of community-managed \\ grids in rural India
}

Anna Melnyk and Abhigyan Singh ${ }^{1}$

\section{Introduction}

Deep within a tropical forest in central India, more than 100 small-scale (1-8kW) decentralised solar mini-grids have been structured by the provincial government. These stand-alone grids are instituted as part of the government's drive for completing rural electrification of the region. At the outset, there is hardly anything technologically exciting about these grids. The grid does not incorporate any intelligence or high-tech innovations and is entirely constituted by mundane technologies, such as solar panels, lead-acid battery-banks and electrical cables. However, it is remarkable that the villagers entirely manage the day-to-day functioning of these grids. The villagers have been able to manage these grids for over a decade communally. This situation raises an intriguing question, i.e. are insights from these sites relevant for a vision of sustainable energy transition (SET) in the global North?

As a product of the global North, a vision of SET that informs policies and infrastructural developments has a strong reliance on high-tech energy innovations and market design. This vision is informed by the universal, singular and homogenous views of SET that are often guided by rational values of efficiency, optimisation and maximisation. At the same time, this vision of SET holds a limiting account of diverse energy-related practices and associated values that are endemic to local communities. In this chapter, we hint at alternative possibilities for SET to decentralised energy by presenting insights from an ethnographic study on decentralised solar mini-grids in rural India. Furthermore, we utilise the case to learn about local knowledge, values, practices and narratives with energy technologies. Overall, in this chapter, we do not aim to provide a solution, but rather take a step towards a long process of construction of a "big picture" of the sustainable transition to decentralised energy.

We start this chapter by introducing a vision of the global North on SET reflected in both academic literature and a key policy document in the European 
Union - the EU directive. Then, after providing relevant background information on the community-managed solar mini-grids in rural India, we extract empirical insights about local narratives, knowledge, values and practices. Finally, to conclude, we combine these insights to reflect upon an inclusive view of the sustainable transition to decentralised energy.

\section{The global North's visions of sustainable energy transition (SET)}

Since 1970, contemporary societies have been facing a significant environmental crisis that has created new societal, institutional and design challenges (Singer 2002). The urgent demand in shifting from non-renewable and extractive options to sustainable ones is motivated by concerns about climate change and the depletion of fossil fuels (Kern \& Smith 2008; Coenen et al. 2012). The value of sustainability has become a cynosure and is now commonly discussed in the context of the energy transition (Cuppen et al. 2016; Van de Poel 2017; Mok \& Hyysalo 2018). It is a crucial concept guiding current low-carbon energy transitions for the last few decades (Smith et al. 2010; Verbong \& Geels 2007; Rae \& Bradley 2012). The contemporary conceptualisation of sustainability in the global North is often linked to "sustainable development". It refers to Brundtland's definition: "[the] development that meets the needs of the present without compromising the ability of future generations to meet their own needs" (WCED 1987, p. 43). Such a link between "sustainability" and "sustainable development" commits to the essentiality of the idea of economic growth (Spangenberg 2004). Technological innovation plays a key role here as they support the simultaneous achievement of both aims - sustainable transition and economic growth.

Engineers and policy-makers in the global North are applying various methods to embed the value of sustainability in technological and institutional designs to facilitate SET (Mok \& Hyysalo 2018; Taebi \& Kloosterman 2015; Van de Poel 2017). The introduction of new energy technologies that embed sustainability has created the opportunity for the empowerment of local communities and, subsequently, the societal interest in the decentralisation of energy production, generation and supply increase (Rae \& Bradley 2012; Koirala et al. 2016; Rogers et al. 2008; Hoppe et al. 2015). Besides a genuine societal interest in decentralisation, a SET through community engagement is also a climate change mitigation strategy (Koirala et al. 2016; Rogers et al. 2008; Becker \& Kunze 2014; Verkade \& Höffken 2019). In the European Union, local SET aligns with the agenda for institutional change set up by the Paris Climate Agreement in 2015.

Indeed, numerous new environmental policies aim to foster SET by involving citizens and local communities in the generation of renewable energy (Koistinen et al. 2018; Heldeweg 2017). When producing and delivering an excess of energy to the grid, the consumers are being transformed into prosumers (Koirala et al. 2016). The Netherlands, the UK and Germany are leaders in promoting and implementing the new agenda for the SET (Becker \& Kunze 2014; Magnusson \& Palm 2019; Hoppe et al. 2015). The possibility of fulfilling such SET is heavily 
interdependent with advanced technologies as it is closely linked with the production of new technologies and economic growth. Innovative technologies, such as blockchain, are often given priority in energy decentralisation as they are considered a secure and privacy-enhancing method of energy transactions among local communities (Aitzhan \& Svetinovic 2018). Using the possibilities provided by encryption algorithms, smart contracts (i.e. a type of contract for blockchainbased infrastructures) and distributed data, self-sufficient energy systems can be created (Wu \& Tran 2018). These innovative technologies do not just enable local communities to meet the value of sustainability but also address other important values like energy security, reliability and privacy (Aitzhan \& Svetinovic 2018).

A reference to advanced technological practices in the context of SET can be found in numerous policy documents. In the EU directive 2018/2001 of the European Parliament and of the council of 11 December 2018 on promoting the use of energy from renewable sources, a crucial policy document, this implicit bias is traceable. This directive contains SET goals that all European Union countries must aim for (Union 2018). Although it is up to each country to decide how to achieve these goals, the directive is still consolidated and delivered across a precise vision of SET. Technological advancements are particularly emphasised and are at the core of the SET vision expressed in the directive (Union 2018). For example:

(76) The Energy Union strategy also recognized the role of the citizen in the energy transition, where citizens take ownership of the energy transition, benefit from new technologies to reduce their bills, and participate actively in the market

(emphasis added, Union 2018, p. 93)

(86) With regard to Intelligent Transport, it is important to increase the development and deployment of electric mobility for roads, as well as to accelerate the integration of advanced technologies into innovative rail

(emphasis added, Union 2018, p. 95)

(5) Member States shall ensure that guidance is made available to all relevant actors, in particular to planners and architects so that they are able properly to consider the optimal combination of energy from renewable sources, of highefficiency technologies, and of district heating and cooling when planning, designing, building and renovating industrial, commercial or residential areas

(emphasis added, Union 2018, Article 18, p. 117)

(1) The Commission is empowered to adopt delegated acts in accordance with Article 35 to amend the list of feedstock set out in Parts A and B of Annex IX by adding, but not removing, feedstock. Feedstock that can be processed only with advanced technologies shall be added to Part A of Annex IX. Feedstock that can be processed into biofuels, or biogas for transport, with mature technologies shall be added to Part B of Annex IX. Such delegated acts shall be 
based on an analysis of the potential of the raw material as feedstock for the production of biofuels and biogas for transport.

(emphasis added, Union 2018, Article 28, p. 128)

The EU directive rests on pushing high-tech technological advancement to achieve economic growth without critical reflection upon alternative ways. The directive holds a strong association with hi-tech energy innovations and market designs - a vision of SET from the global North's perspective. In the SET literature, there is a heavy focus on market mechanisms that hold a techno-optimistic view of technologies' role (Bellekom et al. 2016; Parag \& Sovacool 2016; CamarinhaMatos 2016). Such a vision of the SET brings the implicit bias of technological advancements being taken for granted with accompanying ideas and beliefs in the market's ideals and its design that leads to economic growth. This universal, singular and homogenous view of SET is guided by rational values of efficiency, optimisation and maximisation (see examples: Smith et al. 2010; Ilic et al. 2012; Camarinha-Matos 2016; Saad et al. 2016; Kuzemko et al. 2017; King \& Van Den Bergh 2018). This view frames the way communities' needs, values and visions are understood without taking into account the plurality of local narratives and knowledge. This may lead to strained relations between the local perceptions of desirable economic growth and the vision of SET imposed by the EU directive.

Importantly, we do not try to claim here that economic growth is a particularly negative phenomenon. Rather the opposite, we agree that economic growth in principle aims at empowerment of local communities. However, by imposing the economic growth framework, existing social practices, local knowledge, needs and diverse values of communities might be neglected (Friedman 2006). These aspects are especially crucial for the empowerment of impoverished communities in the EU that are living outside of the technologically advanced world. These communities might have alternative low-technological solutions and local creative strategies for adaptation. Hence, we suggest that there is a need to explore local practices, knowledge, values and narratives about alternative socio-technical arrangements around decentralised energy that could enrich the dominant vision of SET in the global North policies.

To develop an inclusive and encompassing picture of SET, additional empirically grounded discussions are required. To enrich SET visions in the global North, we propose to expand the account of SET by learning from diverse energyrelated practices and associated values that are endemic to the global South. In the following couple of sections, we present a case study and draw several lessons about the alternative socio-technical arrangements around decentralised energy.

\section{Background and context of the empirical case}

In this section, we present empirical observations from an ethnographic research project on community-managed solar mini-grids in rural India. The ethnography was conducted as part of the doctoral research of one of the authors of this chapter (Singh 2019). The main objective of the ethnographic study was to understand 
the local energy-related practices of the villagers, especially when the villagers themselves manage the local decentralised grid. The field-sites were four off-grid villages where each of the villages had a stand-alone solar mini-grid of $3 \mathrm{~kW}(48 \mathrm{~V}$ DC) capacity. These villages are located in Chhattisgarh, a federal state located in central India. These four villages fall within the state's natural reserve, and hence they are officially referred to as "forest villages". See Figures 3.1 and 3.2. These decentralised grids were installed by Chhattisgarh State Renewable Energy Development Agency (CREDA), which is constituted by the Department of Energy of the Government of Chhattisgarh. Each of these villages was inhabited by 35-38 families. The field-visits, as part of the study, were conducted in 2014 and again in 2016. The study included interviews and discussion with various CREDA officials.

CREDA is mandated by the Government of Chhattisgarh to "electrify" remote villages, such as those located within the forest reserve, that cannot be connected to the centralised electricity grid. For such locations, CREDA utilises small-scale off-grid solutions, such as solar mini-grids. The government funds these off-grid

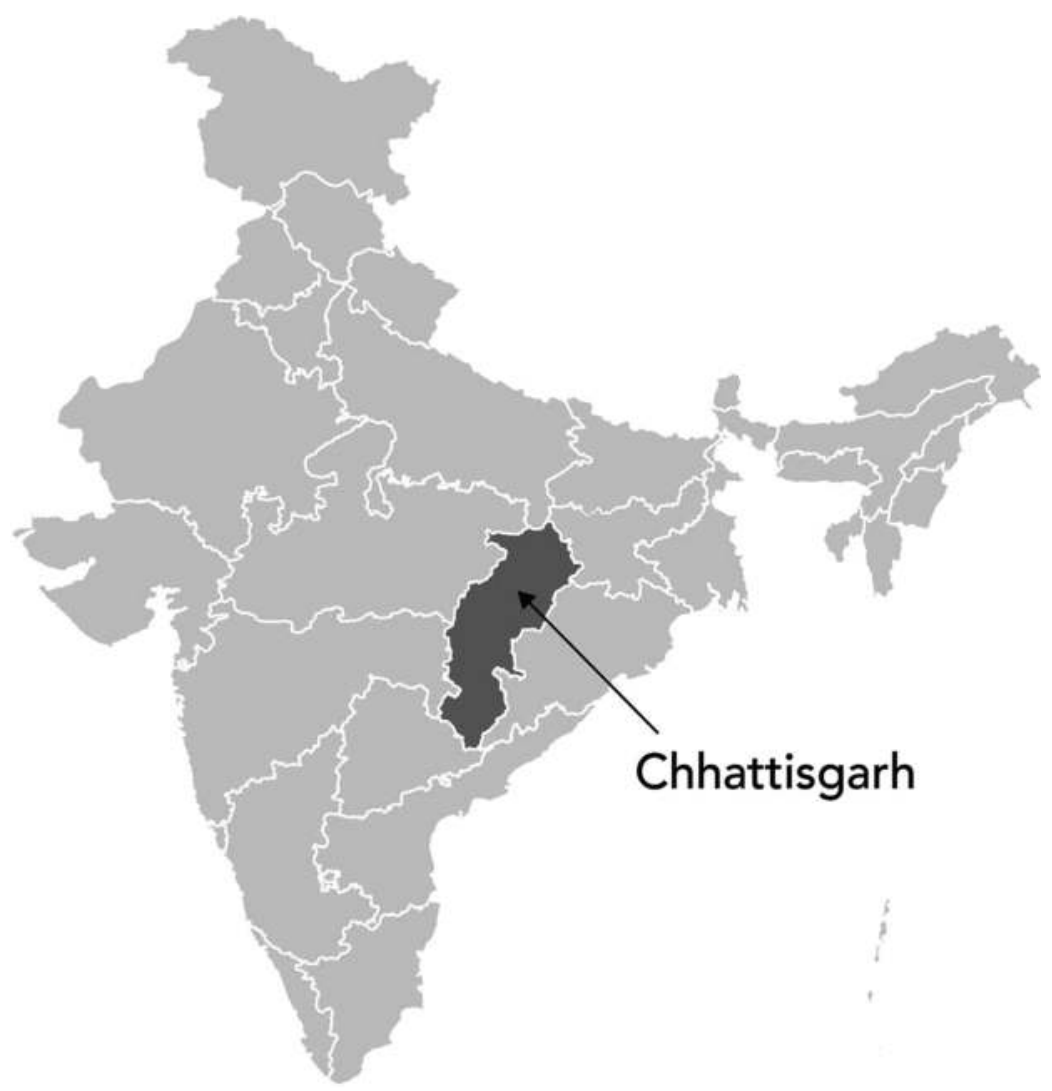

Figure 3.1 Map of India with the location of Chhattisgarh highlighted. 

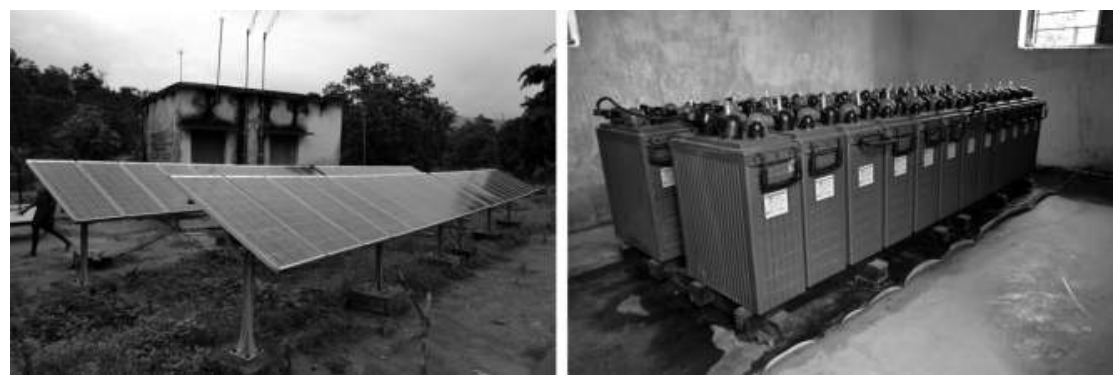

Figure 3.2 Photographs of a mini-grid at the field-site. Notice the solar panels on the ground and a battery-bank inside a control-room.

installations to achieve its ambition of complete electrification of the state of Chhattisgarh. It is worthwhile to note that the Chhattisgarh government's rural "electrification" drive is primarily focused on clean lighting provision. Therefore, the mini-grids installed by CREDA are only for lighting provision and are not aimed at supporting villagers in any local economic activity, such as electric irrigation pumps for agriculture.

CREDA considers $1 \mathrm{~kW}$ capacity to be sufficient for lighting provision for 15 families and targets that each family in a village has access to two $11 \mathrm{~W}$ compact fluorescent lamp (CFL) bulbs that should glow for seven to ten hours per day. Apart from these household-level lighting provisions, CREDA's mini-grids, which are locally referred to as power-plants, are also used for powering a few (three to five) streetlights in a village. Each of the mini-grids includes a batterybank with a capacity to store electricity to power the household-level lights and streetlights for three days without receiving any charging from the sun. The battery-banks, along with energy meters and grid-controlling switches and panels, are safely placed inside a "control-room", a physical room constructed by CREDA at each of the sites. The solar panels are either placed on the roof of the "control-room" or the ground right next to it. A "power distribution network" (PDN) consisting of electrical cables mounted and poles connect the control-room to the houses within a village.

As per CREDA's working policy, a village-level energy committee (Urja Samiti) is installed for every mini-grid. Usually, the local energy committee consists of five volunteers in the roles of grid operator, secretary and members. CREDA officials state that a local energy committee is established for ensuring daily operation of a grid and for reporting the needs for repair and maintenance. Every energy committee includes a grid operator, who is a local volunteer and is nominated by the committee. CREDA seeks a grid operator who is enthusiastic and willing to learn basic operations of a mini-grid. CREDA provides basic operational training to a grid operator. A grid operator is mainly responsible for daily operations, such as turning the grid "on or off", regular cleaning of solar panels and safety of the components of the grid. At the time of the field-visit, these grids 
have already been functioning for over eight years. CREDA officials attribute the significant role of the local energy committee and the villagers in the daily management of the grid.

\section{Decentralisation of energy grids: local practices, knowledge, values, and narratives}

\section{Local practices of improvisation, redistribution, and adaptation}

This ethnographic field-research revealed a wide range of local social practices that enabled the decentralisation of the mini-grids. This nexus of practices comprises practices of improvisation, redistribution of energy and adaptation of minigrids to fit with the dynamics of the social, cultural and economic life of the villagers. CREDA installed these decentralised grids for the primary and sole purpose of lighting provision to the remote villages. However, the villagers reported the installed connections to be limiting and "rigid". They often spoke of their needs for the energy from the grid to be organised differently for the requirements of local contexts, such as religious festivals, marriage, childbirth and illness. For instance, during a marriage ceremony in a local household, energy is required for powering devices, such as music systems, loudspeakers, and colourful lights and also these devices are desired to work beyond the $11 \mathrm{pm}$ limit set by the automatic timer of the grid. In such situations, the villagers creatively redistribute the flow of electricity by reorganising and bypassing components of the grid, such as an automatic timer and load-limiter (see Figure 3.3). Many instances of these practices are visible in these villages; for instance, villagers often tap into the PDN's cables to connect energy-consuming devices such as television sets, CD players,

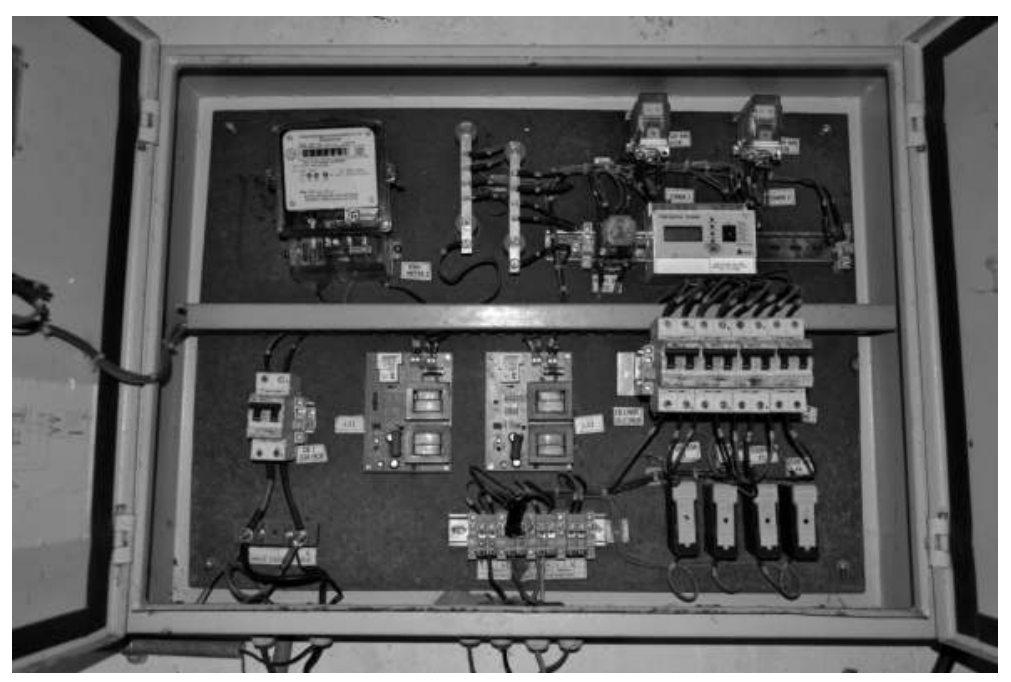

Figure 3.3 Automatic timer and load-limiter. 


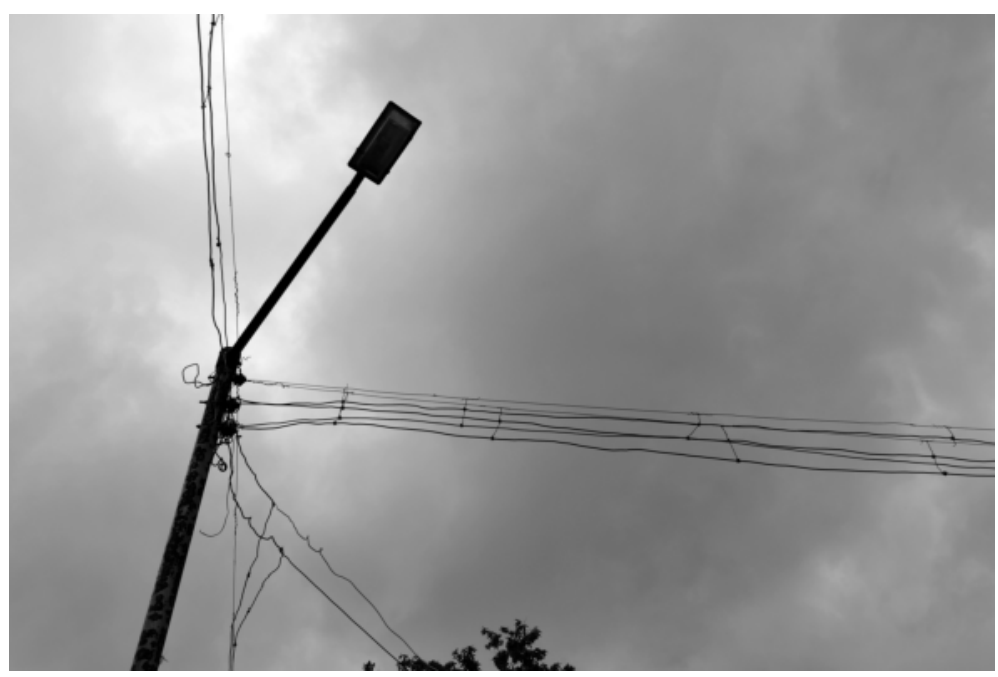

Figure 3.4 Power Distribution Network (PDN) with extra cables connected by the villagers.

music systems and lights (see Figure 3.4). Such contexts foreground the need for reconfiguring the local distribution of electrical energy to power various devices, other than the CFL bulbs installed by CREDA.

The ethnographer observed many intriguing practices to reconfigure the grid in order to address a local problem. For instance, many houses relocated the CFL bulbs provided by CREDA to hang outside of their houses. The villagers narrated that their village remains under threat from herds of elephants. The villagers disclosed that as part of their cultural tradition, they store mahuwa (madhuca longifolia) flowers in their households. The flower is edible and has medicinal value. The villagers said that the wild elephants of the region also eat the flower and can smell the "stored" flowers from a distance. Sometimes a herd of elephants, following the smell of the flower, come searching for it during the night. In their quest, elephants destroy the mud-built houses of the villagers. The villagers explain that the light emitted by a CFL bulb combined with a wind-induced movement of the bulb is sufficient to keep the elephants at bay. This practice of reconfiguring components of the grid enables the villagers to address a local problem through the decentralised grid.

An intriguing aspect of these practices is their shared and socio-communal nature. The villagers elaborated that often any performance of these practices of improvisation, redistribution and adaptation are preceded by deliberations involving the energy committee and the villagers. The grid operator often performs the accompanying "technical" tasks with active participation from other villagers. The role of an energy committee is central for developing a consensus amongst the villagers towards any short-term or enduring improvisations and alterations of 
the grid. CREDA officials clarified that a local energy committee is empowered to develop their own rules for the functioning of the local grid. Further, a committee can determine and execute sanctions against any villager or household in cases of violation of their rules. A benefit of these social and communal practices is a developing sense of ownership amongst the energy committee towards the local grid. CREDA officials state that in the villages where there is a more robust engagement of the local committee with the grid, they also observe better care and protection of the components of the grid. Overall, the existence and performance of these practices of improvisation and adaptation also indicate the villagers' needs and desires to enhance the possibilities offered by a local grid, an intervention for a sustainable energy transition and to connect it with their social, cultural and religious values.

\section{Developing local knowledge and know-how}

These practices of improvisation and reconfiguration of the grids require technical know-how about various components of the grid. The villagers report that their familiarity with the grid's functioning develops by observing and discussing it with the "outsiders", such as electricians, who come to inspect or repair any damaged component of the grid. The villagers state how they built their technical knowhow to negotiate with various components of the grid by participating in periodic maintenance tasks by visiting electricians. An exciting and unintended outcome of this developing local knowledge is the emerging ability of the villagers to do a rudimentary repair of a broken-down device or component of the grid. These practices come in handy when a standard replacement of a damaged item is not available, or if professional repair work is either expensive or is getting delayed.

An associated aspect of these practices of adaptation of the grids is a delicate balance that has to be maintained to avoid overuse of a device at a household that could lead to drawing large amounts of energy from the grid. This situation can potentially lead to complaints from and disputes with other villagers. Hence, such practices require sensorial know-how of local electricity production and storage. The ethnographer was surprised by people's delicate understanding of this. Over the years, the villagers seem to have developed a qualitative understanding of local energy capacity.

\section{Beyond monetary values}

The villagers have designed various non-monetary means of sharing the benefits of energy and the grid. For instance, an electrical socket installed by a household is also used by other villagers for charging their mobile phones. Similarly, a grid operator installed a television and CD player in a room. Pointing to a couple of cots and chairs placed in the room, he narrated how the set-up works as a movie theatre for the village, where villagers gather for communal viewing. By sharing a privately owned device with others, he can avoid the ire of the villagers who are unable to afford these devices (see Figure 3.5). 

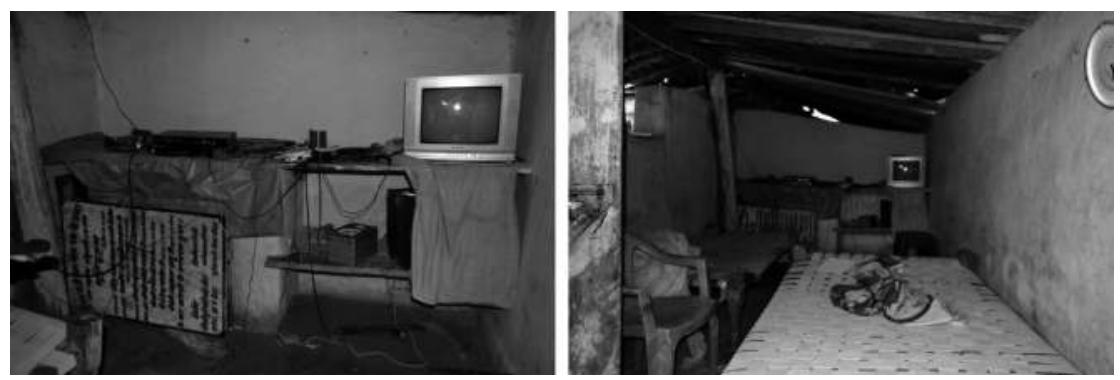

Figure 3.5 A "movie theatre" set-up with a television-set connected to a compact disc (CD) player and with cots and chairs for the villagers to sit.

A discussion on economic benefits and drawbacks of the state-funded decentralised grids falls outside the scope and ambition of this chapter. However, these local practices hint at possibilities of non-market ways for local communities to manage shared production, consumption and exchange of energy through a decentralised grid. CREDA's initial plan was to structure a monetary payment structure, where a grid operator would collect a small monthly fee (INR 5-10) from each household. This collected amount would form a small remuneration for grid operator efforts. CREDA officials reported that payment collection has proved to be a challenging task and they consider it to have been a failure. The payment collection proved difficult due to two main reasons. Firstly, due to economic poverty plaguing these villages, many of the villagers are cash-starved. Most of the villagers do not have any regular employment, and their participation in agricultural activities is primarily for subsistence. Second, grid operators are hesitant to collect monetary payment from their fellow villagers, as this has the potential to strain their local social relations. The values associated with payment collection and market logic seem to be conflicting with the villagers' value of shared and non-monetary means of life in the village.

\section{Local narratives}

CREDA officials, during initial conversations with the ethnographer, had narrated and emphasised various "misuses" and sometimes "abuses" of the mini-grids at the field-sites. They remarked that the villagers often misuse the grid by connecting various power-consuming devices such as radio, television and loudspeaker. They explained that these additional power-consuming devices limit the run-time of the grid and expedite the amount of repair and maintenance. For instance, sometimes the villagers in the process of attaching an extra cable to the PDN damage the existing electrical cables or expose an electrical junction to rainwater and hence introducing safety risks. Similarly, due to an addition of extra electrical load during a local celebration, the battery-bank gets wholly drained in just a few hours. Overall, CREDA officials raised various relevant points of concern associated with these local practices. 
However, during the field-visits accompanied by CREDA officials, the ethnographer was surprised by their informal acceptance of these local practices. Contrary to the narrative of "misuse" and "abuse", the informal stance of the officials is one of acceptance and cautious encouragement for these practices. The ethnographer was amazed by CREDA officials' comments to the villagers that they could make use of the grid as they like. The officials encouraged them to discuss with each other local use of the energy provided by the grid. The emphasis was on building consensus amongst the villagers on use of the grid. Contrary to the initial communication with the ethnographer, the officials stated not having any issues with these practices. The officials' main concern was to avoid any local dispute and hence their emphasis on consensus-building.

Later, an official explained that CREDA has reluctantly accepted these practices, firstly, as these are widespread, and they are unable to control them. Secondly, these practices make the villagers engage and care for the grid, making them into a process of protection of equipment. Hence, it is not surprising that at the time of the field-visits, these grids have been continuously functioning for eight to ten years despite their remote locations.

The narrative and process of consensual local use, appropriation and adaptation of the grid is the core of the informal stance of CREDA. Within the dynamics of this emerging narrative, the conceptual boundaries amongst the meanings of (proper) "use", "misuse" and "abuse" get blurred and negotiated. Taking a more considerate viewpoint, CREDA officials later described the damages caused and safety concerns associated with the local practices as due to lack of awareness and know-how that should be addressed rather than curbed. Overall, these multitudes of local practices have informed the informal policy of CREDA through which the local energy committee is empowered and mandated to configure, appropriate and adapt these decentralised grids.

\section{Composing an inclusive view on sustainable transition to decentralised energy}

As mentioned earlier in the chapter, SET is conceptualised as a technology-laden category in the EU directive. Such a framing leads to the weak picture of the energy transition by informing definitions and policies and shaping the debate. The hegemonic conceptualisation of SET expressed in the EU directive is exclusionary and problematic because it holds a "tunnel vision" on how energy transition should occur through the diffusion of technological innovation and overreliance on market mechanisms. Whereas, as the case study indicated, there might be other ways to engage with energy transition through creative low-tech solutions, for instance. In other words, we suggest that there is a possibility to learn from local practices, knowledge, values and narratives in the global South about alternative socio-technical arrangements around decentralised energy. Although present in energy scholarship (Singh 2019; Kumar et al. 2019; Bombaerts et al. 2020), the systematic inclusion of local values, knowledge, narratives and practices is still missing in the global North's vision on SET and particularly in EU policies. 
Policies can strengthen community bonds with minimal interference with traditions, cultures and social relations by taking the community's knowledge, values, practices and narratives as a starting point. For instance, CREDA's (informal) policy aimed to encourage the villagers to develop consensus to use the grid for their collective goals such as religious celebrations.

In the endeavour of constructing an inclusive view of SET, we draw our inspiration from the work of David Edgerton (2007). The author emphasises the importance of inclusion of local practices into a "big picture" of the narrative of global history (Edgerton 2007). Edgerton (2007) proposes the post-contextual approach, where he emphasises the importance of perceiving local narratives as valuable for the just and fair representation of a "big picture". The author claims that "the point of a post-contextual picture is to give us a different account of the national and global historical context, and the place of technology in it, not merely adding technology to accounts" (Edgerton 2007, p. 85). Incorporation of the local narratives into a "big picture" of SET may facilitate the recognition of local practices, values and knowledge. The local narratives comprise diverse social, cultural, religious and economic contexts for adaptation, appropriation and acceptance of SETs, such as the decentralised grids, by the local communities. As was indicated in the case study, the local narratives are used by the villagers to legitimise intended and unintended "use", "abuse" and "misuse" of the grids. On the one hand, the local villagers, including the energy committee, utilise these narratives to develop consensus within the village. These narratives become key components of implicit and explicit negotiation between the villagers at the one end; and CREDA officials, visiting electricians and eventually CREDA's informal policy at the other end.

Furthermore, incorporation of local knowledge is essential for an inclusive vision of SET as the interactions between material agencies and knowledge production in the ways local people transform and adapt the technologies can enrich a "big picture" of SET (Edgerton 2007, p. 92). This was exemplified in the empirical analysis as practices of improvisation that consist of local approaches to redistribution of energy and adaptation of mini-grids to fit with the dynamics of their life and to address their unmet needs for the energy spanning social and cultural contexts. These contexts, such as festivals, celebrations and rituals of marriage and childbirth, are an integral part of their everyday life that justify the need for alteration in the energy distribution. In other words, such local creative adaptation can be oriented towards the particular needs of the community because these lowtechnological solutions can be made compatible with local practices, knowledge, values and narratives.

Indeed, the empirical case from the global South brings attention to various aspects that may be relevant for design experimentation (Singh et al. 2015, 2019) and policy development in the global North. In a way, the case also hints that for the SET, we do not necessarily need to "push" the latest and "high-tech" innovations. A local creative adaptation and consensus-building in communities may provide spaces for improvisation in a decentralised grid. Such processes have the potential to open a twofold opportunity for SET. First, to engage a local 
community in care, protection and repair through acquired ownership of a decentralised grid. Second, to create localised opportunities to manage shared production, consumption, and exchange of energy. Moreover, it is possible to support local communities by strengthening community bonds and contributing to the wellbeing of locals through creative approaches to energy, localised problemsolving and new forms of ownership. As shown in the example of villagers using lights to keep elephants at bay, local adaptation of the grid has contributed to general wellbeing by preventing damage to health and property.

All in all, the case provides a glimpse of alternative configurations of social life with decentralised energy. While in energy scholarship local empowerment, civic engagement and community ownership are often regarded as a positive side of community energy projects (Koirala et al. 2016; Rogers et al. 2008; Hoppe et al. 2015), in the EU directive such aspects were mostly missing. In our conclusion, we suggest that a vision of SET, where people are not pushed to accept market designs and high-tech innovations, can incorporate local values, knowledge, practices and narratives. Such a vision can open up a space for the emergence of nonmarket structures and non-monetary mechanisms for local engagement in energy decentralisation (Singh et al. 2017, 2018). However, this requires further crosscultural research into a "big picture" of SET through recognising and integrating visions from both the global North and the global South.

\section{Conclusion}

Drawing inspiration from historians of science and technology and utilising empirical findings from an ethnographic field-study on decentralised grids in rural India, in this chapter we have argued that hegemonic conceptualisation of SET does not sufficiently take into account the local narratives, practices, knowledge and values. We first examined the visions on SET implemented in the EU directive and revealed implicit bias about heavy reliance on technological innovation, market design and rational values supporting economic growth. Our empirically informed theoretical approach includes a focus on local practices, narratives, knowledge and a diverse set of values in energy decentralisation discourse on the one hand and the mundane technologies and the practices of improvisation on the other hand. Inspired by the post-contextual approach, this chapter contributes towards a long process of integration of the perspectives from the global South and the global North in the one "big picture" of the SET.

\section{Acknowledgement}

Both the authors, Anna Melnyk and Abhigyan Singh, have contributed equally to this chapter and hence are joint first authors. Abhigyan Singh conducted the reported field-research on solar mini-grids in India as part of his doctoral research. Abhigyan's doctoral research is part of the research programme of University Campus Fryslân (UCF), which is financed by the province of Fryslân in the Netherlands. Anna Melnyk's work on this paper was supported 
by the ValuesChange project that received funding from the European Research Council (ERC) under the European Union's Horizon 2020 research and innovation programme under grant agreement No 788321. The opinions expressed in this document reflect only the authors' views and in no way reflect the European Commission's opinions. The European Commission is not responsible for any use that may be made of the information this document contains. We express our gratitude to the villagers at the field-sites for welcoming Abhigyan and participating in this research. We sincerely thank Chhattisgarh State Renewable Energy Development Agency (CREDA) and its officials for sharing their perspectives, providing relevant background information and enabling the field-visits. Also, we are grateful for all the extensive commenting and feedback done by Johanna Höffken, Ankit Kumar and Auke Pols that helped to improve this chapter.

\section{Note}

1 Authors are co-first authors and have contributed equally to the chapter.

\section{References}

Aitzhan, N. Z., \& Svetinovic, D. (2016). Security and privacy in decentralized energy trading through multi-signatures, blockchain and anonymous messaging streams. IEEE Transactions on Dependable and Secure Computing, 15(5), 840-852.

Becker, S., \& Kunze, C. (2014). Transcending community energy: collective and politically motivated projects in renewable energy (CPE) across Europe. People, Place and Policy Online, 8(3), 180-191. doi: 10.3351/ppp.0008.0003.0004

Bellekom, S., Arentsen, M., \& Gorkum, K.V. (2016). Prosumption and the distribution and supply of electricity. Energy, Sustainability and Society, 6(1). doi:10.1186/ s13705-016-0087-7

Bombaerts, G., Jenkins, K.E., Sanusi, Y.A., \& Guoyu, W. (2020). Energy Justice Across Borders. Cham, Switzerland: Springer Open.

Camarinha-Matos, L.M. (2016). Collaborative smart grids - a survey on trends. Renewable and Sustainable Energy Reviews, 65, 283-294. doi:10.1016/j.rser.2016.06.093

Coenen, L., Benneworth, P., \& Truffer, B. (2012). Toward a spatial perspective on sustainability transitions. Research Policy, 41(6), 968-979.

Cuppen, E., Pesch, U., Remmerswaal, S., \& Taanman, M. (2019). Normative diversity, conflict and transition: Shale gas in the Netherlands. Technological Forecasting and Social Change, 145, 165-175.

Edgerton, D. (2007). Creole technologies and global histories: rethinking how things travel in space and time. Journal of History of Science and Technology, 1, 75-112.

Friedman, B.M. (2006). The moral consequences of economic growth. Society, 43(2), 15-22.

Heldeweg, M. A. (2017). Normative alignment, institutional resilience and shifts in legal governance of the energy transition. Sustainability, 9(7), 1273.

Hoppe, T., Graf, A., Warbroek, B., Lammers, I., \& Lepping, I. (2015). Local governments supporting local energy initiatives: lessons from the best practices of Saerbeck (Germany) and Lochem (The Netherlands). Sustainability, 7(2), 1900-1931. doi: 10.3390/su7021900

Ilic, D., Silva, P.G., Karnouskos, S., \& Griesemer, M. (2012). An energy market for trading electricity in smart grid neighbourhoods. 2012 6th IEEE International Conference on Digital Ecosystems and Technologies (DEST). doi:10.1109/dest.2012.6227918 
Koirala, B.P., Koliou, E., Friege, J., Hakvoort, R.A., \& Herder, P.M. (2016). Energetic communities for community energy: a review of key issues and trends shaping integrated community energy systems. Renewable and Sustainable Energy Reviews, 56, 722-744. doi: 10.1016/j.rser.2015.11.080

Koistinen, K., Teerikangas, S., Mikkilä, M., \& Linnanen, L. (2018). Agent-based change in facilitating sustainability transitions: a literature review and a call for action. Handbook of Engaged Sustainability, 2-2, 1135-1156. doi:10.1007/978-3-319-71312-0_31

Kern, F., \& Smith, A. (2008). Restructuring energy systems for sustainability? energy transition policy in the Netherlands. Energy Policy, 36(11), 4093-4103. doi: 10.1016/j. enpol.2008.06.018

King, L.C., \& Van Den Bergh, J.C. (2018). Implications of net energy-return-on-investment for a low-carbon energy transition. Nature Energy, 3(4), 334-340. doi:10.1038/ s41560-018-0116-1

Kumar, A., Ferdous, R., Luque-Ayala, A., Mcewan, C., Power, M., Turner, B., \& Bulkeley, H. (2019). Solar energy for all? Understanding the successes and shortfalls through a critical comparative assessment of Bangladesh, Brazil, India, Mozambique, Sri Lanka and South Africa. Energy Research \& Social Science, 48, 166-176. doi:10.1016/j. erss.2018.10.005

Kuzemko, C., Mitchell, C., Lockwood, M., \& Hoggett, R. (2017). Policies, politics and demand side innovations: the untold story of Germany's energy transition. Energy Research \& Social Science, 28, 58-67. doi:10.1016/j.erss.2017.03.013

Magnusson, D., \& Palm, J. (2019). Come together-the development of Swedish energy communities. Sustainability, 11(4), 1056. doi: 10.3390/su11041056

Mok, L., \& Hyysalo, S. (2018). Designing for energy transition through value sensitive design. Design Studies, 54, 162-183. doi: 10.1016/j.destud.2017.09.006

Parag, Y., \& Sovacool, B.K. (2016). Electricity market design for the prosumer era. Nature Energy, 1(4). doi:10.1038/nenergy.2016.32

Rae, C., \& Bradley, F. (2012). Energy autonomy in sustainable communities - a review of key issues. Renewable and Sustainable Energy Reviews, 16(9), 6497-6506. doi: 10.1016/j.rser.2012.08.002

Rogers, J., Simmons, E., Convery, I., \& Weatherall, A. (2008). Public perceptions of opportunities for community-based renewable energy projects. Energy Policy, 36(11), 4217-4226. doi: 10.1016/j.enpol.2008.07.028

Saad, W., Glass, A.L., Mandayam, N.B., \& Poor, H.V. (2016). Toward a consumer-centric grid: a behavioral perspective. Proceedings of the IEEE, 104(4), 865-882. doi:10.1109/ jproc.2016.2520760

Singer, P. (2002). One World: The Ethics of Globalization. New Haven: Yale University Press.

Singh, A. (2019). Conceptualizing inter-household energy exchanges: an anthropologythrough-design approach (Doctoral dissertation, Delft University of Technology). doi:10.4233/uuid:57be7165-2726-4a1a-b076-c5ed3988e00b

Singh, A., Strating, A.T., Herrera, N.R., Mahato, D., Keyson, D. \& van Dijk, H.W. (2018). Exploring peer-to- peer returns in off-grid renewable energy systems in rural India: an anthropological perspective on local energy sharing and trading. Energy Research \& Social Science 46, 194-213. doi:https://doi.org/10.1016/j.erss.2018.07.021

Singh, A., Strating, A.T., Romero Herrera, N., van Dijk, H.W., \& Keyson, D. (2017). Towards an ethnography of electrification in rural India: social relations and values in household energy. Energy Research \& Social Science 30, 103-115. doi:https://doi.org /10.1016/j.erss.2017.06.031 


\section{Anna Melnyk and Abhigyan Singh}

Singh, A., van Dijk, H.W., Romero Herrera, N.A., \& Keyson, D.V. (2015). Enabling "new" practices of renewable energy sharing: a cross-cultural approach. Design for Sharing workshop at ACM CHI'15 Conference. Seoul, Republic of Korea. Available at: http://resolver.tudelft.nl/uuid:ef0d858f-499b-4f12-a608-532ca2c4f9b1.

Smith, A., Voß, J.-P., \& Grin, J. (2010). Innovation studies and sustainability transitions: the allure of the multi-level perspective and its challenges. Research Policy, 39(4), 435-448. doi: 10.1016/j.respol.2010.01.023

Spangenberg, J.H. (2004). Reconciling sustainability and growth: criteria, indicators, policies. Sustainable Development, 12(2), 74-86. doi:10.1002/sd.229

Taebi, B., \& Kloosterman, J.L. (2015). Design for values in nuclear technology. In I. Poel, J. Hoven, \& P.E. Vermaas (Eds.), Handbook of Ethics, Values, and Technological Design (pp. 799-823). Dordrecht: Springer.

Union, E. (2018). Directive (EU) 2018/2001 of the European Parliament and of the Council of 11 December 2018 on the promotion of the use of energy from renewable sources. Official Journal of the European Union, 5, 82-209.

Van de Poel, I. (2017). Design for sustainability. In: Kaplan D.M. (Ed.), Philosophy, Technology, and the Environment (pp. 121-142). Cambridge: MIT Press.

Verbong, G., \& Geels, F. (2007). The ongoing energy transition: lessons from a sociotechnical, multi-level analysis of the Dutch electricity system (1960-2004). Energy Policy, 35(2), 1025-1037. doi: 10.1016/j.enpol.2006.02.010

Verkade, N., \& Höffken, J. (2019). Collective energy practices: a practice-based approach to civic energy communities and the energy system. Sustainability, 11(11), 3230. doi: $10.3390 /$ su1 1113230

WCED. (1987). Our Common Future. Brundtland G.H., Angelli S., Al-Athel S., \& Chidzero B. (Eds.). Oxford: World Commission on Environment and Development (WCED).

Wu, J., \& Tran, N.K. (2018). Application of blockchain technology in sustainable energy systems: an overview. Sustainability, 10(9), 3067. 


\title{
4 Bolivia's energy transition in harmony with nature
}

\author{
Reality or delusion?
}

\author{
Paola Villavicencio-Calzadilla ${ }^{1}$ \\ and Romain Mauger ${ }^{2}$
}

\section{Introduction}

Bolivia faces significant energy-related challenges that demand urgent responses. Firstly, while being one of the most biodiverse countries in the world, economic activities and development projects, such as oil and gas exploitation and large infrastructure projects, are leading to biodiversity degradation and socio-ecological conflicts (Romero-Muñoz et al., 2019). The country is also particularly vulnerable to the consequences of anthropocentric climate change. For instance, glacier retreat due to warming temperatures is threatening water supply (Escurra et al., 2014; Seiler et al., 2015; Schoolmeester and Verbist, 2018), therefore jeopardising electricity generation. Secondly, with a poverty rate of $34,6 \%$ (World Bank, 2020b) and a growing population and energy demand (INE, 2014; CAF, 2016, p. 6), Bolivia is struggling to satisfy the basic needs of its population. Thirdly, the country's economy heavily relies on hydrocarbons - especially natural gas - which represented up to $7 \%$ of the GDP and $55 \%$ of exports in value in 2013 (INE, 2020a, b). However, its stability is threatened by hydrocarbons price volatility and looming depletion of reserves - natural gas is set to dry up by 2025 (Villegas, 2018, p. 6). Therefore, Bolivia must urgently find other income resources to reach economic and income diversification (Fattouh et al., 2019, p. 45). To deal with these challenges, Bolivia is undertaking an energy transition from fossil fuels towards renewable energy sources (UNFCCC, 2016, pp. 8-9) that, at least on paper, moves away from traditional anthropocentric paradigms.

Indeed, energy transition plans worldwide follow an anthropocentric approach. The reason is that the existing energy system operates within the dominant humancentred or anthropocentric paradigm. Anthropocentrism sees humankind as more valuable than all other non-human organisms and environmental systems and involves their subordination, denying that "they have value in their own right" (Washington et al., 2017; Kopnina et al., 2018, p. 115). Ecocentrism, in contrast, provides a more radical expression of a re-evaluated, re-envisioned relationship between human beings and nature; one that recognises the material agency and the legal subjectivity of natural entities, ecological integrity and the intrinsic value of all lifeforms and ecosystems, and the sufficient (as opposed to optimal) accommodation of human use and occupancy within ecological constraints (De 
Lucia, 2015; Washington et al., 2017; Kotzé and Villavicencio Calzadilla, 2017, p. 413).

In the current anthropocentric energy system, energy sources are viewed as inert materials (objects) that exist solely to satisfy the needs and desires of human beings (subjects). The value of these resources is defined by their utility to humans rather than their intrinsic value. Yet, this is "a view with grave ecological blindness" (Bosselmann, 2017, p. 151). The anthropocentric approach of the fossil-fuels-based energy system was already evident at the First Earth Summit, held in Stockholm in 1972, which put environmental issues on the global agenda for the first time. For instance, the Stockholm Declaration states that natural resources (including energy sources) must be safeguarded for the benefit of humans (United Nations, 1972, principles 2 and 5). Therefore, while energy needs of all mankind are considered, the general needs of other species are not.

As the transformation of the anthropocentric, centralised, large-scale and unsustainable energy system is imperative to respond to the human-induced global socio-ecological and climate crisis, discourses on energy transition revolve around the notions of "modern energy transition" (Morgan, 2015; Vavilov, 2016), "sustainable energy transition" (Solomon and Krishna, 2011), "just energy transition" (McCauley and Heffron, 2018) and theories of "energy justice" (Sovacool and Dworkin, 2014; Guruswamy, 2015; Jenkins et al., 2016). However, these frameworks follow the same human-centred approach promoted by western ideology and traditions that may not be entirely appropriate to deliver a real transformation towards a future energy system that is more just and less ecologically destructive (Sovacool et al., 2017, p. 678; Castán Broto et al., 2018, p. 645). Indeed, actions to foster "sustainable" or "modern" transitions may have negative socio-environmental impacts, reproduce entrenched forms of inequality and create further injustices (Avila, 2018; Villavicencio Calzadilla and Mauger, 2018; Roddis et al., 2018). Some argue that this anthropocentric energy transition towards renewable energy sources "is a program of economic growth for the Global North which threatens to exponentially increase sacrificed zones" and "will come at the cost of the exploitation of ... territories and communities, all while intensifying the ecological crisis" (Mining Watch, 2019). When renewable energy projects are deployed on an industrial scale, the risk is to replace fossil fuels extractivism by renewable energy extractivism (Howe and Boyer, 2016), promoting forms of "green colonialism" (Willis, 2019; Evans-Pritchard, 2020) or "energy colonialism" (Batel and Devine-Wright, 2017; Dunlap, 2018).

Against this reality, an energy transition based on non-western and nonhuman-centred approach is taking shape in Bolivia. With a view to transcend the anthropocentric orientation of the country's legal system, ${ }^{3}$ a radical regulatory reform has taken place since 2009, aiming to protect Mother Earth or Pachamama. The new Constitution, which recognises the importance of protecting Mother Earth, led to the adoption of new legislation and policy frameworks that, taking an ecocentric approach, recognise and protect the rights of Mother Earth. This innovative regulatory avenue has a direct implication on the country's 
energy system and its transition - toward an ecocentric (energy) system - as it recognises its impact on Mother Earth. On paper at least, these ecocentricoriented regulatory instruments provide a solid legal framework for overcoming the ecologically destructive extractivism of fossil fuels by recognising the intrinsic value of nature and her ecosystems - such as rivers and watersheds - and viewing all living beings as parts of an interconnected and interdependent web of sub-systems (Imran et al., 2014, p. 137). This is important because, as it has been noted, "[n]on human and non-sentient forms of life almost always have no voice, or recognition and status, in energy decision-making fora" (Sovacool et al., 2017, p. 688).

While some studies examined Bolivia's experiment with the rights of nature (Lalander, 2014; Villavicencio Calzadilla and Kotzé, 2018) and others presented the country's regulatory framework applicable to renewable energy sources (Zegada, 2016), this paper is the first offering a critical analysis of the country's energy transition applying a "rights of nature" lens. Despite the fact that the energy transition is a broad topic and will have to take place in all the components of the energy system, this paper focuses on the electricity sector - especially on grid-connected electricity generation - as it is the low hanging fruit of the current energy transition in most countries. ${ }^{4}$ This approach allows for an early analysis of the implementation of the energy transition towards renewable energy sources. This desk-based legal research focuses on the analysis of energy-related policy and legal documents in force in Bolivia as well as scholarly and grey literature. In terms of temporality, this paper centres its developments on Evo Morales' presidential mandates, running from early 2006 to the fall of 2019, as they were marked by a claimed reorientation of the country's policies towards a paradigm of harmony with nature. With this paper we aim to present Bolivia's experience in order to provide a basis for a global discussion and debate about how to rethink and conceptualise an energy transition in harmony with nature.

This paper has five sections. The introduction is followed by a section analysing the constitutional and statutory developments on the rights of Mother Earth in Bolivia and their implications for the country's energy transition. The next section reviews Bolivia's current electricity sector, its normative framework and the related energy transition policies and goals in order to determine their compatibility with the laws on Mother Earth. The fourth section critically examines the contradictions and tensions inside and between the previously discussed policy and regulatory frameworks and provides an example that illustrates such contradictions: the controversial mega hydroelectricity project of $E l$ Bala-Chepete in the Amazon Region of the country. The paper concludes that undertaking an urgent energy transition in harmony with nature is a daunting task, even in a country that has enshrined the rights of Mother Earth in its legal framework if such framework lacks coherence and implementation. Finally, recommendations to facilitate such an energy transition in Bolivia and in any country wishing to go beyond the anthropocentric, ecologically destructive energy system are made. 


\section{Bolivia's constitutional and statutory developments on rights of Mother Earth and their implication over the energy sector}

The election of Evo Morales as President of Bolivia in 2006 started a new chapter in the country's history marked by drastic transformations which included inter alia the implementation of radical constitutional and legal reforms. Following a challenging process that involved broad participation, especially by indigenous people, Bolivians approved a new Constitution and statutory regulations that not only made possible the recognition of ancient indigenous principles, but also the construction of a legal structure for the protection of nature or Mother Earth through an ecocentric approach. ${ }^{5}$

\section{The legal regime on the rights of Mother Earth}

The Bolivian Constitution, approved in $2009,{ }^{6}$ considered one of the most radical constitutions in the world, introduces transformational legal novelties. In addition to being one of the most progressive regarding the recognition of indigenous rights, ${ }^{7}$ it also constitutionalised the protection of Mother Earth or Pachamama and related ancestral indigenous principles, especially those that underpin the Aymara culture, such as Vivir Bien or Suma Qamaña (living well), as an attempt to defend and protect Mother Earth based on her intrinsic value. The incorporation of the ecocentric worldview in the Constitution was a major achievement for Bolivian society. It was especially so for indigenous people and organisations who, in response to ever-increasing environmental degradation, re-imagined the protection of Mother Earth during the constitutional drafting process in a manner that transcends the prevailing anthropocentric orientation of the previous legal and economic systems (Villavicencio Calzadilla and Kotzé, 2018, p. 404).

Although the Bolivian Constitution does not explicitly entrench the rights of Mother Earth, as its Ecuadorian counterpart does (Kotzé and Villavicencio Calzadilla, 2017), it includes ecocentric-oriented provisions recognising the importance of protecting Mother Earth. For instance, when providing for an environmental right of the population, the Constitution extends its protection to "other living things", declaring that the exercise of such a right "must be granted to individuals and collectives of present and future generations, as well as to other living things, so they may develop in a normal and permanent way" (art. 33). ${ }^{8}$ The Constitution also acknowledges that without the integrity of nature a new state will be impossible, as it "recognizes ecological integrity as the basis of the Bolivian constitutional state" (Villavicencio Calzadilla and Kotzé, 2018, p. 403).

According to the Constitution, Vivir Bien is one of the ethical and structural principles of the state (art. 8 (I)). Vivir Bien is an alternative cultural development vision that draws from ancestral practices and philosophies and is founded on ecocentrism. By seeking balance and harmony with nature or Mother Earth, it opposes the dominant neoliberal, consumerist, anthropocentric, growth-without-limits 
paradigm that for decades has promoted the domination and exploitation of nature and of vulnerable people in Bolivia and elsewhere in the world (Gudynas, 2011; Gudynas and Acosta, 2011; Radcliffe, 2012). Therefore, its inclusion as a founding principle guiding state action is highly relevant for a "new" Bolivia as it attempts to create a framework for re-conceptualising the relationship between human and nature on the basis of their interdependence.

The constitutional requirement for a new, integrated form of development towards Vivir Bien in harmony with nature led to the adoption of two radical legal constructs intended to confront juridical anthropocentric orientation. Such statutes, based on an ecocentric counter-narrative, are the Law of the Rights of Mother Earth (Ley de Derechos de la Madre Tierra, 2010) and the Framework Law of Mother Earth and Integral Development for Living Well (Ley Marco de la Madre Tierra y Desarrollo Integral para Vivir Bien, 2012).

The Law of the Rights of Mother Earth is the world's first statutory law recognising the rights of nature or Mother Earth. It enumerates specific rights to which nature is entitled - such as the right to life, to maintain and regenerate her life cycles and structures, and to be restored (art. 7). It also contains a set of legally binding principles - such as the principles of harmony with nature and of defence and respect for her rights - that attempts to go well beyond the principles of anthropocentric sustainable development (art. 2). Moreover, the Law establishes that "all Bolivians" are responsible for the exercise of Mother Earth's rights (arts. 8-9).

The Framework Law of Mother Earth and Integral Development for Living Well (hereafter Framework Law), was created to operationalise the Law of the Rights of Mother Earth in the context of the so-called integral development for living well in harmony with nature. According to the Framework Law, Vivir Bien means "living in complementarity, in harmony and in balance with Mother Earth and societies, in equality and solidarity and eliminating inequalities and mechanisms of control and domination" (art. 5.2). Thus, Vivir Bien must be achieved in a way that is complementary to the rights of humans and the rights of Mother Earth (art. 9). Moreover, to balance development on the one hand and the protection of nature on the other, the Framework Law refers to "integral development" as an alternative form of development that must be promoted and implemented in a way that respects the rights of Mother Earth. Integral development, which is linked to the implementation of integrated measures to create and reinforce social, spiritual and material conditions, capacities and means aimed at facilitating and strengthening community linkages, is therefore not the end result, but the process leading to Vivir Bien in harmony with nature (art. 5.3).

The Framework Law also lays the foundation for the design of environmental policies and serves as a normative umbrella under which other sectoral laws, such as on energy, must operate. It means that this law is of preferential application compared to related laws dealing with natural resources - such as energy sources - and their extraction, and also guides sectoral legislative developments at all levels of the state (national, departmental and municipal). 


\section{Mother Earth's legal framework as a legal basis for an energy transition in harmony with nature}

The Bolivian legal regime on the rights of Mother Earth, analysed in the previous section, provides an opportunity for the Andean country to move away from deeply embedded paradigms - such as the anthropocentric paradigm - towards an altogether more careful ecological approach (Villavicencio Calzadilla and Kotzé, 2018 , p. 423). On paper at least, this legal framework seeks to overcome the ecologically destructive extractivism - for instance, of fossil fuels - that threatens Mother Earth and to provide responses to the country's energy and environmental challenges. Thus, it sets the legal basis for an ambitious transformation of the country's fossil fuels-based energy system by increasing the use of renewable energy sources and fighting climate change through an ecocentric rights-based approach. $^{9}$

Recognising that energy sources constitute strategic resources and that access to them is a fundamental and essential right for the development of the country, the Bolivian Constitution declares that it is the duty of the state to promote and develop the use of new forms of alternative and environmentally friendly energy (arts. 378 (I) and 379 (I)). ${ }^{10}$ Alternative energy sources are essentially renewable energy sources except for large-scale hydroelectricity (Ministerio de Hidrocarburos y Energía, 2011, p. 3). This constitutional mandate calls for the diversification of the energy matrix towards renewable energy sources and integrates the protection of Mother Earth as a condition. Moreover, the Constitution declares that the state and the population have the duty "to conserve, protect and use natural resources in a sustainable manner, as well as to maintain the equilibrium of the environment" (art. 342), and that the exploitation of renewable energy sources must take place "in a sustainable way, [while] respecting the characteristics and natural value of each ecosystem" (art. 380 (I)).

Turning to the Law of the Rights of Mother Earth and the Framework Law, both include key provisions guiding the country's energy transition in harmony with nature. For instance, the Law of the Rights of Mother Earth requires that human activities - including e.g. the exploitation of conventional and alternative sources of energy - must achieve a dynamic balance with the cycles and processes inherent to Mother Earth (art. 2.1). In order to ensure the respect for Mother Earth's rights, the Law declares that it is the state's duty to develop policies and actions to protect Mother Earth, while natural persons and public and private legal entities shall ensure sustainable use of her components, including energy sources (arts. 8-9). In particular, the state has the duty to develop policies to ensure the long-term energy sovereignty by means of savings, the increase of efficiency and the gradual incorporation of clean and renewable alternative sources into the energy matrix (art. 8.4). Such an obligation, which conceives the energy transition as a narrow set of technical changes - energy savings, energy efficiency and transition towards alternative renewable sources - should, however, be interpreted in the light of the other state's duties laid down by the Law. 
In essence, these duties require public policies to avoid causing the overexploitation of Mother Earth's components, the extinction of living populations and the alteration of the cycles and processes that ensure life (art. 8). Instead, the state must develop balanced forms of production and consumption to satisfy the needs of Bolivians for living well, while safeguarding the regenerative capacity and integrity of the cycles, processes and vital balance of Mother Earth (art. 8.2). Moreover, the state must develop policies to protect Mother Earth from the structural causes and effects of global climate change (art. 8.3). Considering that the current energy system is the most responsible sector for climate change worldwide - and the second in Bolivia, after deforestation (ClimateWatch, no date) - this provision intrinsically applies to the country's fossil fuels-based energy system and stresses the duty of the state to transform it by establishing the necessary policies to achieve a shift to clean and renewable energy sources while protecting Mother Earth's rights.

The Framework Law, for its part, establishes that the activities of exploration, exploitation, transformation, industrialisation, transport and commercialisation of renewable and non-renewable natural resources shall be carried out respecting the rights of Mother Earth and guaranteeing the maintenance of her regenerative capacity (art. 15). Thus, by recognising that the economic relations are limited by the regenerative capacity of Mother Earth and her ecosystems, the Framework Law specifies that the state shall progressively create and strengthen more sustainable and cleaner production patterns through, inter alia, "the promotion of the use and exploitation of renewable natural resources" and "the progressive transformation of the country's energy matrix towards renewable and cleaner sources" (art. 15 (1) (2)). On energy specifically, it places on the state the obligations: to establish policies and measures for a gradual increase of renewable energies in the mix; to ensure a gradual but steadily increasing share of electricity generation from alternative energy sources; to develop alternative renewable energy generation plans, programmes and incentives for domestic production and use with priority for solar and wind energy, micro-hydropower and energy savings; and to promote technologies and practices with the highest efficiency of energy production and use "in harmony and balance with the life systems and Mother Earth" (art. 30).

In the light of the above, Bolivia's energy transition in harmony with nature must aim for a future energy system respectful of the rights of nature, therefore guaranteeing the integrity, diversity, equilibrium, resilience, restoration and flourishing of the indivisible, interrelated, interdependent and complementary community of all living systems and living organisms - human and non-human constituting Mother Earth.

The following section explains to what extent the energy regulatory and policy framework in force in Bolivia enables the country's energy transition towards an energy system that safeguards and protects Mother Earth's rights, referring in particular to grid-connected electricity generation as it is the spearhead of the Bolivian transition. 


\section{Bolivia's electricity sector: towards a diversification in harmony with nature?}

Bolivia's electricity policy, actively developed during the mandate of former President Morales, aims first to organise the diversification of an electricity matrix historically relying on hydroelectricity and natural gas. This is actually a general goal of the region's countries (Noura Guimarães, 2020, p. 10). Second, under this policy, Bolivia should also start exporting power to its neighbours.

Over the past decade and a half, electricity generation in Bolivia has been increasingly dependent on natural gas. To cope with a quadrupling demand between the early 1990s and 2018, generation followed a steep curve. As Figure 4.1 shows, from 1992 to the early 2000s, the shares of hydroelectricity and thermal generation (almost exclusively from natural gas) in the total electricity production were comparable. However, over the past 20 years, hydroelectricity generation stagnated while thermal generation (still overwhelmingly from natural gas) tripled (Autoridad de Fiscalización y Control Social de Electricidad (AE), 2019, pp. 30 and 63-65).

As a result, the total installed electricity generation capacity (the sum of all the installed electricity plants connected to the national grid - the SIN) in 2018 was heavily based on natural gas. The same year, out of 2,138.74 MW of total effective capacity connected to the grid, 1,374.8 MW were thermal, 671.9 MW hydropower, and a negligible $92 \mathrm{MW}$ alternative energy (not fossil nor large hydro)

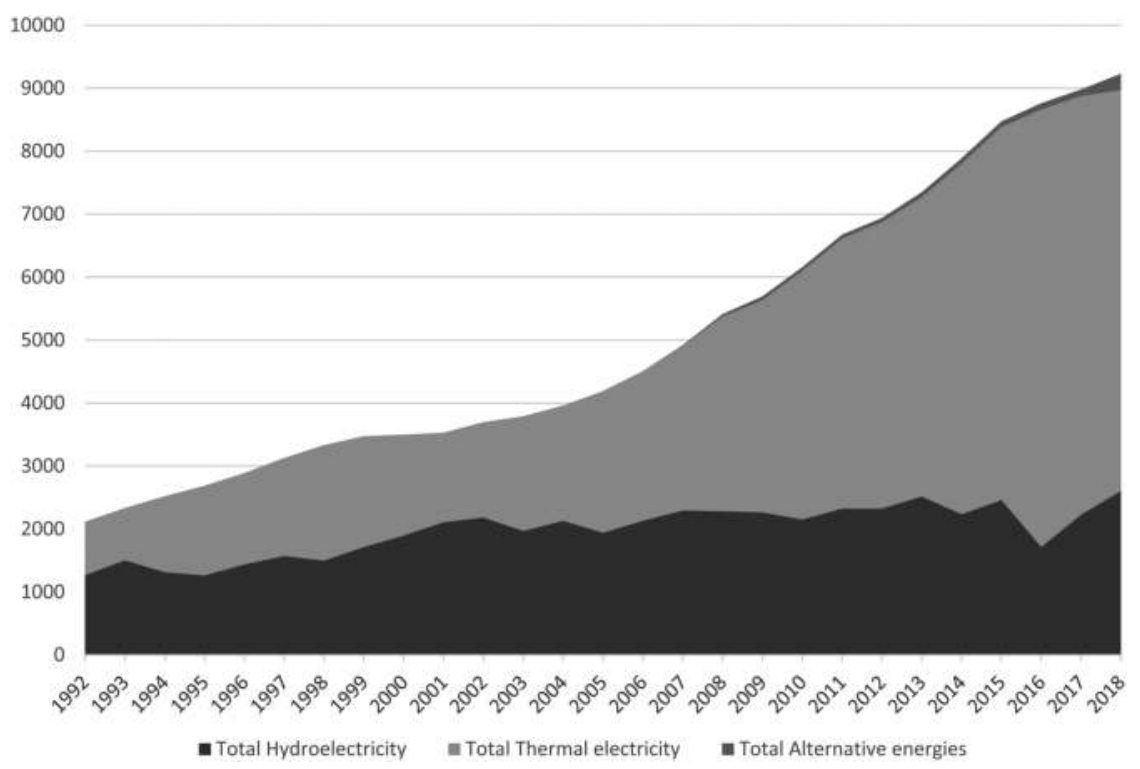

Figure 4.1 Yearly evolution of hydroelectric, thermal generation and alternative energies (GWh) (SIN) (1992-2018). Created by the authors, based on AE's data (2019, pp. 63-65). 
(AE, 2019, p. 17). This situation is the reflection of the orientations taken by the past but also current electricity legal and policy framework.

In principle, according to the country's Mother Earth legal framework, the natural gas and hydroelectricity based electricity system should have started a transformation towards a much higher use of alternative renewable energy sources. However, as of 2020, no piece of legislation on the electricity sector has been adopted since Mother Earth laws entered into force. The only electricity law that exists dates back to 1994 and it was not amended to include the more recent Mother Earth orientation. ${ }^{11}$ Yet, many decrees were adopted, but mainly to reorganise the sector itself, not to change the way electricity is produced (Jimenez Rivera, 2018, pp. 59-61). As a consequence, to analyse the developments related to the energy transition in harmony with nature, we must turn to the energy policy documents.

The electricity-related policy documents adopted over the past 15 years have consistently presented two overarching objectives: diversification of the energy sources, and exportation of electricity to neighbouring countries. Both goals are mentioned in the 2007 National Development Plan (Plan Nacional de Desarrollo), the major policy document adopted before the 2009 Constitution but already aiming at Vivir Bien in harmony with nature (Ministerio de Planificación del Desarrollo, 2007, p. 124). They also appear in pillar 6 of the 2013 General Economic and Social Development Plan (Agenda Patriótica 2025), which sets the long-term development objectives of the country for 2025 (Ministerio de Planificación del Desarrollo, 2013). However, in this central policy document already, diversification means: hydropower first, and some development of other renewable energy sources. Indeed, pillar 6 expects that Bolivia will "fully use its hydroelectric potential and successfully develop large-scale renewable energy projects (such as wind energy, biomass, geothermal or solar)". ${ }^{12}$

To find the numbered targets for the implementation of the electricity policy objectives, it is necessary to analyse the various policy documents adopted since 2014. We commence with the diversification claim. The 2015 Economic and Social Development Plan (Plan de Desarrollo Económico y Social 2016-2020 en el Marco del Desarrollo Integral para Vivir Bien - PDES) foresees an addition of 1,447 MW of hydro (small and large), 1,096 MW of thermal (natural gas burning combined cycles) and $411 \mathrm{MW}$ of alternative energy sources (wind, biomass, solar and geothermal) to be connected to the grid between 2015 and 2020. In total, the grid-connected installed capacity in 2020 should reach 4,878 $\mathrm{MW}$, to be compared with 1,924 MW in 2015 and 2,138.74 MW in 2018 (Ministerio de Planificación del Desarrollo, 2015, pp. 150 and 154).

For the other plans, aiming at 2025, the focus is placed even more on hydropower. The 2014 State Electricity Plan (Plan Eléctrico del Estado Plurinacional de Bolivia 2025) proposes to add 5,552 MW of mega hydroelectricity installations (over $990 \mathrm{MW}$ of capacity), 1,599 MW of large-scale hydroelectricity installations (over $80 \mathrm{MW}$ of capacity), and 1,108 MW of thermoelectricity installations. In contrast, alternative energy sources would add a meagre total of 183 MW - it has been raised to 411 MW by the 2015 PDES as written above. In total, 
the plan foresees a total installed capacity of 4,353 MW in 2025 (Ministerio de Hidrocarburos y Energía, 2014, pp. 85-88 and 124), which is surprisingly less than the 2020 target of the 2015 PDES but also not coherent with the simple addition of all the planned new installed capacity per energy source. Adding to these fluctuating and sometimes contradicting figures, the 2018 Sectoral Development Plan - Energy (Plan Sectorial de Desarrollo Integral Para Vivir Bien - Sector Energía 2016-2020) sets the target of 469 MW of alternative energy sources installed capacity by 2023 (Ministerio de Energías, 2018, p. 55). But it is not clear if this target only concerns the capacity connected to the national grid or also accounts for the capacity connected to isolated systems.

As shown by Figure 4.2, diversification in the policy documents actually means a transition to an electricity matrix dominated by (mega and large) hydroelectricity, with a still significant share from natural gas and a very limited one from alternative sources. This planned electricity matrix is developed to serve the second main electricity policy objective: the exportation of electricity to neighbouring countries - mainly to Brazil - a goal labelled as "Bolivia, regional energy centre". ${ }^{13}$ This is based on the rationale that Bolivia is geographically at the centre of South America, and that it has a high renewable energy potential. This objective is supposed to turn the electricity sector into "one of the most significant contributors to the development of the country" (Ministerio de Hidrocarburos y Energía, 2014, pp. 99 and 108). To reach this goal, four mega hydroelectricity complexes (sometimes with various large-scale dams) are scheduled, in order to

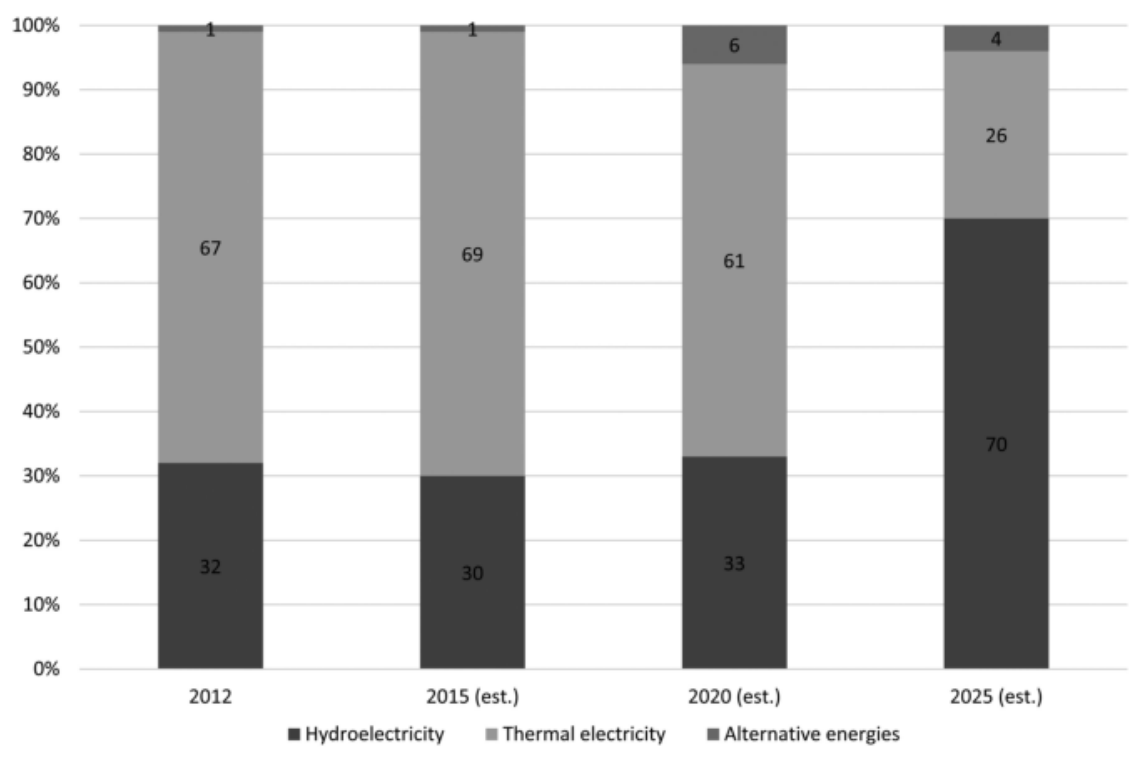

Figure 4.2 Evolution of the electricity generation's share per energy source. Created by the authors, based on the Ministerio de Hidrocarburos y Energía's data (2014, p. 127). 
produce massive electricity surpluses to export (Peredo Beltrán, 2018, p. 16). The increased generation from thermal and new renewable sources would also add to this surplus (Ministerio de Hidrocarburos y Energía, 2014, p. 112). Overall, the electricity policy would translate as follows:

[Eventually,] the development of the electric infrastructure will consist in $3000 \mathrm{MW}$ for the internal demand and $10000 \mathrm{MW}$ for the export of electricity.

(Oficina Económica y Comercial de la Embajada de España en La Paz, 2019, p. 29)

This rise in production is to be followed by an extension of the transmission grid, to be increased three-fold between 2012 and 2025 (Ministerio de Hidrocarburos y Energía, 2014, p. 123), and the construction of interconnections with four neighbouring countries: Argentina, Brazil, Peru and Paraguay (Ministerio de Energías, 2017, p. 71).

In a nutshell, the energy policy of the country does not only aim to answer a steeply increasing local energy demand but also to turn the country into South America's powerhouse. The necessary increased electricity generation is claimed to come from a diversification of the matrix, but Bolivia will in reality still rely on the same non-environmentally friendly energy sources as during the past decades: large hydropower and natural gas.

\section{Rhetoric and contradictions on Bolivia's energy transition in harmony with nature}

This section explores some of the shortcomings and contradictions of the previously analysed legal and policy frameworks on energy and Mother Earth protection and provides a crucial example illustrating such contradictions as well as Bolivia's struggle to achieve an energy transition in harmony with nature.

\section{Contradictions in the legal framework on Mother Earth}

Despite their great importance, the Bolivian Constitution and the statutory regulations on Mother Earth include contradictory provisions that confront and, in fact, undermine the country's aspiration of an energy transition in harmony with nature.

The Constitution contains several provisions regarding the use and exploitation of renewable and non-renewable natural resources in which such activities are explicitly defined as essential purposes and functions of the state (arts. 9 and 316.6). The industrialisation and sale of these resources are even defined as a "national priority of the State" (art. 355 (I)). These provisions are important for the development and promotion of research and the use of new forms of production of alternative energy compatible with the environment (art. 379 (I)). However, they also refer to non-renewable natural resources - such as fossil fuels - which are characterised as "matters of necessity and public utility" (art. 356) and are part of 
the government's post-neoliberal agenda which is dangerously close to a classic neoliberal agenda (Villegas, 2018, p. 10). ${ }^{14}$

Furthermore, while the Constitution includes a single and vague article referring to the development and promotion of research and the use of new forms of production of alternative energy (art. 379 (I)), a lengthy chapter, comprising ten articles, is devoted to hydrocarbons (Title II, Chap. III). Article 360, for instance, declares that it is the prerogative and duty of the state to "promote [the] comprehensive, sustainable and equitable development [of hydrocarbons]" and to "guarantee energy sovereignty". It is on this basis that, for example, the Bolivian government eased environmental standards to allow oil and gas exploration in protected areas traditionally inhabited by indigenous peoples, and already affected by oil and gas exploitation. ${ }^{15}$ While these governmental decisions were defended on the premise that they would contribute to the socio-economic development of the country, ${ }^{16}$ they represent lost opportunities to invest in renewable energy.

Regarding the Framework Law, as discussed earlier, it specifies that the state has the obligation to establish the energy policy and measures to progressively transform the country's energy mix. However, such transformation does not only refer to the gradual increase of renewable energies, but also to the replacement of liquid fuels by natural gas. Thus, while the law omits to provide a timeframe or set specific measurable targets related to the transformation of the energy mix, it moreover reinforces the country's preference for natural gas. Precisely, on this basis, the exploration of shale gas deposits by means of hydraulic fracturing in different regions of Bolivia is under debate. ${ }^{17}$ In addition, the Framework Law's lofty aspirations for a gradual increase in renewable energy sources are held back by other provisions legalising extractivism - mainly of minerals and hydrocarbons as a way of achieving Vivir Bien (art. 26.1), instead of pursuing alternative ways to generate income to meet the economic and social demands, such as investment in renewable energy resources. The pro-extractivist provisions included in the Framework Law not only counterbalance its ecocentric provisions, but also undermine the country's energy transition in harmony with nature.

\section{The contradictions and rhetoric of an energy diversification policy}

The current energy policy of Bolivia reflects internal contradictions and contains goals that run counter to the country's aspiration of an energy transition in harmony with nature.

As discussed earlier, energy policy documents claim that the electricity generation matrix will be diversified towards a higher share of alternative renewable energy sources. Yet, the focus is actually placed on large and mega hydroelectricity projects as well as on thermal generation from natural gas. While Bolivia is already affected by extreme events such as droughts and floods (Perez, 2017), these two water-intensive technologies are not only vulnerable to these events, but they also cause negative impacts on local population, biodiversity and ecosystems (Zarfl et al., 2019; The Union of Concerned Scientists, 2014). 
Despite its environmental impacts, the use of hydraulic fracturing for exploiting shale gas reserves within protected areas has been a feature under the former and the current transitional government (Meng, 2017; Hill, 2015; Mamani, 2020). Moreover, several of the mega hydroelectricity projects announced in Bolivia's policy documents will be located in the Bolivian Amazon region, affecting not only large biodiversity-rich protected areas, but also the indigenous and local populations who live there (Coaquira Siñani, 2010, pp. 67-68; Ribera Arismendi, 2010, chap. 2, 3 and 4), as illustrated by the case of the El Bala-Chepete project. ${ }^{18}$

Although the energy policy states that Bolivia will move from "being solely a hydrocarbon and mining country" to one where renewable and non-renewable natural resources are exploited "in harmony and equilibrium with Mother Earth" (Ministerio de Planificación del Desarrollo, 2013, pp. 13 and 15), building large and mega hydroelectricity plants and thermal power stations will necessarily take a heavy toll on the environment and on local populations, representing a step back in the protection of Mother Earth and in Bolivian society's capacity to live in harmony with nature. Moreover, exporting electricity to neighbouring countries to generate supplementary revenues will lead to an outsizing of the installed capacity, maintaining Bolivia in the extractivist economy (Villegas, 2018, p. 20) it claims to have escaped (Ministerio de Planificación del Desarrollo, 2013, pp. 15-16).

This illusory diversification of the energy matrix breaches constitutional and statutory provisions concerning the protection of Mother Earth. It violates both the constitutional principle of environmental preservation in energy sources exploitation and the requirement of sustainable exploitation of renewable natural resources respecting the characteristics and natural value of ecosystems (arts. 378 (I) and 380 (I)). When projects are located in the Amazonian region, they would furthermore potentially breach the constitutional requirement of "special protection" for this region "because of its high environmental sensitivity, existing biodiversity, [and] water resources" (art. 390 (I)). And, above all, they would threaten the very heart of the new ecocentric paradigm formulated in the Law of the Rights of Mother Earth and the Framework Law. Eventually, it is the entire energy policy of disproportionate generation increase through large hydroelectricity and natural gas, mainly for exports, which represents a serious threat to Mother Earth's rights. This energy policy, which follows an economic development model qualified as "occidental, capitalist, neoliberal and extractivist" (Villanueva I., 2013), while claiming to include Mother Earth's protection as a foundational aspect (Laure, 2016), would hardly lead to an energy system that respects the rights of Mother Earth and guarantees the integrity, diversity, equilibrium, resilience, restoration and flourishing of the community of all living systems.

\section{Damming Mother Earth: when practice falls short of rhetorical promise}

The tensions between the vision of an energy transition in harmony with nature and an extractivist and anthropocentric energy policy are particularly visible in one emblematic case: the hydroelectric Bala-Chepete dam project. The project 


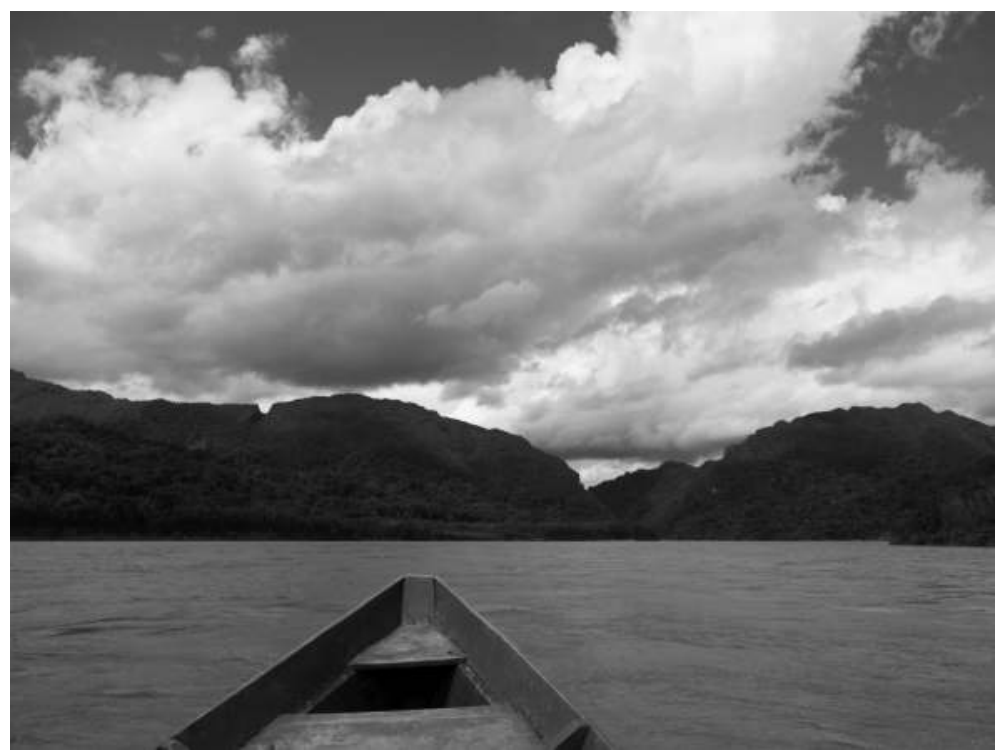

Figure 4.3 The gorge of El Bala, from the Beni River (this zone would be flooded if the El Bala dam project is successful). 2018. Picture taken by the authors.

reveals the actual continuity of the country's energy policy over the past decades (regardless of political changes). In reality, Bolivia follows a common longstanding trend among Amazonian countries, with over a hundred large dams already built on the Amazon river and its tributaries and close to 300 still to come (Castello and Macedo, 2016, pp. 990-992).

The idea of a mega dam in the gorge of El Bala, through which the Beni River runs (see Figure 4.3), dates back to the 1970s. After having been studied for two decades and rejected in the past, the project was reactivated in 2007 to run new feasibility studies and then qualified of national priority (Decreto Supremo $\mathrm{N}^{\circ}$ 29191, 2007; Ribera Arismendi, 2010, p. 107).

The 2014 State Electricity Plan provides that the El Bala project would have an installed capacity of 1,680 MW (Ministerio de Hidrocarburos y Energía, 2014, pp. 110-111). However, the project includes another dam some 55 kilometres upstream: El Chepete. Together, Bala and Chepete dams represent a potential installed capacity of over 3,000 MW (Molina Carpio et al., 2019, p. 2). According to the state power company, the estimated construction cost amounts to between US\$ 6 and 8 billion (ENDE, 2019; Solón, 2019), a sizeable portion of Bolivia's GDP estimated at US\$ 40 billion in 2018 (World Bank, 2020a). The generation costs for this dual project would end up between US\$ 55/MWh and US\$ 81/ $\mathrm{MWh}$, if the project faces no costs overruns, which is unlikely (Ansar et al., 2014; Köberle et al., 2018), and would in any case be uncompetitive for the designated exportation market: Brazil (Solón, 2019). 
According to the former government, this project was supposed to bring economic incomes from electricity exports, and be a stepping stone to turn Bolivia into the regional powerhouse. However, due to its apparent lack of competitiveness on the Brazilian market, the project has been qualified as a political rather than an economic one (Villegas, 2018, p. 18). In addition, hydroelectricity dams were generally presented by the former government as a key technology for fighting climate change (UNFCCC, 2016, pp. 5 and 9).

The potential negative impacts of the El Bala-Chepete project on the environment and local populations, especially indigenous people, are significant. It would flood an area of $771 \mathrm{Km},{ }^{2}$ affecting the Amazonian forest and natural protected areas, especially the Madidi National Park - considered the most biodiverse natural area in the world (Gorman, 2018) - and the Pilón Lajas protected area (Solón, 2017). In addition to causing huge $\mathrm{CO}_{2}$ and methane emissions (Fearnside, 2016; Ribera Arismendi, 2018, p. 4) and having a vastly negative climate footprint, this operation would have major impacts on biodiversity and ecosystems (Pacheco, 2019) and would force thousands of indigenous people out of their land (Heras, 2017; Elwell, 2018). However, it has been denounced that no public consultation of the potentially impacted people has been undertaken following the feasibility studies conducted between 2015 and 2017 (Tribunal Internacional de Derechos de la Naturaleza, 2018, p. 6; Paredes Tamayo and Fernández Reyes, 2019). Yet, early consultation on decisions which could affect the environment or on the exploitation of natural resources is a constitutional obligation affirmed in various provisions. ${ }^{19}$ This apparent disregard for constitutional rules in order to proceed with a mega dam project places the former Bolivian government in the same category as "strong or authoritarian state government[s]" (Schapper and Urban, 2019, p. 1).

Due to all these potential impacts and the absence of consultation, the project met with opposition from the local indigenous groups who resolved to block the gorge in 2016 to stop the feasibility studies (Achtenberg, 2017). In return, they were violently criticised and intimidated by Bolivia's former President and VicePresident, who vowed to ignore them and considered them foreign-funded activists (Achtenberg, 2017; Moorman, 2017, pp. 43-44). Since then, studies have resumed, but at the time of writing, their results had not been published. This unfair project development process, riddled with conflicts between local indigenous communities and the state, directly or through mandated companies, is not new in Bolivia. Misicuni's dam (Hoogendam and Boelens, 2019) and Rositas' dam (Villegas, 2018, p. 10) are other examples of conflictive energy projects in Bolivia. $^{20}$

Thus, the El Bala-Chepete project seems to violate various of the rights recognised to nature in the aforementioned legal framework and especially in the Law of the Rights of Mother Earth. For example, Mother Earth's rights to life, to maintain and regenerate her life cycles and structures, and to be restored, can be considered as threatened by such a project (Tribunal Internacional de Derechos de la Naturaleza, 2018, p. 5). In any case, this project and such kind of developments in the energy sector in Bolivia can in no way be considered to be supportive of an energy transition in harmony with nature. 


\section{Conclusion and recommendations}

Bolivia's ambition to develop an energy transition in harmony with nature aims to confront, on paper at least, the current (anthropocentric) approach to energy transitions and invites to think about alternative ways to understand the energy system. However, as revealed in this chapter, implementing an energy transition that safeguards and protects Mother Earth's rights is a daunting task, even in a country that has adopted ecocentric laws. Of course, law has its limitations and, in the case of Bolivia, the government has overused the rhetoric of living in harmony with Mother Earth, while in practice perpetuating and reinforcing dominant paradigms of extractive economic development based on socially and ecologically destructive projects.

The paper demonstrates that an energy transition in harmony with nature requires not only legal and policy frameworks recognising Mother Earth's rights, but also that these are consistent and effectively implemented. The issue of enforcement is capital, as shown in Bolivia where policy documents and energy projects contradict the essence of the law. Beyond these aspects, an energy transition in harmony with nature implies a radical and urgent transformation of energy infrastructures and policies towards a not only low-carbon but a fundamentally less ecologically damaging energy system. In parallel, such changes must help reaching Vivir Bien, which involves human and non-human communities living together without power asymmetries. This can only happen if the capitalist logic of the destruction of Mother Earth for the ever-increasing production of goods and services for humans is abandoned. Something that was claimed but, at least for the moment, not achieved in Bolivia.

For an energy transition in harmony with nature applicable in Bolivia and anywhere else, we list two overarching recommendations, which can be applied immediately or gradually over time, and always through a justice lens. Yet, we invite further interdisciplinary research to be conducted on this non-western and non-human-centred framework and to propose ideas and mechanisms for its implementation.

Firstly, respect for the rights of Mother Earth to life and to the regeneration of her life cycles and structures must be ensured. This supposes to ban policies and projects that are notoriously destructive of Mother Earth (and her human and nonhuman communities), including: fossil fuels extraction, large and mega dams, any large energy project in a protected area or in biodiversity-rich areas, even when not officially protected (such as parts of the Bolivian Amazon). For all other energy policies and projects, the possible impacts (economic, social and environmental) must be carefully studied, including the cumulative impacts, e.g. of various small dams on a river (Castello and Macedo, 2016, p. 994). The results of these studies must be fully available to the public. Nowadays, there are numerous solutions for small to medium-scale renewable energy projects, which are more prone to be respectful of Mother Earth, economically achievable in developing countries, and socially not detrimental, under some conditions such as being local-community led. 
Secondly, participatory decision-making processes respectful of all (human and non-human) living beings must be developed. To avoid reproducing the injustices of the current energy system, decision-making power on the energy transition must be shared between the various actors involved, including affected local communities and indigenous people as well as, when existing, independent representatives of Mother Earth (such as a Mother Earth Ombudsman). The local communities and indigenous people are often the ones who know best the intrinsic worth of nature and her ecosystems and the representatives of Mother Earth can be entitled to act on her behalf.

\section{Notes}

1 Funding: "The Global Climate Constitution: Governance and Law in a Complex Context" (CONCLIMA-DER2016-80011-P, MINECO/ERDF, EU), State Program for the Promotion of Scientific and Technical Research of Excellence, State Secretariat of Research, Development and Innovation (SEIDI), Ministry of Economy and Competitiveness, Spain.

2 We would like to express our gratitude to all the reviewers for their comments and suggestions.

3 In the context of anthropocentric legal systems, nature is considered as "a lifeless, inert machine that exists to satisfy the needs, desires (and greed) of human beings" (Burdon, 2013, p. 818).

4 As shown by REN 21 (2019, p. 29): “As in previous years, renewables saw far less growth in the heating, cooling and transport sectors than in the power sector".

5 In contrast to the anthropocentrism of the western philosophy that considers nature as a set of resources that can be owned and exploited to satisfy human beings' needs, Mother Earth or Pachamama is defined as "a dynamic living system comprising an indivisible community of all living systems and organisms, which are interrelated, interdependent, and complementary, and which share a common destiny". Thus, Mother Earth is a subject that "takes on the character of collective public interest" (Ley de Derechos de La Madre Tierra, 2010, arts. 3 and 5). An English version of the law can be found at: http://181.224.152.72/ embajad5/wp-content/uploads/2017/12/r ights-of-mother-earth.pdf

6 An English version of the Constitution can be found at: www.constituteproject.org/ constitution/Bolivia_2009?lang=en

7 See, for instance, Lāander (2017, p. 465).

8 Emphasis added.

9 Applying the ecocentric approach to energy systems, Sovacool et al. (2017) consider that "[a]n energy system is right when it tends to preserve the integrity, diversity, resilience, and flourishing of the whole community, involving direct caring relationships and formal rights of nature" (p. 682).

10 The environmental legislation, adopted prior to the Bolivian Constitution but still in force, also refers to this duty (Ley de Medio Ambiente, 1992, art. 74).

11 Ley de Electricidad, 1994.

12 Translation by the authors.

13 See a critic in Villegas (2018).

14 As a general trend already described for Ecuador and Bolivia (Andrade, 2016, p. 118; Renfrew, 2011, p. 584).

15 See, for instance, Supreme Decree 2366, 20 May 2015, legalising exploratory drilling in Bolivia's protected areas and national parks; and Supreme Decree 2549, 14 October 
2015, extending the so-called "oil border" into the Amazonian and Gran Chaco regions of the country.

16 Supreme Decree 2366, ibid., art. 1.

17 See section: 'The contradictions and rhetoric of an energy diversification policy'.

18 See section: 'Damming Mother Earth: when practice falls short of rhetorical promise'.

19 See art. 30 (II) (15) concerning indigenous people; 343; 352; 378 (II); and 391 (I) for being in the Amazonia.

20 This is also the case of Ecuador, the only South American country having enshrined the rights of nature in its Constitution (Kotzé and Villavicencio Calzadilla, 2017; Purcell and Martinez, 2018; Teräväinen, 2019).

\section{References}

Achtenberg, E. (2017) The Growing Resistance to Megadams in Bolivia, Nacla, 14 Feb. Available at: https://nacla.org/blog/2017/02/20/growing-resistance-megadams-bolivia (Accessed 14 April 2020).

Andrade, P. (2016) 'The government of nature: post-neoliberal environmental governance in Bolivia and Ecuador', in de Castro F., Hogenboom B. and Baud M. (eds) Environmental Governance in Latin America. London: Palgrave Macmillan, pp. 113-136.

Ansar, A., Flyvbjerg, B., Budzier, A. and Lunn D. (2014) 'Should we build more large dams? The actual costs of hydropower megaproject development', Energy Policy 69, pp. 43-56. doi: 10.1016/j.enpol.2013.10.069.

Autoridad de Fiscalización y Control Social de Electricidad (2019) Anuario Estadístico Histórico 2018. Available at: https://sawi.aetn.gob.bo/docfly/app/webroot/uploads/ IMG-ANUARIO-cpelaez-2019-09-16-Libro Anuario AE 2018 FINAL_web.pdf

Avila, S. (2018) 'Environmental justice and the expanding geography of wind power conflicts', Sustainability Science 13(3), pp. 599-616. doi: 10.1007/s11625-018-0547-4.

Batel, S. and Devine-Wright, P. (2017) 'Energy colonialism and the role of the global in local responses to new energy infrastructures in the UK: a critical and exploratory empirical analysis', Antipode 49(1), pp. 3-22. doi: 10.1111/anti.12261.

Bosselmann, K. (2017) The Principle of Sustainability, Transforming Law and Governance. 2nd edition. London: Routledge.

Burdon, P. (2013) 'The earth community and ecological jurisprudence', Oñati Socio-Legal Series 3(5), pp. 815-837.

CAF (2016) Estado de la eficiencia energética en Bolivia: identificación de oportunidades. Available at: https://scioteca.caf.com/bitstream/handle/123456789/954/Reporte\%20 EE\%20en\%20Bolivia.pdf? sequence=1.

Castán Broto, V., Baptista, I., Kirshner, J., Smith, S. and Neves Alves, S. (2018) 'Energy justice and sustainability transitions in Mozambique', Applied Energy 228, pp. 645655. doi: 10.1016/j.apenergy.2018.06.057.

Castello, L. and Macedo, M.N. (2016) 'Large-scale degradation of Amazonian freshwater ecosystems', Global Change Biology 22(3), pp. 990-1007. doi: 10.1111/gcb.13173.

ClimateWatch (no date) Greenhouse Gas Emissions and Emissions Targets. Available at: https://www.climatewatchdata.org/countries/BOL (Accessed 3 May 2020).

Coaquira Siñani, T. (2010) Análisis ambiental de la política energética boliviana. La Paz, Bolivia. Available at: http://biblioteca.clacso.edu.ar/Bolivia/cedla/20101109105059/ AMBIENTAL.pdf.pdf.

Dunlap, A. (2018) "The "solution" is now the "problem": wind energy, colonisation and the "genocide-ecocide nexus" in the Isthmus of Tehuantepec, Oaxaca', International Journal of Human Rights 22(4), pp. 550-573. doi: 10.1080/13642987.2017.1397633. 
Elwell, J. (2018) 'Development and duplicity in the case of the Chepete and El Bala dams', The ecologist, 17 Aug. Available at: https://theecologist.org/2018/aug/17/developmentand-duplicity-case-chepete-and-el-bala-dams-jonathan-elwell-investigates (Accessed 14 December 2019).

ENDE (2019) Proyecto hidroeléctrico Chepete-Bala. Available at: https://www.ende.bo/ index.php (Accessed 14 December 2019).

Escurra, J.J., Vazquez, V., Cestti, R., De Nys, E. and Srinivasan, R. (2014) 'Climate change impact on countrywide water balance in Bolivia', Regional Environmental Change 14(2), pp. 727-742. doi: 10.1007/s10113-013-0534-3.

Evans-Pritchard, A. (2020) 'Davos's green colonialism decried by poorer countriesbut the West will crush them anyway', The Telegraph, 24 Jan. Available at: https:// www.telegraph.co.uk/business/2020/01/24/davos-elites-climate-piety-slammedluxury-poor-countries-can/.

Fattouh, B., Poudineh, R. and West, R. (2019) 'The rise of renewables and energy transition: what adaptation strategy exists for oil companies and oil-exporting countries?', Energy Transitions 3(1-2), pp. 45-58. doi: 10.1007/s41825-019-00013-x.

Fearnside, P.M. (2016) 'Greenhouse gas emissions from hydroelectric dams in tropical forests', in Lehr, J.H. and Keeley, J. (eds) Alternative Energy and Shale Gas Encyclopedia. 1st edition. Hoboken, NJ: John Wiley \& Sons, Inc., pp. 426-436.

Gorman, J. (2018) 'Is this the world's most diverse national park?', The New York Times, 22 May. Available at: https://www.nytimes.com/2018/05/22/science/bolivia-madidinational-park.html

Gudynas, E. (2011) 'Buen Vivir: Today's tomorrow', Development. doi: 10.1057/ dev.2011.86.

Gudynas, E. and Acosta, A. (2011) 'El buen vivir mas allá del desarrollo', Quehacer 181,pp. 70-81. Available at: http://www.gudynas.com/publicaciones/reportes/GudynasAcosta BuenVivirDesarrolloQHacer11.pdf.

Guruswamy, L. (2015) 'Global energy justice', International Energy and Poverty: The Emerging Contours. doi: 10.4324/9781315762203.

Heras, C. (2017) 'La hidroeléctrica que amenaza a 5.000 indígenas bolivianos', El Pais, 14 Sept. Available at: https:/elpais.com/elpais/2017/09/05/planeta_futuro/ 1504563761_414612.html.

Hill, D. (2015) 'Is Bolivia going to frack "Mother Earth"?', The Guardian, 24 Feb. Available at: https://www.theguardian.com/environment/andes-to-the-amazon/2015/ feb/23/bolivia-frack-mother-earth.

Hoogendam, P. and Boelens, R. (2019) 'Dams and damages. Conflicting epistemological frameworks and interests concerning "compensation" for the Misicuni project's socioenvironmental impacts in Cochabamba, Bolivia', Water 11(3). doi: 10.3390/w11030408.

Howe, C. and Boyer, D. (2016) 'Aeolian extractivism and community wind in southern Mexico’, Public Culture 28(2 (79)), pp. 215-235. doi: 10.1215/08992363-3427427.

Imran, S., Alam, K. and Beaumont, N. (2014) 'Reinterpreting the definition of sustainable development for a more ecocentric reorientation', Sustainable Development 22(2), pp. 134-144. doi: 10.1002/sd.537.

INE (2014) Bolivia: Población estimada y proyectada y tasa de crecimiento según años calendario, 2000-2050. Available at: https://www.ine.gob.bo/index.php/censos-yproyecciones-de-poblacion-sociales/.

INE (2020a) Exportaciones. Available at: https://www.ine.gob.bo/index.php/estadisticaseconomicas/comercio-internacional/exportaciones/\#1559000614062-undefined (Accessed 3 May 2020). 
INE (2020b) Producto interno bruto por actividad económica. Available at: https://www. ine.gob.bo/index.php/estadisticas-economicas/pib-y-cuentas-nacionales/productointerno-bruto-anual/producto-interno-bruto-por-actividad-economica/ (Accessed 3 May 2020).

Jenkins, K., McCauley, D., Heffron, R., Stephan, H. and Rehnera, R. (2016) 'Energy justice: a conceptual review', Energy Research and Social Science 11, pp. 174-182. doi: 10.1016/j.erss.2015.10.004.

Jimenez Rivera, H. (2018) La nacionalización del sector eléctrico en Bolivia. 1st edition. Vicepresidencia del Estado Plurinacional. Available at: https://www.cis.gob.bo/ publicacion/la-nacionalizacion-del-sector-electrico-bolivia/.

Köberle, A C., Garaffa, R., Cunha, B. S.L., Rochedo, P., Lucena, A. F.P., Szklo, A. and Schaeffer, R. (2018) 'Are conventional energy megaprojects competitive? Suboptimal decisions related to cost overruns in Brazil', Energy Policy 122, pp. 689-700. doi: 10.1016/j.enpol.2018.08.021.

Kopnina, H., Washington, H., Taylor, B. and Piccolo, J. J. (2018) 'Anthropocentrism: more than just a misunderstood problem', Journal of Agricultural and Environmental Ethics 31, pp. 109-127. doi: 10.1007/s10806-018-9711-1.

Kotzé, L.J. and Villavicencio Calzadilla, P. (2017) 'Somewhere between rhetoric and reality: environmental constitutionalism and the rights of nature in Ecuador', Transnational Environmental Law 6(3), pp. 401-433.

Lalander, R. (2014) 'Rights of nature and the indigenous peoples in Bolivia and Ecuador: a straitjacket for progressive development politics?', Iberoamerican Journal of Development Studies 3(2), pp. 148-172. doi: 10.26754/ojs_ried/ijds.137.

Lalander, R. (2017) 'Ethnic rights and the dilemma of extractive development in plurinational Bolivia', International Journal of Human Rights 21(4), pp. 465-481. doi: 10.1080/13642987.2016.1179869.

Laure, T. (2016) 'Una crítica al Plan de Desarrollo del MAS', La Izquierda Diario, 26 May. Available at: http://www.laizquierdadiario.com/Una-critica-a-la-agenda-patriotica-delbicentenario-2025 (Accessed 25 April 2020).

De Lucia, V. (2015) 'Competing narratives and complex genealogies: the ecosystem approach in international environmental law', Journal of Environmental Law 27(1), pp. 91-117. doi: 10.1093/jel/equ031.

Mamani, L. (2020) 'Fracking en Bolivia: comunidades indígenas y reserva natural en peligro', Mongabay, 3 March. Available at: https://es.mongabay.com/2020/03/fracking -bolivia-pueblos-indigenas-reserva-natural/.

McCauley, D. and Heffron, R. (2018) 'Just transition: integrating climate, energy and environmental justice', Energy Policy 119, pp. 1-7. doi: 10.1016/j.enpol.2018.04.014.

Meng, Q. (2017) 'The impacts of fracking on the environment: a total environmental study paradigm', Science of the Total Environment 580, pp. 953-957. doi: 10.1016/j. scitotenv.2016.12.045.

Mining Watch (2019) Declaration of the Regional Gathering: Climate Crisis, Energy Transition and Mining Extractivism in Latin America. September 26-28, Santiago, Chile. Available at: https://miningwatch.ca/blog/2019/11/13/declaration-regionalgathering-climate-crisis-energy-transition-and-mining?_cf_chl_jschl_tk_ $=\mathrm{d} 90318 \mathrm{a}$ 89d87e2deb4afba24530cb10c3aabaa1e-1587841489-0-AdyU7aMpUC̄CaAlfqGm3su p1YxO91YzA7RiYKbQUr5yIOwew7wGw4P0JgtMFXOqEc28b (Accessed 25 April 2020).

Ministerio de Energías (2017) Plan Estratégico Institucional 2017-2020 (PEI). Bolivia. Available at: http://sigvmeea.minenergias.gob.bo/documents/87/download. 
Ministerio de Energías (2018) Plan Sectorial de Desarrollo Integral Para Vivir BienSector Energía 2016-2020 (PSDI). Bolivia. Available at: https://www.minenergias.g ob.bo/wp-content/uploads/2020/03/PLAN-SECTORIAL-SECTOR-ENERGÍA-2019 -AJUSTADO.pdf.

Ministerio de Hidrocarburos y Energía (2011) Política de Energías Alternativas para el Sector Eléctrico en el Estado Plurinacional de Bolivia. Bolivia. Available at: http://sig vmeea.minenergias.gob.bo/documents/17/download.

Ministerio de Hidrocarburos y Energía (2014) Plan Eléctrico del Estado Plurinacional de Bolivia 2025 (PEEP). Bolivia. Available at: https://observatorioccdbolivia.files. wordpress.com/2015/08/peebol2025.pdf.

Ministerio de Planificación del Desarrollo (2007) Plan Nacional de Desarrollo: Bolivia Digna, Soberana, Productiva y Democrática para Vivir Bien-Lineamientos Estratégicos, 2006-2011 (PND) (2007). Bolivia. Available at: http://www.ademaf.gob .bo/normas/ds29272.pdf.

Ministerio de Planificación del Desarrollo (2013) Agenda Patriótica 2025. Available at: http://www.planificacion.gob.bo/uploads/AGENDA_PATRIOTICA2025_MPD.pdf.

Ministerio de Planificación del Desarrollo (2015) Plan de Desarrollo Económico y Social 2016-2020 en el Marco del Desarrollo Integral para Vivir Bien. Available at: http:// www.planificacion.gob.bo/pdes/pdes2016-2020.pdf.

Molina Carpio, J., Monroy, J.L. and Espinoza Romero, D. (2019) Análisis del Estudio de Identificación (EI) del proyecto Chepete El Bala. Available at: http://200.7.160.214:8080/ documents/10184/0/03chepete10_2019/5f6997f9-f3e1-422b-99b2-575c52d820a3 (Accessed 25 April 2020).

Moorman, T. (2017) Dam Politics: Bolivian Indigeneity, Rhetoric, and Envirosocial Movements in a Developing State. University of Mississippi. Available at: https:// egrove.olemiss.edu/cgi/viewcontent.cgi?article=1913\&context=hon_thesis.

Morgan, T. (2015) LPG and the Global Energy Transition. Available at: https://www. wlpga.org/wp-content/uploads/2015/05/LPG-and-the-Global-Energy-Transition.pdf.

Noura Guimarães, L. (2020) 'Is there a Latin American electricity transition? A snapshot of intraregional differences', in Noura Guimarães, L. (ed.) The Regulation and Policy of Latin American Energy Transitions. Elsevier, Inc., pp. 3-20. doi: 10.1016/ b978-0-12-819521-5.00001-2.

Oficina Económica y Comercial de la Embajada de España en La Paz (2019) El mercado de las energías renovables en Bolivia. La Paz. Available at: https://www.icex.es/icex/ es/navegacion-principal/todos-nuestros-servicios/informacion-de-mercados/paises/ navegacion-principal/el-mercado/estudios-informes/DOC2019834483.html?idPais=BO

Pacheco, L.F. (2019) El potencial impacto de las represas Bala y Chepete sobre la biodiversidad. Available at: http://200.7.160.214:8080/documents/10184/0/04chep ete10_2019/d2cce2d7-3761-4f61-8e5c-d0cf4153dbf0 (Accessed 25 April 2020).

Paredes Tamayo, I. and Fernández Reyes, N. (2019) 'El Tipnis y el Madidi, las heridas que sangran en el rostro indígena de Bolivia', El Deber, 14 April. Available at: https://tipnisbolivia.org/2019/04/25/el-tipnis-y-el-madidi-las-heridas-que-sangran-enel-rostro-indigena-de-bolivia/

Peredo Beltrán, E. (2018) Transición Democrática Energética-CASO: Bolivia. Available at: https://issuu.com/ekologistakmartxanboletina/docs/tradener_bolivia_ep_2_

Perez, M. (2017) 'Brown and barren land: Bolivia's historic drought-in pictures', The Guardian, 5 May. Available at: https:/www.theguardian.com/global-developmentprofessionals-network/gallery/2017/may/05/bolivia-historic-drought-water-inpictures 
Purcell, T.F. and Martinez, E. (2018) 'Post-neoliberal energy modernity and the political economy of the landlord state in Ecuador', Energy Research and Social Science 41, pp. 12-21. doi: 10.1016/j.erss.2018.04.003.

Radcliffe, S.A. (2012) 'Development for a postneoliberal era? Sumak kawsay, living well and the limits to decolonisation in Ecuador', Geoforum 43(2), pp. 240-249. doi: 10.1016/j.geoforum.2011.09.003.

REN21 (2019) Renewables 2019 Global Status Report. Paris. Available at: https://www. ren21.net/wp-content/uploads/2019/05/gsr_2019_full_report_en.pdf

Renfrew, D.(2011) 'The curse of wealth: Political ecologies of latin American neoliberalism', Geography Compass, 5(8), pp. 581-594. doi: 10.1111/j.1749-8198.2011.00436.x.

Ribera Arismendi, M.O. (2010) Megarepresas y energía-Represas del Madeira, Cachuela Esperanza, El Bala y Geotermia Laguna Colorada-Actualización 20092010. Programa de investigación y monitoreo ambiental-LIDEMA.

Ribera Arismendi, M.O. (2018) 'Las mega represas no son energía limpia', Ecología en Bolivia, 53(1), pp. 1-6. Available at: http://www.scielo.org.bo/scielo.php? pid=S2074-47062013000100004\&script=sci_arttext\&tlng=en

Roddis, P., Carver, S., Dallimer, M., Norman, P. and Ziva, G. (2018) 'The role of community acceptance in planning outcomes for onshore wind and solar farms: An energy justice analysis', Applied Energy 226, pp. 353-364. doi: 10.1016/j.apenergy.2018.05.087.

Romero-Muñoz, A., Fernández-Llamazares, Á., Moraes R., M., Larrea-Alcázar, D. M. and Wordley, C. F. R. (2019) 'A pivotal year for Bolivian conservation policy', Nature Ecology \& Evolution 3, pp. 866-869. doi: https://doi.org/10.1038/s41559-019-0893-3.

Schapper, A. and Urban, F. (2019) 'Large dams, norms and Indigenous peoples', Development Policy Review, pp. 1-20. doi: 10.1111/dpr.12467.

Schoolmeester, T. and Verbist, K. (2018) The Andean Glacier and Water Atlas-The Impact of Glacier Retreat on Water Resources. Available at: https://unesdoc.unesco.or g/ark:/48223/pf0000265810

Seiler, C., Hutjes, R. W. A., Kruijt, B. and Hickler, T. (2015) 'The sensitivity of wet and dry tropical forests to climate change in Bolivia', Journal of Geophysical Research: Biogeosciences 120(3), pp. 399-413. doi: 10.1002/2014JG002749.

Solomon, B.D. and Krishna, K. (2011) 'The coming sustainable energy transition: History, strategies, and outlook', Energy Policy 39(11), pp. 7422-7431. doi: 10.1016/j. enpol.2011.09.009.

Solón, P. (2017) El caso del Chepete y El Bala. Available at: https://fundacionsolon. org/2017/05/10/el-caso-del-chepete-y-el-bala (Accessed 14 December 2019).

Solón, P. (2019) Impactos económicos de El Bala, Chepete, Rositas y Cachuela Esperanza. Available at: https://fundacionsolon.org/2019/03/11/impactos-economicos-de-el-bala -chepete-rositas-y-cachuela-esperanza/ (Accessed 14 December 2019).

Sovacool, B. and Dworkin, M. (2014) Global Energy Justice: Problems, Principles, and Practices. Cambridge, UK: Cambridge University Press.

Sovacool, B. K., Burke, M., Baker, L., Kotikalapudi, C. K. and Wlokas, H. (2017) 'New frontiers and conceptual frameworks for energy justice', Energy Policy 105, pp. 677691. doi: 10.1016/j.enpol.2017.03.005.

Teräväinen, T. (2019) 'Negotiating water and technology-competing expectations and confronting knowledges in the case of the Coca Codo Sinclair in Ecuador', Water 11(3). doi: 10.3390/w11030411.

Tribunal Internacional de Derechos de la Naturaleza (2018) Audiencia Bolivia caso: Megahidroeléctricas El Bala y Chepete en el Río Beni. Available at: https:// tipnisboliviaorg.files.wordpress.com/2018/08/chepete-el-bala-tidn.pdf 
UNFCCC (2016) Intended Nationally Determined Contribution from the Plurinational State of Bolivia. Available at: https://www4.unfccc.int/sites/ndcstaging/Published Documents/Bolivia (Plurinational State of) First/INDC-Bolivia-english.pdf (Accessed 3 May 2020).

Union of Concerned Scientists (2014) Environmental Impacts of Natural Gas. Available at: https://www.ucsusa.org/resources/environmental-impacts-natural-gas (Accessed 3 May 2020).

United Nations (1972) Declaration of the United Nations Conference on the Human Environment. Available at: https://undocs.org/en/A/CONF.48/14/Rev.1.

Vavilov, S. (2016) Energy Transitions to Modern Renewables: Context, Barriers, and Promises, Governance and Sustainability Issue. University of Massachusetts Boston. Availableat:https://scholarworks.umb.edu/cgi/viewcontent.cgi?article=1013\&context= cgs_issue_brief_series

Villanueva, I.A.D. (2013) La Agenda Patriótica al 2025. Available at: https://www.alainet. org/es/active/65716 (Accessed 25 April 2020).

Villavicencio Calzadilla, P. and Kotzé, L.J. (2018) 'Living in Harmony with Nature? A Critical Appraisal of the Rights of Mother Earth in Bolivia', Transnational Environmental Law 7(3), pp. 397-424.

Villavicencio Calzadilla, P. and Mauger, R. (2018) 'The UN's new sustainable development agenda and renewable energy: the challenge to reach SDG7 while achieving energy justice', Journal of Energy \& Natural Resources Law 36(2), pp. 233-254. doi: 10.1080/02646811.2017.1377951.

Villegas, P. (2018) De Alfredo Stroessner a Evo Morales-El corazón energético de Sudamérica. Available at: https://alibrelibreriasocial.com/el-corazon-energetico-de-s udamerica-de-alfredo-stroessner-a-evo-morales-deliberar-10-18/

Washington, W., Taylor, B., Kopnina, H.N., Cryer, P. and Piccolo, J. J. (2017) 'Why ecocentrism is the key pathway to sustainability', The Ecological Citizen 1, pp. 35-41.

Willis, D. (2019) 'Resisting Green Colonialism: Lithium, Bolivia, and the Green New Deal', New Socialist, 18 Nov. Available at: https://newsocialist.org.uk/bolivia-gnd/ (Accessed 3 May 2020).

World Bank (2020a) GDP Growth (Annual\%)_Bolivia. Available at: https://data.worldbank. org/indicator/NY.GDP.MKTP.KD.ZG?locations=BO (Accessed 25 April 2020).

World Bank (2020b) Poverty Headcount Ratio at National Poverty Lines (\% Of Population)_Bolivia. Available at: https://data.worldbank.org/indicator/SI.POV.N AHC?locations=BO (Accessed 25 April 2020).

Zarfl, C., Berlekamp, J., He, F., Jähnig, S. C., Darwall, W. and Tockner, K. (2019) 'Future large hydropower dams impact global freshwater megafauna', Scientific Reports 9(1), pp. 1-10. doi: 10.1038/s41598-019-54980-8.

Zegada, M.E. (2016) 'The Integration of Renewables into the Bolivian Energy MixLegal Framework and Policies', Renewable Energy Law and Policy 7(1), pp. 71-80. 


\title{
5 Scalar biases in solar photovoltaic uptake
}

\section{Socio-materiality, regulatory inertia and politics}

\author{
Siddharth Sareen
}

\section{The governance of solar energy rollout: from global South to global North}

The need for an integrated focus on the governance of solar energy rollout

During the 2010s, solar photovoltaics (PV) became the fastest-growing energy technology worldwide. Ninety-seven giga watts (GW) of solar capacity was installed in 2019 alone, which equalled 55\% of all renewable energy capacity added that year. At the start of the 2020s, globally installed solar capacity stood at $580 \mathrm{GW}$, or $23 \%$ of $2,537 \mathrm{GW}$ total installed renewable energy capacity (IRENA 2020). Solar energy started the 2020 s poised to be a leading contributor to global low-carbon energy transitions, from leading countries such as China and India to entire global regions like the European Union, most of whose member states envisage significant roles for it in their National Energy and Climate Plans 2030.

Scholarship on solar energy has correspondingly burgeoned, in keeping with quite remarkable growth in the wider literature on energy and sustainability transitions. A strong growth area is notably energy social science research (Sovacool 2014; van Veelen et al. 2019), with a focus on governance, political economy, socio-technical and justice aspects. The expanding field of energy geographies (cf. Bridge et al. 2013; Hansen and Coenen 2015; Calvert 2016) further emphasises socio-spatiality, situatedness (Rutherford and Coutard 2014), multiscalarity (Sareen and Haarstad 2018) and infrastructure (Bolton and Foxon 2015). Research networks on sustainability transitions, energy social science and energy geographies have flourished, with several related journals having become wellestablished in parallel.

Yet lacunae persist despite, and perhaps due to, these rapid scholarly advances. The book this chapter is part of seeks to address two specific tendencies: a limited focus on the global South compared to the vast number of global North-based studies that dominate energy social science research, and a disjuncture between scholarship that focuses on rapid transitions and work that foregrounds justice concerns. This is not to say that no such attempts have been made: several energy scholars straddle contrasting regional contexts in their bodies of work and there is 
discernible interest in topics like deep, rapid and just transitions and deep, equitable decarbonisation (Newell and Mulvaney 2013; Healy and Barry 2017; Geels et al. 2017; Sareen 2020). At multiple scales, energy scholars note patterns of disparity left unaddressed or even exacerbated by ongoing energy transitions (Bouzarovski 2014; Sovacool et al. 2020). It is nonetheless fair to say that energy social science research could do with more integration of work that cuts across contrasting empirical contexts, cross-fertilises bi-directional insights between the global South and global North (Cherunya et al. 2020) and probes the effects of the major sociomaterial shifts currently taking place in energy sectors across the globe.

\section{Channelling research insights from Indian to Portuguese transitions}

This chapter contributes an attempt in the direction of integrating work across contrasting contexts, notably from the global South, which has led these developments, to the global North. As a starting point, it builds on research in western Indian states during 2016 (Sareen 2018; Sareen and Kale 2018) as part of a large comparative research project on the political economy of electricity distribution sectors in 15 Indian states (Dubash et al. 2018). In Sareen and Kale (2018), the authors draw from work on rapid solar energy rollout in two Indian states, Gujarat and Rajasthan, to discuss three dimensions of energy justice: affordability, equity, and inclusion and participation. This is consistent with generic conceptualisation of justice as recognition-based, distributive and procedural, respectively (Fraser 2009; also see Wood and Roelich 2020). Among the concerns Sareen and Kale (2018) raise in relation to just solar rollouts, energy federalism is notable: transitions are governed at multiple scales with overlapping domains, exhibiting a polycentricity that is applicable to much climate governance (Jordan et al. 2018). In these Indian cases, both the federal and state governments exercise authority over solar energy rollout, but other actors are co-constitutive of its governance: solar developers who procure and implement solar projects, agencies with a brief to accelerate transitions to low-carbon energy and alleviate energy poverty (e.g. by disbursing small-scale solar equipment to poor households with low energy access levels), private companies rolling out bottom-of-the-pyramid solar energy appliances and greenfield developers acquiring land for solar plants. This captures a very specific moment in solar energy rollout in India: Gujarat led this development as early as 2008, even prior to the national solar policy of 2011, and rapidly installed $1 \mathrm{GW}$ of solar capacity; the solar segment of Rajasthan's financially constrained energy sector had begun to take off by 2016, sowing the seeds for its position in 2020, when it is poised to take over the mantle of the clear leader in solar energy among all Indian states. For this chapter, this distinction between the first-mover and financially constrained follower is important.

Having identified some key patterns from the two Indian states based on Sareen and Kale (2018), the chapter next turns to a relatively financially constrained context in the global North, namely Portugal in Europe. Portugal has been one of the European leaders on renewable energy rollout, first with 
hydropower and then with a major wind power component during the 2000s. Like Gujarat, Portugal witnessed a big push for solar energy in 2008, when it briefly held the world record for the biggest solar plant which was then being developed with a $46 \mathrm{MW}$ capacity. This pales in comparison to the sort of solar plants that have come up since, which run into several hundred MW, and are often clustered as even larger solar parks that can exceed $1 \mathrm{GW}$. Yet it did not serve as the precursor to comparably rapid growth in Portugal, which was badly impacted by the economic recession during 2008-2015. Solar energy witnessed limited growth during this period. Installed capacity grew steadily and modestly: $175 \mathrm{MW}$ in 2011, $418 \mathrm{MW}$ in 2014, $673 \mathrm{MW}$ in 2018 (DGEG 2020). The first big jump only came in 2019, when cumulative installed capacity reached $914 \mathrm{MW}$. Of this, 527 MW was large-scale; by comparison, small-scale solar comprised 163 of 418 MW in 2014 and 387 of 914 MW by 2019 (DGEG 2020). There are several parallels between Portugal's experience with solar energy rollout and that of Rajasthan: financially constrained energy sectors (Sareen 2018; Sareen and Haarstad 2018), relatively high levels of energy poverty (in relation to their respective global regions, namely Europe and India; cf. Bhide and Monroy 2011; Sadath and Acharya 2017; Horta et al. 2019; Gouveia et al. 2018) and a delayed escalation of solar energy rollout entering 2020, with ambitious future targets. Whereas Rajasthan, with a population of over 75 million, envisages $50 \mathrm{GW}$ of installed solar energy capacity by 2025 , Portugal, with a population of 10 million, targets up to $10 \mathrm{GW}$ by 2027.

\section{Methodological cross-fertilisation through three drivers of scalar biases}

The chapter explores how insights on the governance of solar rollout from the Indian states relate to the Portuguese case. The mode of transferring insights was primarily methodological: solar rollout in Portugal was studied using an approach similar to Sareen and Kale (2018), but with a considerably expanded empirical basis. While the focus on solar rollout in the Indian states was tangential to a larger project on the governance of electricity distribution, the study in Portugal was part of an ongoing project commenced in April 2017 directly focused on solar rollout governance. Fieldwork in India featured 56 expert interviews in the electricity sector split evenly between the states over a span of two months; fieldwork in Portugal featured 80 expert interviews conducted during five months of data collection during 2017-2019, complemented by field visits to several solar plants and participant observation in relevant workshops, seminars and conferences. This empirical work is both multi-sited and multi-scalar and has served as the basis for various published (Sareen et al. 2018; Sareen and Haarstad 2018; Sareen and Grandin 2020; Sareen 2020) and upcoming articles. Thus while the book chapter reports limited new data, the focus is on explicating the insights generated through this cross-fertilisation of an approach, first applied in the global South, to study solar rollout governance in a global North context. Despite this generic distinction, which runs through the book, my argument does not use the cases as ones that are inherently different; as pointed out above, the solar rollout experience 
in Portugal has distinct parallels with the Indian states, especially Rajasthan, in terms of the financial constraints in both energy sectors.

The insights identified pertain to three drivers of scalar biases in the governance of solar rollout: (i) the socio-materiality of energy infrastructure, (ii) regulatory inertia and path dependence in the sector and (iii) political influence in sectoral development. The chapter explains the empirical grounding of these drivers and discusses them in relation to recent energy social science research. As a contribution to the overarching focus of the book, the chapter addresses how these drivers are relevant for balancing urgency and justice in the governance of multi-scalar solar projects. It is argued that the drivers are broadly applicable, particularly where energy sectors face tight financial constraints, a quite common state of affairs especially in global South contexts, but often also in the global North. The implication for energy policy is to explicitly enable solar rollout at lower scales like households and communities in order to advance salutary justice effects of energy transitions. Simultaneously, there is a need to streamline the bureaucratic and technocratic requirements for large-scale solar projects in order to enable rapid low-carbon energy transitions. These policies can be implemented in parallel by a range of diverse actors who together constitute the assemblage of solar rollout governance. The rapid developments in solar rollout in global South contexts like India mark a clear instance where energy social science research can widen its range, by taking on board the approaches and insights that emerge from such studies and mobilising them in place-specific ways in studies of solar rollout in varied global North settings.

The chapter is structured as follows. The next section presents the three drivers of scalar biases and locates them within recent research in the field of energy geographies. A subsequent background section discusses the governance of solar energy rollout in relation to these drivers, first briefly for the Indian states and then for Portugal. Next, an empirical and analytical section provides further insights into how these drivers manifest in Portugal based on a methodological approach adopted from the Indian study. A concluding discussion argues that such crossfertilisation of approaches from global South-focused studies to global North regions can enlarge the analytical range of energy geographies scholarship across contexts where energy transitions pose challenges of governance.

\section{Three drivers of scalar biases: socio-materiality, regulatory inertia and politics}

Renewable energy sources, most notably solar PV, have achieved and gone beyond electric grid parity in terms of cost competitiveness during the 2010s. Responsive to the increasing diffusion of low-carbon energy technologies, the field of energy geographies has grown rapidly (Bridge 2018). Whereas energy transitions are often discussed in terms of transitions from fossil fuels to low-carbon renewable energy sources, the dynamics within the renewable energy sector merit distinct attention. The emergence of these sources at particular scales is reciprocally related with energy geographies, i.e. with the geographies territorialised 
by and constitutive of energy infrastructure. Energy geographies define the spatial concentration (horizontal scales) and the multi-level decision-making (vertical scales) that give shape to new energy infrastructures; as these infrastructures emerge, they in turn reconfigure energy sectors, territorially remaking energy geographies. This recent but strong suite of scholarship offers numerous insights that overlap with and draw from other fields like science and technology studies, political economy and just transitions research on infrastructure and sustainability (Bridge 2018; Hess and Sovacool 2020; Newell and Mulvaney 2013). For the drivers of biases in solar rollout posited here, engagement with treatment of scalar aspects in these overlapping fields is fruitful.

Driver 1: Insofar as these scalar aspects pertain to the infrastructure itself, energy social science research foregrounds the socio-materiality of the electricity sector. To limit the scope of this discussion, the focus is limited to electricity, as the most relevant part of the energy sector for solar energy rollout. The generation, transmission and distribution of electricity is clearly a technical and material concern. It is moreover social in that it affects the everyday lives of people who use electricity in various forms for diverse purposes. The way that electricity is embodied and made available through energy infrastructure - based on decisionmaking by networked actors - defines the scope of its use, in terms of physical access, affordability, monitoring and measurement by and for a variety of actors. Thus, socio-materiality is one key driver.

Socio-materiality has received great conceptual and empirical attention from energy scholars of global North contexts. A notable example is an edited volume by Gailing and Moss (2016) that focuses on Germany, where the national energy transition ("Energiewende") has included explicit attention to aspects of scale, such as in moves toward urban scale ownership of energy sector infrastructure and services. Bridge et al. (2013) provide a comprehensive geographical conceptualisation of low-carbon socio-technical transitions in the UK. These contributions have made significant headway since Lawhon and Murphy (2012) pointed out the need for more attention to space and place in scholarship on infrastructure transitions. Yet they find fewer matches in global South contexts, especially beyond urban socio-material reconfigurations. In their consideration of landscapelevel energy solutions that are globally applicable, Kiesecker and Naugle (2017) attend to associated land use effects. Yet knowledge on how these effects, which vary by technology, are determined in the full range of global contexts merits broader examination. It is here that attention to socio-materiality in relation to scalar biases of solar energy rollout can help. The choice of technology is apt for such exploration, given the modular nature of solar PV, which can be installed at scales that range from a few panels for a single household to hundreds of hectares for large solar plants.

Driver 2: The supply- and demand-side functioning of this sector as well as the supply-demand interface is characterised by innovation and regulation, which continuously engage with and act on each other to bring about sectoral change. These activities pertain to legal and financial aspects, bureaucratic and technocratic requirements and the general codification and institutionalisation of the 
electricity sector. There is inevitably path dependence in these trajectories, which sets up the need for adaptive regulation; hence regulatory inertia is a second key driver.

Regulatory inertia has received attention in both global North and global South contexts. This is typically in political science work, where governance scholars recognise the potential limiting effects of path dependence in rapidly evolving sectors where infrastructure investments (thermal plants, transmission grids) typically span several decades (Lockwood et al. 2017; Cherp et al. 2018). Yet much of this work focuses on the role of governments; the field of energy geographies has shown that there are other actors who are relationally involved in co-shaping regulation, at urban (Haarstad 2016; Bouzarovski and Haarstad 2019), regional (Truffer and Coenen 2012) and translocal scales (Sareen and Grandin 2020). This recognition has taken hold amongst political scientists working on polycentric governance (Jordan et al. 2018). Sareen and Kale (2018) flag path dependence in relation to energy federalism, and Kivimaa et al. (2017) highlight the relevance of and distinct challenges to shifting governance practices at multiple scales as a concern in contemporary scholarship. An explicit focus on how regulatory inertia drives scalar biases in diverse contexts can advance this research.

Driver 3: During sectoral change, the field of actors is by definition also subject to change, as new entrants emerge and incumbents adapt their activities to retain relevance across scales. These dynamics of change are fraught, contingent and determined through relational processes whereby actors interact to contest and modulate changes in ways that best serve their self-interest and reduce their exposure to risk from uncertainty. These processes transcend the electricity sector into broader political and economic entanglements through which the sector is governed, with the allocation of benefits and burdens from energy infrastructure transitions in the balance. Thus, politics is the third key driver of scalar biases.

Politics is inextricably linked with changes in a sector as economically important as energy, often with numerous powerful incumbent interests. A recent trend in scholarship, as exemplified by Dubash et al. (2018), is to articulate the specific nature of such political influence. As the comparative work on electricity distribution governance across 15 Indian states has shown (Dubash et al. 2018), there is incredible variation even at sub-national scales. Most global or multicountry analyses do not probe such differences as they tend to compare like with like at the national scale; yet large countries such as India or China can exhibit rich diversity comparable to global regions like Europe, and their subnational regions have diverse political priorities (cf. Arndt et al. 2017), much like European Union member states (cf. Bouzarovski 2014). Yet few studies combine fine-grained contextualisation of political influence with analytical cross-fertilisation between global North and global South energy transitions. Approaching politics as a driver of scalar biases can direct attention to its effects on multiscalar sectoral transitions in diverse contexts and ease the challenging task of integration over time. 


\section{The governance of solar energy rollout: from India to Portugal}

The implications from the studies on two western Indian states (Sareen 2018; Sareen and Kale 2018) can be summed up in terms of these three drivers of scalar biases and related to the solar energy rollout in Portugal. At the time of these studies in 2016, both Gujarat and Rajasthan had heavy dependence on fossil fuels, based on domestic and international imports for coal thermal plants. They had to meet renewable energy source targets that ratcheted up annually and thus needed to install solar energy capacity. Land was easily available in the barren western reaches of both states, whereas energy demand was concentrated in urban and industrial centres. In terms of socio-materiality as a driver of scalar biases, this necessitated investment in transmission infrastructure to set up large solar plants far from centres of energy consumption, with row upon row of modules often spreading across tens or hundreds of acres. Portugal showed a similar dynamic with weakly developed grid infrastructure in its southern regions where the solar resource was highest (Sareen and Haarstad 2018). It, too, envisaged a move away from dependence on fossil fuel imports and - having built up hydro and wind power capacity - eyed solar expansion as technology costs declined.

Regulatory inertia was evident in the Indian states through the governance approach to solar energy rollout, which led to installing large, spatially concentrated solar plants that profited primarily large industrial actors (Yenneti and Day 2016; Yenneti et al. 2016; Sareen and Kale 2018). There was a continuing push for fossil fuels even as solar energy became economically competitive, despite new coal and gas investments effectively locking in high emissions for another three decades. Portugal saw similar parallel pushes for sectoral growth rather than a phase-out of fossil fuel dependence rapidly replaced by solar. Until 2018, consortia to start offshore oil exploration remained a distinct possibility, and two existing coal plants continued to have extended lifespans based on upgrade investments. Traditional allocation of limited grid capacity to fossil fuel plants held up licences for solar developers. Incentives for small-scale solar - defined in Portuguese legislation as plants up to $250 \mathrm{~kW}$ in size - were decreased after initial support and capacity only grew modestly for self-consumption during the late 2010s (Sareen et al. 2018). Thus, adaptive regulation was not evident to enable multi-scalar lowcarbon energy transitions.

Finally, politics featured heavily in both the Indian states and in Portugal. Gujarat adopted a strategy to heavily subsidise rapid solar growth early on, based on good sectoral finances and a top-down push to establish it as a solar leader (Sareen and Kale 2018; Chatterjee 2020). Rajasthan was reeling under financial constraints with repeated sectoral bailouts and took up large-scale solar through auctions once it achieved grid parity on costs. Portugal is a hybrid example of both approaches; it initially subsidised solar energy heavily, then curtailed such investment during the financial crisis of 2008-2015 and thereafter phased out subsidised feed-in tariffs to capitalise on the cost competitiveness of solar energy. Most notably, its July 2019 solar auctions set a new world record at the time, with a lowest bid below $€ 15$ per MWh and an average cost at two-fifths of the annual 
average rate on the wholesale electricity market (Sareen 2020). This will add 1.35 GW of cheap solar capacity to its grid by 2021 . Across cases, the political economy of these developments prioritised large-scale solar plants that made up the bulk of large additions, with limited growth in small-scale capacity.

Having given a brief comparative overview of the similar trends across these distinct yet comparable contexts in terms of the three drivers of scalar biases in solar energy rollout, the next section provides greater empirical analysis of developments in Portugal in terms of each driver.

\section{The drivers of scalar biases in Portuguese solar energy rollout}

This section sequentially analyses how the three drivers can deepen our understanding of solar energy rollout in Portugal, in ways enabled by adopting the methodological approach of the research conducted on the Indian states. As explained in the introduction (also see Sareen and Kale 2018), and also detailed in specific instances below, this approach centred on expert interviews conducted with energy sector stakeholders and brought a multi-scalar and multi-sited focus to solar energy rollout.

Socio-materiality: The main driver of solar rollout in Portugal was cost reduction in the solar PV technology. This is true globally, with the effects of developments as far away as China being felt directly at national and local scales. A representative from a regional ecological association discussed this in reference to a solar plant of over $200 \mathrm{MW}$ planned by an Irish-Chinese consortium in Alcoutim:

The environmental impact assessment suggested adding solar panels as one of the highlights along Via Algarvina [a heritage route affected by the solar plant], or making a detour in the Via Algarvina. ... The developer laid the foundation stone in early April 2017, with the Minister of Economy from Lisbon in attendance and other bigwigs from Faro [regional headquarter]. That was the first time the Chinese investor saw the landscape, I think, then tried finding alternatives. ... The Portuguese Environment Agency responds to a developer proposal by working many publicly paid hours to suggest an alternative proposal that the developer can then easily adopt, and it's already accepted before details become public. ... Our position is pro smaller plants, and that people should be encouraged to install solar solutions in their own households.

(interview dated 20 September 2017)

The modular nature of solar PV means that it can be installed at both large and small scales, with a wide range of spatial distribution or concentration in high solar irradiation regions. This distinguishes it from fossil fuels that require transport infrastructure and strong supply chains to ensure reliable generation. Yet this quote illustrates that this scalar scope was not exploited effectively. Rather, the impact of a large solar plant on the local context was imposed top-down by 
powerful actors. Clearly, political dynamics interplay with socio-materiality; these are discussed as the third driver below.

Other socio-material aspects of solar energy include temporal output profiles limited to sunlight hours and premium plant siting locations based on electric grid access. Hence, legacy electricity market pricing protocols and transmission infrastructure determine value propositions for solar developers. A solar developer summed up the challenges he faced during technological niche expansion:

The problem with current developments around solar energy in Portugal is that solar developers are being exposed to future risk. With an increase in the renewable energy component, the variable cost of energy generation will tend to zero. This means that energy purchase prices on a competitive market will witness substantial decrease. The problem for solar developers is that their investment today will buy less generating power at higher rates than competitors who might invest a couple of years in the future. ... The market has to move to incentivising flexibility. Instead, it is still rewarding steady base load and placing risk on those producing renewable energy which has more flux. This is the marginal cost based pricing logic of the market and it disfavours renewable energy.

(interview dated 28 September 2017)

These problems were compounded by material limitations of weak grid infrastructure in southern Portugal. While this limited the quantum of solar PV that could be installed, a European agreement to invest in strengthening grid infrastructure and expanding interconnections in 2018 improved future prospects, with further investments foreseen in the National Energy and Climate Plan 2030 in 2019.

Regulatory inertia: The past decade of solar PV trends demonstrate how vital regulations are towards shaping an industry and thus rapid energy sector transitions. Large-scale solar PV took off in Portugal due to energy policies that offered subsidies, which created the initial conditions for actors interested in this emerging sector to organise and prepare to grow such investment. Yet regulations did not maintain a consistent trajectory. Large solar PV developers had to go through messy processes to acquire solar PV plant licences and lacked clarity over the availability of the electric grid. One frustrated solar developer explained:

Right now grid capacity is stuck with big solar project licenses the government has given out in Ourique and Alcoutim, where the law could be applied to open that capacity up for small companies. But instead the companies with licenses take two years, then ask for a year extension on some basis, even knowing that they will need more time beyond that, which should be a breach but gets granted.

(interview dated 22 August 2018)

Small solar PV actors showed enthusiasm to invest in and install plants, but the incentives that attracted them were lowered too quickly and too much for 
continued growth. Small solar PV had a strong start in the 2010s, with attractive initial feed-in tariffs that were rapidly reduced, then renewed on a year-byyear basis from 2013 onwards. With early adopters and quick payoffs options exhausted, small solar PV prosuming to the grid came to a standstill at $170 \mathrm{MW}$. An early adopter of small-scale solar PV linked this with entrenched regulations that favoured the large incumbent company, EDP:

The problem we have now is how we can meet such a high level of ambition if you look at EDP which is the most important player in the country in terms of electricity production and they are investing zero in solar in Portugal besides supporting some self-consumption by small consumers, which is basically a business case for them. They do not want to build a power plant. And the reason is the way the market is working. If we want to reach the necessary level of ambition, you have to change the current market rules.

(interview dated 16 August 2018)

A self-consumption law imposed the limitation that solar PV generated had to either be consumed by a single user entity or injected to the electric grid in exchange for a nominal tariff set far below the retail electricity price. This made small-scale solar PV unattractive for those whose electricity consumption profiles did not match its production profile, such as small families with nobody home during main solar production hours. Adding energy storage was not yet cost-effective at household scale until 2020. Thus, small businesses and public buildings could not benefit from production during holidays. In short, small players could only invest in solar PV to sell electricity at very low rates to the grid while making savings on self-consumption by reducing their grid electricity consumption.

Thus at the large scale, regulations failed to provide a clear picture and actors were unfairly penalised in various ways, such as having to invest in greenfield development without then being able to procure a licence, and having to deal with lack of policy visibility by paying high interest rates for investment capital. Whereas at the small scale, regulations excluded actors from a fair option to share in installing and benefitting from solar PV plants. This inability or unwillingness to calibrate regulations to enable fair multi-scalar rollout terms halted small solar PV capacity after initially rapid growth.

Politics: The most decisive driver in terms of scalar biases, revealing transsectoral dynamics, proved to be politics. Poorly designed wind energy contracts by a government in the 2000s raised sectoral debt. This modulated decisions on solar PV during the 2010s in contrasting ways. First, renewable energy suffered a legitimacy crisis in public perception due to its weaponisation in political rhetoric, which the political opposition mobilised to come into power in 2011 (Sareen and Haarstad 2018; Sareen 2020). This government politically opposed renewable energy during a period of austerity politics. The Socialist Party, back in power in 2015, found subsidising renewable energy politically unviable, with squeezed fiscal room as Portugal sought to retain financial credibility and exit both the economic recession and deeply unpopular austerity measures. Hence, financial 
incentives to solar PV remained largely dry when these were still required for the technology to compete at market prices.

The formation of a new Ministry of Environment and Energy Transition in October 2018 and the re-election of the Socialist Party government in the October 2019 elections brought signs of evolution in solar energy governance after years of dithering. These developments mark the institutionalisation of a new appetite for low-carbon energy transitions. A ministry representative explained their approach:

Stated intent in solar has been $5 \mathrm{GW}$, but translated into not even $10 \%$, maybe $500 \mathrm{MW}$, due to grid constraints, financial constraints, investors speculating on licenses. So to achieve $47 \%$ renewable energy by 2030 compared to $31 \%$ by 2020 , which is a big jump, two procedures. First to attract foreign investors to come to Portugal, which is a challenging thing but also something where we are well positioned and also have experience with renewables although not with solar. [Second] we are looking at agriphotovoltaics and trying to not rely solely on large-scale solar. So we are looking at legislation on decentralised solar production, to open up for communities and local businesses. Right now one installation can feed a single consumer, with community energy all households in condominiums, all service buildings, can share with other consumers with complementary consumption patterns.

(interview dated 7 March 2019)

This policy push bore clear results for large-scale solar with successful solar auctions in July 2019 with competitive bids for $1.35 \mathrm{GW}$ that fetched a world record low price. A further $700 \mathrm{MW}$ of capacity was successfully concluded in August 2020 and set another world record. Consequently, large solar PV capacity in Portugal looks set to exceed $2 \mathrm{GW}$ by 2021. Legislation enabling energy communities came into force in January 2020, and while it is too early to comment on the effect here, this is a promising development for small-scale solar rollout. A solar energy researcher in Portugal pointed out that "there is a need for fungible models for community solar energy. Automation is clearly part of the way forward, time-of-use is too much of a demand for ordinary people. You cannot bother with waiting till 10pm when you have a little child" (interview dated 6 March 2019). Attention to politics and changing power dynamics as a driver thus directs focus to questions of grid digitalisation, new economic models and how new laws will be operationalised and implemented.

Adoption of technical measures like the solar auctions and small-scale solar PV laws has insulated it from national politics. Two vision documents launched in 2019 underscore this: a National Energy and Climate Plan 2030 and a Carbon Neutrality Roadmap 2050. These specify ambitious solar targets - up to $9 \mathrm{GW}$ by 2027 - for Portugal to decarbonise electricity and systematically electrify other sectors.

Thus, solar energy rollout in Portugal has so far been geared towards big solar developers, who can mobilise millions of Euros in investment, to the detriment of 
participation by smaller players. Yet there are signs of emerging efforts to address such scalar biases. Arguments that support scalar biases include: easier coordination of electricity markets in a highly connected technological sector with massive grid infrastructure; easier monitoring and regulation with a small number of large players; and economies of scale for economic competitiveness. Equally, there are reasons to be wary of such a scalar bias. An oligopoly by large actors can: subdue interest in technologies and scales of deployment that are socio-ecologically desirable; enable exploitation of regulatory lags to abuse control over electricity infrastructure and exclude smaller players; and maintain high prices instead of translating cost declines in solar PV technologies into societal benefits.

\section{Implications for balancing urgency and justice in solar energy rollout}

The concluding discussion reflects on the cross-fertilisation of a methodological approach from a study focused on the global South to a global North context. It is argued that the results that ensued have enlarged the analytical range of energy geographies scholarship across contexts where energy transitions pose challenges of governance. This enlargement takes the form of three drivers of scalar biases during solar energy rollouts that can be analytically generative in a wide range of contexts. While they inevitably overlap, the drivers capture distinct core dynamics that modulate the expression of scalar biases during solar rollout. As the drivers point to tendencies that are found in all low-carbon energy transitions and manifest in diverse situated ways, a variety of studies that employ these drivers will increase their explanatory power across global South and global North contexts. This can be a step towards a more integrated field of energy geographies research, where we can move beyond binaries such as global South and global North and engage with the richness of socio-spatial patterning interlaced across contexts.

The implications of the drivers go beyond this integrative push. They speak directly to the overarching aim of this book, which focuses on balancing concerns of urgency and justice in relation to ongoing low-carbon energy transitions. Solar energy rollout foregrounds this tension in terms of scalar biases evident in the Indian and Portuguese cases discussed above. Rapid rollout takes the form of large-scale solar plants that contribute little to socio-economic justice even as they accelerate climate change mitigation. This is not inevitable; nevertheless, analysis of the governance of solar energy rollout displays a strong bias in favour of such large-scale infrastructural shifts benefitting primarily large actors and entrenched modes of sectoral operation. At the same time, small-scale solar rollout remains quite modest and steady rather than scaling up, which limits its impact for climate change mitigation. The drivers of scalar bias again foreground reasons for this, in terms of the socio-materiality of the energy sector, its regulatory inertia and the nature of political influence, which combine to impose bureaucratic and technocratic barriers to rapid expansion of small-scale solar energy initiatives.

There are notable similarities in how these trends play out in India and Portugal, which suggests that closer analytical attention to global South and 
global North contexts may increase the explanatory power of energy transition studies across contexts. The challenges present themselves differently in notable ways across contexts - India's sheer population numbers and lower energy development level dictate a need to expand energy access rapidly, accompanied by political economic implications, whereas Portugal's isolated geography places limits on electric grid interconnections. Yet the drivers that modulate decisions across these contexts are qualitatively similar. This congruence of scalar biases across contexts suggests that the drivers themselves are what underlie the dilemma between urgency and justice in energy transitions. In other words, the dilemma is one premised on entrenched modalities of governance and energy infrastructure. Without addressing these situated questions of infrastructure, regulation and politics, low-carbon energy transitions are unlikely to achieve justice.

In the Portuguese case, an analysis using the three drivers identified these key areas to focus on for future changes to multi-scalar solar energy rollout: the implementation of new community energy legislation, the performance of future innovatively designed solar PV auctions and the expansion of limited electric grid infrastructure in conjunction with installing solar capacity. This approach does not treat scalar biases as an end in themselves or simply evaluate them as a negative phenomenon. Rather, by taking point of departure in scalar biases and seeking to explain them, they are treated as widespread characteristics of energy transitions that can provide vital analytical entry points to identify governance challenges of a given energy transition case. Future research that employs the same drivers - socio-materiality, regulatory inertia and politics - or a different configuration of variants adapted to other cases can test how much further it is possible to extend the explanatory power of such an approach and whether it can be generalised to all energy transitions. Given that energy is a deeply political sector, that energy infrastructure is irrefutably socio-material and that rapid evolution inevitably courts the risk of regulatory inertia that lags behind innovation in their reciprocal relationship, these drivers are likely to yield deep explanation of energy transitions.

\section{References}

Arndt, C., Miller, M., Tarp, F., Zinaman, O. and Arent, D., 2017. The Political Economy of Clean Energy Transitions. Oxford, Oxford University Press.

Bhide, A. and Monroy, C.R., 2011. Energy poverty: a special focus on energy poverty in India and renewable energy technologies. Renewable and Sustainable Energy Reviews, 15(2), pp.1057-1066.

Bolton, R. and Foxon, T., 2015. Infrastructure transformation as a socio-technical process: implications for the governance of energy distribution networks in the UK. Technological Forecasting and Social Change, 90, pp.538-550.

Bridge, G., 2018. The map is not the territory: a sympathetic critique of energy research's spatial turn. Energy Research \& Social Science, 36, pp.11-20.

Bridge, G., Bouzarovski, S., Bradshaw, M. and Eyre, N., 2013. Geographies of energy transition: space, place and the low-carbon economy. Energy Policy, 53, pp.331-340. 
Bouzarovski, S., 2014. Energy poverty in the European Union: landscapes of vulnerability. Wiley Interdisciplinary Reviews: Energy and Environment, 3(3), pp.276-289.

Bouzarovski, S. and Haarstad, H., 2019. Rescaling low-carbon transformations: towards a relational ontology. Transactions of the Institute of British Geographers, 44(2), pp.256-269.

Calvert, K., 2016. From 'energy geography' to 'energy geographies' Perspectives on a fertile academic borderland. Progress in Human Geography, 40(1), pp.105-125.

Chatterjee, E., 2020. New developmentalism and its discontents: state activism in Modi's Gujarat and India. Development and Change, in press, https://doi.org/10.1111/dech .12579 .

Cherp, A., Vinichenko, V., Jewell, J., Brutschin, E. and Sovacool, B., 2018. Integrating techno-economic, socio-technical and political perspectives on national energy transitions: a meta-theoretical framework. Energy Research \& Social Science, 37, pp.175-190.

Cherunya, P.C., Ahlborg, H. and Truffer, B., 2020. Anchoring innovations in oscillating domestic spaces: why sanitation service offerings fail in informal settlements. Research Policy, 49(1), 103841.

DGEG (Directorate General for Energy and Geology) 2020. Renewables Summary Statistics 183: February 2020. Accessed on 27 April 2020 at http://www.dgeg.gov.pt.

Dubash, N., Kale, S. and Bharvirkar, R., eds., 2018. Mapping Power: The Political Economy of Electricity in India's States. New Delhi, Oxford University Press.

Fraser, N., 2009. Scales of Justice: Reimagining Political Space in a Globalizing World. New York, Columbia University Press.

Gailing, L. and Moss, T. eds., 2016. Conceptualizing Germany's Energy Transition: Institutions, Materiality, Power, Space. London: Palgrave.

Geels, F.W., Sovacool, B.K., Schwanen, T. and Sorrell, S., 2017. Sociotechnical transitions for deep decarbonization. Science, 357(6357), pp.1242-1244.

Gouveia, J.P., Seixas, J. and Long, G., 2018. Mining households' energy data to disclose fuel poverty: lessons for Southern Europe. Journal of Cleaner Production, 178, pp.534-550.

Haarstad, H., 2016. Where are urban energy transitions governed? Conceptualizing the complex governance arrangements for low-carbon mobility in Europe. Cities, 54, pp.4-10.

Hansen, T. and Coenen, L., 2015. The geography of sustainability transitions: review, synthesis and reflections on an emergent research field. Environmental Innovation and Societal Transitions, 17, pp.92-109.

Healy, N. and Barry, J., 2017. Politicizing energy justice and energy system transitions: fossil fuel divestment and a "just transition". Energy Policy, 108, pp.451-459.

Hess, D.J. and Sovacool, B.K., 2020. Sociotechnical matters: reviewing and integrating science and technology studies with energy social science. Energy Research \& Social Science, 65, 101462.

Horta, A., Gouveia, J.P., Schmidt, L., Sousa, J.C., Palma, P. and Simões, S., 2019. Energy poverty in Portugal: combining vulnerability mapping with household interviews. Energy and Buildings, 203, 109423.

IRENA 2020. Renewable Energy Statistics 2020. Abu Dhabi: International Renewable Energy Agency.

Jordan, A., Huitema, D., Van Asselt, H. and Forster, J. eds., 2018. Governing Climate Change: Polycentricity in Action? Cambridge, Cambridge University Press.

Kiesecker, J. and Naugle, D. 2017. Energy Sprawl Solutions: Balancing Global Development and Conservation. Washington DC, Island Press. 
Kivimaa, P., Hildén, M., Huitema, D., Jordan, A. and Newig, J., 2017. Experiments in climate governance-a systematic review of research on energy and built environment transitions. Journal of Cleaner Production, 169, pp.17-29.

Lawhon, M. and Murphy, J.T., 2012. Socio-technical regimes and sustainability transitions: insights from political ecology. Progress in Human Geography, 36(3), pp.354-378.

Lockwood, M., Kuzemko, C., Mitchell, C. and Hoggett, R., 2017. Historical institutionalism and the politics of sustainable energy transitions: a research agenda. Environment and Planning C: Politics and Space, 35(2), pp.312-333.

Newell, P. and Mulvaney, D., 2013. The political economy of the 'just transition'. The Geographical Journal, 179(2), pp.132-140.

Rutherford, J. and Coutard, O., 2014. Urban energy transitions: places, processes and politics of socio-technical change. Urban Studies, 51(7), pp. 1353-1377.

Sadath, A.C. and Acharya, R.H., 2017. Assessing the extent and intensity of energy poverty using multidimensional energy poverty index: empirical evidence from households in India. Energy Policy, 102, pp.540-550.

Sareen, S., 2018. Energy distribution trajectories in two Western Indian states: comparative politics and sectoral dynamics. Energy Research \& Social Science, 35, pp.17-27.

Sareen, S., ed., 2020. Enabling Sustainable Energy Transitions: Practices of Legitimation and Accountable Governance. Cham, Palgrave Macmillan.

Sareen, S., Baillie, D. and Kleinwächter, J., 2018. Transitions to future energy systems: learning from a community test field. Sustainability, 10(12), 4513.

Sareen, S. and Grandin, J. 2020. European green capitals: branding, spatial dislocation or catalysts for change? Geografiska Annaler: Series B, Human Geography, 102(1), pp.101-117.

Sareen, S. and Haarstad, H., 2018. Bridging socio-technical and justice aspects of sustainable energy transitions. Applied Energy, 228, pp.624-632.

Sareen, S. and Kale, S.S., 2018. Solar 'power': socio-political dynamics of infrastructural development in two Western Indian states. Energy Research \& Social Science, 41, pp. $270-278$.

Sovacool, B.K., 2014. What are we doing here? Analyzing fifteen years of energy scholarship and proposing a social science research agenda. Energy Research \& Social Science, 1, pp.1-29.

Sovacool, B.K., Hook, A., Martiskainen, M., Brock, A. and Turnheim, B., 2020. The decarbonisation divide: contextualizing landscapes of low-carbon exploitation and toxicity in Africa. Global Environmental Change, 60, 102028.

Truffer, B. and Coenen, L., 2012. Environmental innovation and sustainability transitions in regional studies. Regional Studies, 46(1), pp.1-21.

Van Veelen, B., Pinker, A., Tingey, M., Aiken, G.T. and Eadson, W., 2019. What can energy research bring to social science? Reflections on 5 years of Energy Research \& Social Science and beyond. Energy Research \& Social Science, 57, 101240.

Wood, N. and Roelich, K., 2020. Substantiating Energy Justice: creating a Space to Understand Energy Dilemmas. Sustainability, 12(5), 1917.

Yenneti, K. and Day, R., 2016. Distributional justice in solar energy implementation in India: the case of Charanka solar park. Journal of Rural Studies, 46, pp.35-46.

Yenneti, K., Day, R. and Golubchikov, O., 2016. Spatial justice and the land politics of renewables: dispossessing vulnerable communities through solar energy mega-projects. Geoforum, 76, pp.90-99. 


\title{
6 Energy transitions in a post-war setting
}

\author{
Questions of equity, justice and \\ democracy in Sri Lanka
}

\author{
Gz. MeeNilankco Theiventhran
}

\section{Introduction}

An exceptional technological transformation of the global energy system is anticipated in the next half-century or so, with alternatives, mainly renewable energy sources gradually replacing the conventional fossil fuel sources. Amongst all our technological infrastructures, energy systems are arguably those that are most deeply embedded in modern economies and societies. Energy transitions require considerable reconfiguration in the sociopolitical and economic spheres of society. This will have impacts especially for vulnerable population groups and disadvantaged communities (Sovacool, 2017; Healy and Barry, 2017). Communities in the periphery of existing power structures will be most affected since they lag behind and have little or no role in the policymaking, planning or implementation (Munro, 2019; Golubchikov and O'Sullivan, 2020).

Energy is high on the political agenda globally owing to concerns over increasing energy needs for development, security of supply, rising costs and climate change (Potocnik, 2007; Sovacool, 2014). It is not easy to reconcile these needs with international climate commitments. Energy systems and energy transitions engender and give expression to power relations, fairness, and comparative advantage. A key challenge is thus to ensure equity and justice in energy transitions whilst accommodating these other commitments (Bulkeley and Fuller, 2012).

The chapter contends that in countries coming out of prolonged conflicts, energy transitions raise particular equity and justice issues where democracy may be undermined. In the face of changing dynamics, political fluidity and economic challenges, as well as competing interests, the introduction of renewable energy systems may contribute to ethnic, religious, regional, gender or socio-economic inequities. The discussion sheds light on the difficulty and complexity of energy transitions in post-war societies. Sri Lanka as a case study illustrates how renewable energy projects as part of post-conflict development become spaces for contestation through different discourses in the post-war context, and how the new energy economy produces political outcomes. It illustrates the interlinkages between spatial politics and political economy and how energy transitions concern structural differences that have evolved over time and space. 
The chapter begins by distinguishing between post-conflict and post-war settings and contends that the tendency to think that post-war societies are also postconflict is misplaced. In fact they are significantly different. It is crucial to be conflict-sensitive; otherwise, energy transitions are likely to deepen conflicts and possibly undermine the viability of renewable energy projects. The following section underlines the basis for energy transitions in post-war societies and analyses why and how energy transitions are part of post-war transitions. The chapter then proceeds to a discussion on energy challenges in post-war Sri Lanka. Case studies examine challenges to democracy, equity and justice raised by renewable energy projects in the post-war setting. The case studies underline how, whilst private investment, innovation and scale are essential for renewable energy uptake, equity and justice need more attention in post-war societies, where technocratic interventions may do more harm than good.

\section{Post-war state and post-war setting}

Energy transition is a nonlinear progression; the nature and condition of the state determine and influence energy transition pathways. In a post-war state, the transition from war and the energy transition need to be understood together, not least the actors, interests and dynamics in play. A post-war transition focuses on development to achieve the peace dividend and socio-economic advancement. Technocratic interventions then often stem from international development assistance, whose premise for the interventions is normally a post-conflict peace and development narrative. But there are differences between post-war and post-conflict. These differences are important.

\section{Differentiating post-war and post-conflict}

Scholarship on energy and energy transitions in societies emerging from conflict frame these societies as post-conflict societies (Gonzalez-Salazar et al., 2017; Lappe-Osthegea and Andreas, 2017). Once the war is over, either through negotiated settlements or through military victory, the next phase has been termed a post-conflict setting, and the state and the society are framed as post-conflict (MacGinty, 2016; Toft, 2010; Langer and Brown, 2016). But, in reality, the end of a war does not mean or guarantee that the conflict has ended or is resolved (Walter, 2004).

Post-war transition connotes fundamental and intense changes in society ("transition"), after the ending of large-scale organised violence ("post-war"), without necessarily addressing the direction, the drivers or the outcome of these changes (Klem, 2018). In post-war, the conflict may well remain, if in different forms and means. The root causes of conflict - which led to war - may remain and need addressing. The key actors, issues, institutions and history are still partly or entirely in place at the end of the war, and inevitably continue to play out post-war. In the post-war setting, the transition towards peace is just the beginning and not the end of the conflict, and the initial "peace" is in fact 
little more than the mere "absence of violence" (Galtung, 1969). Cleavages and antagonisms persist at the end of war; energy transition in these settings needs special care as it may tend to maintain or even exacerbate the cleavages and divisions.

In the particular case of the end of war through military victory, the victor concentrates on suppressing further manifestations of conflict. Ministering to conflict manifestations often could make a qualitative difference to people's lives (Paris et al., 2009; Rocha Menocal, 2011). But without addressing the causes of the conflict, the conflict may remain dormant only to re-emerge years or even generations later.

\section{Technocratic interventions and the quest for democracy}

Internationally supported efforts to deal with conflict manifestations often boil down to technocratic interventions (such as reform of government institutions under the "Good Governance" agenda). This applies also to the energy sector. Here as elsewhere, the technocratic view is often poorly equipped to deal with behaviour and perceptions. The affective dimension of conflict, including elements of hatred, prejudice, grievance, fear and insecurity, is a key to resolving underlying conflict but is often overlooked by technocratic interventions. These "peacebuilding" interventions are commonly supported by bilateral and multilateral actors to advance liberal peace with "peace through development" set as the goal to achieve longstanding peace (Stokke, 2009).

It has been emphasised that development practices in former war zones often exploit resources and increase inequalities that worsen the vulnerabilities of people (Bender, 2011). In post-war states - whether weak or strong - development presupposes democracy or, at least, a good measure of genuine popular participation. Strong states have been defined as states that are able to ensure internal political stability, economic growth and the possibility of social development, as well as to mobilise resources for achieving their goals (Tsygankov, 2015). In weak post-war states, development is commonly used to build state authority, capacity and legitimacy (Call and Wyeth, 2008). However, strong states too may prefer to undermine democracy, justice and equity and push for development to gain political advantage and address socio-economic needs. Jarstad and Sisk (2008) point out that democracy and peace do not always move forward hand in hand.

Post-conflict literature about development initiatives as technocratic interventions suggests that these do not take the post-war setting and its problems of democracy into consideration. The interventions are top-down, and they may aggravate the underlying, unresolved tensions. Most are liberal and focus on the relationships between states, markets and citizens (MacGinty and Hamieh, 2010). Considerations of state and markets may outweigh considerations about the citizens, not least in a post-war setting achieved through military victory. The losers become even more vulnerable. Technocratic interventions must take note of the importance of the value of democracy in the post-war settings. 


\section{Energy transitions in post-war societies}

Trajectories of post-war states share some common characteristics. The end of war brings a huge sense of relief, and the post-war states then prioritise the economy and development as a way to rebuild (Paris and Sisk, 2009; Langer and Brown, 2016). The trajectories are conditioned by factors such as mode of government, governance structure, donor aid, international relations and local political dynamics. Notably, actions of the post-war state are determined by how the war has ended. If the war has ended with a peace deal, it guides the state's actions. But in the case of one-sided military victory for the state, then as the victor the state has attained the power to decide largely on its own (Licklider, 1993; Luttwak, 1999; Toft, 2010).

Energy is a critical sector of the post-war state and cuts across socio-political and economic lines, and influences economic priorities and development goals. Energy is an integral part of any post-war state-making, since it potentially powers the state, empowers people, drives the economy and accelerates development. The needs to address social inequalities and socio-political grievances, post-war reconciliation and the quest for state-building are part of the post-war state. These competing interests and demands make energy governance challenging.

\section{The energy trilemma}

Post-war governments focus on economic recovery and securing energy. Making energy affordable is also a key requirement of their energy transition (Flores and Nooruddin, 2008). Affordable and uninterrupted energy supply is a primary goal of any energy governance in post-war states. There is a need to transit from preexisting policies, procedures and energy sources to address the energy demand and reconfigure it to new local and global realities. However, the global goal for decarbonisation has also made states commit to cutting emissions and moving towards renewables. Energy is at the centre of climate change mitigation, and energy transition efforts mostly incorporate renewable energy solutions as well as energy efficiency moves. However, energy governance encompasses several dimensions including accessibility, affordability and availability. Central to energy governance is the challenge of the "energy trilemma" involving the interconnected and often competing demands of energy security, environmental sustainability and energy equity (Gunningham, 2013). As societies in transition, post-war societies are often compelled to choose between availability and affordability. Societies are compelled towards trade-offs between the different aspects of the trilemma. Not unsurprisingly, energy supply and security tend to top the list of priorities, with little room to also address the climate challenge and equity. Balancing the energy trilemma is difficult due to the post-war condition (Mulligan, 2010; Lappe-Osthegea and Andreas, 2017).

\section{Need for energy equity and justice}

In a post-war setting, energy equity needs far more attention, since memories of conflict remain fresh and wounds remain unhealed. Energy projects need to 
consider local contexts and how the transition from war to peace evolves over time and space. This understanding is crucial for any energy project in a post-war state - especially when it is executed in the former war zones or among the people affected by war, as in Sri Lanka. Ethnic and religious tensions make energy transition in post-war societies complex, given major factors such as the multicultural nature of society and regional power dynamics. It is essential to explore the impact of the energy transition on the economic, cultural and social aspects of communities. The energy equity aspect of the energy trilemma is decisive for developing countries. Attention needs to be drawn to the poorest in the societies and the embedded inequalities of energy systems.

\section{Energy: a development paradox}

Development is a central component of peacebuilding literature (MacGinty and Sanghera, 2012). Achieving peace through development is the liberal peacebuilding narrative, which suits post-war governments whose focus generally lies more in the direction of development than building substantive peace (Stokke and Uyangoda, 2011). Development is seen as a way of building the peace; with energy being one main pillar of their development paradigm. Energy governance and transition should also play a key role in ensuring that communities feel that development projects are for the greater common good. Renewable energy projects are part of this development matrix, seen as ensuring energy security and affordability to communities affected by the war. An interesting aspect of renewable energy projects is that they fit well with the three narratives: clean and green initiatives, post-war development and ensuring energy access to communities.

Yet the above mentioned three narratives have pitfalls. Even though renewable energy projects are clean and green, it does not mean they are useful or do no harm to their communities or to the environment. As discussed below, some renewable energy projects have caused equity and justice issues and undermined democracy. When certain sections of society challenge renewable energy projects, the "clean and green" narrative enables the government to convince many, whilst suppressing opposing voices. In a post-war state, when the victor's peace is in place, these narratives play a pivotal role in shaping public perceptions. The "clean and green" narrative offers a feel-good perspective, and is easier to sell among the communities even if undermining equity and justice.

\section{Energy challenges in post-war Sri Lanka}

Sri Lanka is a lower-middle-income country in South Asia, and is in a transitional phase after a long civil war. Colonial legacy and the ethnic conflict have long undermined peace and development. The ethnic conflict has its roots in independence from the British in 1948. Ethnic marginalisation and ethnocentric politics play a major role in Sri Lankan affairs, including policymaking which has questioned fundamental democratic principles of the modern state. Sri Lanka is also transitioning from a rural-based economy towards a more urbanised economy 
oriented around manufacturing and services, one of the main challenges of this being energy supply. Economic growth has slowed and reached and 18-year low in 2019 according to a poll conducted by Reuters (Aneez, 2019). The high level of public debt is another problem for the Sri Lankan government. Hence, moving towards clean energy alternatives to ensure energy security and affordability has been challenging. The following section discusses the Sri Lankan post-war context and its energy challenges.

\section{Long road to a post-war state}

Sri Lanka was engaged in a civil war that lasted for nearly three decades. The ethnic conflict began as an outcome of a post-colonial state formation and became a full-fledged war in the early 1980s (Stokke, 1998; Uyangoda, 2010). The war came to an end in May 2009, with the government of Sri Lanka as the victor after annihilating the Liberation Tigers of Tamil Eelam (LTTE).

The end of the war had two distinctive features. First, the military victory of the Sri Lankan state brought peace in the form of victor's peace. Its viewing of the issues determines its politics and implementation. Ten years have passed since the war ended, and ground realities vastly differ from textbook-style post-conflict reconciliation and peacebuilding. It was expected that Sri Lanka would adopt an inclusive development approach to enhance reconciliation among communities and heal the wounds of the war. But the actions of the Sri Lankan state have made national minorities feel cornered and disappointed, which has led to a state narrative of "simultaneously being a victor and victim".

The Sri Lankan state with its Sinhala-Buddhist majoritarian hegemonic ambitions feels like a victim of the ethnic conflict in that the prolonged conflict has undermined the development of the country. The post-war development initiatives need to be understood in this setting. The conduct of post-war Sri Lankan society in general and of the Sri Lankan state in particular could be more clearly understood in terms of the victor-cum-victim articulation. Successive Sri Lankan governments have adopted this argument, describing themselves as the victim while celebrating victory. These political overtones convey the military success over the LTTE in several ways, the most problematic one being seeing victory as a triumph of Sinhalese against Tamils, a minority that challenged the authority of the majority (Wickramasinghe, 2014; Stone, 2014; Seoighe, 2016).

Second, the post-conflict literature argues that post-conflict states are generally weak and fragile (Ohlson and Kovacs, 2009). On the contrary, by the end of the war, Sri Lanka became a "strong state" and softly authoritarian, through undermining and weakening of democratic institutions of governance (De Votta, 2014). The Sri Lankan style of soft authoritarianism had three key features: majoritarian nationalism, developmental economic populism and militarised national security patriotism.

These three features guided the trajectory of the post-war Sri Lankan state and became the "new normal" for Sri Lankans. A short-lived good governance regime in place from 2015 to 2019 was seen as "abnormal". The deep-rooted nature of these three features underlined the post-war state-society nexus and undermined democratic principles. 


\section{Energy challenges}

Energy is a key priority area for Sri Lanka in its post-war developmental planning (World Bank, 2019). Sri Lanka aspires to move towards renewable and sustainable energy amid rising energy demand, alongside destabilisation of hydropower production due to climate change, plus limited public finance and private sector reluctance curtailing new ventures. Meanwhile, Sri Lanka is also on the lookout for cheap energy. Hence, Sri Lanka's ambitions of transitioning to clean energy are politically and socially challenging.

Firstly, Sri Lanka's Ministry of Power and Renewable Energy has forecast that demand for electricity will grow annually by 7-8\% (ADB, 2015; World Bank, 2019). Meeting this growing demand with low cost and reliable as well as sustainable energy is a big challenge.

Secondly, hydropower, the leading renewable source of electric power, has experienced climate anomalies in the past decade leading to reduced output (World Bank, 2007). To reduce its heavy reliance on polluting fossil fuel, Sri Lanka needs to find renewable energy options besides hydropower.

Thirdly, Sri Lanka has limited public financial resources and needs to engage with the private sector (ADB, 2015; Chen et al., 2018). Government policy and practice impacts on the diffusion of innovations, and vice versa. There is a need for clear cohesive policy towards the business environment, with appropriate subsidies and tax concessions to attract investment. Entrepreneurs generally see an opportunity for innovation and often can mobilise the resources needed for effective and sustainable operation. In other words, despite sound goals, innovation may fail to materialise if entrepreneurs do not adopt it. Lack of consumer finance and market infrastructure seem the main barriers to expanding renewable energy in Sri Lanka.

Fourthly, Sri Lanka has historically sought the least expensive option to generate power to keep down costs to the consumer (ADB and UNDPm, 2017; PEC, 2019). The cost of renewables is still high in most cases, and coal being the cheapest option has been preferred despite adverse implications to the environment and human health.

The above factors stand alongside Sri Lanka's commitment to the Paris climate declaration and its Nationally Determined Contributions (NDCs). It pledged at the 22nd UNFCCC Conference of Parties in Marrakech, Morocco, as part of the Climate Vulnerable Forum, to use only renewable energy resources by 2050 .

Over the past decade, Sri Lanka's energy challenges can be summarised as a battle between coal and renewables. Sri Lanka's energy policy promotes coal, while wanting renewables in the energy mix to fulfil its international commitments. As discussed below, this duality presented an opportunity for renewable energy, where actors who were willing to invest in solar and wind projects were considered positively as post-war state Sri Lanka's energy concerns included energy security and environmental sustainability.

\section{Three key factors}

Energy projects, specifically renewable energy projects, thus became part of the post-war development paradigm in Sri Lanka. This has played out in several 
interesting ways: a discourse about renewable energy in former war zones; the spatial politics of who controls renewable energy spaces; and how energy economy produces political outcomes. Renewable energy initiatives in the former war zones produced two opposing narratives in the public sphere: state-centric majoritarian and ethnic-centric minoritarian.

The government and its institutions argue that Sri Lanka's development needs the sites for wind and solar parks to cater to national requirements. The areas formerly controlled by the rebels are now fully controlled by the government. Therefore, the government is convinced that it has the right to decide on its own regarding land use. Almost all the government officials at the policy level in the capital Colombo echoed these views during the interviews. The views expressed by the officials can be understood through two different sets of thinking. First is a majoritarian nationalistic viewpoint: there is no need to ask or think about minorities or their concerns. The second is state-centric: it is the right of the state to do what it deems necessary. Both fail to acknowledge or understand the concerns of the local people. Whereas during the interviews and focus group discussions with people in the former war zones, they expressed dismay over the renewable projects and felt that they were being imposed on them without consultation, let alone consent. The sentiment shared by many during private conversations is that it gives them a feeling of a "defeated community", and the action of the government is seen as "insult based on ethnic identity" - according to a group of affected women. The low level of trust between the people and the authorities persists in former war zones. The opposing narratives that are in play clearly raise the questions of equity, justice and democracy.

The civil war was waged for the control of territory, which was the dominant arena for legitimisation and delegitimisation of the conflict (Stokke, 2006). When renewable energy projects started to occupy land (both public and private) in the former war zones, it became conflictual. As Lefebvre and Nicholson-Smith (2009) argued, spaces are always contested rather than fixed; political, economic and social forces shape them. Identity, agency and democracy are all closely connected with the control of space. In a post-war environment, control of space enables the state to downplay the military aspect and showcase the civilian nature of the state to propagate normalcy. Controlling spaces helps the state to control social processes. The communities, on the contrary, through creating new social spaces, try to win over the spaces. Bridge et al. (2013) discuss a geographical perspective on energy transition, attuned to spatial variation and argue that the low-carbon energy transition will generate new patterns of uneven development.

Post-war development projects are seen as an opportunity for multilateral, bilateral and local elites and the business community. It can be termed a "political marketplace", a system of governance based on transactions in which political services and allegiances are exchanged for material reward in a competitive manner (De Waal, 2016). Renewable energy attracts interest since it is (at least where given subsidies and incentives) profitable and it is less controversial. Investing in post-war renewable energy projects offers profit, patronage and a "feel good story". Especially for multilateral and bilateral donors, renewable energy projects in the former war zones 
tick all the boxes - development, private sector involvement, public-private partnership, economic reconstruction, peacebuilding. Hence, they become popular.

\section{Method}

We now turn to the concrete research studies in Sri Lanka. This section outlines the research design, the approach to data collection and how the data is analysed. This is followed by a brief background introduction to the study sites to help understand the nature and selection of the sites.

\section{Research design, data collection and analysis}

The fieldwork was conducted in 2018 and 2019. It focused on renewable energy projects implemented in the Northern Province, specifically in former war zones, addressing issues with those projects from a perspective at different levels. The primary data was collected through 42 semi-structured interviews, 14 focus group discussions, and participant observation. The secondary data was collected through documents, communications, reports and newspaper articles. The initial interviews were conducted in the capital Colombo with the policymakers and bureaucrats. This data was used during the interviews at the case sites with the communities and the local administrators. Then the outputs from the case sites were further explored by again interviewing the policymakers and bureaucrats in the capital. This process helped to understand the gaps in knowledge and communication flaws. It facilitated understanding the different narratives in play regarding each of the field sites. The interviews were conducted in both the local languages, Tamil and Sinhala. The quotes used in this paper are translated by the author.

\section{Background of the study sites}

Territories have certain features in terms of social and political power (Brenner et al., 2003). The field sites manifest the power relations and the discourses attached. The selection of the field sites was determined by the following: it should be located in a former war zone; it should have a renewable energy project which began after the end of the war; and it should have faced protest and resistance by the local communities. Two field sites were identified that fulfilled the desired categorisation and also had differences. One was a solar farm and the other was a wind farm; one is completed and in operation, and the other is in the construction phase.

Both field sites are situated in the Northern part of Sri Lanka and in former war zones. The solar farm is located in the district of Vavuniya, the wind farm is located in the district of Mannar. In both districts, ethnic Tamils are the majority and comprise more than $80 \%$ of the population demographically. These were pioneering renewable energy projects in the district. Understanding the sociopolitical dynamics and the political economy of these projects will shed light on the operationalisation of renewable energy projects in a post-war setting. 


\section{Case studies}

Through two tales from the former war zones, this section maps out the contested constellations of the energy transition projects. Both cases illustrate the dynamics in play at renewable energy sites, where opposing narratives shape and reshape the renewable energy futures in the former war zones in particular and the country in general.

\section{Solar farm in Vavuniya}

After the end of the war, in its attempt to encourage private investment in solar energy, the government called for proposals for solar parks in former conflict areas. It allowed the private sector to invest in solar facilities. The first solar farm, with 35,000 PV modules and $10 \mathrm{MW}$ peak output capacity, located on an area of 21.85 ha (54 acres), was commissioned in 2016 and became operational in late 2017. The Vavuniya District is in a multicultural region, known as the gateway to the North. It is a kind of "border region" where the national majority Sinhalese are a minority, and the national minority Tamils are the majority. The site is partly on state land and partly on private land with the state land leased to the company, which has in addition bought the private land. On one side of the solar farm is a Tamil village and on the other is a Sinhalese village.

The area itself had some geographical contestation over the years. Traditionally the Tamils were the inhabitants of the area and in the mid-1980s - in the aftermath of the 1983 anti-Tamil-pogrom - Sinhala Buddhists were colonised into Tamil areas, and Vavuniya was one of those areas (Peebles, 1990). Therefore, any state-sponsored activity, which is termed "development" in the district, creates suspicion already. The solar farm was no different. The site attracted attention when the people in the Tamil village staged a protest in March 2018 against the solar farm. They complained that the heat emitted by the panels made life painful for the families living next to the farm. The protest was mainly on the grounds of health hazards; but there were also politics attached.

A villager of ethnic Tamil origin who took part in the demonstration explained it in the following manner:

When the solar plant became operational, the heat it produced was too much for the people living close by. We were worried, we were asking for an explanation, we were asking for help. No one cared. We are poor people, who have felt the brunt of the war and have returned from the IDP camps emptyhanded. Solar was alien to our area. We even heard that solar radiation might cause cancer.

(Interview with the villager, 12 December 2018)

The villagers were concerned; they were very open about their concerns with the authorities. The initial reaction of the authorities was that the Tamil ethnic 
minority was opposing the private venture undertaken by a company because it was owned by a member of the Sinhala ethnic majority. There was no communication between the communities and the authorities. The villages complain that both authorities - administrative and political - were hostile towards them. It created conflicting reactions from the local communities. The protest became political.

Initially there were no media attention to the protest, but later we got some media attention. We were determined to continue the protest until government gives us a solution. Later we heard from the local politicians that the company was donating a community hall for us. We were asking for a solution, not a community hall. Why they are not consulting with the concerned communities. Why are they using proxies? It means they are not genuine.

(Interview with the local activist, 18 December

The solar farm became the subject of post-war confrontation between the state and the protesting community. Weeks later, following discussion with the local authorities, the private company that owns the solar farm agreed to build a community hall for the village as a goodwill gesture. This move raised suspicion among those protesting against the solar farm. They questioned the motive of the company in building a community hall. They argued that the company's refusal to talk to the villagers is a matter of concern and that the company was using the local authorities and the central government to protect their interests.

The central discourse on this issue was thus initially on ethnic lines. But then in June 2018, the people living on the other side of the solar park - the Sinhalese villagers - also staged a protest against the solar farm, citing the heat emitted as a health issue. This protest put to rest the ethnic aspect and emphasised the overarching equity and justice aspect of post-war development.

Both Sinhalese and Tamil villagers complained during the focus group discussion conducted in December 2018 that they were not informed about the solar farm and that their main concern was the lack of public consultation and that neither the authorities (local and central) nor the company spoke to them regarding the initiative. The Tamil villagers also protested that the solar farm is feeding electricity into the national grid. At the same time, they do not have electricity in their village and questioned the purpose of having a solar farm in the village when the village itself was in the dark. Sinhalese villagers acknowledged during the interviews the need for a solar farm and saw it as a positive developmental initiative, but shared concerns about the health issues and lack of consultation.

This solar farm demonstrates how renewable energy projects can be undermined by both the state and by the communities if democratic principles are not adhered to, and equity and justice questions are not addressed. State and private sector together see renewable energy projects as initiatives for clean and green energy which ensures energy security. The communities in the post-war societies 
see this as projects imposed on them by the state without consultation. A common thread among policymakers, administrators and the private sector is the following argumentation:

This is a government authorised project; the private company has bought the land; it is selling electricity to the government; so, there is no issue. The country needs electricity, and we must be happy that it is produced through renewable means rather than using fossil fuels.

(Interview with the policymaker, 15 November

This ethos at the centre remains the core of the problem, which needs to be understood through the narratives of the post-war state. As discussed earlier in this chapter, the decision-makers and implementors recognise renewable energy projects as clean and green post-conflict development projects to establish energy security. This undermines local concerns, needs and complexities.

The interviews in the field showed that awareness about renewable energy projects among the local-level politicians and the local-level administrators (from village officer to district secretariat) is very low. The general impression is that renewable energy infrastructures are like a traditional development project, which should bring economic and livelihood benefits to the communities. This misconception also played its part in local communities' resistance.

Such initiatives involve several institutions at the local and central levels, with most of the local authorities working under instructions from the central government without a comprehensive picture of the situation. This itself is a problem and the communication gap between sections of the authorities and the general reluctance to take responsibility points to the deficiencies in planning, policymaking and implementation.

\section{Wind farm in Mannar}

In 2014, the government decided to build a wind farm facility of $100 \mathrm{MW}$ on Mannar Island in the Northern Province with the financial support of the Asian Development Bank. The project is owned and administered by the Ceylon Electricity Board (CEB), the state-run power supplier. The 132-hectare land earmarked for the wind farm was private land owned by several individuals and was acquired using an old colonial land acquisition Act, which is still in practice in Sri Lanka. The Act confers powers on the Minister of Land to acquire private land for "a public purpose" by merely declaring through a gazette notification that the private property is required for a "public purpose" and that he/she is exercising power vested in him/her to acquire it.

In the process, the government took over the land needed for the wind power project and then informed the landowners about it. Discussions with the landowners began only after the land was acquired. The land acquisition process inherently disadvantaged the landowners as the state has the power to acquire any piece 
of land it deems necessary. The only option for the landowners was litigation. Most of the landowners are the people who were badly affected and displaced by the conflict and returned to their places of origin a few years after the end of the war. They are economically and politically marginalised.

Our options are limited, and it is an inherited land from my parents, and my brothers also have a say on this. I do not want to give this piece of land away, but my brothers feel otherwise. All are happening because we are vulnerable people. We are not against development or producing electricity, but why our lands are being confiscated. We are a lost community, government is not bothered about us and they do not need to. Because we are minorities.

(Interview with a landowner who lost land, 26

November 2019)

The above was a comment made by one of the landowners who has lost the land for the project. She feels that the post-war setting makes it easy for the state and the authorities to function to their liking without consulting the concerned community. It shows that the decisions are acted upon as top-down imposition, and it makes the marginalised powerless and vulnerable. It questions the notion of democracy and its applicability in the post-war context.

Sri Lanka is a free country now. The state can undertake any project anywhere to its liking without any consultation. We need to move forward with development, and we need more energy. Wind farms are environmentally friendly. Some people are opposing it for political reasons.

(Interview with the policymaker, 14 November

This is how a policymaker from the capital Colombo, who works on renewable electrification, views the project. The wind power project in the former war zone is seen as a "national requirement" by the state and its agencies.

Local-level bureaucrats were mostly positive to this initiative from the beginning, but they too feel let down by how the things are being done. One of the senior local administrators said,

When this was initiated, we supported it wholeheartedly. We were promised that the district would be developed and the people will get jobs, and the economic situation of the district will improve. Nevertheless, over the last five years, nothing has happened. It is disappointing; we see a tendency where war-affected areas are looked upon as places for profit-making.

(Interview with an official at the district secretariat, 28 November 2019)

The general public of the area and the district - most of whom were initially not aware of the project - became unhappy with the way the project was initiated. Over time, mixing the district priorities, mistrust, misinformation and political 
overtones made people wary of the project. The feeling of the local public can be summarised as:

We can't discern why this wind power project is taking precedence over other development priorities. We are a community that is distressed by war and displacement. We are still finding our feet with our basic livelihood issues. The government has failed us miserably, but now they are venturing this to their needs. We are talking about putting food into our plates, not about having electricity to watch a movie.

(Interview with the local activist, 30 November

This case demonstrates the multifaced nature of equity and justice concerns. The project is a top-down project owned by the government. The way in which the land is reclaimed by the state has brought out three issues. First, the law that made this possible itself is draconian and violates fundamental principles of democracy. (Expropriation laws exist in other countries but are seldom applied except for extremely urgent or national security purposes.)

Second, in a post-war setting where ethnic sensitivities are alive, there needs to be careful consideration when it comes to operationalising development projects. Primary local development needs to be implemented first before going ahead with projects which are of national significance. The sequencing is vital; otherwise, it will jeopardise equity issues. Thirdly, the state both deciding on the project, and taking the land from the landowners without at least prior consultation, if possible voluntary settlement, and compensation, involves injustice. It ticks the "renewable kilowatt-hours" box but goes against the fundamental principle of Agenda 21 that, in order to be sustainable, any development must have the understanding and engagement of those involved.

\section{Discussion and conclusions}

Both the case studies outline the multifaceted democracy, justice and equity quandary in the renewable energy projects in the post-war society. Intertwining postwar development and renewable energy uptake creates opportunities as well as challenges. The challenges are mainly faced by those who are at the bottom of the power structure, and it goes unnoticed and rarely gets attention unless they make their protest visible. The case studies point out that from the outset there are competing non-compatible discourses on both the sites, one from the victor and the other from the victim.

The solar project illustrates several of the topics introduced above; such as how the goals of affordable, clean energy for all are conflicted by national and/ or international goals. It also shows how post-war sensibilities and ethnicity were ignored and played a role. And equally evident are the broader energy transition issues related to equity and democracy, where peripheries are typically marginalised in relation to the centre. 
Ironically, the fact that the two ethnic communities in the solar farm case found a common enemy in "big brother" in Colombo might conceivably contribute towards reducing the residual ethnic conflict tensions. The issue of power and cultural context is perhaps typical of authoritarian states, post-conflict or not, such as monarchies or colonies that have little tradition of local participation and democracy. Ensuring equitable energy transitions will be more challenging in such environments.

Conventional post-war development discourse runs risks of failing if it neglects underlying or residual causes of conflict. This becomes even more likely if the ensuing state has a "victor" mentality toward certain regions or groups. Inclusivity is a keyword especially in (residually) conflictual situations. The international commitments on climate can tend to skew priorities in a direction that further leads to inequitable energy solutions.

The competing discourses stem from the political economy of renewable energy. Post-war Sri Lanka - achieved through military victory - looks to consolidate itself economically and politically where the government tries to please its electoral constituencies. Awarding contracts to private entities to engage in renewable energy ticks most of the boxes the government envisions. It enhances government-private sector relations, renewables become part of the energy mix without government spending, it fulfils the global commitments, strengthens energy security and sends a message to the ethnic minorities about who is in control.

These sites also have become a battleground for spatial control, and due to the fluid nature of the long-lasting and still underlying conflict, renewable energy projects are looked upon as "land grabbing from traditional minority areas", where renewable energy is acting as a pretext. Land is a contentious issue in post-conflict settings (Pritchard, 2016; Van Leeuwen and Van der Haar, 2016; Unruh and Williams, 2013) and it is not new in Sri Lanka. Sri Lanka's ethnic conflict has its origins in land grabbing through settlement colonisation in the name of development. In the post-war setting, renewable energy projects are also seen in this vein, and the conduct of the government and private sector raises more questions than answers. Further, the justice and equity issues countenance the concerns of the local communities. The democratic deficit in the post-war state makes these entanglements possible.

Much of the current research on energy addresses technical issues concerning innovations that are cheap to mass-produce as well as ensure lower emissions, while there is also interest in matters relating to energy security and venturing towards renewables from fossil fuels. The questions of equity and justice have remained peripheral for policymakers and administrators. Democratising energy is fundamental in any energy transition, and it is even more important in the countries which are coming out of conflict and in the post-war state. Post-war societies need energy, there is urgency, but the matter of the fact is that equity and justice should not be compromised to have a sustainable transition.

The chapter argues that even though renewable energy projects are seen in a favourable light, putting them into practice in post-war settings is bound to pose 
profound socio-political and economic challenges that could create equity and justice questions. The starting point for any energy transitions in the post-war environment should be the understanding that energy injustice is being produced historically, geographically and materially. In other words, energy inequity, injustice and vulnerability are more than matters of prices and income and involves structural differences that have evolved over time and space.

Actors involved in the energy transitions should be sensitive to equity and justice issues when dealing with energy transitions in post-war societies as shown in the case of Sri Lanka where renewable energy can give rise to societal inequality, questions on justice and democracy deficit, which can lead to ethnic suspicions and can reopen the old wounds of civil war. To make energy transitions sustainable and inclusive in the post-war contexts, considerations of equity and justice are more important than those of technology and economy. Addressing questions of equity and justice will play a key role in energy transition pathways to achieve energy democracy.

\section{References}

ADB (2015). Assessment of Power Sector Reforms in Sri Lanka, Country Report [online] Philippines: Asian Development Bank. Available at: https://www.adb.org/sites/default/ files/institutional-document/173762/sri-power-sector-reforms.pdf [Accessed 16 Feb. 2020]. ADB and UNDP (2017). 100\% Electricity Generation through Renewable Energy by 2050: Assessment of Sri Lanka's Power Sector [online] ADB \& World Bank. Available at: https://www.adb.org/publications/electricity-generation-renewable-energy-2050-sri -lanka [Accessed 12 Feb. 2020].

Aneez, S. (2019). Sri Lanka's 2019 growth to hit 18-year low after Easter bombings: Reuters poll. Reuters. [online] 10 May. Available at: https://www.reuters.com/article/ us-sri-lanka-economy-growth-idUSKCN1SG0R8 [Accessed 15 Mar. 2020].

Bender, G. (2011). Post conflict reconstruction in Africa. Insight on Africa, 3(1), pp.71-90.

Brenner, N. (2003). State/space: A Reader. Malden, MA: Blackwell Publishers.

Bridge, G., Bouzarovski, S., Bradshaw, M. and Eyre, N. (2013). Geographies of energy transition: Space, place and the low-carbon economy. Energy Policy, 53, pp.331-340.

Bulkeley, H. and Fuller, S. (2012). Low Carbon Communities and Social Justice [online] Available at: https://www.jrf.org.uk/report/low-carbon-communities-and-social-justice [Accessed 19 Feb. 2020].

Call, C.T. and Wyeth, V. (2008). Building States to Build Peace. London: Lynne Rienner.

Chen, H., Yu, Y., Shi, X. and Wen, F. (2018). Development of variable renewable energy policy in developing countries: A case study of Sri Lanka. International Journal of Public Policy, 14(1/2), p.10.

De Waal, A. (2016). Introduction to the Political Marketplace for Policymakers [online] London: London School of Economics and Political Science. Available at: https://ww w.lse.ac.uk/internationalDevelopment/research/JSRP/downloads/JSRP-Brief-1.pdf [Accessed 24 Feb. 2020].

DeVotta, N. (2014). Parties, political decay, and democratic regression in Sri Lanka. Commonwealth \& Comparative Politics, 52(1), pp.139-165.

Edward Flores, T. and Nooruddin, I. (2008). Democracy under the gun understanding postconflict economic recovery. Journal of Conflict Resolution, 53(1), pp.3-29. 
Galtung, J. (1969). Violence, peace, and peace research. Journal of Peace Research, 6(3), pp.167-191.

Golubchikov, O. and O'Sullivan, K. (2020). Energy periphery: Uneven development and the precarious geographies of low-carbon transition. Energy and Buildings, 211, pp.1-11.

Gonzalez-Salazar, M.A., Venturini, M., Poganietz, W.-R., Finkenrath, M. and Leal, M.R.L. (2017). Combining an accelerated deployment of bioenergy and land use strategies: Review and insights for a post-conflict scenario in Colombia. Renewable and Sustainable Energy Reviews, 73, pp.159-177.

Gunningham, N. (2013). Managing the energy trilemma: The case of Indonesia. Energy Policy, 54, pp.184-193.

Healy, N. and Barry, J. (2017). Politicizing energy justice and energy system transitions: Fossil fuel divestment and a "just transition.” Energy Policy, 108, pp.451-459.

Jarstad, A. and Sisk, T.D. (2008). From War to Democracy: Dilemmas of Peacebuilding. Cambridge: Cambridge University Press.

Klem, B. (2018). The problem of peace and the meaning of 'post-war.' Conflict, Security \& Development, 18(3), pp.233-255.

Langer, A. and Brown, G.K. (2016). Building Sustainable Peace: Timing and Sequencing of Post-Conflict Reconstruction and Peacebuilding. Oxford: Oxford University Press.

Lappe-Osthege, T. and Andreas, J.-J. (2017). Energy justice and the legacy of conflict: Assessing the Kosovo C thermal power plant project. Energy Policy, 107, pp.600-606.

Lefebvre, H. and Nicholson-Smith, D. (2009). The Production of Space. Malden, MA; Oxford: Blackwell.

Licklider, R.E. (1993). Stopping the Killing: How Civil Wars End. New York: New York University Press.

Luttwak, E.N. (1999). Give war a chance. Foreign Affairs, 78(4), pp.36-44.

MacGinty, R. (2016). International Peacebuilding and Local Resistance: Hybrid Forms of Peace. Basingstoke, Hampshire: Palgrave Macmillan.

MacGinty, R. and Hamieh, C.S. (2010). Made in Lebanon: Local participation and indigenous responses to development and post-war reconstruction. Civil Wars, 12(1-2), pp.47-64.

MacGinty, R. and Sanghera, G. (2012). Hybridity in peacebuilding and development: An introduction. Journal of Peacebuilding \& Development, 7(2), pp.3-8.

Mulligan, S. (2010). Energy, environment, and security: Critical links in a post-peak world. Global Environmental Politics, 10(4), pp.79-100.

Munro, F.R. (2019). Renewable energy and transition-periphery dynamics in Scotland. Environmental Innovation and Societal Transitions, 31, pp.273-281.

Ohlson, T. and Kovacs, M.S. (2009). Peace through democracy? the challenges of post-war democratization in weak and war-torn states. In: A. Swain, R. Amer and J. Öjendal, eds., The Democratization Project: Opportunities and Challenges. New York: Anthem Press, pp.165-182.

Paris, R., Newman, E. and Richmond, O.P. (2009). New Perspectives on Liberal Peacebuilding. Tokyo: United Nations University Press.

Paris, R. and Sisk, T. (2009). The Dilemmas of Statebuilding: Confronting the Contradictions of Postwar Peace Operations. London: Routledge.

PEC (2019). Report on Sustainable Sri Lanka 2030 Vision and Strategic Path [online] Available at: http://www.presidentsoffice.gov.lk/wp-content/uploads/2019/05/Final-v2 .4-Typeset-MM-v12F-Cov3.pdf [Accessed 10 Feb. 2020].

Peebles, P. (1990). Colonization and Ethnic Conflict in the Dry Zone of Sri Lanka. The Journal of Asian Studies, 49(1), pp.30-55. 
Potocnik, J. (2007). Renewable Energy Sources and the Realities of Setting an Energy Agenda. Science, 315(5813), pp.810-811.

Pritchard, M.F. (2016). Contesting land rights in a post-conflict environment: Tenure reform and dispute resolution in the centre-West region of Côte d'Ivoire. Land Use Policy, 54, pp.264-275.

Rocha Menocal, A. (2011). State building for peace: A new paradigm for international engagement in post-conflict fragile states? Third World Quarterly, 32(10), pp.1715-1736.

Seoighe, R. (2016). Inscribing the victor's land: Nationalistic authorship in Sri Lanka's post-war Northeast. Conflict, Security \& Development, 16(5), pp.443-471.

Sovacool, B.K. (2014). What are we doing here? Analyzing fifteen years of energy scholarship and proposing a social science research agenda. Energy Research \& Social Science, 1, pp.1-29.

Sovacool, B.K. (2017). Contestation, contingency, and justice in the Nordic low-carbon energy transition. Energy Policy, 102, pp.569-582.

Stokke, K. (1998). Sinhalese and Tamil nationalism as post-colonial political projects from 'above', 1948-1983. Political Geography, 17(1), pp.83-113.

Stokke, K. (2006). Building the Tamil Eelam State: Emerging state institutions and forms of governance in LTTE-controlled areas in Sri Lanka. Third World Quarterly, 27(6), pp.1021-1040.

Stokke, K. (2009). Crafting liberal peace? international peace promotion and the contextual politics of peace in Sri Lanka. Annals of the Association of American Geographers, 99(5), pp.932-939.

Stokke, K. and Uyangoda, J. (2011). Liberal Peace in Question: Politics of State and Market Reform in Sri Lanka. London; New York: Anthem Press.

Stone, J.G. (2014). Sri Lanka's Postwar Descent. Journal of Democracy, 25(2), pp.146-157.

Toft, M.D. (2010). Securing the Peace: The Durable Settlement of Civil Wars. Princeton, NJ: Princeton Univ. Press.

Tsygankov, A. (2015). A Strong State: Theory and Practice in the 21st Century [online] Available at: https://valdaiclub.com/a/valdai-papers/valdai_paper_15_a_strong_state_ theory_and_practice_in_the_21st_century/ [Accessed 5 Mar. 2020].

Unruh, Jon and Williams, R. (2013). Land and Post-Conflict Peacebuilding. Hoboken: Taylor and Francis.

Uyangoda, J. (2010). Sri Lanka in 2009: From civil war to political uncertainties. Asian Survey, 50(1), pp.104-111.

Van Leeuwen, M. and Van Der Haar, G. (2016). Theorizing the land-violent conflict nexus. World Development, 78, pp.94-104.

Walter, B. F. (2004). Does conflict beget conflict? Explaining recurring civil war. Journal of Peace Research, 41(3), pp.371-388.

Wickramasinghe, N. (2014). Sri Lanka in 2013: Post-war oppressive stability. Asian Survey, 54(1), pp.199-205.

World Bank (2007). Estimating Global Climate Change Impacts on Hydropower Projects: Applications in India, Sri Lanka and Vietnam [online] Washington, DC: World Bank. Available at: http://documents1.worldbank.org/curated/en/959321468308635333/pdf/ wps4344.pdf [Accessed 28 Feb. 2020].

World Bank (2019). Sri Lanka Energy InfraSAP: Final Report. http://documents.worldban k.org/curated/en/843901561438840086/pdf/Sri-Lanka-Energy-Infrastructure-Sector-A ssessment-Program-Executive-Summary.pdf [Accessed 17 Feb. 2020]. 


\title{
7 Energising change \\ Clean cooking and the changing social position of women
}

\author{
Mini Govindan and Rashmi Murali
}

\section{Introduction}

India is undergoing a clean cooking revolution and the recent flagship programme of the government - the Pradhan Mantri Ujjwala Yojana (PMUY), launched in the year 2016 - is a testament to it. ${ }^{1}$ The programme is laudable for its unique approach, design and implementation strategy and has succeeded in distributing more than 80 million subsidised liquefied petroleum gas (LPG) connections to women from underprivileged households. ${ }^{2}$ This clean cooking initiative is pertinent to prioritise the urgency of achieving the goal of universal access to clean cooking solutions by 2030, a subset of the Sustainable Energy for All (SE4All) initiative, ${ }^{3}$ more so since nearly 688 million people in India still lack access to clean cooking (IEA, 2018).

PMUY, however, is not entirely bereft of challenges. Affordability of refills, behavioural patterns in cooking choices and issues with supply chain and access are some of the barriers that have affected the performance of PMUY as a programme (CAG, 2019). In addition, the presence of easily available subsidised kerosene to $\mathrm{BPL}^{4}$ families has a limiting effect on the use of LPG (Swain \& Mishra, 2020). Studies have indicated that the share of total LPG consumers who use LPG as their primary cooking fuel is about $60 \%$, and it has largely remained unchanged since 2011 (IIPS and ICF, 2017). Smith (2017) estimates that even if LPG penetrates $90 \%$ of the population by the next decade, there would still be a sizeable population relying on inefficient traditional cook stoves. Moreover, traditional stoves using solid fuels remain the primary choice for rural consumers due to their affordability and easy access (Banerjee, 2019). These arguments, thus, build the case for the promotion of energy-efficient improved cook stoves. Moreover, clean cook stoves present opportunities for women to be gainfully employed as entrepreneurs and providers of energy supply and services. This is bound to further encourage gender equality in employment and improve the effectiveness of the value chain, thus correspondingly contributing to achieving the SDG goals (5 and 7).

With this logic and a mission to develop and disseminate technological interventions that would also help address social issues, Technology Informatics and Design Endeavour (TIDE), a civil society organisation from Karnataka, India, 
entered the area of clean cooking and started various development programmes. Their flagship programme provides clean cooking technology and capacity building to rural women. Women are engaged through entrepreneurial-based empowerment training to take up responsibilities as cook stove builders, thus opening livelihood opportunities for them.

Their efforts have thereby contributed to scaling up the number of women energy entrepreneurs throughout the clean cooking value chain, along with testing innovative implementation approaches and building evidence to inform policy and practice about successful gender-inclusive business models. Several research agencies have documented TIDE's work in the field of clean cooking. A study by (Lockhart, 2013) provides a comprehensive assessment of TIDE's model in terms of creating green social entrepreneurship that provided alternate economic opportunities to women, and created space for environmental and health awareness, actuating improvements in women's social position. The One World Foundation India (2011) has also documented the various aspects of TIDE's model, technology, capacity building, financial and dissemination models and impacts on the ground. Further, the impact of TIDE's collaborative work with WWF India, wherein trained women cook stove builders constructed more than 300 Sarala stoves in 14 villages of Gundri and Makkampalayam, saw an almost 35\% reduction in fuel wood usage and reduced smoke in the kitchens (WWF, 2018). On the other hand, Selco Foundation's evaluation of the Sarala stoves revealed that unless proper maintenance is done, the stoves do not retain the expected efficiency (Selco Foundation, 2017).

A number of studies have also highlighted the importance of having women as a key part of the distribution model (World Bank, 2011; Smith \& Dutta, 2011; Köhlin et al., 2011), since they can leverage their existing networks to promote the adoption and use of new technologies, especially those related to cooking. Besides, projects in which women-targeted approaches were followed and women were included in the supply side of the value chain, often resulted in empowerment (Bolton, 2015). For example, among the participants of an entrepreneurship training project in Kenya, women sold almost three times as many new cook stoves as men (Shankar et al., 2015a). The increased women's capacity to engage effectively within the improved cook stove value chain served as an effective means to facilitate entrepreneurial empowerment. Increasing women's engagement in the energy business model may have additional benefits for the family and community. It is estimated that women reinvest nearly $90 \%$ of their income back into their families' education, health and nutrition as compared with $35 \%$ for men (Borges, 2007).

There are several studies that have argued for the inclusion of women in the value chain, from product development to sales (Price, 2019; Gill et al., 2015; Pearl-Martinez, 2014; Shell Foundation, 2020), which also add value to the emerging energy justice debate. Energy justice scholarship, which addresses inequalities in energy production, distribution and consumption has expanded beyond a focus on fuel poverty. Developed as both an analytical and practical decision-making concept by Hall et al. (2013), the popular framework proposed 
by Sovacool et al. (2016) calls for ensuring balance of all the competing aims and trade-offs in the energy sector to be inherently more just and equitable in their societal outcomes rather than favouring different factions within society. Though the inclusion of gender in energy justice is not explicit in the framework, it resonates with its core idea in terms of equitable sharing of outcomes, which involves social and gender inclusion at every step of the energy value chain.

The specific case of TIDE, which recognises the urgency of switching to clean cooking while also providing entrepreneurship opportunities for women, warrants further focused analysis, to understand the realisation of justice goals in contemporary social formations. Moreover, understanding the deeper issues of evolving social positions of women, deeply embedded in the overlapping dynamics of local cultural practices, are also important for achieving comprehensive justice objectives.

\section{Understanding the context}

\section{TIDE technology}

Over the years, several clean cooking programmes have been launched globally and in India, such as LPG deployment (from the 1970s), the National Biogas and Manure Management Programme (1981), the National Programme on Improved Cook stoves (1986), supply of piped natural gas (since 2014), the Unnat Chulha Abhiyan (2014), the Pradhan Mantri Ujjwala Yojana (2017) and even the constitution of the Global Alliance on Clean Cook stoves in 2010 (CEEW, 2017; Clean Cooking Alliance, n.d.). TIDE also recognised the urgency of switching to clean cooking and came up with its own smokeless cook stove design, known as the Sarala stove, in 2002.

The Sarala stove is a natural draft, front feeding, two-pan mud stove with a chimney that uses any agro-residue as feed (see Figure 7.1). It was developed by the Indian Institute of Science (IISc), Bangalore as a simplification of its predecessor - the ASTRA stove (Bhogle, 2003). The total cost of the stove, including charges of the stove builder (INR 200 or USD 2.73), amounts to around INR 1,000 (USD 13.63), which is borne in part by TIDE (70\%) and in part by the household $(30 \%)$ who make in-kind contributions of mud and bricks.

TIDE, upon successful completion of training, provides women cook stove builders a mould to build the stoves on-site, comprising cast iron components like a grate, fuel feeding guiding frame, and support rods. The smoke arising from the stove during cooking is let out from the stove to outside the house through a cement or galvanised iron (GI) pipe, which serves as the chimney. Every three months, the chimney needs to be cleared of accumulated soot. With regular maintenance the stove can comfortably last around 8-10 years.

TIDE's activities are mostly focused around the Indian state of Karnataka, which is one of the most prosperous states of India and was ranked second in terms of per capita income in the year 2017-2018 (Government of Karnataka, 2019). The Sarala stove programme was initiated and is concentrated in Tumakuru 

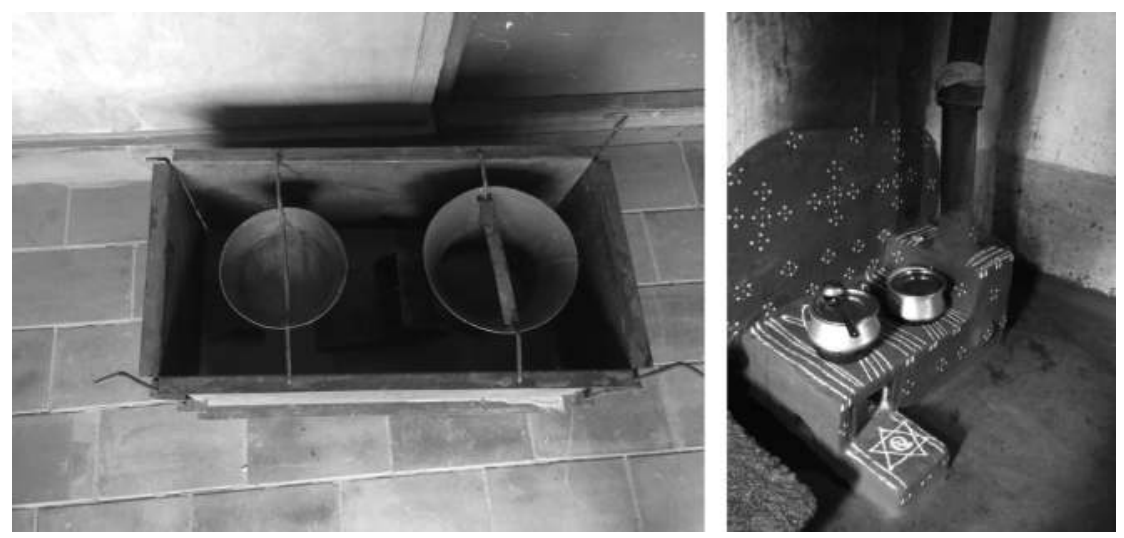

Figure 7.1 Cook stove mould (left), finished mud stove (right). Source: Authors' field photographs.

district of the state. Before the programme was designed, the challenges of uptake in the community, the demand factors and the potential areas for economic growth in the community were investigated, all with a gendered lens.

Most scholarly work on women's entrepreneurship in the cooking domain has emphasised on the importance of context in relation to socio-economic factors, cultural sensitivities and intra-household dynamics amongst other things (Cecelski, 1995; IRADE, 2009; Practical Action, 2014). Studies have also indicated that with education, training and investment, women can build businesses or be employed in the design, production, marketing, sale and maintenance sectors of new energy technologies and services (Shankar et al., 2015a; APEC, 2019).

In the wake of the energy justice movement, TIDE's activities have become more relevant since prominence is given to the involvement of women belonging to disadvantaged social groups like Scheduled Caste (SC) and Scheduled Tribes (ST), along with women belonging to the more advantaged groups like upper castes in aspects of development, marketing and dissemination of their technologies. In the Indian context, it resonates with Jenkins, McCauley \& Forman's (2017) idea of dovetailing energy justice and policymaking to manage the translation of universally accepted values into real life.

\section{The modernity of caste and gender}

Indian society is based on the hierarchy of social order of caste system and the explanations of caste in contemporary India are both complex and often conflicting. Caste, which is commonly known as "Jati" is a form of hierarchical social stratification characterised by hereditary transmission of a lifestyle that often includes an occupation, food patterns, ritual status and customary social interaction and exclusion based on cultural notions of purity and impurity. Some 
scholars have analysed caste in terms of three key effects: social separation, graded status, and occupational specialisation (Dumont, 1980), while others have raised the ideological dimension associated for example with ideas of purity and impurity, ritual ranking or the moral-bodily constitution of human difference and interaction (Dumont, 1980). In examining the various issues of stratification, many historians and social anthropologists point to the British colonial period as a key turning point in changing caste sentiment among Indians (Riser-Kositsky, 2009). The British transformed caste from a loose, discriminatory hierarchy into an officially structured and state-sanctioned hierarchy. In modern Indian society, castes are officially classified into four administrative categories (as per the Indian Constitution) - Scheduled Caste (SC) and Scheduled Tribes (ST) ranked as the lowest, Other Backward Classes (OBC) is a collection of low to middle ranking castes and the General Category/Open category denotes the upper castes.

In India, gender as a marker of disparity is pervasive and the literature analysing gender disparity is huge. Disparities based on gender in education among girls, especially in terms of school enrolment, in India has also been examined extensively in literature (Bandyopadhyay \& Subrahmanian, 2008; Desai, 2007). Financial inclusion for women and their credit worthiness is another crucial domain where gender gaps are glaring (Khera, 2018; Ghosh \& Vinod, 2017; Chatterjee et al., 2019). Studies have shown gender to be a discriminating factor when it comes to decisions regarding access to healthcare services and financing in India (Kapoor et al., 2019; Moradhvaj \& Saikia, 2019; Saikia et al., 2016; Rajeshwari, 1996). Women and girls are also disproportionately and adversely affected by environmental degradation, as research suggests (Agarwal, 1992; Agarwal, 1997). Furthermore, India is ranked low among the medium human development nations of the world in the Gender Development Index, with a score of 0.829 , placed in group 5, which is also indicative of ingrained gender disparities in the Indian socio-economic development context. ${ }^{7}$

Given the multifaceted nature of disparity in India, both gender and caste continue to be important indicators of intergroup disparity. These kinds of disparities limit opportunities, especially for lower castes such as SC/ST and women ( Murthi, et al., 1995; Jeffrey \& Basu, 1996). In an assessment of gender-caste overlap, Deshpande (2002) observed that the economic condition of women continues to be defined and constrained by their caste status. Lower-caste women are also worse off than upper-caste women in terms of in terms of standard of living, prevalence of domestic violence, suggesting that caste and gender intersect in increasing or decreasing women's vulnerability. The Gender Caste Development Index (GCDI) for India clearly identifies that SCs lag behind OBCs, who, in turn, lag behind the upper-caste women for most of India (Rao et al., 2007).

At the same time, there has been the traditional distinction between lowercaste and upper-caste women based on the relative egalitarianism and greater freedom of movement of the former. The lower-caste women are seen to have lower taboos on public visibility, greater autonomy to seek gainful employment outside their homes and communities and a higher degree of mobility compared to their upper-caste counterparts (Deshpande, 2002). In a bid to acquire status mobility, 
the ever-increasing emulation of upper-caste practices or "sanskritisation" lower caste can also produce widening caste and gender divides. The lower-caste men, while displacing ignominious obligations of caste hierarchies, also tend to impose new restrictions on women's autonomy and mobility which again exemplifies how caste interlocks with gender inequality (Still, 2017). Scholars have examined women's collective honour or dignity, a notion that can be measured by the degree of respect shown by others. The failure to maintain the traits of dignity can bring dishonour to the family and sully the purity of their caste (Kabeer, 2000).

To address some of the historical disadvantages and deep-rooted caste inequities and discrimination, India has had a long-standing policy of affirmative action to honour the Indian Constitution, which enshrined a commitment to equality in its directive principles. Fixed quotas or "reservations" were constitutionally mandated for the most socio-economically disadvantaged sections of society ( $\mathrm{SC} /$ ST) in all public sector employment, seats in higher educational institutions, and elected positions. These quotas were further extended to OBCs and the most recent 124th Amendment Bill 2019 seeks to provide for the advancement of "economically weaker sections", through $10 \%$ reservation in government jobs and higher educational institutions - a shift in focus from caste as basis of quotas (The Economic Times, 2019 ${ }^{9}$. National Commissions have been set up for SCs and STs and there are various economic schemes announced from time to time creating employment or granting welfare payments or other benefits to the socially disadvantaged.

Various government programmes and schemes have also been launched to provide equal opportunities for women. Beti Bachao Beti Padhao, Mahila-eHaat, Mahila Shakti Kendra, Support to Training and Employment Programme for Women (STEP) and Pradhan Mantri Ujjwala Yojana (PMUY) among others are programmes and initiatives devised towards empowering the women of India (Ministry of Women and Child Development, n.d.). In addition, specialised schemes have been formulated for the economic upliftment of women belonging to lower or backward castes. The New Swarnima loan scheme and the Mahila Samriddhi Yojana for SC and OBC women by the Ministry of Social Justice and Empowerment, Scheme for strengthening education among ST girls in low literacy districts by the Ministry of Tribal Affairs, and specific provisions under the Mahila Coir Yojana of the Coir Board are among many schemes targeting women of SC/ST/OBC communities (Ministry of Social Justice and Empowerment, n.d.; Ministry of Tribal Affairs, n.d.; Coir Board, 2014).

However, it is also often argued that these affirmative actions have contributed to an increased caste consciousness and resulted in the continuance of caste influence in contemporary Indian society (Mosse, 2018; Jayal, 2014; Jodhka \& Manor, 2017; Munshi, 2017). Few studies examining the effect of political reservations for SC, ST and women candidates indicated a reduction in incidence, and to some extent intensity, of poverty among SC, ST and women, as well as among lowincome communities in general (Kaletski, Elizabeth; Prakash, Nishith, 2016) (Chin $\&$ Prakash, 2010). Various studies have also documented the challenges of affirmative actions in terms of achieving positive socio-economic and cultural outcomes. Jaffrelot (2006) has noted that the quotas for higher status civil service posts were 
not filled in any significant way until the 1980s. While this situation has certainly improved, a more recent study by Bhojani, et al., 2019) describes the limited direct impact of affirmative action, especially in the case of quotas in government jobs, possibly because of poor implementation. Deshpande \& Yadav (2006) have also argued that caste and gender closely intersect in defining outcomes of the reservation. For instance, their analysis finds that in higher education, even within each caste, those in higher economic classes do better as compared to lower classes, with women lagging in both low economic class and caste groups. Common criticism of the affirmative actions and social policy has been the argument of treating caste as a static or residual problem addressed through remedial provisions, safeguards like quotas/reservations and complaint handling, rather than as a dynamic relational problem that the state is generally bound to address (Mosse, 2018).

There has also been a large volume of scholarly work and journalistic commentary that is devoted to questioning whether the old caste hierarchies are valid any more since the Indian economy is increasingly becoming market-oriented and globally integrated and the castes do not necessarily follow a linear hierarchy (Kapur et al., 2010; Damodaran, 2008; Banerjee et al., 2009; Chandrashekhar \& Ghosh, 2014). Caste-based hereditary occupational linkages are no longer rigid and have become flexible enough for people to opt out of their family and caste occupations to pursue better caste-free opportunities like agriculture, industry or white-collared jobs. However, even today, to a larger extent, certain castes do not have freedom to get into the domain which is the specialty of a particular caste. For instance, priestly duties and officiating ceremonies and weddings are still traditionally limited to upper-caste men (Brahmins). Scholars have aptly noted that breakdown of barriers is evident between "adjacent" castes rather than between castes at the extreme of the hierarchy (Mosse, 2018). (Karanth, 1996) argues that caste-based hereditary occupations and social mobility in the rural areas also led to "dual culture", where there is adherence to traditional values in one context and modern and egalitarian ones in another.

\section{Objectives}

The present chapter attempts to examine some of the fundamental questions related to clean cooking and the changing social position of women: how does the involvement of women in the clean cooking supply chain affect gender equality through the distribution of benefits for women and men? And does economic autonomy of women entrepreneurs aid in changing social positions and gender relations within the household and beyond?

\section{Approach and methodology}

It is often argued that qualitative methods are more appropriate for studies related to gender since it aids the researchers to capture the description given by men and women in the context of the positions they occupy in everyday life (Maldonado, et al., 2013). To gauge the impacts of a women-centric design of energy interventions 


\section{8}

on the changing social position of women, the study employed key informant interviews and focus group discussions (FGDs), which are considered a valuable tool for collecting rich qualitative data, and have proven to be effective and appropriate in understanding the views of women, in particular as it allows them to speak more openly among their peers . Further, this approach gives researchers an opportunity to understand the space better, considering multiple viewpoints. Hence, FGDs were used as a "self-contained" method rather than in combination with other methods like surveys that seek quantitative data. ${ }^{10}$ The essence of the qualitative data was retained by using verbatim quotes representing common viewpoints wherever applicable.

The study was undertaken in two villages of Tumakuru district in Karnataka Shivasandra in Gubbi taluk and Kollihatti in Tiptur taluk (see Figure 7.2). ${ }^{11}$ These villages were selected in consultation with TIDE and local leaders (both men and women) and were primarily based on the dissemination and uptake of cook stoves and the entrepreneurial training received by women. TIDE has trained around 200 women in Tumakuru district, mostly in the selected taluks. Around 25 women cook stove builders are very active. In Kollihatti village alone around 25 women have been trained by TIDE, of whom 16 are presently active. Some of them, like Kathyayini, have graduated to becoming master trainers, and have trained hundreds of women in Karnataka and other states.

Separate FGDs were conducted with one group of men and women from each village and the segregation was done to understand gender perceptions better and to avoid influence of perception of one on the other. Key informant interviews were conducted with women entrepreneurs and project implementers from TIDE. Specific checklists covering relevance of cook stoves in the current context, empowerment-based entrepreneurial training, financial autonomy, increased agency in terms of making decisions, and the challenges and opportunities of being cook stove entrepreneurs were used. Participation in the discussions was entirely voluntary, and prior consent was taken from the participants, who were informed about the purpose and nature of the research and format of interviews.

The study was supported by Climate Technology Centre and Network (CTCN) ${ }^{12}$ hosted jointly by the United Nations Environment Programme (UNEP) and the United Nations Industrial Development Organization (UNIDO), as part of a larger study undertaken in India and Nepal to assess the efforts to incorporate women into the value chain, specifically in the clean energy sector. Cases in the domain of grid and off-grid electrification and clean cooking were selected based on pre-determined criteria like the level of gender inclusion in different stages of the energy project cycle, namely conceptualisation, formulation, implementation and monitoring and evaluation.

\section{Results and discussion}

Shivasandra and Kollihatti are two of the several villages in rural Tumakuru that still depend on inefficient and polluting stoves to meet their primary cooking requirements. This is despite the fact that more than three million LPG 
KARNATAKA

ADMINISTRATIVE DIVISIONS 2011

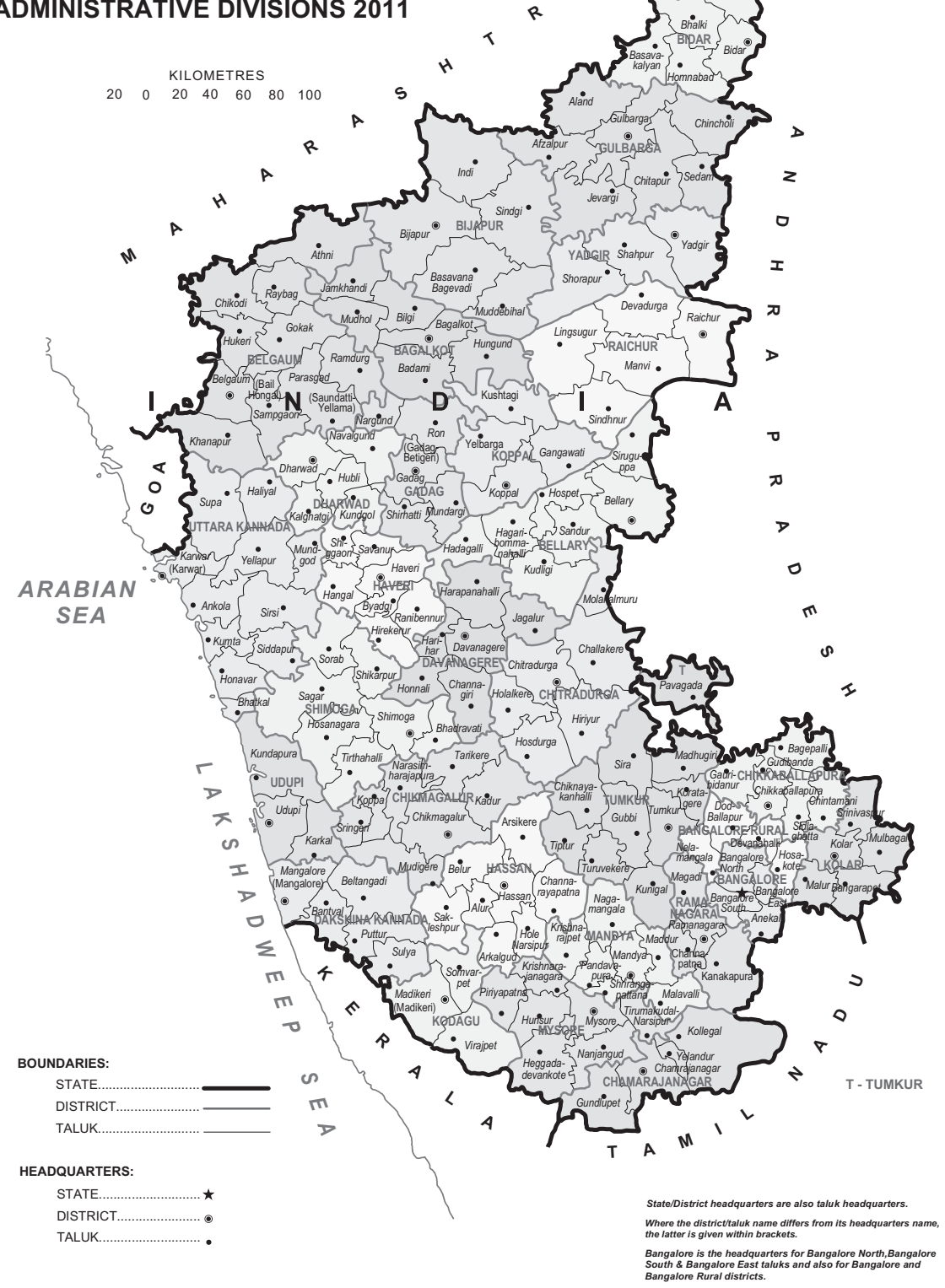

Figure 7.2 Map of Karnataka with administrative divisions. 
connections have been released in Karnataka (till July 2019) under the Ujjwala scheme (PMUY, 2019). This is in part due to inability of the consumers to afford LPG refills, and due to traditional behavioural preferences for food cooked on traditional mud stoves. Agriculture and allied activities, which form the primary source of employment for the village community, were also the highest contributor to the district GDP in 2012-2013. ${ }^{13}$ The female workforce participation in rural areas of Tumakuru is notably high, at $44 \%$, many of whom are cultivators and agricultural labourers. However, the relatively stagnant agriculture sector is facing declining prospects for stable and remunerative employment opportunities for both men and women. Even the per capita income of farmers cultivating high value flower crops formed only $53 \%$ of India's per capita income, while those growing food crops earned only 28\% of India's per capita income (2012-2013). Off-farm employment also contributed significantly to the income of farmers in the district. Tumakuru's proximity to Bangalore (the state capital) also contributed to people looking towards non-farm employment having more economic prospects than the farm sector (Jamakhandi, 2014).

Tumakuru has an equal population of upper caste, who are socially and economically privileged, and do not qualify for most of the affirmative action schemes operated by the government of India, and lower castes and tribes which receive support from the government for their social and economic upliftment. Prominent castes of Tumakuru include Lingayat and Vokkaligas, Other Backward Classes (OBC) like Golla, Kuruba, Thigala, Ediga, Uppara and SC/ST like Madiga and Holeya, which are also spread across the district.

\section{Effects of entrepreneurial-based empowerment training}

Although Tumakuru has actively been a part of PMUY, the recurring cost of LPG for low-income families was putting pressure on household budgets. An efficient stove that could be fuelled with cost-free available biomass was thus still attractive. For instance, the Gubbi taluk has the highest forest cover in the district and availability of biomass is of least concern. Hence the households chosen by TIDE for dissemination of Sarala stoves are the ones that are unable to afford LPG cylinders and the recurring costs of refills. Awareness campaigns were conducted in the villages to educate the community about the need to transition from polluting to clean cooking technologies. As Sarala stoves resemble traditional mud stoves, women did not have to make any behavioural changes in accepting them. Users sufficiently value the advantages of the improved stoves if it is an attractive wellengineered version of a traditional technology (Shrimali et al., 2011). Once $80 \%$ of the households of a village shifted to smokeless stoves, it got the tag of "Smokeless Village". Studies have also indicated that high-performing biomass stoves can be a transitional or interim solution even when infrastructure barriers prevent access to the cleanest options (WHO, IEA, GACC, UNDP, World Bank, 2018).

Moreover, TIDE has clearly recognised that achieving clean cooking solutions is not just dependent on dissemination of clean cook stoves but also through 
the full inclusion of women through the entire value chain. Evidence also suggests that women can play a critical role in the promotion, sale and adoption of improved cook stoves due to their roles and experience as primary cooks in the household and leveraging their existing networks (Köhlin et al., 2011). In the recent past, there has been an expansion of efforts to use women entrepreneurs to market and distribute clean cooking solutions through women's advocacy groups and women's networks to increase distribution and sales (Global Alliance for Clean Cook stoves, 2011). Hence the programme engaged the most motivated women in the villages, irrespective of their socio-economic background, to become entrepreneurs in an in-depth training programme developing their confidence, product knowledge, and business skills, including stove building, sales, marketing, servicing and accounting. The training revolved around skill building with a strong focus on enhancing leadership qualities. It also sought time commitment from women to carry forward the entrepreneurial opportunities. Studies have also demonstrated that when trainings follow a focused approach like being agency-based, there is substantial increase in women's capacity and willingness to identify and pursue economic opportunities and build strong relationship skills (Shankar et al., 2015b).

In a bid to form progressive civility, women belonging to social groups like Scheduled Caste (Madiga, Holeya) and Scheduled Tribes received training along with women belonging to the dominant Lingayat and Vokkaliga communities. In order to be able to induct women for training, continuous efforts at creating awareness were undertaken by TIDE. These efforts were successful in bringing women, across social strata, together for availing entrepreneurship and livelihood prospects. Caste-free association can be even otherwise noticed in the village, especially in public spheres such as participation in panchayat, ${ }^{14}$ MGNREGA $^{15}$ and other development programmes. Successful trainees are provided moulds required for making the Sarala cook stoves. The cook stove entrepreneurs are then equipped to go from house to house for cook stove construction, and one stove builder can construct three to five stoves in a day. Experienced entrepreneurs have also become trainers and train other women to become entrepreneurs. The programme is now managed by a group of 15 women entrepreneurs, who handle everything from raw materials, construction, operation and maintenance and marketing, after the initial hand-holding by TIDE.

Training imparted to women cook stove builders has empowered them to position themselves to play a crucial role in increasing awareness and demand for clean cooking by leveraging women-to-women communication strategies. This kind of intervention has been particularly beneficial since studies have indicated that, at the entrepreneurial level, women's participation in the energy sector is constrained by many of the gender-specific challenges, notably access to credit and ownership of property and other assets (Baruah, 2015). This is in spite of an array of programmatic efforts that have been targeted at realising greater involvement of women in supply-side operations (Ramani \& Heijndermans, 2003). Hence, this consignment model has lowered the barriers to entry, allowing women from economically underprivileged households to become cook 
stove entrepreneurs. Other studies have also emphasised TIDE's model as a good example aimed at promoting entrepreneurial and livelihood opportunities for women (Global Alliance for Clean Cookstoves, 2013). Moreover, the imperative to engage women in energy entrepreneurship is especially great due to an essentialist belief that "household energy is a woman's concern" (Khamati-Njenga \& Clancy, 2003, p. 38). Nevertheless, this initiative has tapped the aspirational quotient among the otherwise socially marginalised groups like SC/ST/OBC to break the shackles of hereditary and hierarchical principles of enforced occupational and labour identities and take up cook stove building as an income generating opportunity.

The programme proved to be effective in creating additional livelihood opportunities for successful women stove builders, who were otherwise constrained by insufficient income and the seasonal nature of agriculture. Financial autonomy made the women entrepreneurs less dependent on their husbands or other male members of the family for their material wellbeing. On average, women earned around 70 USD a month and were able to exercise more agency at an individual level where they could control the profits they made, but were also able to communicate, negotiate and participate in the mundane household responsibilities. They even influenced household decision making as a result of improved bargaining power. These findings from the study resonate with the findings of the study by Johns Hopkins University, Babson College and ICRW (2019) which clearly state that, at the household level, social norms may begin to shift as women are able to contribute to household earnings and are also able to negotiate with their partners and participate in household decision making (Johns Hopkins University, Babson College and ICRW, 2019). Moreover, the women did gain some respect within the household and their extended families due to engaging in roles that involved physically moving throughout the community and interacting with diverse community members. An extensive literature review conducted by ENERGIA found many examples where women's empowerment increased as a result of participation in energy projects (ENERGIA, 2006).

This kind of proactive initiative, which concentrated not only on skill building but also on the ability of women to pursue entrepreneurial activities, is particularly relevant because, despite early efforts to include women throughout the improved cook stove value chain, the marketing and sales force remains dominated by men (Ramanathan \& Carmichael, 2008). Data from Global Entrepreneurship Monitor, Women's Report (2013) has noted that in every economy sampled, women had lower capability perceptions and greater fear of failure compared with men. Moreover, women disproportionally face psychosocial challenges that impede their self-efficacy, motivation, and drive to take on new endeavours (Chegini, 2010).

This initiative qualifies to be termed as successful in addressing the urgency of clean energy transition by reaching consumers who were enrolled for PMUY but were reluctant to avail LPG refills due to economic reasons. A recent study on LPG adoption and impact of PMUY in rural Karnataka suggests that though many consumers enrolled for the scheme, it is not matched by the sales of LPG 
cylinders (Kar et al., 2019). The study also finds that LPG refills remain low in rural Karnataka, especially among PMUY beneficiaries. Other studies have also demonstrated that women have the potential to increase sales and adoption when provided with other empowerment training like agency-based training (Shankar, et al., 2015a).

Hence, by leveraging women's ability to reach remote consumers, this initiative by TIDE has been able to increase access to energy and empower women at the same time.

\section{Socio-cultural norms: caste and gender}

TIDE's intervention, which enabled financial autonomy for women cook stove builders, also posed several challenges for them within the village community. The caste of certain women cook stove builders became a hindrance for them in terms of business opportunities. Though Constitution and emergence of human rights norms have eroded the legitimacy of caste-based discrimination, it is silently practised in several parts of the country, including the study villages. For instance, certain occupations like barber and cobbler amongst others are carried out exclusively by members of certain castes even today. Likewise, heterogeneity in caste preference for marriage is not acceptable and the decisions of match making are managed by parents. However, it is also interesting to note that there is an increasing process of "sanskritisation" in the villages, which is exemplified by the convergence in habits, practices, festivals and rituals, towards the direction of the upper caste. Also there is no discrimination in the use of public utilities like stand posts and hand pumps across caste categories.

Nevertheless, the silent or invisible practices of caste discrimination in the community became evident when women cook stove builders of lower castes were not allowed to enter kitchens of upper-caste households to build cook stoves. Kitchens and food in Indian (mostly Hindu) culture are associated with purity, and the presence of lower-caste people in the kitchen, who were in older times considered impure, is still considered to defile the purity of the place. ${ }^{16}$ A study on caste discrimination in rural Karnataka showed maximum number of respondents from the study sample of Tumakuru did not allow people of lower castes to enter kitchens of upper-caste households (Maruthi \& Peter, 2018). Hence, the women cook stove builders had to face this socially constructed hierarchical bias in their jobs as they were allowed only to enter kitchens and build stoves for members of their own caste and not others. Hence at an individual level, women of lower castes occasionally suffered disproportionately from psychological disempowerment.

Such discrimination was also seen between the prominent Lingayat and Vokaliga communities, the main reason being the difference in food habits practised by the communities. Vokaligas, who are principally non-vegetarians, are afraid to enter the kitchen of vegetarianism practicing Lingayat due to the notional concept of "purity".

Expressing her views as a cook stove builder, Hemalatha from Shivasandra village said, "can you even believe that in spite of the fact that we celebrate festivals and fairs together, I am not allowed to build stoves in the Lingayat households just 
because we are non-vegetarians?" She further added that, "even though am a proud Vokaliga, such discrimination by fellow Lingayats in such matters is really hurtful".

Due to these notions of purity and impurity, the women entrepreneurs found it more beneficial to work in villages other than their own where their caste identities could easily be camouflaged and be less marked by exclusion, and also where they were identified more for their work. It may also be due to the relatively higher degree of mobility enjoyed by women of lower castes than those of upper castes, where customs are more orthodox and restrictive, especially in terms of women's mobility. Earlier studies have noticed that increased caste status is associated with a greater subordination of rural women (Banerjee \& Raju, 2009; Eswaran, Ramaswami \& Wadhwa, 2013; Joshi et al., 2017) and this is even indicated in lower levels of labour force participation by them. On the other hand, women from low-status castes display higher labour force participation rates, fewer patriarchal restrictions on mobility and greater decision-making autonomy (Chen, 1995; Kapadia, 1995; Eswaran, M., Ramaswami, B., \& Wadhwa, W., 2013). However, a related argument is that increase in wealth and income among low-ranked castes can have a negative impact on the status of women: as these castes emulate the customs, practices and patriarchal codes of higher-ranked castes, women become disempowered (Srinivas, 1977) and it also brings status-enhancing restrictions on their mobility and decision making (Still, 2017; Deshpande, 2017).

Conversely, in the study villages, the factors of masking caste identity have helped lower-caste women escape the discrimination experienced back home and enjoy new freedoms and formerly denied social honour by working as cook stove builders in the neighbouring villages. Hence, some of the most productive entrepreneurs of the lower castes accessed markets beyond their immediate locality and this also resulted in far-reaching stove diffusion. Studies have also shown that migrants could experience better working conditions with mixed caste groups and forge better relations with them (Mosse, 2018). However, the study does not indicate that the lower-caste women entrepreneurs have managed to improve their collective social standing within the village of their origin.

For an organisation like TIDE, which strives to bring changes through women's entrepreneurship and subsequent empowerment through designing market and policy initiatives, which give women from all background an opportunity to become entrepreneurs, neutralising the influence of repressive caste- based norms and its undesirable outcomes becomes a difficult proposition.

\section{Empowerment and social change}

The stove builders of the study villages are prime examples of how entrepreneurship-based empowerment training and personal initiative could potentially increase women's abilities to be successful energy entrepreneurs. However, while the women cook stove builders discharged their duties effectively in their own and neighbouring villages, they did not anticipate another challenge - pre-existing gender norms, which are often discriminatory towards women. Such norms follow from long-standing traditions of patriarchy, which dictate standards of 
morality and behaviour for women, to mould them into socially acceptable ideals of a "good woman". As the stove builder programme involved routine travel for women to other villages and even states to receive and to impart training, initial reluctance came from the women themselves as they feared the opinion of society. Patriarchal societies often label women as "loose" and cast aspersions on their character for moving freely, without being accompanied by male or older female relatives (Batliwala et al., 1998).

Shivamma, a successful cook stove builder and a mother of two opined that, "While I was excited to be a cook stove builder, my initial fear was what people will say? I hail from a respectable family". Another cook stove builder, Jayamma, couldn't agree more. She commented, "Appropriate social behaviour for women is always decided by men, and women are just expected to be obedient and submissive".

Slander on women's conduct also happened when male members from TIDE's team accompanied them to outstation trainings. TIDE's team being gender diverse would have both men and women accompanying the cook stove builders for outstation visits. However, men travelling with women irrespective of their caste background were not appreciated by the community. Gupte (2013) observes that honour is largely centred on the behaviour of women and as Welchman \& Hossain (2005) argue, is vested in male control over women and specifically women's sexual conduct. Although concerns regarding the safety of women cook stove builders while travelling were also raised, unwanted moral judgements were made on the conduct of these women disregarding the women's own notions of propriety, morality and appropriate social behaviour. Scholarly work has also clearly indicated that while male honour rests on their ability to control women's bodies (Rao, 2018; Hebbar, 2018), female honour entails conforming to appropriate and sanctioned roles and codes of conduct (Still, 2011; Grover, 2011). All these problematic and contentious concepts of women's honour directly and indirectly reinforced the patriarchal conservatism in the study villages and dissuaded some of the stove builders from expanding their geography of work and pursuing newer avenues.

Women cook stove builders, hence, were constrained by social norms of defined honour morality, imposed on them beyond their households, which dictate their roles and behaviours, their ability to make choices, achieve their goals, and control their lives. These factors limited the space for women to exercise their newly acquired empowerment through entrepreneurship. Moreover, the notion of economic empowerment becomes relative and dependent on their positioning within the larger milieu of gender norms. Such instances reveal how deeply entrenched norms do not get dispelled despite progress on other indicators of social development such as a high literacy rate (around $75 \%$ for Tumakuru). Other studies have also clearly revealed that social empowerment is still hindered by factors like intra-household dynamics, women's traditional positions in society and other restrictive social norms, and could off-set the economic impacts of empowerment training such as increasing their skill set and market linkages (ILO, 2017).

Overall, the programme has been successful in adding value to the emerging energy justice debate by empowering women as entrepreneurs and simultaneously 
addressing the issue of urgency of clean energy transition through successfully diffusing clean cook stoves. The increased empowerment of women within the household was, however, not reflected in the wider community due to compounding constraints based on caste or perceived morality and at times resulted in social ostracisation. Nonetheless, trained women from all caste groups continue to be entrepreneurs and have experienced economic empowerment. As the programme pays sufficient attention to scalability to serve a larger customer base, it continues to attract women to enroll in their entrepreneurial trainings. Therefore, more opportunities need to be created for women in all quarters to bring about structural changes in their social position.

\section{Conclusion}

By building women's ability to become energy entrepreneurs, TIDE attempted to effectively address the urgency of transitioning to clean energy and empowerment of women at the same time. This furthered efforts to create just energy systems by transforming benefits to the household and individuals. Women's ability to earn their own income also increased their sense of status and bargaining power within the household and their agency to accumulate autonomous assets.

However, the existing and endured caste-based contexts permeated into everyday life and determined the endowments and opportunities available to women and constrained their agency beyond household. Although TIDE trained women as stove builders and master trainers from all communities, in a bid to form progressive civility in a seemingly caste discrimination-free community, in practice the trained women could not be agents for the elimination of caste practices, but rather became inadvertent actors in their reconstitution. While it is commonly accepted that caste is monopolistically practised in the "private space", women cook stove builders had to face this hierarchical bias in their jobs in the form of exclusion as they were allowed only to enter kitchens and build stoves for members of their own caste and not others. As a result, women cook stove builders were forced to go to other neighbourhoods or regions where their caste identity could easily be camouflaged.

Women cook stove builders also encountered another peculiar challenge when they had to travel outstation for trainings, along with men from TIDE. While concerns were raised about safety and security, moral judgements were also made on their conduct since they are expected to be bearers of the honour of the family and the community. The so-called female honour which entailed conforming to appropriate and sanctioned roles and codes of conduct disregarded women's own notions of propriety, morality, and appropriate social behaviour. Hence, such "concerns" often resulted in reduced mobility for women and hampered broadening their horizons.

In societies that are characterised by spatially distributed caste practices and where gender prejudices are disguised as concerns, bringing in social change by just introducing technological solutions and creating entrepreneurial opportunities for women may seem to be a difficult and highly optimistic proposition. For an organisation like TIDE, which strives to bring changes through women's 
entrepreneurship and subsequent empowerment, addressing such entrenched caste and patriarchal control may not be an immediate possibility. Nevertheless, the noble goal of creating women entrepreneurs should not be abandoned; rather it should hinge on more inputs from various quarters including state and society to bring about concrete transformative changes, since gender norms are not static or timeless social structures but a shifting complex of social relationships.

\section{Acknowledgement}

We thank Climate Technology Centre \& Network (CTCN) for supporting this study and Ms Shanar Tabrizi, Knowledge Management Specialist, CTCN for her valuable input during the course of the study. We are also grateful to Ms Dhairya Dholakia, Mr Amit Kumar and Dr Debajit Palit, TERI, for their continued guidance and support.

\section{Notes}

1 Any type of cooking is considered to be safe if it is more fuel efficient and/or emissions meet WHO guidelines. Currently available options that can be considered clean include: electricity, renewable energy (solar), Liquid Petroleum Gas (LPG) and highest performing biomass stove. Most of the high performing biomass stoves may often not meet the WHO guidelines, but offer some benefits and can be a transitional or interim solution when different forms barriers prevent access to the cleanest options.

2 https://pmuy.gov.in

3 www.seforall.org/interventions/big-markets-for-clean-fuels

4 Below Poverty Line.

$51 \mathrm{INR}=0.014$ USD (as on 7 September 2020).

6 Caste or jati is believed to have originated from the Varna system (roughly 3000 years old) where the society was categorised into mutually exclusive, endogamous, hereditary and occupation specific groups: Brahmans (the priests and teachers), Kshatriyas (warriors and royalty), Vaisyas (traders, merchants, and businessmen) and Sudras (all manual jobs) at the bottom.

$7 \mathrm{http}$ //hdr.undp.org/en/content/gender-development-index-gdi

8 Sanskritisation is a process of imitation by which a lower caste or tribe or any other group changes its customs, rituals, ideology and way of life in the direction of a higher or more often twice-born caste (Srinivas, 1995).

9 As with any affirmative actions, caste-based quotas are mired in controversy, where scholars have argued for upholding of meritocratic values as well as raised the need for reservation for economically weaker sections irrespective of caste background.

10 Sociological abstracts have quoted that the proportion of studies that rely solely on focus groups has been increasing in recent years (Morgan, 1996).

11 Taluk: sub-division of district.

12 For details, please visit www.ctc-n.org

13 www.investkarnataka.co.in/district-profiles-tumakuru

14 Panchayat or Village Council refers to an elected body at the village level for local selfgovernance.

15 The Mahatma Gandhi National Rural Employment Guarantee Act (MGNREGA), enacted in 2005, provides legal right to wage employment for guaranteed 100 days a year, to rural households. 
16 Discrimination is also prevalent in Indian Christianity. The Hindu Dalits converted to Christianity continue to be referred to by their caste names. Conversion to Christianity has not changed the social condition of the Dalits. Prakash Louis. (2007). Dalit Christians: Betrayed by State and Church. Economic and Political Weekly, 42(16), 1410-1414. Retrieved April 28, 2020, from www.jstor.org/stable/4419488

\section{References}

Agarwal, B., 1992. The Gender and Environment Debate: Lessons from India. Feminist Studies, 18(1), pp. 119-158.

Agarwal, B., 1997. Gender, Environment, and Poverty Interlinks: Regional Variations and Temporal Shifts in Rural India, 1971-1991. World Environment, 25(1), pp. 23-52.

APEC, 2019. Empowering Women as Managers. Germany: Renewables Academy (RENAC) AG.

Bandyopadhyay, M., \& Subrahmanian, R., 2008. Gender Equity in Education: A Review of Trends and Factors. Brighton, UK: Consortium for Educational Access, Transitions and Equity (CREATE).

Banerjee, M., 2019. Increasing the Share of Cleaner Cooking Among Rural Households of India [Online]. Available at: https://www.orfonline.org/expert-speak/increasing-the-s hare-of-cleaner-cooking-among-rural-households-of-india-50882/.

Banerjee, A., Bertrand, M., Datta, S., \& Mullainathan, S., 2009. Labor Market Discrimination in Delhi: Evidence from a Field Experiment. Journal of Comparative Economics, 37(1), pp. 14-27.

Banerjee, A., \& Raju, S., 2009. Gendered Mobility: Women Migrants and Work in Urban India. Economic and Political Weekly, 44(28), pp. 115-123. www.jstor.org/stable /40279264.

Baruah, B., 2015. Creating Opportunities for Women in the Renewable Energy Sector: Findings from India. Feminist Economics, 21(2), pp. 53-76. doi:10.1080/13545701.2 014.990912 .

Batliwala, S., Anitha, B., Gurumurthy, A., \& Wali, C.S., 1998. Status of Rural Women in Karnataka. Bangalore: National Institute of Advanced Studies.

Bhogle, S., 2003. Rural Women as Agents of Improved Woodstove Dissemination: A CaseStudy in Huluvangala Village, Karnataka, India. Energy for Sustainable Development, 7(3), pp. 70-75.

Bhojani, U., Madegowda, C., Prashanth, N.S., Hebbar, P., Mirzoev, T.,; Karlsen, S., \& Mir, G. 1., 2019. Affirmative Action, Minorities, and Public Services in India: Charting a Future Research and Practice Agenda. Indian Journal of Medical Ethics, 4(4), pp. 265-273.

Bolton, S., 2015. Establishing a Women-Driven Clean Cookstove Distribution Network in Eastern Indonesia. Boiling Point, 66 pp. 14-17.

Borges, P., 2007. Women Empowered: Inspiring Change in the Emerging World. New York: Rizzoli.

CAG, 2019. Report of the Comptroller and Auditor General of India on Pradhan Mantri Ujjwala Yojana. s.l.: CAG.

Cecelski, E., 1995. From Rio to Beijing: Engendering the Energy Debate. Energy Policy, 23(6), pp. 561-575.

CEEW, 2017. Access to Clean Cooking Energy In India. State of the Sector. New Delhi: CEEW. 
Chandrashekhar, C., \& Ghosh, J., 2014. Are Our Labour Markets Less Segmented Now? Published in The Hindu Business Line [Online]. Available at: https://www.thehindu businessline.com/opinion/columns/c-p-chandrasekhar/Are-our-labour-markets-less-s egmented-now/article20721274.ece [Accessed 3103 2020].

Chatterjee, R. et al., 2019. The Real Story of Women's Financial Inclusion in India. New Delhi: Microsave Consulting.

Chegini, M., 2010. Study of Relation of Psychological Factors of Empowerment and Entrepreneurship. American Journal of Economics and Business Administration, 2(1), pp. 86-89.

Chen, M., 1995. A Matter of Survival: Women's Right to Employment in India and Bangladesh. In Martha C. Nussbaum and Jonathan Glover (Eds.), Women, Culture and Development. Oxford: Clarendon Press, pp. 37-58

Chin, A., \& Prakash, N., 2010. The Redistributive Effects of Political Reservation for Minorities: Evidence from India. Journal of Development Economics, Elsevier, 96(2), pp. 265-277.

Clean Cooking Alliance, n.d. Resources: Five Years of Impact- 2010-2015 [Online]. Available at: https://www.cleancookingalliance.org/resources/reports/fiveyears.html [Accessed 05 March 2020].

Coir Board, 2014. Skill Upgradation and Quality Improvement Scheme [Online]. Available at: http://coirboard.gov.in/wp-content/uploads/2014/07/SchemeSUandQI. pdf.

Damodaran, H., 2008. India's New Capitalists: Caste, Business, and Industry in a Modern Nation. s.1.: Springer.

Desai, S., 2007. Gender Disparity in Primary Education: The Experience in India [Online]. Available at: https://unchronicle.un.org/article/gender-disparity-primary-educationexperience-india.

Deshpande, A., 2002. Assets versus Autonomy? The Changing Face of the Gender-Caste Overlap in India. Feminist Economics, 8(2), pp. 19-35.

Deshpande, A., 2017. Stigma or Red Tape-Roadblocks in the Use of Affirmative Action. Working papers 280. Delhi: Centre for Development Economics, Delhi School of Economics.

Deshpande, S., \& Yadav, Y., 2006. Redesigning Affirmative Action. Economic and Political Weekly, 41(24), pp. 2419-2424.

Dumont, L., 1980. Homo Hierarchicus: The Caste System and its Implications. complete English edition ed. Chicago: University of Chicago Press.

ENERGIA, 2006. From the Millennium Development Goals: Towards a Gender-Sensitive Energy Policy Research and Practice: Empirical Evidence and Case Studies. The Hague: ENERGIA.

Eswaran, M., Ramaswami, B., \& Wadhwa, W., 2013. Status, Caste, and the Time Allocation of Women in Rural India.. Economic Development and Cultural Change, 61(2), pp. 311-333. doi:10.1086/668282.

Ghosh, S., \& Vinod, D., 2017. What Constrains Financial Inclusion for Women? Evidence from Indian Micro data. World Deevelopment, 92, pp. 60-81.

Gill, B. et al., 2015. The Value of Engaging Women in the Energy Provisioning Process. A Case Study on the Shramik Bharti Experience. New Delhi: TERI.

Global Alliance for Clean Cookstoves, 2013. Scaling Adoption of Clean Cooking Solutions through Women's Empowerment: A Resource Guide. Washington, DC: Global Alliance for Clean Cookstoves.

Government of Karnataka, 2019. Economic Survey of Karnataka, 2018-19. s.1.: s.n. 
Grover, S., 2011. Marriage, Love, Caste and Kinship Support: Lived Experiences of the Urban Poor in India. New Delhi: Social Science Press.

Gupte, M., 2013. The Concept of Honour: Caste, Ideology and Patriarchy in Rural Maharashtra.. Economic and Political Weekly, 48(18), pp. 72-81.

Hall, S.M., Hards, S., \& Bulkeley, H., 2013. New Approaches to Energy: Equity, Justice and Vulnerability. Introduction to the Special Issue, Local Environment, 18(4), pp. 413-421.

Hebbar, N., 2018. Subjectivities of Suitability: 'Intimate Aspirations' in an Engineering College [Online]. Available at: https://journals.openedition.org/samaj/4578.

IEA, 2018. SDG 7: Access to Clean Cooking [Online]. Available at: https://www.iea.org/ sdg/cooking/ [Accessed 3 December 2019].

IIPS and ICF, 2017. National Family Health Survey-4, 2015-16. Mumbai: IIPS.

ILO, 2017. Empowering Young Women through Business and Vocational Training. Evidence from Rural Egypt. Impact Report Series, Issue 8. Switzerland: ILO.

India Today, 2020. International Women's Day: 5 Govt Schemes Working for Women Empowerment [Online]. Available at: https://www.indiatoday.in/education-today/gkcurrent-affairs/story/international-women-s-day-5-govt-schemes-working-for-women -empowerment-1653587-2020-03-08 [Accessed 31 March 2020].

IRADE, 2009. Gender Analysis of Renewable Energy in India: Present Status, Issues, Approaches and New Initiatives. s.1.: IRADE.

Jaffrelot, C., 2006. The Impact of Affirmative Action in India: More Political than Socioeconomic. India Review, 5(2), pp. 173-189. doi:10.1080/14736480600824516.

Jamakhandi, B.R., 2014. Economic Analysis of Agricultural Transformation Process in Karnataka Towards Inclusive Growth. PhD Thesis, University of Agricultural Sciences, Bangalore.

Jayal, N.G., 2014. Affirmative Action in India: Before and After the Neo-Liberal Turn. Sage Journals, 27(1), pp. 117-133.

Jeffrey, R. \& Basu, A. M., 1996. Girls' Schooling, Women's Autonomy and Fertility Change in South Asia. Health Transition Review, 6(2), pp. 231-233 .

Jenkins, K., McCauley, D., \& Forman, A., 2017. Energy Justice: A Policy Approach. Energy Policy, 105, pp. 631-634.

Jodhka, S., \& Manor, J., 2017. Introduction. In Jodhka S. \& Manor J (Eds.), Contested Hierarchies, Persisting Influence: Caste and Power in Twenty-First Century India. Hyderabad: Orient Black Swan, pp. 1-38.

Johns Hopkins University, Babson College and ICRW, 2019. Women's Energy Entrepreneurship: A Guiding Framework and Systematic Literature Review. Research Report RA7. The Hague: ENERGIA, International Network on Gender and Sustainable Energy.

Joshi, S., Kochhar, N., \& Rao, V., 2017. Are Caste Categories Misleading? Relationship between Gender and Jati in Three Indian States. Working Paper. s.1.: The World Bank, Policy Research Working Paper 8109.

Kabeer, N., 2000. Social Exclusion, Poverty and Discrimination Towards an Analytical Framework. IDS Bulletin, 31(4), pp. 83-97.

Kaletski, Elizabeth, \& Prakash, Nishith, 2016. Affirmative Action Policy in Developing Countries: Lessons Learned and a Way Forward, WIDER Working Paper, \# 2016/52, ISBN 978-92-9256-095-9. Helsinki: The United Nations University World Institute for Development Economics Research (UNU-WIDER).

Kapadia, K., 1995. Siva and Her Sisters: Gender, Caste, and Class in Rural South India. Boulder, San Francisco/Oxford: Westview Press. 
Kapoor, M. et al., 2019. Missing Female Patients: An Observational Analysis of Sex Ratio Among Outpatients in a Referral Tertiary Care Public Hospital in India. BMJ Open, 9(8): e026850. doi: 10.1136/bmjopen-2018-026850

Kapur, D., Prasad, C.B., Pritchett, L., \& Babu, D.S., 2010. Rethinking Inequality: Dalits in Uttar Pradesh in the Market Reform Era. Economic andPolitical Weekly, 45(35), pp. 39-49.

Kar, A., Pachauri, S., Bailis, R., \& Zerriffi, H., 2019. Using Sales Data to Assess Cooking Gas Adoption and the Impact of India's Ujjwala Programme in Rural Karnataka. Nature Energy, 4, pp. 806-814.

Karanth, G., 1996. Caste in contemporary rural India. Caste: Its Twentieth Century Avatar, pp. 87-109.

Khamati-Njenga, B., \& Clancy, J., 2003. Concepts and Issues in Gender and Energy. s.1.: Energia.

Khera, P., 2018. Closing Gender Gaps in India: Does Increasing Womens' Access to Finance Help? IMF Working Paper, p. WP/18/212.

Köhlin, G., Sills, E., Pattanayak, S.K., \& Wilfong, C., 2011. Energy, Gender and Development: What are the Linkages? Where is the Evidence?. Background Paper to the 2012 World Development Report, The World Bank.

Kohlin, G., Sills, O., Pattanayak, S., \& Wilfong, C., 2011. Energy, Gender and Development: What are the Linkages? Where is the Evidence? Social Development Working Paper. \# 125. Washington, DC: World Bank.

Lockhart, S., 2013. Green Social Entrepreneurship as a Poverty Reduction Strategy. TIDE India's Use of Technological Innovation for Healthier and More Sustainable Communities. In: J.Heyman \& M. Barrera, ed. Ensuring a Sustainable Future: Making Progress on Environment and Equity. s.1.:Oxford University Press, pp. 112-135.

Maldonado, M. et al., 2013. Focus Group Discussion as Tool to Study Gender Relations in Urban Community Members. Enfermería Y Perspectiva De Género, 29, pp. 450-462.

Maruthi, I., \& Peter, P., 2018. Caste Discrimination Practices in Rural Karnataka; Working Paper 418. The Institute for Social and Economic Change.

Ministry of Social Justice and Empowerment, n.d. Schemes and Programmes [Online]. Available at: http://socialjustice.nic.in/SchemeList/index?mid=24541.

Ministry of Tribal Affairs, n.d.. Schemes Guidelines [Online]. Available at: https://tribal .nic.in/Schemes.aspx.

Ministry of Women and Child Development, n.d.. Women Empowerment Schemes [Online]. Available at: https://wcd.nic.in/schemes-listing/2405.

Moradhvaj \& Saikia, N., 2019. Gender Disparities in Health Care Expenditures and Financing Strategies (HCFS) for Inpatient Care in India. SSM-Population, 9. https://do i.org/10.1016/j.ssmph.2019.100372.

Mosse, D., 2018. Caste and Development: Contemporary Perspectives on a Structure of Discrimination and Advantage. World Development, 110, pp. 422-436.

Munshi, K., 2017. Caste and the Indian Economy. Cambridge Working Papers in Economics: 1759 [Online]. Available at: https://www.repository.cam.ac.uk/bitstream /handle/1810/286669/cwpe1759.pdf?sequence=1 [Accessed 104 2020].

Murthi, M., Guio, A.-C. \& Drèze, J., 1995. Mortality, Fertility, and Gender Bias in India: A District-Level Analysis. Population and Development Review, 21(4), pp. 745-782.

One World Foundation India, 2011. Sarla Stoves: Fuel Effivcient Stove Dissemination Programme [Online]. Available at: https://oneworld.net.in/wp-content/uploads/gkc _oneworld_sarla_stove_dissemination_programme.pdf [Accessed 0503 2020]. 
Pearl-Martinez, R., 2014. Women at the Forefront of the Clean Energy Future. White Paper- Initiative Gender Equality for Climate Change Opportunities(GECCO). Washington, DC: IUCN-USAID.

PMUY, 2019. State-Wise PMUY Connections Released [Online]. Available at: https://pm uy.gov.in/released-connections.html.

Practical Action, 2014. Gender and Livelihoods Impacts of Clean Cookstoves in South Asia [Online]. Available at: https://cleancookstoves.org/binary-data/RESOURCE/file /000/000/363-1.pdf.

Price, R., 2019. The Benefits of Involving Women in Energy System Supply Chains. Policy Brief \#3. s.1.: ENERGIA.

Rajeshwari, 1996. Gender Bias in Utilisation of Health Care Facilities in Rural Haryana.. Economic and Political Weekly, 31(8), pp. 489-494.

Ramanathan, V., \& Carmichael, G., 2008. Energy, Poverty and Gender: A Synthesis. Washington, DC: World BAnk.

Ramani, K., \& Heijndermans, E., 2003. Energy Poverty and Gender: A Synthesis. Washington, DC: The World Bank. https://www.esmap.org/sites/esmap.org/files/Rpt _GBL_EnergyPovertyGender.pdf.

Rao, N., 2018. Fertility, Reproduction and Conjugal Loyalty: Renegotiating Gender Relations amongst Dalits in Rural Tamil Nadu [Online]. Available at: https://journals .openedition.org/samaj/4575.

Rao, N., Verschoor, A., Deshpande, A., \& Dubey, A., 2007. Gender Caste And Growth Assesment- India. s.1.: School of Development Studies- the Overseas Development Group.

Riser-Kositsky, S., 2009. The Political Intensification of Caste: India Under the Raj. Penn History Review, 17(1, Article 3.), pp. 31-53.

Saikia, N., Moradhvaj, \& Bora, J.K., 2016. Gender Difference in Health-Care Expenditure: Evidence from India Human Development Survey. Plos One, 11(7), p. e0158332. doi:10.1371/journal.pone.0158332.

Selco Foundation, 2017. Clean cooking: Pre - Evaluation on TIDE Sarala Stoves \& Possible Firewood Cook Stove Alternatives [Online]. Available at: https://selcofoundat ion.org/wp-content/uploads/2017/03/Evaluation-of-TIDE-Sarala-Stove-and-Alternati ves.pdf [Accessed 0503 2020].

Shankar, A.V., Onyura, M.A., \& Alderman, J., 2015a. Agency-Based Empowerment Training Enhances Sales Capacity of Female Energy Entrepreneurs in Kenya. Journal of Health Communications, 20(sup1), pp. 67-75. doi:10.1080/10810730.2014.1002959.

Shankar, A.V., Onyura, M.A., Ojode, M., \& Millam, E., 2015b. Fostering Agency and Wellbeing in Women: An Evaluation of the IMAGINE Initiative. Development Practice, 25(3), pp. 375-388. doi:10.1080/09614524.2015.1016868.

Shell Foundation, 2020. Insights on Engaging Rural Women in Energy Value Chain. s.1.: Shell Foundation.

Shrimali, G., Slaski, X., Thurber, M.C., \& Zerriffi, H., 2011. Improved Stoves in India: A Study of Sustainable Business Models. Energy Policy, 39(12), pp. 7543-7556.

Smith, K., \& Dutta, K., 2011. Cooking with Gas. Energy for Sust Dev, 15, pp. 115-116.

Smith, K.R., 2017. Editorial: Why Both Gas and Biomass are Needed Today to Address the Solid Fuel Cooking Problem in India: A Challenge to the Biomass Stove Community. Energy for Sustainable Development, 38, 102-103.

Sovacool, B., Heffron, R., McCauley, D., \& Goldthau, A., 2016. Energy Decisions Reframed as Justice and Ethical Concerns. Nature Energy, 1, p. 16024. 
Srinivas, M., 1977. The Changing Position of Indian Women. Man, 12(2), pp. 221-238..

Still, C., 2011. Spoiled Brides and the Fear of Education: Honour and Social Mobility among Dalits in South India.. Modern Asian Studies, 45(5), pp. 1119-1146.

Still, C., 2017. Dalit Women: Honour and Patriarchy in South India. New Delhi: Vikram Jain Books.

Swain, S.S., \& Mishra, P., 2020. Determinants of Adoption of Cleaner Cooking Energy: Experience of the Pradhan Mantri Ujjwala Yojana in rural Odisha, India. Journal of Cleaner Production. doi:10.1016/j.jclepro.2019.119223.

The Economic Times, 2019. Lok Sabha clears 124th Constitution Amendment Bill to give quota for general category. [Online] Available at: https://economictimes.indiatimes.co $\mathrm{m} /$ news/politics-and-nation/lok-sabha-clears-124-constitution-amendment-bill-to-give -quota-for-general-category/articleshow/67441684.cms?from=mdr

Welchman, L., \& Hossain, S., 2005. 'Honour,' Rights and Wrongs. In (Eds) L. Welchman \& S. Hossain, "Honour": Crimes, Paradigms, and Violence against Women. London: Zed Books, pp. 1-21.

WHO, IEA, GACC, UNDP, World Bank, 2018. Policy brief \#2: Achieving Universal Access to Clean and Modern Cooking Fuels and Technologies. s.l.: Department of Sustainable Development, UNDESA.

World Bank, 2011. Household Cookstoves, Environment, Health, and Climate Change: A New Look at an Old Problem. s.1.: World Bank.

WWF, 2018. Each Stove a Story of Change. Taking the Pressure Off Forests with Fuel Efficient Stoves [Online]. Available at: https://www.wwfindia.org/news_facts/feature_s tories/each_stove_a_story_of_change.cfm [Accessed 0503 2020].

WWF, n.d. Featured Stories [Online]. Available at: https://www.wwfindia.org/news_facts /feature_stories/each_stove_a_story_of_change.cfm [Accessed 0503 2020]. 


\title{
8 "Women don't ride bicycle[s], only men ride bicycles"
}

\section{Gender and justice in mobility transitions}

\author{
Mary Greene and Anne Schiffer
}

\section{Introduction}

It is increasingly recognised that energy is a deeply social issue, reflected in the concept of "just transitions" that has emerged over the past decade (Agyeman, 2013; Shove and Walker, 2014). Yet, the intersection of gender and energy needs to be better understood, especially from a lived experience perspective (Anfinsen and Heidenreich, 2017; Greene, 2018b; Schiffer, 2020). Everyday mobility practices constitute a key domain of daily energy demand and are of central relevance to questions of sustainable development. However, debates on energy access have thus far been heavily focused on techno-centric and decontextualised accounts of electricity as a driving force of development. This emphasis is also enshrined in the United Nations Sustainable Development Goal 7, which envisions "access to affordable, reliable, sustainable and modern energy for all" (Wu and Wu, 2015). Here, the term modern energy is predominantly used to describe access to electricity and clean cooking fuels. However, a much wider range of daily activities, including everyday mobility practices such as car driving and cycling, are intertwined with energy access and resource use. As a consequence of the policy silos in which energy-related decision-making takes place, the nexus between access to modern energy and mobility in daily life has been largely overlooked (Schiffer, 2020; SEforAll, 2019). As Schiffer (2020: 4) highlights: electricity targets "are commonly set in isolation from transport strategies ... an issue that transcends both industrialised and developing world contexts. Yet in everyday life different dimensions of energy are all experienced as part of the same system".

Recent advances in practice-centred energy research have sought to move beyond decontextualised approaches to highlight energy consumption as centrally implicated in people's participation in a range of everyday social practices (cf. Giddens, 1984; Schatzki, 1996; Warde, 2005). In the context of connecting energy and mobility, practice approaches have revealed the ways in which energy-intensive mobility modes (e.g. car driving) and low-carbon modes (e.g. cycling) allow socially valued practices to be accomplished (Cass and Faulconbridge, 2016; Shove et al., 2015). Examples include performing domestic roles, getting to work and school, shopping, visiting friends and so on. Responding to the now-well-documented critiques of techno-centric approaches 
to analysing energy systems and behaviour change (Warde, 2005; Corsini et al., 2019), practice-based approaches have highlighted how energy and mobility needs, expectations and practices evolve in tandem with broader normative, socio-technical, developmental and governance contexts (Shove et al., 2012; Greene and Rau, 2018; Greene and Fahy, 2020). With regard to everyday mobility, such work highlights variation in access to energy and mobility modes and the practices this enables. In doing so, it demonstrates the importance of considering the broader contexts in which increasingly energy-intensive mobility practices emerge (Cairns et al., 2014).

While practice-based research is making significant advances in understanding socio-technical dynamics of resource use, cross-cultural situated comparisons between industrialised and developing countries have been limited (Baruah, 2017; Greene, 2018b; Greene and Schiffer, 2018). Recent advances in social science energy research are progressing comparative energy research among largely developed, European contexts (e.g. Jensen et al., 2018 and www.energise-project .eu). This work is revealing the value of qualitative comparative investigations for understanding biographic, social, cultural and governing factors shaping variation in energy practices. However, to date, little work has engaged in international comparative analysis between industrialised and developing contexts to explore the evolution of energy practices over longer societal timescales from contextually situated, experiential perspectives. As a result, energy access related decision-making processes that take place at intergovernmental levels and span industrialised and developing countries have been largely removed from the lived experiences, challenges and opportunities people face in daily energy practice. Building on an emerging body of research advancing situated analysis of energy systems change, the research discussed in this chapter emerged as a response to recent calls for more cross-cultural energy research (Greene, 2018b; Greene and Schiffer, 2018). In doing so it seeks to move beyond European comparative work, to advance an international comparative approach that helps uncover insights into the lived experience of energy systems change in different development trajectories of industrialised and developing world contexts.

Perhaps as a consequence of the broader omission of comparative research between diverse contexts, the interaction between energy practices and social (in)equity has, as of yet, been relatively under-explored (Walker, 2013; Sayer, 2013; Greene, 2018a). Following this, little is known about how power, capability and already existing patterns of social differentiation across categories such as gender, socio-economic status and socio-historical context shape experiences of energy systems change (Walker, 2013; Greene, 2018b). As a consequence of this sidelining, equity within energy focused practice-based research has been a blind spot for socially differentiated experiences of individuals' everyday performances across diverse development contexts (Greene, 2018b; Greene and Rau, 2018). This includes the gendered ways in which energy consumption and demand are patterned and experienced (Greene, 2018a; Munro and Schiffer, 2019; Schiffer, 2020), as well as how socio-technical development pathways shape different opportunities to participate in daily social practices across contexts. 
In order to address this gap, recent work has sought to develop practice theoretical approaches by placing issues of power and equity as central to understanding practice dynamics (Walker, 2013; Watson, 2016). From the limited available data on gender and consumption there are clear indications that gendered roles and relations of power in society transpose into gendered patterns and performances of energy, including mobility and other daily consumption-related practices, at home and in the workplace (cf. Heisserer and Rau, 2015; Räty and CarlssonKanyama, 2010; Schiffer, 2020). For example, Greene (2017, 2018a) and Schiffer (2020) identify relationships between gendered roles, such as responsibility for domestic care, labour participation, and performance of everyday consumption practices, including those relating to food, mobility and laundry. Such work is revealing how everyday practices evolve in gendered ways and work to shape wider opportunities for participating in social life (see also Govindan and Murali, this volume).

However, as yet, little research has explored how these differentiated patterns of practice emerge over time and between diverse societies. As outlined, a key gap exists concerning comparative experience-centred research exploring gendered energy practices across different development contexts. As a result, little is known about how processes of modernisation and development have shaped the performance of everyday energy practices in uneven or similar ways in different developmental contexts (Greene, 2018b; Greene and Schiffer, 2018). This is despite the particular potential of such work for revealing insight into the role of governing structures and socio-technical development pathways in shaping dynamics of energy access, demand and practice. In the context of achieving just transitions, and in response to the relative neglect of themes of gender (in)equity, such work could usefully bring light to how disparity and diversity impact opportunities to participate in everyday energy systems and inform future transition policies and pathways.

In response to these gaps, this research advances a situated, historic comparative analysis of gendered mobility practices in Ireland and The Gambia to arrive at a better understanding of common and divergent experiences of energy systems and developmental change processes in the context of everyday mobility. The cases of Ireland and The Gambia represent distinct and contrasting development trajectories that offer a unique opportunity to explore the processes under investigation. Particular attention is paid to documenting the gendered experiences of modernising processes in the case contexts as they have evolved over the course of the past century. Building on this, the analysis seeks to progress understandings of how capability, equity and difference in participation in everyday mobility arise, focusing in particular on car driving and cycling.

\section{Capability, equity and practice}

Despite the overall sidelining of disparity, equity and justice in practice-based energy research, some advancements are emerging. Recent attempts to consider these issues have sought to apply normative judgement to processes of social 
reproduction and change. For Walker (2013), bringing an equity lens to bear on practice analysis of social change entails paying attention to patterns of inequality, social differentiation and variety in situated practice dynamics. Combining Sen's capability approach with practice theory, Walker suggests that patterns of variability and difference can be analysed by studying social differentiation in individuals and their everyday practices. This approach to social analysis may involve exploring social differentiation in terms of people's capability to participate in and perform energy-related practices, such as those related to everyday mobility. Building on Shove et al.'s (2012) often utilised model of practice, the term capability used here refers to the culmination of meanings (dominant social meanings and norms guiding practices), materials (access to material stuff and technologies) and competences (skills, knowhow and techniques needed to perform a practices) in relation to a specific energy practice, such as car driving or cycling (cf. Shove et al., 2012; Walker, 2013).

In this chapter, we seek to advance Walker's theorisation to explore equity through the lens of capability-in-practice in the context of mobility practice careers (Greene and Rau, 2018). In the context of this study, capability-in-practice seeks to explore both gendered patterns of recruitment to practices as well as how mobility-related meanings, materials and competences evolve and are patterned differently along categories of social difference (in this case gender). Capabilityin-practice can be analysed at different scales and temporalities, including within and between societies and across different periods of time. Studying cross-sectional differences in groups' or individuals' capability to perform practices along categories such as gender and socio-economic status is important for understanding and promoting equity within and between societies (Walker, 2013). Exploring the ways in which categories of social difference intersect (cf. Collins and Bilge, 2016) in shaping differential patterns of capability to participate in various energyconsuming practices is thus an important avenue of inquiry for informing just transitions (Greene, 2018b).

In addition to cross-sectional analysis of variation, analysis across different temporal scales, including that of individuals' lifecourses and biographies, are useful for uncovering differentiation in terms of how practices are taken up, maintained and changed over time (Warde, 2005; Hards, 2012; Greene, 2017). Central to this is a need to move away from a mere analysis of mobility meanings to also studying how practices are performed in relation to social contexts. To this, Greene and Rau (2018) have advanced the concept of "careers" as a means of exploring the ways in which people's practices develop over longer biographic time scales. A career lens involves exploring socially differentiated experiences of recruitment to, and defection from an everyday practice, as well as how capability to participate evolves in terms of meanings, materials and competences. It furthermore entails exploring how gendered social roles and lifecourse pathways intersect with and shape patterns of energy practice career development (Greene, 2018a). However, as of yet, there is a paucity of comparative historical energy research that considers how gendered patterns of capability and resource use develop over longer timescales and across distinct developmental contexts 
(Greene and Rau, 2018; Schiffer, 2020). This research seeks to address this gap by exploring how gendered "careers of practice" emerge in relation to capability. To this, it focuses on uncovering the gendered and related socio-cultural ways in which opportunities to participate in various mobility practices enable or constrain participation in other everyday life practices.

In exploring how gendered mobility careers emerge, our framework also integrates sociological perspectives on gender and performance. Here it is recognised that gender is fundamental to how we are constructed and evolve, shaping how a person is treated as well as what are considered appropriate ways for them to act (Butler, 1990). In suggesting that people are only "culturally intelligible" as gendered beings, as a girl/boy, woman/man, cultural ideas about gender are crucial to how people's practices are constructed, embodied and performed. The lived experience of everyday life is central to the binary masculine-feminine opposition. This is most notably illustrated by gendered structuring of social space, which is characterised by the traditional confinement of women to circumscribed private and domestic sites as opposed to the masculine locations of the public sphere (McNay, 1999; Greene, 2018a; Munro and Schiffer, 2019).

Knowledge about gendered patterns of participation and capability, in terms of who carries out practices and to what end, is important for planning transitions to more just energy futures. Comparative research approaches provide an important means of studying the intersection of everyday practices with broader gendered norms and socio-technical development pathways (Bartlett and Vavrus, 2016). Supporting the conceptualising of energy as the outcome of participation in socially recognisable practices, comparative research enables exploration of the ways in which inequity and disparity in opportunities to participate arise and their relation to broader social change and development processes (Kumar, 2018). In exploring how gendered (in)equity issues relating to mobility practices emerge and evolve over time, the remainder of this chapter advances a cross-cultural comparative investigation between Ireland and The Gambia. The focus is on exploring how capability in everyday mobilities have evolved historically across the two distinct developmental contexts. In doing so, it reveals that, despite differences in terms of rates and paces of change, gendered norms and inequalities in everyday mobility practices transcend national contexts and levels of development.

\section{Cross-cultural comparative analysis}

The data discussed in this chapter forms part of a larger comparative investigation exploring the lived experience of energy systems change over time through a qualitative biographic-practice methodology. As previously stated, as of yet, situated research which compares the lived experiences of energy systems change between industrialised and developing contexts has been under-explored, especially over longer-term developmental trajectories (Greene, 2018b; Schiffer, 2020). While some innovative comparative work between industrialised and developing countries is emerging (see Sareen, this volume), key gaps in understanding remain, especially regarding how dynamics in everyday practices intersect with broader 
social change processes that take place over longer time frames. To this, we argue that comparative biographic-practice research is well suited to advancing insights into the ways in which globalising development processes interact with spaces and practices of daily life across culturally distinct contexts.

In exploring everyday mobility dynamics and their intersection with broader social change processes, Ireland and The Gambia represent interesting contexts for analysis. While both countries have shared an overall trend of development towards increasingly resource-intensive socio-technical systems, this process has been characterised by different contexts and rates of change. As an industrialised European country, Ireland has experienced transformational socio-technical development over the course of the latter 20th and early 21 st century, moving from a poor, primarily agrarian society to a wealthy, (post)industrial economy, currently ranked third out of 189 countries on the Human Development Index. In contrast, The Gambia, which ranks 174 on the Human Development Index, has experienced significant political and economic upheaval over the past several decades and has only recently begun to modernise and neoliberalise its economy. However, despite these differences, both countries have historically been characterised by patriarchal social structures that have played a crucial role in shaping the evolution of mobility practices. To this end, a comparative contextual analysis holds much potential for revealing commonalities and differences in how energy transitions are experienced in situated times and places including in relation to the gendering of everyday practices.

Focusing on everyday practices as a lens through which to understand sociotechnical change processes, the comparative research employed a qualitative, biographic-practice methodology to understand and analyse the evolution of individuals' careers regarding everyday domestic practices across a number of domains, including food, mobility and other energy-consuming practices (e.g. laundry). The analysis presented in this chapter focuses on the case of mobility practices and more specifically car driving and cycling, to illustrate and discuss processes relating to equity and the evolution of gendered careers and practicebased capabilities.

In recent years, biographic-practice methodologies have received increased attention within sustainability and energy research as offering contextual, dynamic and human-centred approaches to researching consumption and demand (cf. Henwood et al., 2015; Schiffer, 2020), and practice careers (Hards, 2012; Greene and Rau, 2018; Greene and Schiffer, 2018). Biographic inquiry treats and studies individual lives as embedded within situated, temporal, spatial and social contexts (Elder and Giele, 1998; Blue et al., 2014; Schiffer, 2020). Providing "a sophisticated stock of interpretive procedures for relating the personal and the social" (Chamberlayne et al., 2000: 2), biographic-practice methods enable detailed contextualised understandings of social life to reveal how the past impacts upon the present (West and Merrill, 2009). Recent applications of biographic-practice methods in practice-based consumption research have highlighted their potential for exploring how lives, practices and contexts intersect in energy systems change (cf. Greene, 2018a). In addition, comparative analysis enables a deeper 
appreciation of how these processes play out in the context of different developmental pathways (cf. Bartlett and Vavrus, 2016).

Across both Ireland and The Gambia a total of 31 semi-structured biographic interviews were conducted with middle and older-aged participants ranging from 50 to approximately 100 years of age (in The Gambia exact ages are not always known). As such the developmental period under investigation ranged from circa the 1930s to 2018. While this sample size is limited, sampling criteria nonetheless sought to capture diversity among dimensions of age, socio-economic status, education and geographical location within the community. It also constituted nearly equal gender representation, with 15 men and 16 women across both cases.

As is characteristic of qualitative research, the study aimed for theoretical rather than representative generalisability by providing rich insights into patterns and processes shaping dynamics as they play out in the context of individuals' lives. Theoretical sampling is common in qualitative approaches in which small sample sizes are employed to prioritise depth over breadth, focusing on detailed description and uncovering contextual processes over more statistically representative or generalisable findings. The exploratory and context-focused perspective of this research sought to uncover processes and mechanisms through a grounded, inductive and theoretically guided framework. Despite these findings not being generalisable in a statistically representative sense, it is maintained that theoretical insights into the operation of social processes and contexts can be revealed by exploring the realm of the experiential and performative. As Silverman contends, "since the basic structures of social orders can be found anywhere, it does not matter where we start our research" (2008: 134).

In Ireland, biographic interviewing involved constructing detailed accounts of individuals' wider biographic history and changing domestic energy practices over the course of their lives. Interviews were conducted with a diverse spectrum of 19 individuals spread across two case contexts, Galway and Dublin (cf. Greene, 2017 for further information). In The Gambia, interviews built on ongoing ethnographic energy research and repeated immersions in the coastal community of Kartong between 2010 and 2019 (cf. Schiffer, 2016; Munro and Schiffer, 2019; Schiffer, 2020). These formed part of a human-centred design methodology aiming to understand and influence long-term changes of socio-economic, socio-technical, environmental, political and cultural dimensions that shape local "energy metabolisms" (Schiffer, 2020). In order to facilitate cross-cultural and longer-term comparisons of the intersections of gender and justice in energy systems change, the authors collaborated and conducted biographic semi-structured interviews with 12 elders in Kartong in January 2018. To this, the biographic interview schedules developed for the Irish case were adapted for implementation with the Gambian sample.

For the purpose of this comparative investigation, the chapter limits discussion to a consideration of broad themes emerging in relation to gendered careers of mobility practices. Analysis of individuals' biographic experiences and careers of practice employed a combined practice theory and capability frame. This framework was applied in an analytical process to uncover insights into the intersections 
of gendered lives and socio-technical contexts in shaping access to, and participation in, everyday mobility practices and the activities they enable.

\section{Gender and mobility}

This section provides a contextual overview of Ireland and The Gambia, followed by analysis through the lens of gendered mobility-related meanings, competences and materials. Ireland and The Gambia's development pathways have been characterised by different socio-political and infrastructural developments. These contexts have shaped differential mobility access and patterns of recruitement and participation. However, while the cases differ in terms of the rates and pace of change observed, regarding gendered mobilities, car driving and cycling emerged as empirically significant in both contexts. Furthermore, both of these mobility modes also commonly represent conflicting carbon-intensive and polluting (car driving) versus low-carbon and active (cycling) alternatives (e.g. Siiba, 2020; Okokon et al., 2018). Focusing on car driving and cycling, the analysis below presents and discusses the evolution of gendered practice careers across the two cases. In doing so it highlights shared and divergent experiences across the themes of "mobility meanings, socialisation and early recruitment" to practices, followed by the development of "gendered competences, material access and changing mobility practices".

\section{Introducing contexts of car driving and cycling careers}

As an industrialised context, Ireland's infrastructural development followed a car-centric pathway characteristic of the post-World War II era in industrialised world contexts (McDonald and Nix, 2005). Over the course of the 20th century, the proportion of Irish citizens obtaining driving licences increased, with associated car ownership and usage steadily rising. Furthermore, large-scale car-centric infrastructural developments oversaw a nation-wide building of motorways and roads to support increased car driving. This was supported by a range of car-centric national and employment-based policies that played a central role in recruitment of increasing numbers to driving and the expansion and normalisation of car driving in Ireland. These developments have positioned Ireland as one of the most car-dependent societies in Europe (European Commission, 2019).

In The Gambia, successive government changes since independence from the UK in 1965 have been associated with infrastructural developments (Schiffer, 2020). Following the 1994 coup d'etat, in which Yahya Jammeh seized power of the country, road infrastructure started to drastically improve the physical connection of Kartong with other parts of The Gambia. In turn, this shaped increasing recruitment to motorised transportation, offering access to urban markets, new forms of employment as well as extraction of local resources such as fish and mineral sands (Schiffer, 2016, 2020). Nonetheless, everyday mobility within the community continued to be predominantly based on walking and cycling. Such 
low-carbon modes were, however, slowly replaced with motorised transport for distance travel from the later 20th century onwards.

\section{Gendered mobility meanings, socialisation and early recruitment}

Despite the differences in broader socio-technical development contexts, both Ireland and The Gambia are historically characterised by patriarchal structures. Narratives of men and women in both contexts highlight gendered experiences of mobility socialisation. Socialisation here refers to "the ways in which individuals learn skills, knowledge, values, motives, and roles appropriate to their position in a group or society" (Bush and Simmons, 1981: 134). Early childhood experiences marked the initial commencement of men and women's mobility careers, with differential and gendered patterns of performance continuing throughout the lifecourse. Across both cases, women's mobility experiences in the past were largely based on less resource-intensive mobility modes, such as walking (Ireland and The Gambia) and public transport (Ireland). Women were less likely to develop capabilities in car driving (Ireland and The Gambia) or cycling (The Gambia) and generally experienced more restricted mobility careers over the course of their lives. In contrast, despite differences in terms of the rate and pace of transitions to motorised transport, across both cases, men had earlier access to car driving and subsequently became longer and more consistent car driving practitioners. Early socialisation provided contextual experiences that were crucial for setting individuals on mobility career trajectories and inculcating gendered mobility-related dispositions and images that acted as reference points for comparison in later life.

Observation of and participation in gendered mobility contexts and practices in early socialisation shaped the emergence of gendered mobility meanings and forms of competence. Individuals in both cases spoke about their childhood mobility experiences, reflecting on highly gendered mobility practices among adults. Regarding the Irish context, only one participant had a mother driving in childhood. For others, mothers generally used buses or walked to the shops for groceries with their daily mobility paths configured in the locality around the home. In contrast, most individuals noted that their fathers had a much greater mobility range and drove and owned cars. Narratives revlealed that cars were initially used by fathers almost exclusively for activities in the public sphere, largely centred on employment. The car was attached to images of masculinity, as illustrated by Claire's ${ }^{1}$ account:

My mother never learned to drive, so she would walk us to school in the morning. Dad would be gone with the car and she didn't drive ... It was always Dad's car. You know it was that very old fashioned "it's Dad's car". It was just very standard at the time. It was just the way it was.

It was later, from largely the 1980 s onward, that car driving began to become linked with private sphere activities such as shopping, school runs and family outings. These changing meanings were associated with the increasing feminisation 
in the context of women's growing recruitment to car driving in the last two decades of the 20th century.

In Kartong, car driving did not emerge as a significant mobility practice until road construction following the aforementioned 1994 coup d'etat. Rather, during the mid and later parts of the 20th century, households typically relied on cycling and walking to travel within and beyond the settlement area. However, in contrast to Ireland, where cycling had been an established and accessible mobility mode since the late 1800 s, it was only in the late 1950 s that recruitment to cycling and the practice of cycling developed in Kartong.

Following gendered patterns of car expansion in Ireland, cycling emerged as an overwhelmingly male-oriented activity in Kartong. Men in the community were the first to own bicycles (materials) and learn to cycle and maintain bikes (competence). For many decades, cycling continued to be performed almost exclusively by boys and men and was associated with wider meanings concerning gendered roles and activities. Buba's comment resonates with other participants' reflections on cycling: "women don't ride bicycle[s], only men ride bicycles". Observations recorded over the period of repeated immersion reveal that it has only been possible to observe Gambian girls riding in the community this past decade (Schiffer, 2020).

In Kartong, the early male cycling recruits were afforded the benefits of expanded agency presented by their recruitment to this higher range mobility mode. Relative to the predominant mode of walking at the time, recruitment to cycling increased the possible range of their daily mobility practices, providing greater agency to participate in a wider range of social and economic activities outside the home. Men were more likely to travel greater distances outside the home, while women's day-to-day lives predominantly focused around domestic spheres (Schiffer, 2020). This was related to broader patterns of gendered patriarchal power relations. As Fatou recalls: "Normally men travelled more than women ... At that time women [were] controlled".

While all Irish participants were recruited to cycling at a young age, participants' narratives revealed gendered differences in terms of cycling practices and the activities these enabled during childhood and adolescence. The period of adolescence was characterised by gradually increasing agency, resulting in a corresponding broadening range of mobility as participants reported they were afforded more opportunities to go out by themselves. The bicycle was a crucial mode of transport for all individuals during this period. However, relative to boys, girls tended to experience more mobility restriction. While boys generally reported using their bicycles to travel greater distances from home to engage in socialising and sometimes employment-related activities, girls were more likely to report restrictions placed by their parents on their range of mobility. As Martha recalls: "My father would keep a tab on me, making sure I didn't go too far from home or to certain places ... and I had to be back every evening at 8 o'clock and much earlier during the winter". In contrast, these types of restrictions were notably absent from Irish male narratives of mobility experiences and speak to the gendered meanings of mobility socialisation and early recruitment. 


\section{Gendered competences, material access and changing mobility practices}

In Kartong, gendered access to resources led to predominately male-oriented bicycle competences and ownership (materials). This was associated with recruitment of boys and men to new "sharing practices" (Schiffer, 2020), in which initially scarce bicycles were used communally amongst boys and men in the community. In this context, narratives also revealed new degrees of social dependency experienced by early male cyclists in Katrong, who were relied upon by the community to facilitate wider communication and consumption-related tasks. As Lamin recalls:

Few in the community ... had the opportunity to acquire bicycles. They [were] totally the source of means of communication. Like if ... somebody died and you wanted to communicate to the relatives in the other localities, you would go to that particular person with the bike and borrow it from him.

Thus, despite overall patterns highlighting the development of higher range mobility practices in favour of boys and men, a more nuanced analysis of lived experiences highlights a greater complexity to these developments. As the account above suggests, narratives reveal the increased social dependency placed on early male recruits cycling in The Gambia. Interestingly, this theme also emerged in relation to car driving. For example, a number of participants drew attention to the increased social pressure placed on the initial car drivers in the community who were depended on to support a range of activities and practices. Ousman reflects on this perceived negative aspect of increased social dependency experienced by early male car recruits in the community:

The dependency on you would be very high because if people have problems they would come to you ... There [was] a disadvantage because there could be relatives who could have [a] serious emergency and they would not be in possession of [a] car. Like somebody's [is in] labour, a serious accident happens, maybe a child fell from a tree, the leg got broken. You know, or any other related emergency ... they will come ... The dependency was too high because maybe [the] entire village of ... maybe 1,000 inhabitants, only [one] vehicle, one driver, you know, one car. The rest could not drive ... But now you are the owner of the car and are the only qualified driver, so the service is entirely on you. So, the dependency was super-high ... Yeah, the high dependency on you is that any time people needed you, there is no restriction and there is no privacy; they will knock at your door and you will [have to] get up and solve their problem.

Over time, the use of motorised vehicles grew in the Kartong community. This process was supported with successive improvements in road infrastructure. However, the increasing recruitment to car driving and car ownership occurred in a socially differentiated and gendered manner. Men, and especially those of higher social positioning, had earlier access to car driving skills and technologies for private use. Ousman further reflects: 
The first, you know, privileged families that had cars in their compounds and the first drivers, you know, in history ... [Then] previously only men [were seen] driving ... [It] used to be only men but now even my wife wants to drive. But [it is still] men with their private cars [that] take their wives out.

Thus, despite emerging changes, gendered patterns of exclusion continue to exist. Visible changes to women's car driving capabilities in Kartong have only started to emerge in the past several years with increasing numbers of women starting to learn to drive (Schiffer, 2020). However, despite women slowly taking up car driving, today the emphasis on male capabilities continues to be observed in relation to the increasing uptake of motorised mobility among men in Kartong (Schiffer, 2020). In this respect, car driving is largely centred on commercial activities where men are employed as drivers for taxis, bush taxis (large minivans) and trucks as well as related employment and business opportunities. Such opportunities provide an important context for framing male recruitment to car driving. Ousman recalls: "I was a manager in one of the community lodges ... And as a manager, I had a vehicle under me ... so I was forced to learn how to drive". More recently a "car wash" which operates an electric vacuum cleaner has been established in Kartong as an example of a male business venture (Schiffer, 2020). As such, historic exclusion also spills over into subsequently gendered employment opportunities directly or indirectly associated with mobility modes and capabilities.

In the Irish case, where motorised driving practices were established much earlier, men reported recruitment to car driving usually in their late teens or early twenties. However, like The Gambia, many men were recruited to car driving for work-related activities. Following their recruitment, most men reported being consistent car drivers for most of their lives. In contrast, most women were recruited to driving later in their lifecourse, during their 30s or even 40s. Women's mobility started to change near the end of the 20th century, most notably marked by wider socio-political changes providing room for women's increased participation in employment roles outside the home (cf. Greene, 2018a). In their earlier lifecourse, many older women had experienced mobility restriction and isolation prior to learning to drive, with many indicating they were essentially housebound during early years of childrearing as their husbands took the car to work. Many women reflected on the increasing range of opportunities developing car driving competences presented for them in their daily lives, as Claire's account illustrates: "It was fantastic! It really opened up a whole lot of things ... the independence and freedom...it just opened up a lot of new avenues that you couldn't do on a bike."

Mobility restriction experienced in their earlier lifecourses shaped women's attachment to car driving in later life, with interviewees stressing it as a fundamental symbol of their independence that they were unwilling to ever forfeit. For example, in recent years, Martha and her husband James had toyed with the idea of downsizing to one car. However, Martha's experience of isolation during her early motherhood years and hard-worked path towards achieving mobility independence as a woman led to a deep and complex emotional connection to her car: 
having lived with no car to having two cars, we do consider two cars in the house ... a luxury, yes I do, but it's kind of that and then ... you know even though the conscience niggles at me from time to time, like since James has retired I was weighing up and toying with the insurance and petrol and everything else, you know, considering giving my car up ... But in the end I decided against it and you know it boils down to that I couldn't possibly face feeling that housebound again, that's something I just couldn't give up now ... it took me a long time to have the opportunity to learn to drive, and then to get a car. It was a huge thing. If I gave it up I think I would have felt I have sacrificed something, like a part of myself because it took me a long, long time to get it. It was a real mark, sense of ... I wouldn't say a goal but you know when you strive for something and you get it?

Martha's experience was typical of the experiences of older and middle-aged Irish women who were recruited to driving later in their lifecourse. The commonality of this theme across the women's accounts shows how what is a subjective experience is in fact historically structured, as similar patterns in meanings and attachments to practices are configured by shared gendered biographic experiences.

As a consequence of their later recruitment, women in the Irish case practiced multi-modality for longer in their lifecourses than men. Unlike Martha, for a number of women, practices of multi-modality, in which daily mobility practices combined walking, public transport and travelling as passengers in maledriven cars, persisted even after they had learned to drive. This was largely due to these women not having access to material resources needed for purchasing and maintaining a private car. Across age groups, women from lower socio-economic backgrounds tended to be recruited to car driving later and indicated longer periods in their lifecourse characterised by no car driving and multi-modality. In terms of private ownership of a car, relative to men, most women did not own a personal car until much later in their lifecourse. Savings obtained from part time jobs or employment taken up after child rearing were cited as important in these cases. Women from lower socio-economic groups in particular were more likely to car share using their husband's car. It was only around the period of the late 1980s and early 1990s that most driving women in the Irish sample reported full recruitment to driving. This mirrors broader patterns in the expansion of driving in Ireland, reflecting the growing participation of Irish women in the labour force in part- or full-time employment and associated rises in the number of cars and licences per capita. This has resulted in a dramatic feminisation of the Irish car driving landscape, with Irish women now driving significantly more than men. For example, the proportion of women driving to work in Ireland on a daily basis increased from $27 \%$ in 1985 to over $65 \%$ in 2016 . Comparatively, the proportion of men driving to work rose from $43 \%$ in 1985 to $53 \%$ in 2016 (CSO, 2016).

In Ireland, women's increasing recruitment to car driving was related to gradually changing norms regarding what the car should be used for. Over time, the car became linked with a growing array of practices and activities constitutive of everyday life. While the car was initially considered an exclusive activity 
reserved only for men and male work-related activities, with women's increasing recruitment, the car became linked to new practices such as food shopping, bringing children to school and an increasing range of recreational activities. In addition, wider contextual processes associated with changing labour participation of women and broader planning and infrastructural developments were noted as key dynamics leading to the eventual normalisation of car use among both men and women. Examples include the supermarketisation of food provisioning and associated processes of spatial distancing between sites and services (cf. Greene, $2018 b$ ). Further and ongoing research is needed to document to what extent developmental dynamics will lead to similar processes regarding the convergence of men and women's car driving rates in The Gambia.

\section{Reflections on gendered mobility careers}

As this snapshot into the historic comparative analysis of development of everyday mobility reveals, gendered forms of practice-based capability and exclusion have emerged across both cases. These insights point to the highly important role of gender in structuring capability-in-practice across contrasting development contexts. Despite differences in the exact development pathways that historically framed the evolution of mobility careers in Ireland and The Gambia, similar processes of gendered disparity emerged in both cases.

While there were variances between both Ireland and The Gambia in terms of the rate and pace of change towards higher range mobility modes, similar processes concerning gendered socialisation and the development of gendered mobility meanings, materials and competences were evident. For example, across both cases, women have historically experienced more mobility restriction and have been presented with fewer opportunities to develop capability in higher range mobility modes. Instead of focusing on differences regarding levels of development, these insights reflect shared patriarchal orderings and norms governing everyday life. Here, car driving (Ireland and The Gambia) and cycling (The Gambia) have historically been understood as predominantly male practices (meanings), with skills being largely learnt by male practitioners (competences) who were also more likely to have access to resources and vehicle ownership (materials). These gender disparities in mobility capability have also been reflected in different opportunities to participate in mobility-related economies and employment opportunities.

The comparative analysis has thus revealed power-laden and gendered forms of exclusion regarding the development of mobility-related capabilities. It has also highlighted gendered differences in terms of the temporal rhythms and goal orientations of daily mobility patterns. In Ireland, women's mobility careers were much more likely to reflect multi-modal transport forms, including mixing walking, public transport and travelling in cars as passengers. Women's everyday mobility patterns have historically been more confined in distance whilst involving relatively more varied and complicated transport routes. Women's mobility careers have been primarily oriented towards fulfilment of family 
activities and caring responsibilities, such as dropping children to school and shopping for family or attending to other family-based errands and activities. This contrasted with men's typical daily commutes which often involved longer but more direct journeys and routes to places of work. Similarly, in Kartong, women's daily journeys were more likely to be locally based and related to domestic and seasonal food growing activities. In contrast to Irish women, who reported multi-modality and greater use of public transport systems, the everyday mobility of women in the Gambian case were not long ago almost entirely based on walking.

These differences in mobility modes reflect varying socio-economic, spatial and infrastructural landscapes in the two contexts. Nonetheless, across both cases, shared findings highlight similar processes concerning the intersection of energy use with gendered power dynamics. Gendered patterns of mobility disparity have been revealed through men's access to higher range mobility practices and women's experiences as historically associated with local, less resource-intensive travel related to domestic roles. However, despite findings highlighting patterns of higher range mobility development in favour of men, a more nuanced analysis of lived experiences adds a greater complexity to these dynamics. For example, narratives highlighting the increased social dependency placed on early male recruits to both cycling and car driving in The Gambia reveals complex responsibilities for the wider community faced by men. Furthermore, across both the Irish and Gambian cases, recruitment experiences of men to driving were sometimes fraught by personal strains associated with meeting employment-based demands and were not always experienced as choice. Such accounts highlight the importance of situated analysis for revealing variations and complexity in lived experiences of energy systems change as well as variability of experiences both within and across gender categories.

This is significant because mobility and other forms of energy continue to be predominantly considered through techno-centric policy approaches. This includes visions of technological "leapfrogging" that will allow developing countries to bypass polluting fossil fuel based energy systems of industrialised nations (Nikolaeva et al., 2018). Yet, analysis of Irish and Gambian mobility careers reveals that development trajectories in both contexts are both shaped by and shape gendered norms and social roles, embodied and performed in private and public space (cf. Butler, 1990). In other words, achieving sustainable mobility development is not simply a question of technological access but the outcome of participation in socially recognisable and gendered practices. In the urgency to deliver low-carbon technological pathways, there is therefore a danger that within a techno-centric approach, mobility (in)equity between men and women is overlooked. A more socially informed perspective reveals the importance of considering the ways in which gendered mobility norms and forms of capability coevolve with wider contexts and opportunities for participating in daily economic and social life. Importantly, this can support the development of gender-sensitive policy interventions to enable more equitable approaches in the context of sustainable mobility practice transitions. 


\section{Conclusion}

Recent advances in practice-based approaches to energy demand have highlighted energy as a deeply social issue reflecting and shaping the socio-economic and infrastructural contexts of societies. However, little work has explored questions of gender, justice and equity in energy systems change through a cross-cultural comparative practice-based frame. With a focus on gender and moblity, this chapter has sought to highlight the potential of, and call for greater focus on, crosscultural comparative work on energy practices to advance understanding of the interrelation between lives, practices and contexts in socio-technical change.

Using car and cycling mobility careers as a vehicle for analysis, the comparative investigation across the Irish and Gambian cases reveals the importance of situated insights for uncovering gendered experiences and their relation to wider questions of (in)equity in everyday consumption practices. Although differences between the two cases were observed in terms of the specific rates and pace of mobility development, across both contexts, higher range mobility practices have evolved in gendered ways, dominated in their performance by men. Higher range mobility practices (car driving and cycling) have been gendered in terms of the development of capability across the elements of meanings, materials and competences. Car driving and cycling practices evolved as male-dominated activities, with men having greater access to mobility resources and developing necessary competencies to operate and maintain mobility-related technologies. Gendered inequities in mobility capabilities have historically developed across a range of modality modes but were most notable in relation to dominant car driving in Ireland and the use of motorised transport as well as bicycles in The Gambia. However, the analysis presented here also demonstrates that over-simplistic views of "men reaping all the benefits" don't hold sway and that more nuance is essential in understanding social pressure and inequity as experienced by both women and men.

Conclusions from this study suggest that the qualitative insights emerging from comparative biographic approaches are of immense policy relevance in the context of designing just transition pathways. As the analysis here illustrates, understanding gendered consumption practices and how these are intertwined with broader socio-economic and socio-cultural factors is important for improving understanding of social dynamics of energy systems change as well as enhancing mitigation and adaptation efforts. Comparison across different contexts of development as is the case here has highlighted gender as a much broader and more significant factor in shaping mobility practices. Such insight can help shed light on current lived experiences and has the potential for informing policy to achieve more sustainable mobility futures. Findings relating to persistent patterns of gendered mobility exclusion, suggest that gender-sensitive policies are needed to address disparities in energy practices and performances. Such accounts illustrate the need for policy to enable equitable access to energy, including energy demand associated with everyday mobility. However, achieving gender equity, for example in relation to women's car driving capabilities in terms of developing 
driving skills (competences), enabling private car ownership and associated fossil fuel dependence (materials), may come into conflict with urgent climate action needed. Furthermore, without considering gendered practices and inequities in the urgency to decarbonise mobility, policy makers might prioritise some mobility practices (e.g. employment) over others (e.g. bringing children to school), thereby unwittingly increasing gender inequalities.

A more useful way of framing mobility equity is therefore in relation to mobility range and ease of access to participate in daily activities that mobility-related energy consumption enables. For example, multi-modality in Ireland was a symptom of lower socio-economic status and therefore did not stem from personal choice or agency. To achieve equitable levels of higher range mobility for women, whilst promoting low-carbon modes of transport, gender-sensitive policies should explore how desirable alternatives to private car ownership can be made accessible in a way that accounts for the interaction of gendered life experiences with broader socio-technical systems.

More contextual and experience-centred comparative work in this area can help address gaps concerning differentiation in gendered experiences and processes in energy systems change. To this end, expanding the scope of analysis to consider other contexts and domains of energy systems dynamics can offer valuable insights into social dimensions of energy. The comparative biographicpractice approach to exploring the evolution of gendered differentiation in capabilities has applicability beyond the study of mobility to a wider range of energy-related experiences and practices. Such an approach can fruitfully add to the growing body of work focused on addressing knowledge gaps concerning gendered patterns of power and (in)equity in energy practices including progress towards "affordable, reliable, sustainable and modern energy for all". For example, Govindan and Murali's (this volume) analysis unpacks the intersection between transitions to clean cooking fuels and changing social positions of women in India. Similarly, Abdullahi (2017: 46) argues that women in Nigeria are both energy consumers and producers and that without considering their voices in energy transitions renewable interventions "risk being inappropriate or failing". Comparative biographic-practice approaches to analysing a spectrum of energy-related capabilities can advance understanding of the evolution of gendered energy performances within the context of socio-historical and wider developmental change processes.

In summary, delivering the urgent climate action needed, while ensuring equitable energy and mobility access, necessitates an inclusion and recognition of the different capabilities of people within a society including men and women. With its emphasis on understanding disparities in daily life experiences and their intersection with broader social-technical change processes, a biographic-practice approach offers a useful framework for exploring how differences in capability and subsequent participation in energy practices arise. Research exploring energy practice related meanings, materials and competences advances understanding of the intersection of power, (in)equity and the gendered development of capabilities as the basis for designing just energy transitions. 


\section{Acknowledgement}

We kindly acknowledge funding received through the SHAPE Energy Research Design Challenge that enabled this collaboration.

\section{Note}

1 Please note that names related to direct quotes from research in Ireland and The Gambia have been changed.

\section{References}

Abdullahi, A.A. (2017). An analysis of the role of women in curbing energy poverty in Nigeria. Journal of Sustainable Development Studies, 10(2), 45-60.

Agyeman, J. (2013). Introducing Just Sustainabilities: Policy, Planning, and Practice. London: Zed Books.

Anfinsen, M., \& Heidenreich, S. (2017). Energy \& Gender: A Social Science and Humanities Cross-Cutting Theme Report. Cambridge.

Bartlett, L., \& Vavrus, F. (2016). Rethinking Case Study Research: A Comparative Approach. London: Routledge.

Baruah, B. (2017). Renewable inequity? Women's employment in clean energy in industrialized, emerging and developing economies. Natural Resources Forum, 41(1), 18-29. doi:10.1111/1477-8947.12105.

Blue, S., Greene, M., \& Morosanu, R. (2014). Time and practice. In C. Foulds \& C.L. Jensen (Eds.), Practices, the Built Environment \& Sustainability-A Thinking Note Collection (pp. 25-27). Cambridge, Copenhagen, London: GSI, DIST, BSA CCSG.

Bush, D.M., \& Simmons, R. (1981). Socialization processes over the life course. In M. Rosenberg \& R.H. Turner (Eds.), Social Psychology: Sociological Perspectives (pp. 133-164). New York: Basic.

Butler, J. (1990). Gender Trouble: Feminism and the Subversion of Identity. London: Routledge.

Cairns, S., Harmer, C., Hopkin, J., \& Skippon, S. (2014). Sociological perspectives on travel and mobilities: A review. Transportation Research Part A: Policy and Practice 63, 107-117.

Cass, N., \& Faulconbridge, J. (2016). Commuting practices: New insights into modal shift from theories of social practice. Transport Policy, 45, 1-14. doi:10.1016/j. tranpol.2015.08.002.

Chamberlayne, P., Bornat, J., \& Wengraf, T. (2000). Turn to Biographical Methods in Social Science: Comparative Issues and Examples. London: Routledge.

Collins, P.H., \& Bilge, S. (2016). Intersectionality. Cambridge: Polity Press.

Corsini, F., Laurenti, R., Meinherz, F., Appio, F.P., \& Mora, L. (2019). The advent of practice theories in research on sustainable consumption: Past, current and future directions of the field. Sustainability (Switzerland), 11(2). doi:10.3390/su11020341.

CSO (2016). Census of Population 2016-Profile 6 Commuting in Ireland. Central Statistics Office, Dublin. Available from: https://www.cso.ie/en/releasesandpublica tions/ep/p-cp6ci/p6cii/p6mtw/ [Accessed 3 March 2020].

Elder, G.H., \& Giele, J.Z. (1998). Methods of Life Course Research: Qualitative and Quantitative Approaches. London: Sage Publishing. 
European Commission (2019). 'Transport in the European Union-Current Trends and Issues', Brussels: Directorate-General for Mobility and Transport (DG MOVE). Available from: https://ec.europa.eu/transport/sites/transport/files/2019-transport-in -the-eu-current-trends-and-issues.pdf [Accessed 8 January 2020].

European Commission \& Giddens, A. (1984). The Constitution of Society: Outline of the Theory of Structuration. Cambridge: Polity Press.

Greene, M. (2017). Energy Biographies: Exploring the Intersection of Lives, Practices and Contexts in Energy Systems Change. PhD Thesis, National University of Ireland, Galway.

Greene, M. (2018a). Paths, projects and careers of domestic practice: Exploring dynamics of demand over biographical time. In A. Hui, R. Day, \& G. Walker (Eds.), Demanding Energy: Space, Time and Change (pp. 233-256). Hampshire, UK: Palgrave Macmillan Publishers Ltd.

Greene, M. (2018b). Socio-technical transitions and dynamics in everyday consumption practice. Global Environmental Change, 52, 1-9. doi:10.1016/j.gloenvcha.2018.05.007.

Greene, M., \& Fahy, F. (2020). Steering demand? Exploring the intersections between policy, practice and lives in Ireland. Energy Research \& Social Science, 61, 1-10.

Greene, M., \& Rau, H. (2018). Moving across the life course: The potential of a biographic approach to researching dynamics of everyday mobility practices. Journal of Consumer Culture, 18(1), 60-82.

Greene, M., \& Schiffer, A. (2018). Learning from past and current energy transitions to build sustainable and resilient energy futures: Lessons from Ireland and The Gambia. In P. Sumpf \& C. Büscher (Eds.), SHAPE ENERGY 'Research Design Challenge': Control, Change and Capacity-Building in Energy Systems (pp. 57-66). Cambridge: SHAPE ENERGY.

Hards, S. (2012). Tales of transformation: The potential of a narrative approach to proenvironmental practices. Geoforum, 43(4), 760-771.

Heisserer, B., \& Rau, H. (2015). Capturing the consumption of distance? A practicetheoretical investigation of everyday travel. Journal of Consumer Culture, 0(0), 1-21.

Henwood, K., Pidgeon, N., Groves, C., Shirani, F., Butler, C., \& Parkhill, K. (2015). Energy Biographies Research Report. Available from: http://energybiographies.org.

Jensen, C.L., Goggins, G., Fahy, F., Grealis, E., Vadovics, E., Genus, A., \& Rau, H. (2018). Towards a practice-theoretical classification of sustainable energy consumption initiatives: Insights from social scientific energy research in 30 European countries. Energy Research \& Social Science. doi:10.1016/j.erss.2018.06.025.

Kumar, A. (2018). Justice and politics in energy access for education, livelihoods and health: How socio-cultural processes mediate the winners and losers. Energy Research \& Social Science, 40, 3-13. doi:10.1016/j.erss.2017.11.029.

McDonald, F., \& Nix, J. (2005). Chaos at the Crossroads. Kinsale, Cork: Gandon Books.

McNay, L. (1999). Gender, habitus and the field: Pierre Bourdieu and the limits of reflexivity. Theory, Culture and Society, 16(1), 95-117.

Munro, P.G., \& Schiffer, A. (2019). Ethnographies of electricity scarcity: Mobile phone charging spaces and the recrafting of energy poverty in Africa. Energy and Buildings, 188-189, 175-183. doi:10.1016/j.enbuild.2019.01.038.

Nikolaeva, A., Adey, P., Cresswell, T., Lee, J.Y., Nóvoa, A., Temenos, C., (2018). Commoning mobility: Towards a new politics of mobility transitions. Transactions of the Institute of British Geographers, 44, 346-360. doi:10.1111/tran.12287.

Okokon, E.O., Taimisto, P., Turunen, A.W., Amoda, O.A., Fasasi, A.E., Adeyemi, L.G., Juutilainen, J., \& Lanki, T. (2018). Particulate air pollution and noise: Assessing 
commuter exposure in Africa's most populous city. Journal of Transport \& Health, 9, 150-160. doi:10.1016/j.jth.2018.04.003.

Räty, R., \& Carlsson-Kanyama, A. (2010). Energy consumption by gender in some European countries. Energy Policy, 38(1), 646-649.

Sayer, A. 2013. Power, sustainability and wellbeing: An outsider's view. In Shove, E. $\&$ Spurling N. (Eds.), Sustainable Practices: Social Theory and Climate Change (pp. 292-317). Oxon: Routledge.

Schatzki, T.R. (1996). Social Practices: A Wittgensteinian Approach to Human Activity and the Social. Cambridge: Cambridge University Press.

Schiffer, A. (2016). Empowered, excited, or disenfranchised? Unveiling issues of energy access inequality and resource dependency in The Gambia. Energy Research \& Social Science, 18, 50-61. doi:10.1016/j.erss.2016.04.011.

Schiffer, A. (2020). Reframing Energy Access: Insights from The Gambia. London: Routledge.

SEforALL (2019). Switching Gears: Enabling Access to Sustainable Urban Mobility. Vienna: Sustainable Energy For All.

Shove, E. (2015). Linking low carbon policy and social practices. In Y. Strengers \& C. Maller (Eds.), Social Practices, Intervention and Sustainability: Beyond Behaviour Change (pp. 31-44). Oxon: Routledge.

Shove, E., Pantzar, M., \& Watson, M. (Eds.) (2012). The Dynamics of Social Practice: Everyday Life and How It Changes. London: SAGE.

Shove, E., \& Walker, G. (2014). What is energy for? social practice and energy demand. Theory, Culture and Society, 31(5), 41-58. doi:10.1177/0263276414536746.

Siiba, A. (2020). Active travel to school: Understanding the Ghanaian context of the underlying driving factors and the implications for transport planning. Journal of Transport \& Health, 18. doi: 10.1016/j.jth.2020.100869.

Silverman, D. (2008). Doing Qualitative Research. London: SAGE.

Walker, G. (2013). Inequality, sustainability and capability: Locating justice in social practice. In E. Shove \& N. Spurling (Eds.), Sustainable Practices: Social Theory and Climate Change (pp. 181-196). Oxon: Routledge.

Warde, A. (2005). Consumption and theories of practice. Journal of Consumer Culture, $5(2), 131-153$.

Watson, M. (2016). Placing power in practice theory. In A. Hui, T. Schatzki, \& E. Shove (Eds.), The Nexus of Practices: Connections, Constellations, Practitioners. London: Routledge.

West, L., \& Merrill, B. (2009). Using Biographical Methods in Social Research. London: SAGE.

Wu, J., \& Wu, T. (2015). Goal 7-Ensure Access to Affordable, Reliable, Sustainable and Modern Energy for All. UN Chronicle, LI(4). Available from: https://unchronicle.un.or g/article/goal-7-ensure-access-affordable-reliable-sustainable-and-modern-energy-all [Accessed 20 April 2020]. 


\title{
9 Energy transitions in the global South Towards just urgency and urgent justice
}

\author{
Johanna Höffken, Auke Pols, and Ankit Kumar
}

This book has explored energy transitions unfolding in the global South against the backdrop of an urgency vs justice dilemma. In the age of the Anthropocene the urgent need for de-carbonising our energy systems can be at odds with taking seriously questions of social and environmental justice. With public debates pushing the importance of urgency, ${ }^{1}$ often at the expense of justice questions, we have argued that a politics of just energy transitions is needed to navigate the dilemma.

The analyses presented in this book show different facets such a focus can uncover, from studying solar and wind farms in post-war Sri Lanka to legal frameworks that aim to protect the rights of Mother Earth in Bolivia; from following energy provision infrastructures in Lebanon to lower-caste women entrepreneurs installing clean cookstoves in South India; or from comparatively tracing Gambian and Irish mobility practices, governing solar energy technology rollouts in Portugal or questioning sustainability in Indian smart grids.

Following such narratives helps us detect angles and approaches that characterise promising pathways for engaging with a politics of energy transitions in the Anthropocene. They are part of a broader research landscape that we look at through three lenses in this concluding chapter: a methodological, a theoreticalconceptual and an empirical lens. We propose that these lenses could sharpen and re-focus our attention when navigating the landscapes of energy transitions. The chapter ends by suggesting how urgency, justice and related connotations offer both productive tensions and reinforcing potential. This can enrich, open up and bring into focus our understanding and efforts to shape energy transitions.

\section{Energy transitions under three lenses}

Informed by the chapters presented in this book and by broader reflections on the current social scientific work on energy transitions we highlight some promising research angles and approaches. Although neither exhaustive nor exclusive, they can be seen as a critique, as well as a driver for, current and future (research) engagements. It is not our aim to define a research agenda for a whole field, as has recently been suggested for the field of sustainability transitions research or for the field of science, technology and society studies (STS) respectively (Köhler et al., 2019; Sovacool et al., 2020). While such endeavours have their use, this 
conclusion follows the wider aim of this book, which is to draw lessons from a range of studies and perspectives embedded in energy transition and justice work in the global South. Our hope is hereby to contribute to, inspire and set in motion inquiries that engage with the politics of energy transitions in a variety of ways, contributing to a variety of agendas. In what follows, we identify what we consider fruitful ways of engaging with energy transitions research. Grouping them under three lenses is of analytical and structural value. In practice, we expect that their main value lies in the ways in which they are combined.

\section{Methodological lens: comparisons and looking beyond}

One approach that we consider promising when engaging with energy transitions is the comparative method. Though not new in the field of energy, most research has focused on comparisons within conventionally accepted categories such as comparisons between industrialised nations, or comparisons between global South nations. Greene and Schiffer (this volume) remind us about the value of engaging in comparisons between developed and developing countries. By comparing the evolution of mobility careers in Ireland with that unfolding in The Gambia they argue that car and cycling mobility careers in both countries are, surprisingly, not so different after all. Centrally, gender emerges as a significant factor in shaping mobility practices in both countries. Such North-South comparisons help to deconstruct simplistic assumptions either about development-status as the default explanation for incomparability, or as the default explanation for difference.

Work on comparative urbanism informed by postcolonial theory can be instructive for global comparative energy transitions research. Urban studies scholars have long been engaged in methodological discussions about the issue of comparison (e.g. Pickvance, 1986; Brenner, 2001; Robinson, 2011). One key lesson from these rich discussions is the danger of unreflectively taking cities - or in our case interventions for energy transitions - from the global North as the default or benchmark for comparisons. Greene and Schiffer's contribution proceeds on a more equal footing, avoiding that the variables and topics to be considered are restricted to certain locations (Robinson, 2011). They show that a North-South comparison does not necessarily have to end in identifying an "advanced" North and a South that needs to "catch up" or "leapfrog" by eliminating its differences with the North (see also Kumar and Shaw (2020); Kumar and Taylor Aiken (2020) for more examples of South-North comparisons).

In the academic literature, perspectives and approaches developed in the global North remain the benchmarks for comparison. Sareen's contribution flips this relation by suggesting how insights from governing the roll-out of solar technologies in Rajasthan (India) can be relevant for endeavours in Portugal. It contributes to work that takes the plea for "learning from the global South" seriously by taking findings developed in the global South as yardsticks for actions implemented in the North. Scholars in critical energy research also increasingly engage with South-South comparation work (Mohan and Tan-Mullins, 2019; Shen and Power, 2017). ${ }^{2}$ What all these approaches of critical comparison have in common is their 
aim to deconstruct unquestioned benchmarks often set by and relevant for the global North. Critical comparative engagement with energy transitions is a powerful way to unearth their politics and to foster equity and learning.

The call for a broader engagement with perspectives outside one's own discipline and practice is considered valuable when tackling complex socio-technical problems, including energy transitions. Increasingly, scholars in energy research look beyond academic silos and approaches. Social sciences and humanities scholarship on climate and energy ethics and justice are examples of such scholarly cross-fertilisation (Foulds and Robinson, 2018; Jenkins et al., 2020a). By studying the role of regulatory arrangements that are to promote Bolivia's energy transitions "in harmony with nature", the contribution by Villavicencio-Calzadilla and Mauger makes the case for gaining insights at the intersection between legal and social energy studies. Their chapter reminds us of the importance of legal and policy frameworks underpinning energy transitions and what these sources can tell us about opportunities and challenges to shape them. Besides looking for perspectives beyond disciplinary boundaries, increasingly, calls for a more societally engaged role of academia surface, pointing to the value of engaging with non-academic communities and activists (Jenkins et al., 2020b; Schneider, 2019). Whether within or outside academia, calls for broader engagement remind us about our own epistemic bubbles and the opportunities (and challenges) that emerge when engaging with the unfamiliar.

\section{Theoretical-conceptual lens: rich and diverse}

A lot of current research on energy transitions in the global South reverts to a certain set of theoretical approaches, including transition studies (Broto et al., 2018; Hansen et al., 2018), political economy (Brown and Cloke, 2017) or political ecology (Gent and Tomei, 2017). This book nuances and enriches current theoretical and conceptual thinking by adding perspectives that foster critical thought when engaging with energy transitions. Though all contributions in this book add inspiring angles for thinking about energy and change, here, we will put three of them into the spotlight.

Following an assemblage perspective, Abi Ghanem makes the case to move away from a technology-focused approach when studying energy transitions. She traces the system of electricity provision in Lebanon with an assemblage perspective, highlighting the spatiality and temporality of infrastructure as well as the everyday dynamics of the formal and informal electricity service production. Here, assemblage thinking offers a rich analytical tool which helps understand energy (transitions) more holistically, including questions of embedded practices, access and justice. It also shows us how informal arrangements for energy provision, rather than being part of a "mafia" that should be eradicated by top-down government action, can offer opportunities for community-based local energy transitions. In Melnyk and Singh's contribution we are reminded of the importance of decentring the dominant perspectives and understanding and scrutinising concepts from a Southern/less dominant perspective. The authors do so by 
questioning the dominant high-tech visons and narratives of sustainable energy transitions as proposed and perpetuated by the North, particularly in the EU Directive 2018/2001 on promoting the use of energy from renewable sources. When aiming to enable visions of sustainable energy futures they emphasise the importance of considering local and contextualised knowledge and values, as essential ingredients for more inclusive and just vision building. This includes examining possibilities for low-tech rather than high-tech technologies, community- rather than market-based interactions and wellbeing rather than economic growth imperatives.

In the Govindan and Murali chapter, the issue of intersectionality (Crenshaw, 1989) emerges as a promising focus when analysing energy transitions (see Datta and Ahmed, 2020, for more on infrastructure and intersectionality). The authors show how casteist practices and gender prejudices affect female cook stove entrepreneurs in South India. Paying attention to the compounding of inequalities or disadvantages, including caste and gender, but also poverty, race or education, highlights important dimensions of the politics of energy transitions. A different yet equally important intersection comes to the fore in Theiventhran's chapter. By studying the justice trade-offs that emerge in energy transitions within a post-war Sri Lanka, the author points us to the sensitive dynamics unfolding at the intersection of energy and/in post-war settings.

One argument we bring forth is to recognise the heterogeneous ways in which energy transitions unfold. Accounting for such heterogeneity, including dynamics and power relations, requires a rich and diverse set of theoretical and conceptual approaches to understand and shape energy transitions. Theoretical and conceptual diversity helps deconstructing or de-privileging any single theory or dominance of concepts. Some have argued that more diversity does not necessarily lead "to productive research and legacy", rather it contributes to a fragmentation of the field (Sovacool et al., 2020, p. 26). Yet, we find that overly focusing on homogenising research agendas and approaches may fall into the same trap as the dominant Anthropocene narrative we challenge in this book. The urgency versus justice theme describes how demands for urgent collective action can overrule issues of justice and the recognition of heterogeneity.

\section{Empirical lens: global South}

The diverse contributions presented in this book all focus on energy transitions as they unfold in the global South. Understood only from a geographical perspective, this focus describes a demarcation that is underpinned by a nation-based understanding of the global South. Such an understanding is often connected to narratives of a "Third World", of the "periphery" regions outside Europe and North America, where the poor and politically and culturally marginalised people reside (Dados and Connell, 2012). We agree with the many critiques, including the lack of acknowledging heterogeneity, colonial histories, power and agency (e.g. Said, 1977; Sparke, 2007; Trefzer et al., 2014) that such a flat understanding of the global South as a fixed geographical block evokes. Global North and global 
South are notions "constructed and reconstructed through various discourses" and cannot be seen as "pregiven, stable unities or wholes" (Abnave, 2016, p. 35).

Aiming to "find evidence of global South within the global North" and vice versa, Trefzer et al. (2014) propose to understand the global North/global South paradigm as "nestled within each other" (p.4). Rather than restricting the global North and South to geographical associations, they conceptualise them as markers for (compromised) power: they suggest using global South as a framework to detect the manifold inequalities, while the concept of global North helps to uncover "contingent and interconnected spaces of wealth and privilege" (Trefzer et al., 2014, p. 4). With this they can see "South" (and "North") everywhere, from North to South and East to West.

We sympathise with this understanding, as it highlights the variety of forms and spaces where power and privilege unfold. However, discarding this geographical dimension of the global North/South does not recognise that colonial and neocolonial histories have shaped geographies in the South in particular ways, affecting the possibilities how agency, identity and power can unfold and shape futures. Furthermore, the Anthropocene narrative reminds us that those who will suffer most from the climate crisis are not only determined by power relations, but also by geographical location and characteristics. ${ }^{3}$ We find that a more sensitive conceptualisation of the global South is emerging when keeping a geographical focus, while at the same time conceiving of the global South as "an open-ended and inclusive category" (Sparke, 2007, p. 123).

In this book, we have observed the dilemma between urgency and justice along the demarcations of global North and global South. Global South has been useful for an accounting of more complex, place-specific understandings of situated lived experiences in the context of energy transitions. Our aim was to give space for analyses that tell different stories without diminishing people to victims and without homogenising experiences and contexts. By localising the urgency-justice debate along the global North-South demarcation we do not aim to cement simplistic correlations. Rather, we aim to encourage further explorations of the shifting dynamics of urgency and justice as they unfold amidst intensifying global interdependencies.

\section{Urgency and justice: from productive tension to reinforcing power}

This book has opened the space for energy transition narratives describing the dilemma of urgency and justice. Giving voice to other empirical, methodological or conceptual narratives enriches our understanding and possibilities for actions. The question about urgency and justice in energy transitions is thus not so much about choosing one over the other. Rather than taking sides, we propose to see this dilemma as describing a productive tension, reminding us not to subscribe to singular narratives. It reflects to us that interventions always come with tradeoffs, the detecting of which is the start of finding a balance. Such a balance cannot be understood as a static equilibrium, but rather a continuous calibration of 
focus. The different lenses which we have presented in this chapter can help in this endeavour.

This does not mean, however, that the urgency versus justice dilemma is the only productive backdrop against which we can see and understand the unfolding of energy transitions. When engaging in a less dualistic and more integrative way of thinking about urgency and justice we can see them as two parts of the same coin: rather than being oppositional, both notions can reinforce each other's thrust. Following this train of thought, urgency has both a time/action as well as an agenda setting/prioritisation connotation. Our efforts to study energy transitions would thus foreground the importance to foster both an urgent justice as well as a just urgency agenda. We cannot see one without the other in an era in which the state of the planet grows ever more alarming, an era in which it is especially the poor and marginalised who suffer most from consequences brought about by the resource-intensive lifestyles of the affluent.

Framing the unfolding of energy transitions against the backdrop of urgency and justice highlights aspects relating to timing, prioritisation, fairness and equity, as essential questions to consider in our efforts to understand and shape change. Urgency and justice issues emerge in many dis- (but also) heartening realities we currently witness, underlining their topicality and relevance. At the same time, features of urgency and justice in energy transitions are no new themes and relate to and overlap with other notions in critical debates of energy research and practice. For example, one can trace connotations of urgency and justice in the ideas of scale and participation. Scale and scaling up are ongoing concerns in energy transition work (e.g. Naber et al., 2017). Urgency in relation to scale highlights facets of expansion, outreach and replication when designing and implementing energy interventions. If we look at the notion of justice we can find it resonating in and with work on participation (e.g. Visvanathan, 2005). Issues of justice form an integral part of the diverse questions on how to give people a voice and letting them participate in energy interventions.

We can also see features of urgency and justice in the notions of impact and context. The quest and question for "having impact" is being tackled on a variety of agendas, not only through ex-post impact assessments of energy interventions or through the sustainable development goals (SDGs) and their indicators. Also, the notion of impact is increasingly found in the financial sector promoting impact investments, amongst others in energy innovations (e.g. Barman, 2020). Within academia, debates about impact relate to questions around the impact (energy) research has on effecting socio-environmental change (e.g. Rau et al., 2018). Calls for context-sensitivity, -awareness and -consideration are a longstanding concern of critical research on energy (e.g. Agarwal, 1983). Thus, questions of making context matter are at the heart of many analyses, and the chapters of this book are no exception to this.

Energy transitions have been studied against a variety of backdrops and the identified notion-pairs are meant to suggest neither exclusivity nor completeness. Though each notion stands in its own right, as notion-pairs they can be seen as variations of the theme of urgency and justice. This is instructive, as 
they show similar dynamics to the ones suggested for urgency and justice. The notions open up a productive tension and/or have reinforcing potential: for example, the tension between aiming for scale-up might be at odds with meaningful participation; or the reinforcing power that can emerge when impact and context are thought of together. Similar to the lenses suggested above, they add different colour-shades against which the landscape of energy transition can be understood and shaped. With this they enrich, open up and bring into focus an urgency and justice agenda for a politics of energy transitions in the Anthropocene.

As we are writing the conclusion of this book (November 2020), the COVID-19 pandemic continues to show that struggles for urgency and justice are not isolated from other crises. With the COVID-19 virus spreading all over the world, human health-related priorities and actions emerge on global agendas. Along with capturing international attention have come shifts in financial resource distribution. These shifts affect energy transitions in the global South, as funds threaten to dry up. This jeopardises the future and impact of ongoing work and efforts. ${ }^{4}$ While this threat is not to be taken lightly, from a more optimistic perspective, the challenges brought about by the recent global health crisis also offer chances for reflection and reorientation of action. They offer chances to rethink our energy transitions and how we imagine, study and shape them, not only on a local, but also on a global level. More importantly, those challenges show that issues of urgency, justice and health are fundamentally related to each other - as they all touch upon the deep-rooted question of how we want to live together on this planet.

\section{Notes}

1 For example, leading newspapers are changing their language when reporting about environmental issues, referring to climate crisis (instead of change) or global heating (instead of warming): www.theguardian.com/environment/2019/may/17/why-the -guardian-is-changing-the-language-it-uses-about-the-environment, accessed $25 \mathrm{Nov}$ 2020.

2 See also developing work on India's role in Sub Saharan Africa: www.ankitk.com/ 2020/09/new-research-agenda-indian-in-sub.html, accesssed 1 December 2020.

3 The same, of course, holds for the potential different regions have for example for solar or for wind energy.

4 One example is the off-grid renewable energy sector: www.powerforall.org/insights/e conomics/covid-economic-impact-renewable-energy, accessed 1 December 2020.

\section{Bibliography}

Agarwal, B., 1983. Diffusion of rural innovations: Some analytical issues and the case of wood-burning stoves. World Development, 11(4), pp.359-376.

Abnave, V., 2016. Europe's south and global south: Historical difference and global conjuncture. Social Scientist, 44(9/10), pp.35-45.

Barman, E., 2020. Many a slip. Historical Social Research—Historische Sozialforschung, 45(3), pp.31-52. 
Brenner, N., 2001. World city theory, globalization and the comparative-historical methodReflections on Janet Abu-Lughod's interpretation of contemporary urban restructuring. Urban Affairs Review, 37(1), pp.124-147.

Broto, V.C., Baptista, I., Kirshner, J., Smith, S. and Alves, S.N., 2018. Energy justice and sustainability transitions in Mozambique. Applied Energy, 228, pp.645-655.

Brown, E. and Cloke, J., 2017. Energy and development: The political economy of energy choices. Progress in Development Studies, 17(2), pp. vii-xiv.

Crenshaw, K., 1989. Demarginalizing the intersection of race and sex: A black feminist critique of antidiscrimination doctrine, feminist theory and antiracist politics. $u$. Chi. Legalf., pp.139-167.

Dados, N. and Connell, R., 2012. The global south. Contexts, 11(1), pp.12-13.

Datta, A. and Ahmed, N., 2020. Intimate infrastructures: The rubrics of gendered safety and urban violence in Kerala, India. Geoforum, 110, pp.67-76.

Foulds, C. and Robison, R. (Eds.), 2018. Advancing energy policy: Lessons on the integration of social sciences and humanities. Palgrave Pivot. https://doi.org/10.1007 1978-3-319-99097-2

Gent, D. and Tomei, J., 2017. Electricity in Central America: Paradigms, reforms and the energy trilemma. Progress in Development Studies, 17(2), pp.116-130.

Hansen, U.E., Nygaard, I., Romijn, H., Wieczorek, A., Kamp, L.M. and Klerkx, L., 2018. Sustainability transitions in developing countries: Stocktaking, new contributions and a research agenda, Environmental Science \& Policy, Volume 84, 2018, pp.198-203.

Jenkins, K.E., Spruit, S., Milchram, C., Höffken, J. and Taebi, B., 2020a. Synthesizing value sensitive design, responsible research and innovation, and energy justice: A conceptual review. Energy Research \& Social Science, 69, p.101727.

Jenkins, K.E., Stephens, J.C., Reames, T.G. and Hernández, D., 2020b. Towards impactful energy justice research: Transforming the power of academic engagement. Energy Research \& Social Science, 67, p.101510.

Köhler, J., Geels, F.W., Kern, F., Markard, J., Onsongo, E., Wieczorek, A., Alkemade, F., Avelino, F., Bergek, A., Boons, F. and Fünfschilling, L., 2019. An agenda for sustainability transitions research: State of the art and future directions. Environmental Innovation and Societal Transitions, 31, pp.1-32.

Kumar, A. and Shaw, R., 2020. Transforming rural light and dark under planetary urbanisation: Comparing ordinary countrysides in India and the UK. Transactions of the Institute of British Geographers, 45(1), pp.155-167.

Kumar, A. and Taylor Aiken, G., 2021. A postcolonial critique of community energy: Searching for community as solidarity in India and Scotland. Antipode, 53(1), pp. 200-221.

Mohan, G. and Tan-Mullins, M., 2019. The geopolitics of South-South infrastructure development: Chinese-financed energy projects in the global South. Urban Studies, 56(7), pp.1368-1385.

Naber, R., Raven, R., Kouw, M. and Dassen, T., 2017. Scaling up sustainable energy innovations. Energy Policy, 110, pp.342-354.

Pickvance, C.G., 1986. Comparative urban analysis and assumptions about causality. International Journal of Urban and Regional Research, 10(2), pp.162-184.

Rau, H., Goggins, G. and Fahy, F., 2018. From invisibility to impact: Recognising the scientific and societal relevance of interdisciplinary sustainability research. Research Policy, 47(1), pp.266-276.

Robinson, J., 2011. Cities in a world of cities: The comparative gesture. International Journal of Urban and Regional Research, 35(1), pp.1-23. 


\section{Höffken et al.}

Said, E.W., 1977. Orientalism. Georgia Review, 31(1), pp.162-206.

Schneider, F., Giger, M., Harari, N., Moser, S., Oberlack, C., Providoli, I., Schmid, L., Tribaldos, T. and Zimmermann, A., 2019. Transdisciplinary co-production of knowledge and sustainability transformations: Three generic mechanisms of impact generation. Environmental Science \& Policy, 102, pp.26-35.

Shen, W. and Power, M., 2017. Africa and the export of China's clean energy revolution. Third World Quarterly, 38(3), pp.678-697.

Sovacool, B.K., Hess, D.J., Amir, S., Geels, F.W., Hirsh, R., Medina, L.R., Miller, C., Palavicino, C.A., Phadke, R., Ryghaug, M. and Schot, J., 2020. Sociotechnical agendas: Reviewing future directions for energy and climate research. Energy Research \& Social Science, 70, p.101617.

Sparke, M., 2007. Everywhere but always somewhere: Critical geographies of the Global South. The Global South, 1(1), pp.117-126.

Trefzer, A., Jackson, J.T., McKee, K. and Dellinger, K., 2014. Introduction: The global south and/in the global north: Interdisciplinary investigations. The Global South, $8(2)$, pp.1-15.

Visvanathan, S., 2005. Knowledge, justice and democracy. In: Leach, M., Scoones, I. and Wynne, B. (Eds.) Science and Citizens: Globalization and the Challenge of Engagement. London: Zed Books, pp.83-94. 


\section{Index}

Abdullahi, A.A. 150

accessibility 96

actors 94-95, 99, 108

affordability 96-98, 106

Amazon 57, 66n15, 67-70

antagonisms 95

Anthropocene 2-12; narrative 3, 5

anthropocentrism 55-57, 67, 70

assemblage 9, 18-38, 156

bilateral 95, 100

biographic interviews 140; biographic

and lifecourse 137; biographic-practice approach or methodology 138-139, 150; comparative biographic 135,140 , 149-150

Buen Vivir 3, 10; see also Vivir Bien built environment 28, 33

capability: capability-in-practice 137,147 ; competences 137, 141-150; gendered patterns of 137; materials 137-150; meanings 137-150; see also Sen A. car driving 136-149; recruitment to (car) driving 145-146

careers of practice 138, 140; gendered practice careers 141 ; mobility practice careers 137; practice careers 139

case studies 94, 102, 106

caste 8,11

Chakrabarty, Dipesh 2, 10

citizens $2,6,11$

clean cooking 134,150

cleavages 95

climate 1, 10-11; change 1-3, 5, 40, 55-56, 60-61, 69, 93, 96, 99; emergency 8

colonialism 3, 97-98, 104; carbon 5

communities 6, 8-9, 93, 97-98, 100-101, 103-104, 107 comparative analysis 147; comparative research or investigation $135,140,149$; cross-cultural 135, 138-141, 149; in energy research 135; experience-centred 136, 150; international 135; historic 147; see also biographic

comparisons 155-156; North-South 155, South-South 155-156

constitution 56-66

Covid-19 160

cycling 134-149; bicycle 134, 143-144, 149; recruitment to 143

decarbonisation 96

decolonising 4

defeated community 100

Delanda, Manuel 24, 32

Deleuze, Gilles 24

democracy 1, 6-10, 93-95, 97, 100, 105-108; and distributional justice 6 developing countries 70

development 1, 5, 6, 8, 10, 93-108; assistance 94; goals 96; human 4-5

diesel generators 19; air pollution 19, 22; co-ownership 29; mafias 21, 28, 31

discourse 100, 103, 107

discrimination 116, 123-124, 126, 128

diversification: economic diversification 55; energy diversification 60, 62-67 drivers 80-82, 84-85, 89-90

ecocentric 57, 60, 66-67, 70

economic growth 40-42

economy 93, 96-97, 100-101, 107-108

Edgerton, D. 50

electricity 99, 103-108

emissions 5-6

energy 1, 4-11; access 5, 6, 8, 11, 134-153; alternative $60-66,70$; bullying 7 ; decentralised 23, 32, 39-40, 42-51; 


\section{Index}

delivery 6; efficiency 96; energy and mobility 134-135; governance 96-97; justice $8,23-25,31,56,70-71$; projects $6,10,11$; renewable 4-6, 10, 93-94, 96-97, 99-104, 106-108; research 5; technologies 4, 5, 7; transitions 1 , 4, 8-11, 40-41, 49-51, 93-94, 96, 107-108; trilemma 96-97; unequal access 19 energy transition in harmony with nature 55-70

entrepreneurship 112-114, 121-122, 124-125, 127

environmental conflicts 55, 69 equity 93-97, 100, 103, 106-108, $135-137,139,149$; gender equity 136 , 138 ; mobility equity 148,150 ; social equity 135 ; see also inequity

ethical 1, 4

EU directive 40-42, 49, 51

everyday life 134, 138, 146-147; everyday mobility 134-139, 141, 147-149; see also lived experience

everyday practice 136-139; gendered practice 141, 148, 150; patterns of practice 136; sharing practices 144 ; see also mobility practice

exportation: of electricity $62-65,67-69$; of natural gas 55

extractivism 56-57, 60, 66-67, 70

former war zones 95, 97, 100-102

Framework Law of Mother Earth and Integral Development for Living Well 59-61, 66

Gambia see The Gambia

The Gambia 136-149

gender 4, 7-8, 11; gender and mobility 134-153

globalisation 2

global South 157-158 global warming 2-3 good governance 95,98

government 95-100, 102-107

hacking 29

heterogeneity 25,157 ; of electricity provision 28

human 2-4, 7; agency 2

hydroelectricity 57, 60, 62-64, 66-67, 69; and mega dam 68-70

hydropower 99

India 39-40, 42-49

indigenous: people 58, 66-67, 69, 71; principles 58 ; rights 58 inequalities 95-97

inequity $138,149-150$; gender inequity 136-138; mobility inequity 148 ; social inequity 135; see also equity

informal electricity provision $18-38$

infrastructures 18-38; as affective 25;

failures 26 ; hybrid 20,26 ; socio-

material relations 25

innovation 94, 99

institutions 94-95, 98, 100, 104

international climate commitments 93

intersectionality 11,157

Ireland 136, 138-143, 146-147, 149-150

justice 1-4, 7-12, 93-97, 100, 103, 106-108; distributional 6-7; gender

7-8; racial 7-8

just transition 134, 137, 149

just urgency 159

\section{Kataeb party 26}

law of the Rights of Mother Earth 59, 60

Lebanon 18-38; history of electricity provision 26; politics 20, 26, 29; political parties 26

lifecourse 137, 142, 145-146; see also biographic

lived experience 134-135, 138, 144, 148-149; see also everyday life

local community 66-67, 69-71

low-carbon 4-10

marginalised 105-106

market 3, 5-7, 95; actors 7; mechanism 6 methodology: archival research 25 ; interviews 25; methodological lens 155-156 military victory $94-96,98,107-108$

mining 67

minority 98, 102-103, 107

mobility $134-150$; carbon-intensive 141; low-carbon 134, 141-142, 148, 150; mobility (in)equity 148; see also equity: inequity

mobility careers $138,142,147-149$; of exclusion 145; gendered mobility careers 138, 147; gendered patters of recruitment 137 ; mobility restriction 143-147

mobility practice $134-150$

mobility transition 134-153; see also mobility careers

Mother Earth 56-71

multiepistemic literacy 4

multilateral 95, 100 
narrative $1,3-7,97,100-104$

natural gas $55,62-67$

Palestinian Liberation Organisation 26

patriarchal 139, 142-143, 147

peace 94-98; deal 96

peacebuilding 95, 97-98, 101

planetary 2-4; boundaries 3

policymakers 101, 104, 107

policymaking $93,97,104$

political 1-5, 9-12; Anthropocene 4,

12; economy 93, 101, 107; human 3; institutions 2, 3; marketplace 100

politics $1-4,7,10,12,78-92$; of justice 3-4

postcolonial: scholars 4; sensibility 11 ; theory 3

post-conflict 93-95, 98, 104, 107

post-contextual approach 50

post-political 3, 4, 12

post-war 10, 93-108; setting 93-96, 99, 101, 103, 105-106; societies 93-94, 96-97, 103, 107-108; state 94-99, 104, 107

power 93, 96-97, 99, 101, 104-108

practice-based research 135

Practice theory 137,140

private $6,7,11$; commodity 7 ; resource 7 productive tension 158

public consultation 69,71

racialisation 3,7

Rafic Hariri 27

regulatory inertia 78-90

reinforcing power, potential 159, 160

resilience 26

rights of nature 57-61

scalar biases 78-90

scale 159
Science and Technology Studies 20

Sen, A. 137

social history 26

socio-cultural $6,8,11-12$

socio-materiality 78-91

solar farm 101-103, 107

solar mini-grids 39-49; local knowledge

47-50; narratives 48-50; practices $45-50$

space 93, 97, 100, 108

spatial: control 107; politics 93, 100

Sri Lanka 93-108

state 6-7

steadfastness 26

sustainable development goals 7, 134

sustainability $7,9,40-41$

Tamil 98, 101-103

technocratic interventions 94-95

temporality $137,139,147$; longer

timescales or timeframes 137,139

theoretical approaches 156-157

time 93, 97, 103, 105, 108

trade-offs $157-158$

training 112-126

urgency $1,3-4,7-8,11-12$; of

collective action $4 ; v s$. justice 2 ,

4, 8; and justice 1-10

urgent justice 159

value chain $111-113,118,121-122$

visions $156-157$

Vivir Bien 58-66, 70

wind farm 101, 104

Yasser Arafat 26

zoecentric 2 


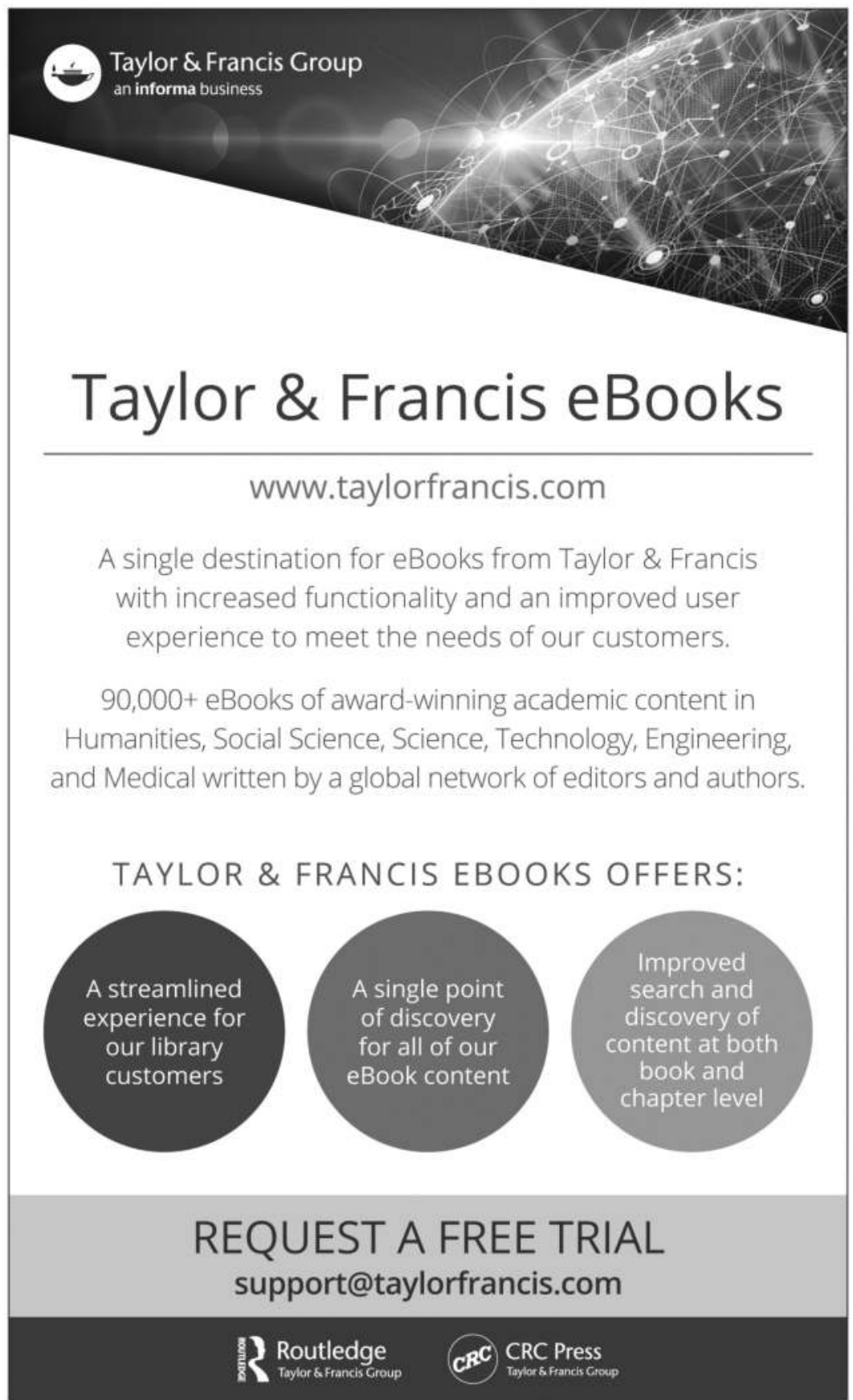

